GEAP - 13588

AEC RESEARCH AND

DEVELOPMENT REPORT

MARCH 1970

\title{
RESULTS OF SEFOR ZERO POWER EXPERIMENTS
}

U.S. ATOMIC ENERGY COMMISSION

CONTRACT AT(04-3)-540

\section{GENERAL ELECTRIC}




\section{DISCLAIMER}

This report was prepared as an account of work sponsored by an agency of the United States Government. Neither the United States Government nor any agency Thereof, nor any of their employees, makes any warranty, express or implied, or assumes any legal liability or responsibility for the accuracy, completeness, or usefulness of any information, apparatus, product, or process disclosed, or represents that its use would not infringe privately owned rights. Reference herein to any specific commercial product, process, or service by trade name, trademark, manufacturer, or otherwise does not necessarily constitute or imply its endorsement, recommendation, or favoring by the United States Government or any agency thereof. The views and opinions of authors expressed herein do not necessarily state or reflect those of the United States Government or any agency thereof. 


\section{DISCLAIMER}

Portions of this document may be illegible in electronic image products. Images are produced from the best available original document. 

GEAP-13588

AEC Research and Development Report

March 1970

RESULTS OF SEFOR ZERO POWER EXPERIMENTS

\section{AUTHORS}

L. D. Noble

F. Mitze1*

B. Sarma

D. Wintzer*

Y. S, Lu

G. Kessler*

G. R. Pflasterer

R. A. Becker

L. Mansur

APPROVED :

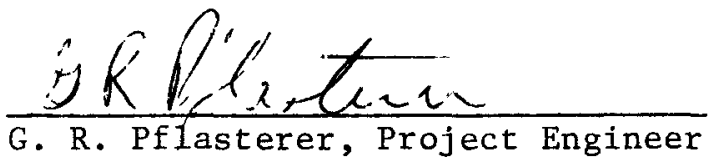

SEFOR Research and Development Program

Breeder Reactor Development Operation

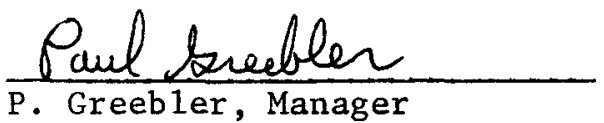

Nuclear Engineering Subsection
Prepared for the

Southwest Atomic Energy Associates

for Transmittal to the

U. S. Atomic Energy Commission

Under Contract AT (04-3)-540

Printed in U.S.A. Available from tbe

Clearing House for Federal Scientific and Tecbnical Information

National Bureau of Standards, U.S. Department of Commerce

Springfield, Virginia

Price: $\$ 3.00$ per copy

* Kernforschungszentrum Karlsruhe, 75 Karlsruhe, Germany

+U. S. Atomic Energy Commission, Division of Reactor Development and Technology, Washington, D. C.

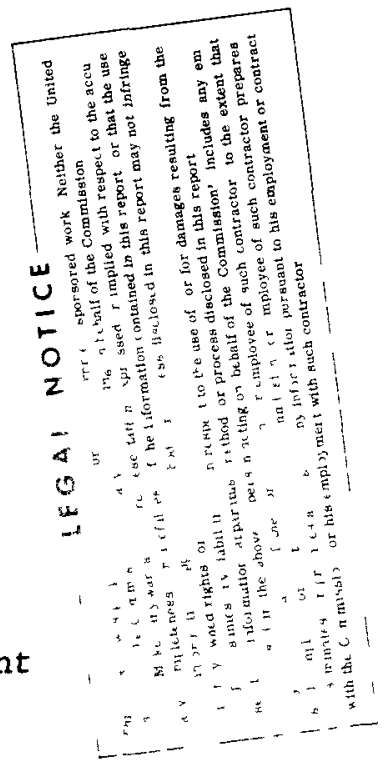

BREEDER REACTOR DEVELOPMENT OPERATION • GENERAL ELECTRIC COMPANY SUNNYVALE, CALIFORNIA 94086 


\section{LEGAL NOTICE}

This report was prepared as an account of Government sponsored work. Neitber the United States, nor the Commission, nor any person acting on behalf of the Commission:

A. Makés any warranty or representation, expressed or implied, with respect to the accuracy, completeness, or usefulness of the information contained in this report, or that the use of any information, apparatus, method, or process disclosed in this report may not infringe privately owned rights; or

B. Assumes any liabilities with respect to the use of, or for damages resulting from the use of any information, apparatus, method, or process disclosed in this report.

As used in the above, "person acting on bebalf of the Commission" includes any employee or contractor of the Commission, or employee of such contractor, to the extent that such employee or contractor of the Commission, or employee of sucb contractor prepares, disseminates, or provides access to, any information pursuant to bis employment or contract with the Commission, or bis emplovment with such contractor. 


\section{ABSTRACT}

The SEFOR experimental program is comprised of a series of tests beginning with low power tests, proceeding through static and frequency response tests at various power levels up to full power, and culminating in a series of sub-prompt and super-prompt critical transients.

The results of the low (zero) power tests are reported here and are compared with calculations. The agreement between experiment and calculation is generally good. The tests were conducted at low power and included such experiments as the approach to the minimum critical core size, calibration of the reflector control, measurement of fission rate distributions, material reactivity worth measurements, uniform non-nuclear heating of the reactor to determine the reactivity temperature coefficient, and the measurement of the ratio $(l / \beta)$ of the prompt neutron lifetime to the effective delayed neutron fraction. 


\section{CONTENTS}

Page

Abstract

Section I

Introduction, Summary of Results,

1.1 and Sequence of Measurements

1.2

Introduction, Summary of Results

Sequence of Measurements

Prediction of the Minimum Critical Size

2.1.1 Calculated Results

2.1.2 Calculational Methods

2.1.3 Uncertainty Estimates

(Assembly I-A) 
CONTENTS (Continued

Page

Section $\mathrm{V}$

Foll Activation Measurements

5.1

Description and Results of

Measurements

5.1.1 Fission Rate Distributions

5.1.2 Determination of Approximate Fission Ratios

Comparison of Experimental and

Calculated Results

5.2.1 Comparison of Fission Rate 98

Distributions

5.2.2 Comparison of Calculated and Measured Fission Ratios

Section VI

6.1

6.2

6.3

Section VII

\section{1}

7.2

7.3

7.4
Analysis and Results of Noise

Measurements

Description of the Experiment

6.1.1 Experimental Method and

Instrumentation

6.1.2 Analysis and Corrections

115

119

Experimental Results

125

with Experiment

Zero Power Reactivity Coefficient

Measurements

Flow and Pressure Coefficients of Reactivity

Calculation of the Uniform Temperature 137

Reactivity Coefficients

7.2.1 Doppler Coefficient Calculations 138

7.2.2 Definition and Calculation of 141

Expansion Coefficients

Temperature Coefficient Measurements 145

7.3.1 Temperature Coefficient Measure- 145 ment in Assembly I-D

7.3.2 Temperature Coefficient Measure- 145 ment in Assembly I-E

Comparison of Experimental and 146

Calculated Results 
Appendix III

Appendix IV

Appendix V

Appendix VI

Appendix VII

Appendix VIII
Counting Rate Corrections and Effects of Detector Location

A Simple One-Group Model for the Partially Loaded Core

In-Hour Relation for SEFOR

Fine Reflector Calibration Data

Inherent Source Measurement

Temperature Dependent Reactivity Data in Assembly I-E 


\section{LIST OF ILLUSTRATIONS}

Critical Approach Using In-Core Detector No.1

Fine Reflector INo.3 Calibration Curve

Fine Reflector No.8 Calibration Curve

Fine Reflector No.3 Calibration Curve 

at $650^{\circ} \mathrm{F}$ (Assembly I-E)

Location of Material Worth Measurements

Radial Dependence of Stainless Steel Rod Worth (Assembly I-B)

4-5

Location of Material Worth Measurements in Assembly I-D

$4-6$

Radial Dependence of Fuel Rod Worth (Assembly I-D) 
LIST OF ILLUSTRATIONS (Continued)

Figure

4-12

$4-13$

$5-1$

$5-2$

$5-3$

$5-4$

$5-5$

$5-6$

$5-7$

$5-8$

5-9

$5-10$

$5-11$

$6-1$

$6-2$

$6-3$

$6-4$
Title

Page

Axial Flux Distribution for Group Twelve (310 to $91 \mathrm{ev}$ )

Axial Flux Distribution for Group Thirteen (less than $91 \mathrm{ev}$ )

Foil Holder Rod

Foil Holder Rod Locations (Assembly I-D)

Pu-239 Fission Distribution in Rod FB

U-238 Fission Distribution in Rod FB

U-235 Fission Distribution in Rod FB

U-235 Axial Fission Distribution at Core Radial Boundary

U-238 Axial Fission Distribution at Core Radial Boundary

Pu-239 Radial Fission Distribution at Axial Position 3

U-235 Radial Fission Distribution at Axial Position 3

U-238 Radial Fission Distribution at Axial Position 3

Ratio of U-238 Fission in Central Channel and Adjacent Fuel Region

Experimental Set-up for Noise Recording

Frequency Response for Channel 1

Frequency Response for Channel 2

Correlation Functions from Measurement No.2
91

100

101

122

81

$81 \mathrm{~A}$

102

103

104

105

106

108

124 


\section{LIST OF ILLUSTRATIONS (Continued)}

Figure

Title

$\underline{\text { Page }}$

$7-1$

$7-2$

$7-3$

$7-4$

$7-5$

$7-6$

7-7

$7-8$

$7-9$

$7-10$

$7-11$

$I-1$

$\mathrm{I}-2$

$\mathrm{I}-3$

III-1

III-2

III-3
Pressure-Reactivity Measurements (Assembly I-E) 134

Flow-Reactivity Measurements (Assembly I-E) 135

Flow-Reactivity Measurements (Assemb1y I-I) 136

In-Core Thermocouple and Main Primary RTD's 149 $(10 / 22 / 69)$

In-Core Thermocouple and Main Primary RTD"s 150 $(10 / 25 / 69)$

In-Core Thermocouple and Main Primary RTD's $(10 / 25 / 69-10 / 26 / 69)$

In-Core Thermocouple and Main Primary RTD's

152 $(10 / 26 / 69-10 / 27 / 69)$

In-Core Thermocouple and Auxiliary Primary RTD's $(10 / 25 / 69)$

In-Core Thermocouple and Auxiliary Primary RTD's $(10 / 25 / 69-10 / 26 / 69)$

154

In-Core Thermocouple and Auxiliary Primary RTD's (10/26/69-10/27/69)

Temperature Reactivity Feedback (Assembly I-E) 158

SEFOR Fuel Channel

167

$\begin{array}{ll}\text { SEFOR Fuel Rod } & 168\end{array}$

SEFOR Full Core Geometry $\left(350^{\circ} \mathrm{F}\right) \quad 169$

Ratio of Counting Rates in He-3 Detectors 190

Count Rate Ratio Between He-3 Detector and 191

Source Range Monitors

Ratio of Count Rates in Source Range

Monitors 
GEAP-13588

LIST OF ILLUSTRATIONS (Continued

Figure

I I I -4

IV-1

V-1
Title

Page

Effect of Reflector Position on CountingRate Ratios

Simplified SEFOR Model

Asymptotic Reactor Period for SEFOR
196

$193 / 194$

204 
GEAP-13588

\section{LIST OF TABLES}

Calculated $k$ for SEFOR and ZPR-3 Assembly 47 Mockups

Results of Synthesis and Diffusion Theory Calculations

Calculated Reflector Control Reactivity Assembly I-D

Material Reactivity Worth Measurements (Assembly I-D) Measurements (Assembly I-D) Material Reactivity Worths 


\section{LIST OF TABLES (Continued)}

Table

$$
\text { 4-7 }
$$$$
\text { 5-1 }
$$$$
\text { 5-2 }
$$$$
\text { 5-3 }
$$$$
\text { 5-4 }
$$$$
\text { 5-5 }
$$$$
\text { 5-6 }
$$$$
\text { 6-1 }
$$$$
\text { 7-1 }
$$$$
\text { 7-2 }
$$$$
\text { 7-3 }
$$$$
\text { 7-4 }
$$$$
7-5
$$$$
7-6
$$$$
\text { 7-7 }
$$$$
7-8
$$

Title

Page

SEFOR Critical Checks (September 13 to October 7)

Foil Isotopic Compositions

88

Foil Positions in Foil Holder Rods

Fission Rate Measurements for Pu Fuils

95

Fission Rate Measurements for Enriched

96

Uranium Foils

Fission Rate Measurements for Depleted

Uranium Foils

Fission Cross Section Near Core Center

$111 / 112$

Results of Noise Analysis

126

Pressure-Reactivity Measurements

130

(Assemb1y I-E)

Flow-Reactivity Measurements (Assembly I-E)

Flow-Reactivity Measurements (Assembly I-I)

$132 / 133$

U-238 Doppler Calculations

Expansion Reactivity Coefficients for Fully Loaded SEFOR Core 512 Rod Core

Temperature Coefficient Measurements in Assembly I-D

Uniform Temperature Coefficient of Reactivity between $350^{\circ} \mathrm{F}$ and $760^{\circ} \mathrm{F}$ 

SEFOR and ZPR-3 Assembly 47 


\section{LIST OF TABLES (Continued)}

\section{Table}

VII -1

VII-2

VIII-1

VIII -2

VIII-3

VIII-4

VIII-5

VIII-6

VIII-7

VIII-8

VIII-9

VIII-10 $\underline{\text { Title }}$

$\underline{\text { Page }}$

218

Inherent Source Measurement (Assembly I-A)

$219 / 220$

Inherent Source Measurement (Assembly I-D)

223

Temperature Reactivity Measurements

224

Temperature Reactivity Measurements

225

Temperature Reactivity Measurements

226

Temperature Reactivity Measurements

227

Temperature Reactivity Measurements

228

Temperature Reactivity Measurements

229

Temperature Reactivity Measurements

230

Temperature Reactivity Measurements

231

Temperature Reactivity Measurements

232 


\section{INTRODUCTION, SUMMARY OF RESULTS, AND SEQUENCE OF MEASUREMENTS}

\subsection{INTRODUCTION}

The Southwest Experimental Fast Oxide Reactor (SEFOR) is a 20 $\mathrm{MW}(\mathrm{t})$ fast spectrum reactor fueled with mixed $\mathrm{PuO}_{2}-\mathrm{UO}_{2}$ and cooled with sodium. SEFOR has characteristics similar to large, soft spectrum, fast breeder reactors fueled with mixed $\mathrm{PuO}_{2}-\mathrm{UO}_{2}$ for economic electrical power generation. SEFOR will be used to obtain physics and engineering data at fuel compositions, temperatures, and crystalline states characteristic of power reactor operating conditions. SEFOR is particularly designed for the systematic determination of the Doppler coefficient of reactivity at temperatures up to the vicinity of fuel melting.

The SEFOR Project consists of two major parts: the design and construction of the reactor and a related research and development program. Funds for the design and construction of the facility are being provided by the Southwest Atomic Energy Associates (a group of seventeen investor-owned utility companies located in the South and Southwest part of the United States), together with the Karlsruhe Laboratory of the Federal Republic of Germany, Euratom, and the General Electric Company.

The United States Atomic Energy Commission is supporting the research and development program. The $R$ and D Program consists of two phases:

Phase I - Pre-Operational Research and Development

Phase II - Post Construction Research and Development

Work performed in Phase I of the program under Task 1, planning the 
experimental program, has been reported in references 1 through 4. The SEFOR facility is described in references 5 and 6 , and the physics design of the core is described in references 6 through 9 .

This report describes work performed in Phase II of the program under Task 10.3, Wet Critical Tests. The purpose of Task 10.3 is to determine such information as the minimum critical mass of the core, reflector control calibration data, material reactivity worths at various radial distances from the core center, and low power reactivity temperature coefficients.

\subsection{SUMMARY OF RESULTS}

Agreement between experiment and calculation is generally good. Representative results are summarized in Table 1-1. The minimum critical core fuel loading ( $284 \mathrm{Kg}$ fissile $\mathrm{Pu}$ ) was predicted ${ }^{(10)}$ to within $0.2 \%$ ( 1 fuel rod), and the magnitude of the reflector control strength ( $10 \$)$ is within the predicted ${ }^{(10)}$ range of $11.2 \pm 1.8 \$$. The measured ratio of $\ell / \beta, 2.0 \times 10^{-4}$ seconds, is about $10 \%$ higher than the calculated value and is in agreement with similar comparisons of experiment and calculation in the SEFOR critical assembly mockup in ZPR-III ${ }^{(11)}$. Measured and calculated reactivity worths of fuel and $\mathrm{B}_{4} \mathrm{C}$ rods agreed within 10 to $15 \%$, with the largest disparities occurring near the core center, while the experimental fission rate distributions agree with the calculations throughout most of the core, but show deviations as large as $25 \%$ near the core boundaries. These disparities indicate that the flux distributions (and consequently the temperature distributions which will occur during operation at power) may be somewhat flatter than calculated. The Joppler coefficient is relatively insensitive $(8,12)$ to the spatial temperature and flux distribution however, and calculations which might give better agreement 
Experiment

1 nimum Critical Core Size

(Mass of $\mathrm{Pu}-239+\mathrm{Pu}-241$ )

Reflector Control Strength

Ratio $(\ell / B)$ of neutron lifetimeto effective delayed neutron fraction.

Fuel Rod Worth near core center

${ }_{4}{ }_{4}$ Rod Worth near core center

Fission Ratios near Core Center

$$
\begin{aligned}
& \sigma_{\mathrm{f}}^{238} / \sigma_{\mathrm{f}} 235 \\
& \sigma_{\mathrm{f}}^{239} / \sigma_{\mathrm{f}} 235
\end{aligned}
$$

Flow and pressure coefficients of reactivity

Uniform Temperature coefficient of reactivity in the

following temperature ranges

$$
\begin{aligned}
& 350^{\circ} \mathrm{F} \text { to } 450^{\circ} \mathrm{F} \\
& 450^{\circ} \mathrm{F} \text { to } 550^{\circ} \mathrm{F} \\
& 550^{\circ} \mathrm{F} \text { to } 650^{\circ} \mathrm{F} \\
& 650^{\circ} \mathrm{F} \text { to } 760^{\circ} \mathrm{F}
\end{aligned}
$$

Measured

$284.3 \mathrm{Kg}$

$9.7 \$$

$2.0 \times 10^{-4} \mathrm{sec}$

$+35 c$

$-71 c$

0.0252

0.905

0
Calculated

$284.9 \mathrm{Kg}$

$11.2 \$$

$1.8 \times 10^{-4} \mathrm{sec}$

$+40 c$

$-82 c$
$-0.67 \mathrm{c} /{ }^{\circ} \mathrm{F}$

$-0.64 \mathrm{C} /{ }^{\circ} \mathrm{F}$

$-0.60 \mathrm{C} /{ }^{\circ} \mathrm{F}$

$-0.57 \mathrm{C} /{ }^{\circ} \mathrm{F}$
0.0256

0.894

0

*The calculated total non Doppler effect is a constant $-0.36 \mathrm{c} /{ }^{\circ} \mathrm{F}$ throughout this temperature range. 
with experiment should have only a small ( $3 \%$ ) effect on the calculated Doppler coefficient.

The measurement of reactivity feedback effects of flow, pressure, and temperature are in very good agreement with calculation. As expected, the reactivity effects of sodium flow and cover gas pressure are essentially zero over the entire operating range of these variables. The measured temperature reactivity feedback data between $350^{\circ} \mathrm{F}$ and $760^{\circ} \mathrm{F}$ at zero power are in very good agreement with the calculations (within about $2 \%$ over tiris entire temperature range) using the predicted (13) Doppler $\mathrm{T} \frac{\mathrm{dk}}{\mathrm{dT}}$ of -0.0082 and total expansion coefficient of $-0.36 \mathrm{c} /{ }^{\circ} \mathrm{F}$. Since the Doppler effect contributes about $40 \%$ of the calculated uniform temperature coefficient in the $350^{\circ} \mathrm{F}$ to $760^{\circ} \mathrm{F}$ temperature range, the close agreement between the calculated and the measured temperature coefficient is an indication that the Doppler effect is not drastically different from its predicted value.

\subsection{SEQUENCE OF MEASUREMENTS}

During the zero power tests which are reported here, experiments were performed on 5 major different core loadings, or arrangements, of fuel, $\mathrm{Be} 0$, and $\mathrm{B}_{4} \mathrm{C}$ rods within the core. These 5 different core loadings have been designated Assembly I-A, through Assembly I-E, and the core loadings are illustrated in Figures 1-1 through 1-5. In addition, a fine reflector was calibrated on another loading, Assembly I-F, and a portion of the reactivity flow coefficient measurements were performed on Assembly I-I. The latter two loadings are shown in Figures $1-6$ and $1-7$.

The first critical loading was Assembly I-A shown in Figure 1-1 which contained 550 fuel rods, $96 \mathrm{Be} 0$ tightener rods and no $\mathrm{B}_{4} \mathrm{C}$ rods. 
The excess reactivity of this assembly with all reflectors raised was nine cents at a sodium temperature of $350^{\circ} \mathrm{F}$.

After measurements to evaluate the inherent $n$.utron source strength were performed in Assembly I-A (see Appendix VII), 13 fuel rods and $4 \mathrm{BeO}$ tightener rods were added on the core periphery to provide enough excess reactivity for calibration of the reflectors. This loading was designated Assembly $I-B$ and is illustrated in Figure 1-2. This loading was critical with one reflector completely lowered and a fine reflector raised about $87 \%$ of its stroke. The estimated excess reactivity of this assembly with all reflectors raised was $\$ 1.35$ at a temperature of $350^{\circ} \mathrm{F}$. In addition to the reflector calibrations, the reactivity worth of fuel, $\mathrm{B}_{4} \mathrm{C}$, and stainless steel rods were measured at different locations in the core. Fuel rod reactivity worth measurements in this assembly revealed that a number of fuel rods were low (by as much as 40\%) in reactivity worth when compared to a standard rod. An extensive investigation, which is reported in reference 14 , demonstrated that these rods were deficient in plutonium.

The very low worth rods in Assembly $I-B$ were removed and replaced with rods from the core puriphery. A minimum critical loading of 522 fuel rods and 100 BeO tightener rods that is shown in Figure 1-3 was attained. This loading, Assembly I-C, was less than 1 cent supercritical with all reflectors raised at $350^{\circ} \mathrm{F}$.

Some of the finel rods in Assembly I-C were moved to the core periphery and $\mathrm{B}_{4} \mathrm{C}$ rods, as well as additional fuel rods and BeO tightener rods, were added to the core to completely fill the 108 fuel channels. The adjustment in loading was performed in incremental steps and critical checks were performed at the end of each step. The resulting full size core loading was designated Assembly I-D and is illustrated in 
Figure 1-4. This assembly was critical at $350^{\circ} \mathrm{F}$ with one fine reflector completely lowered and the other fine reflector raised about half way. The estimated excess reactivity at $350^{\circ} \mathrm{F}$ with all reflectors raised was $\$ 1.8$. Experiments which were performed in Assembly I-D included control rod calibrations, material worth measurements, noise measurements to determine $l / B$, measurement of the inherent neutron source, fission rate distribution measurements, and a measurement of the temperature dependent feedback between $350^{\circ} \mathrm{F}$ and $400^{\circ} \mathrm{F}$.

In order to provide enough excess reactivity to compensate the expected reactivity feedback upon heating the reactor to $760^{\circ} \mathrm{F}$, and to accomodate the loading of guinea pig rods which contain $33 \%$ more $\mathrm{Pu}$ than a standard fuel rod, the fuel and $\mathrm{B}_{4} \mathrm{C}$ distribution within the core was changed. The resulting core loading was called Assembly $\mathrm{I}-\mathrm{E}$ and is illustrated in Figure $1-5$. At $350^{\circ} \mathrm{F}$ this assembly was critical with two reflectors lowered and one fine reflector approximately $40 \%$ raised. The estimated excess reactivity with all reflectors raised at $350^{\circ} \mathrm{F}$ was about $\$ 3.4$. Measurements in this assembly included reflector calibrations at two different temperatures (i.e. with two different critical reflector configurations for the same core loading), measurement of the flow and pressure coefficients of reactivity, and reactivity temperature effects between $350^{\circ} \mathrm{F}$ and $760^{\circ} \mathrm{F}$.

A symmetrical loading of $\mathrm{B}_{4} \mathrm{C}$, and guinea pig rods was arranged within the core to provide enough excess reactivity for the approach to full power operation. This loading, Assembly I-F that is shown in Figure 1-6, was critical at $350^{\circ} \mathrm{F}$ with three reflectors lowered and one fine reflector raised approximately one third of its complete stroke. A fine reflector was calibrated with this loading.

A final core loading was Assembly I-I. This loading was obtained by removing two standard fuel rods and one tightener rod from each of 
GEAP -13588

two different fuel channels in Assembly $\mathrm{I}-\mathrm{F}$ and replacing them with Instrumented Fuel Assemblies (IFA's). Each IFA, which contains two temperature-instrumented fuel rods and a central tightener rod, as well as sodium temperature thermocouples and a flow meter, are described in detail in reference 15. A portion of the reactivity flow coefficient measurements were then performed on this core. The loading for this core is shown in Figure 1-7. 
GEAP-13588

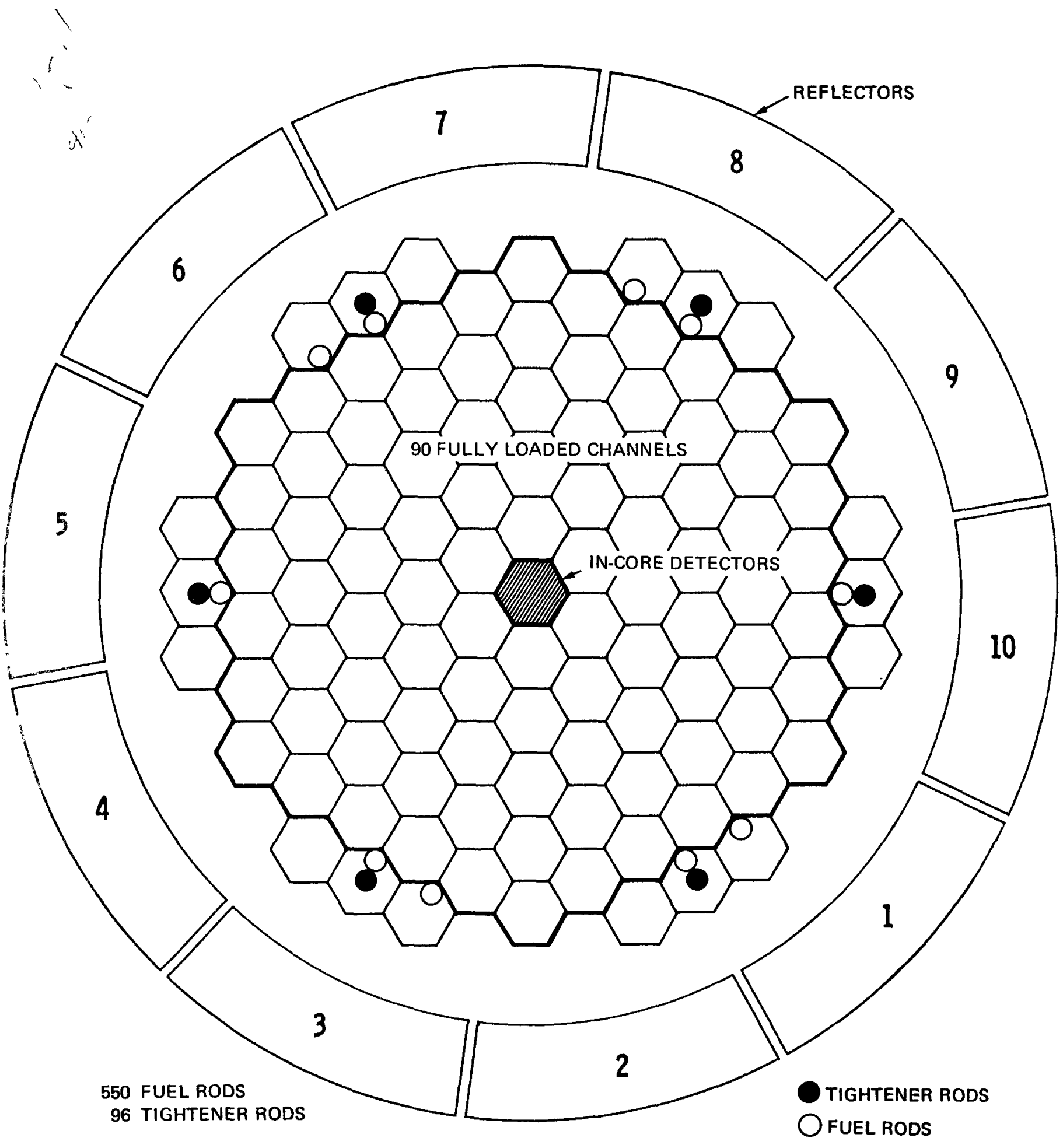

FIGURE 1-1. SEFOR INITIAL CRITICAL CORE LOADING (ASSEMBLY I-A) 


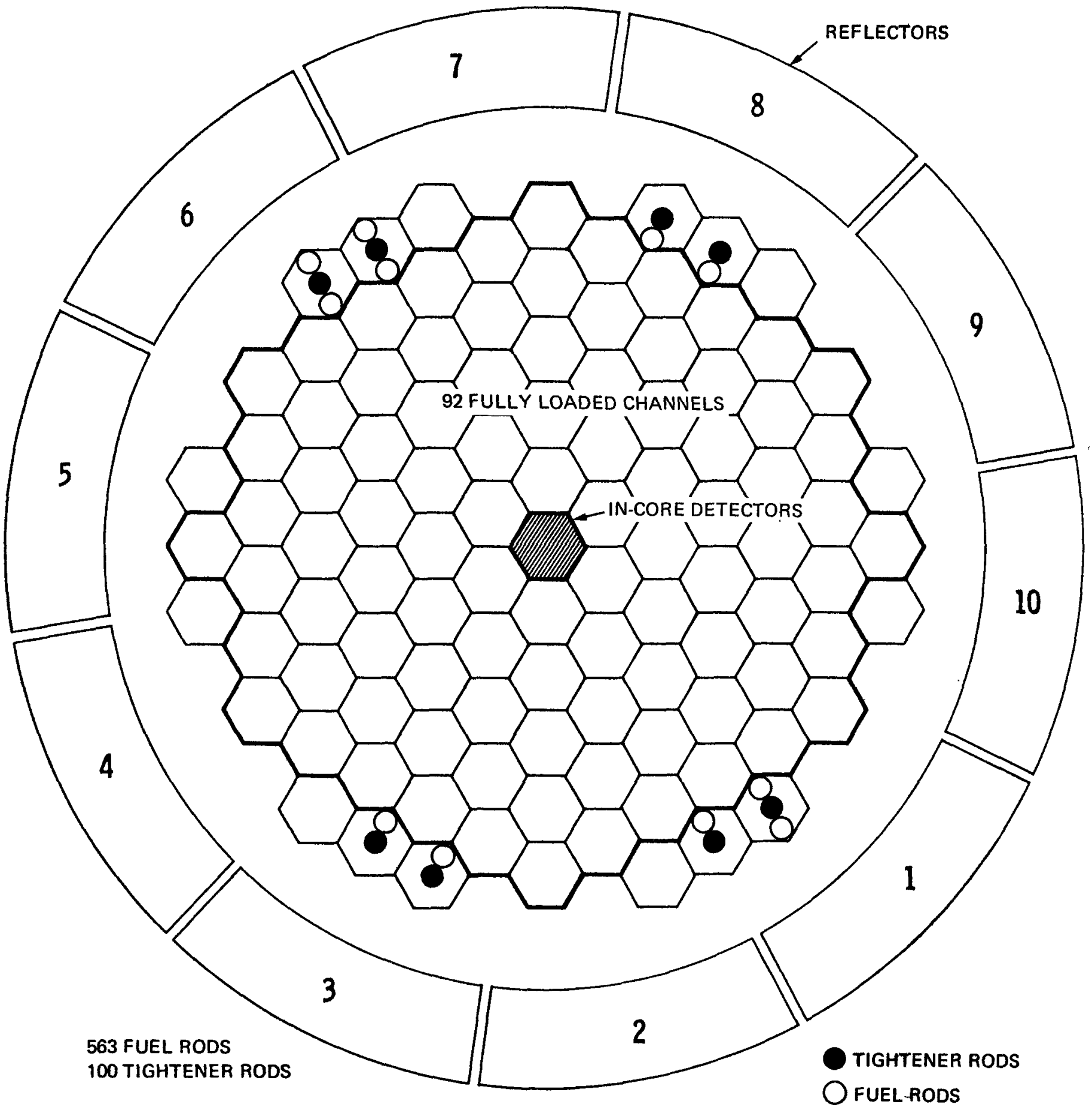

FIGURE 1-2. SEFOR CORE LOADING (ASSEMBLY I-B) 


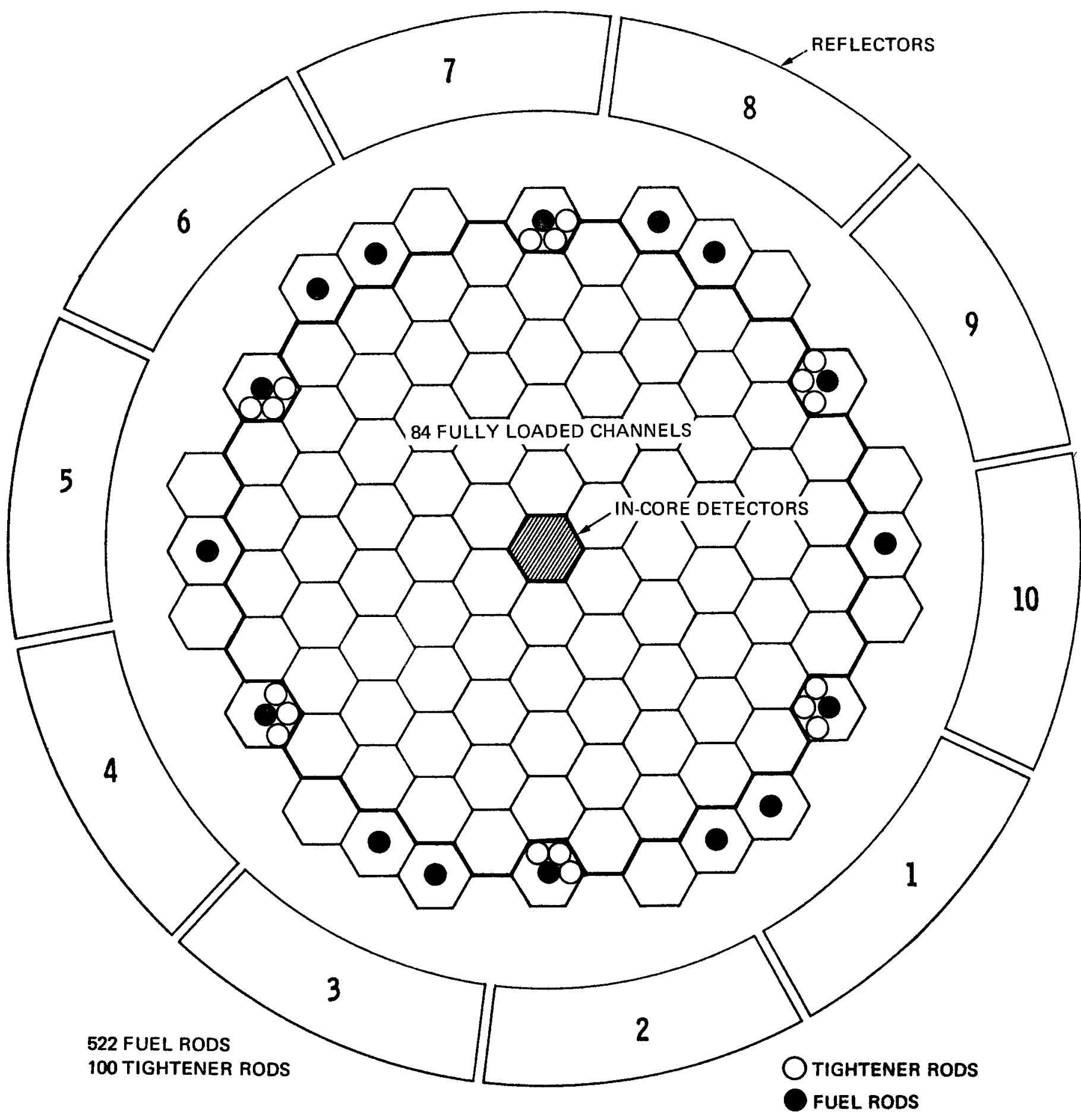

FIGURE 1-3. SEFOR MINIMUM CRITICAL LOADING (ASSEMBLY I-C) 


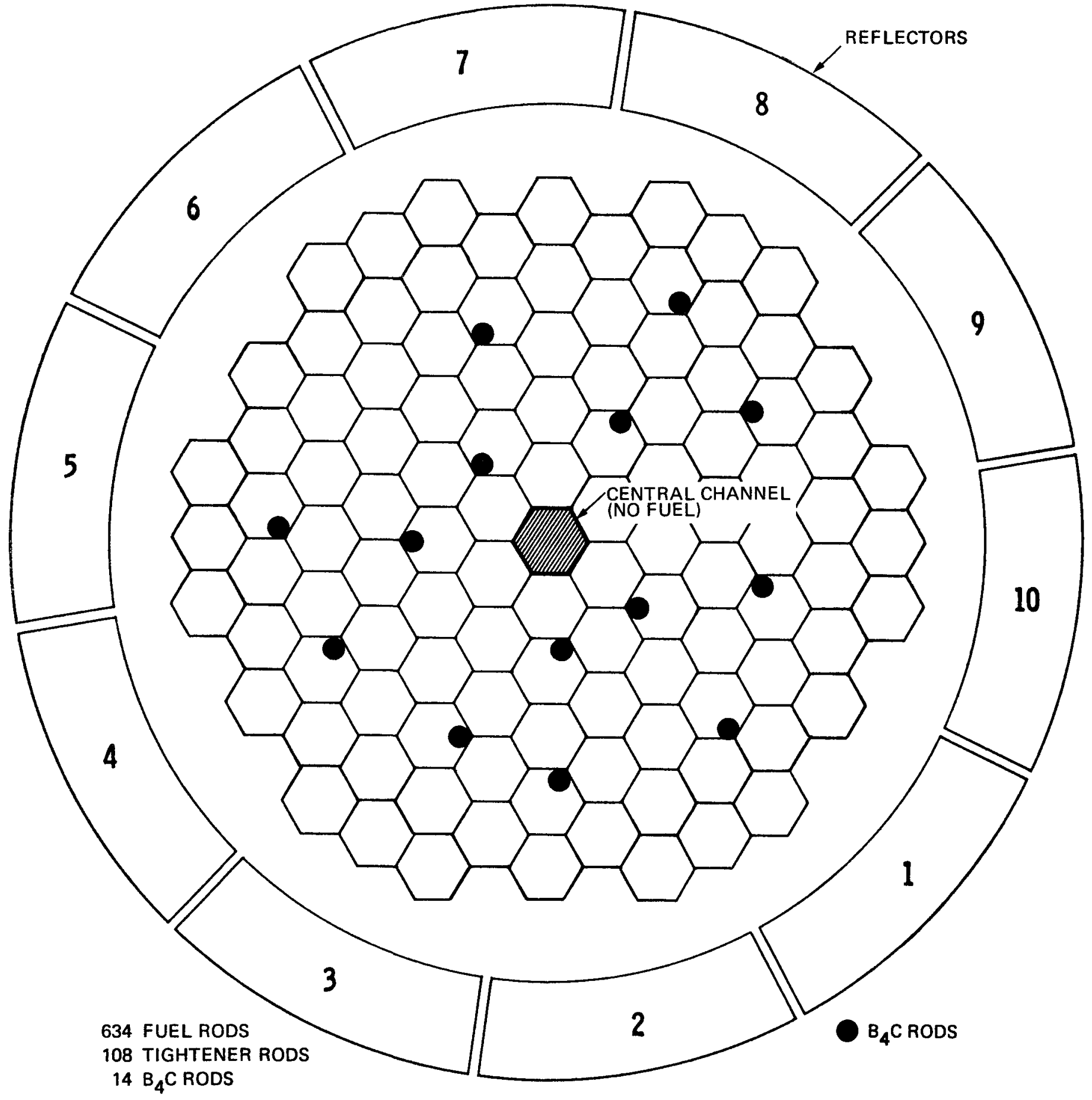

FIGURE 1-4. CORE LOADING FOR ASSEMBLY I-D 
GEAP-13588

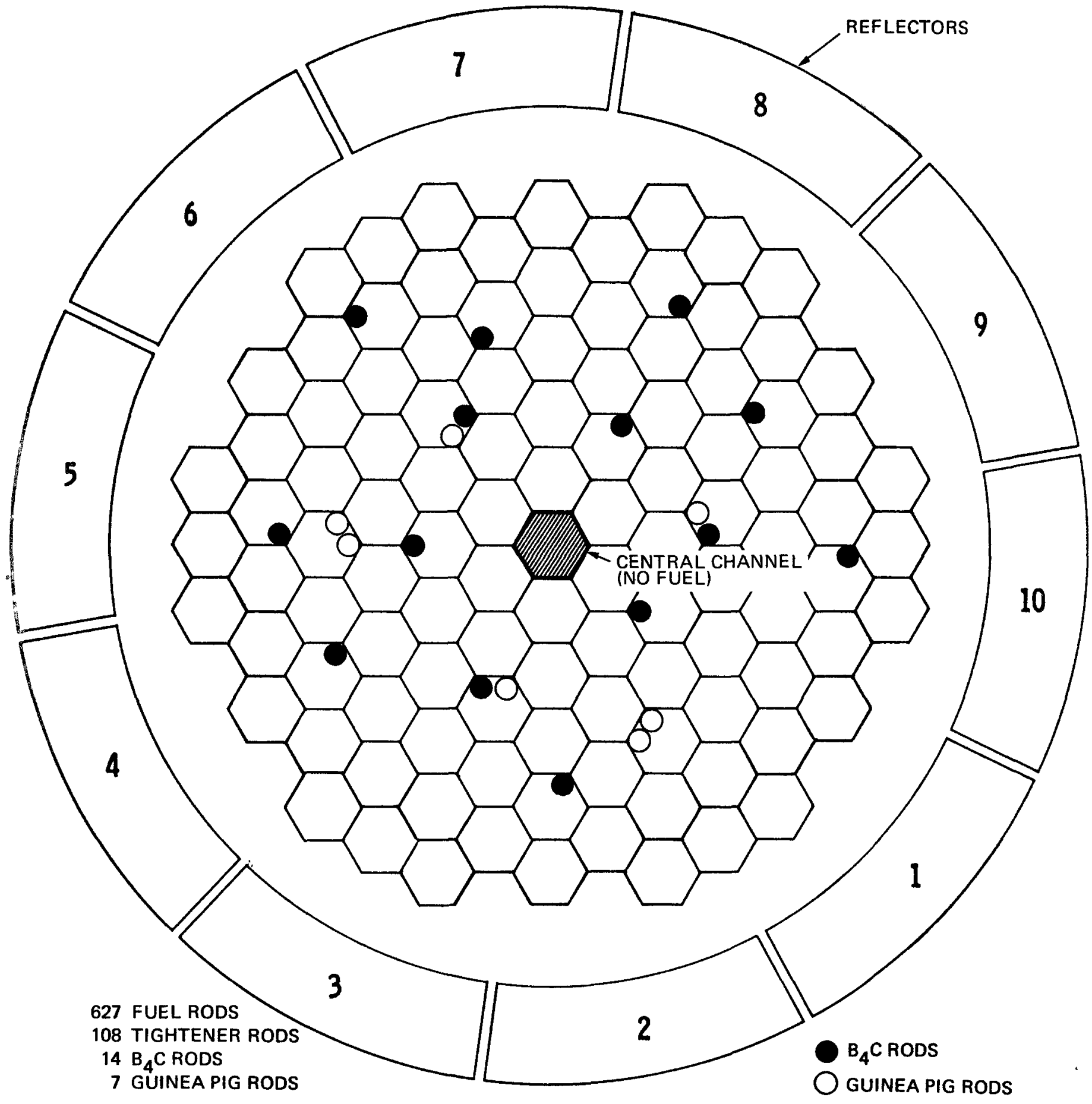

FIGURE 1-5. CORE LOADING FOR ASSEMBLY I-E 


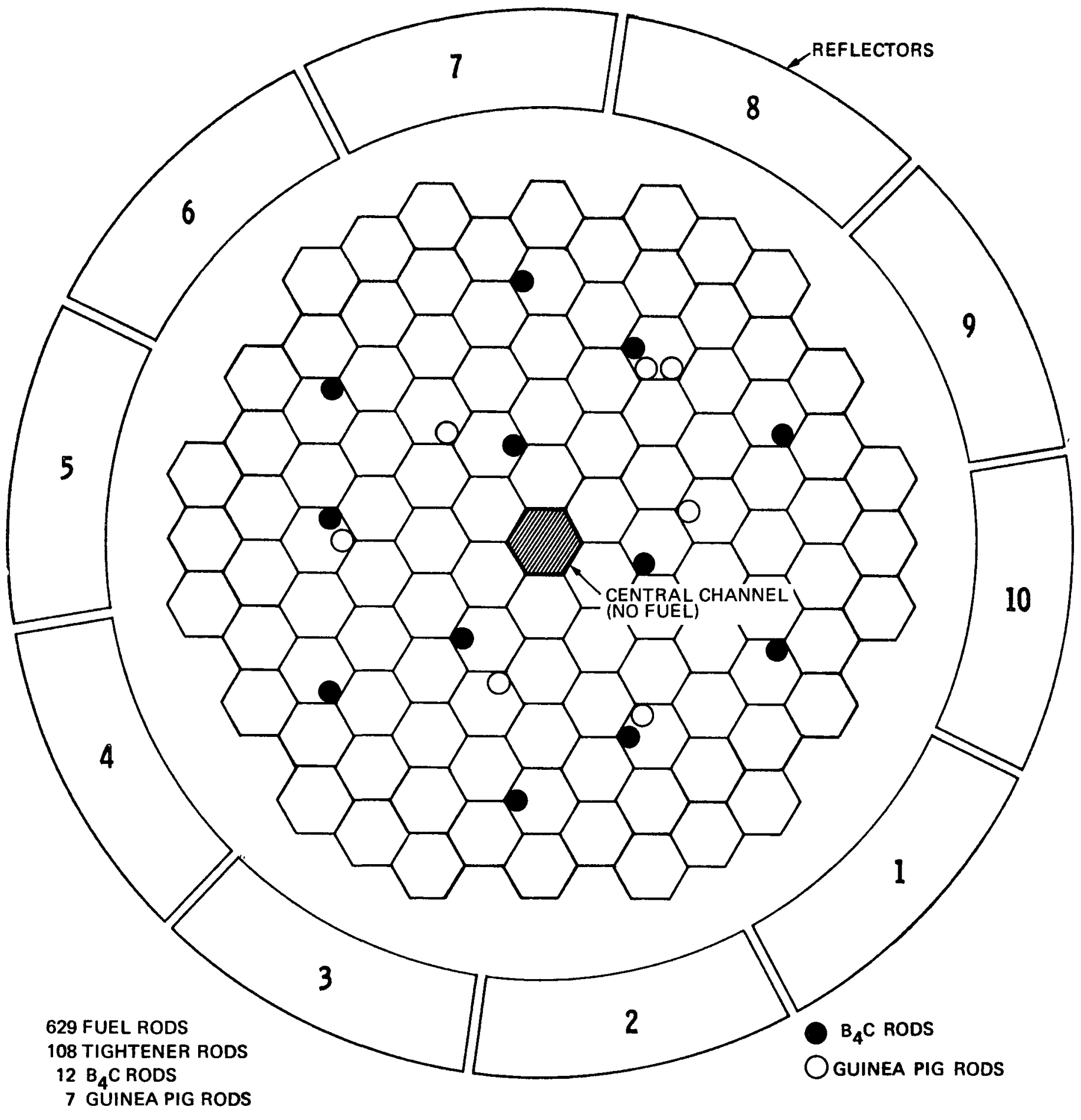

FIGURE 1-6. CORE LOADING FOR ASSEMBLY I-F 


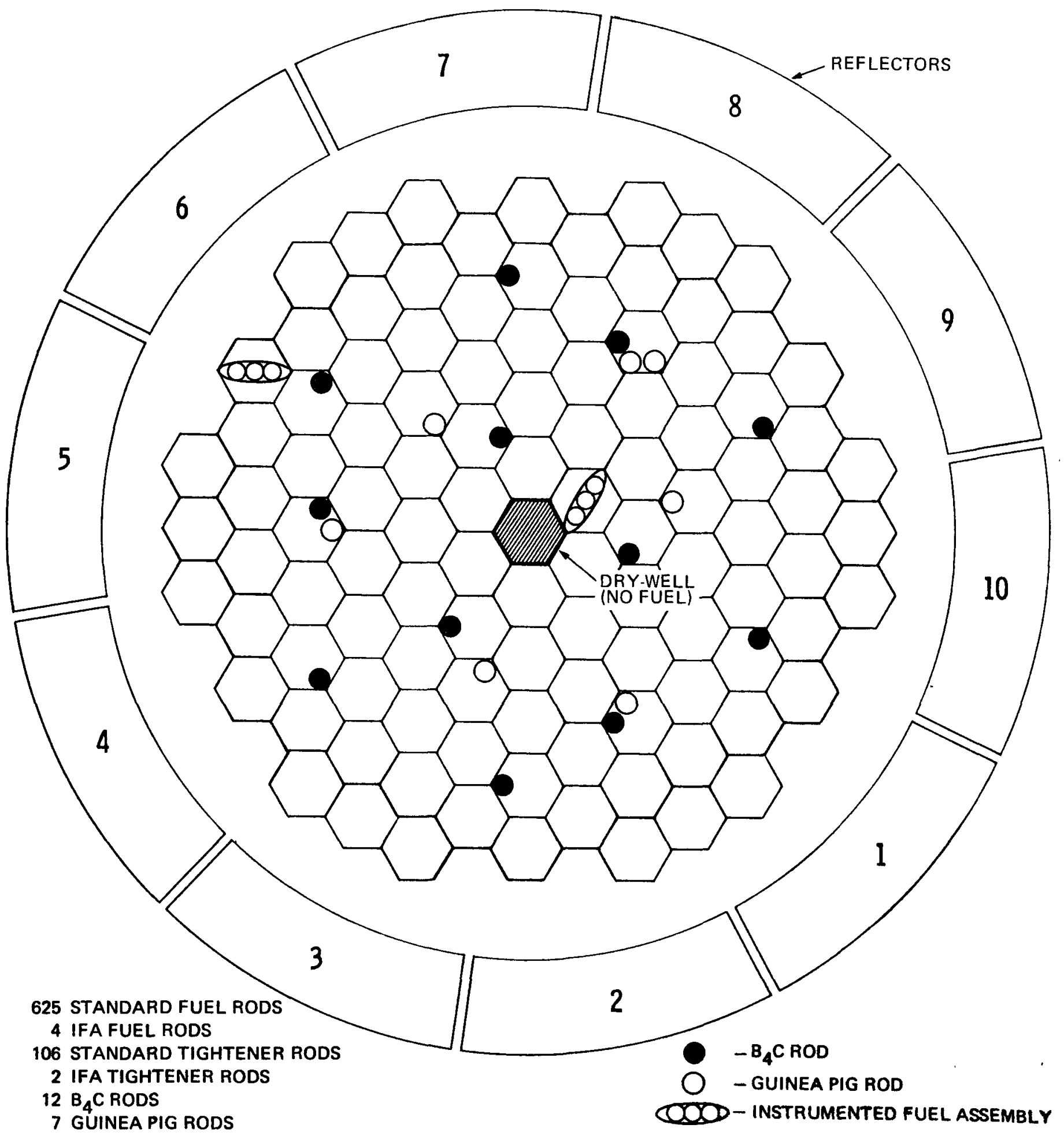

FIGURE 1-7. CORE LOADING FOR ASSEMBLY I-I 


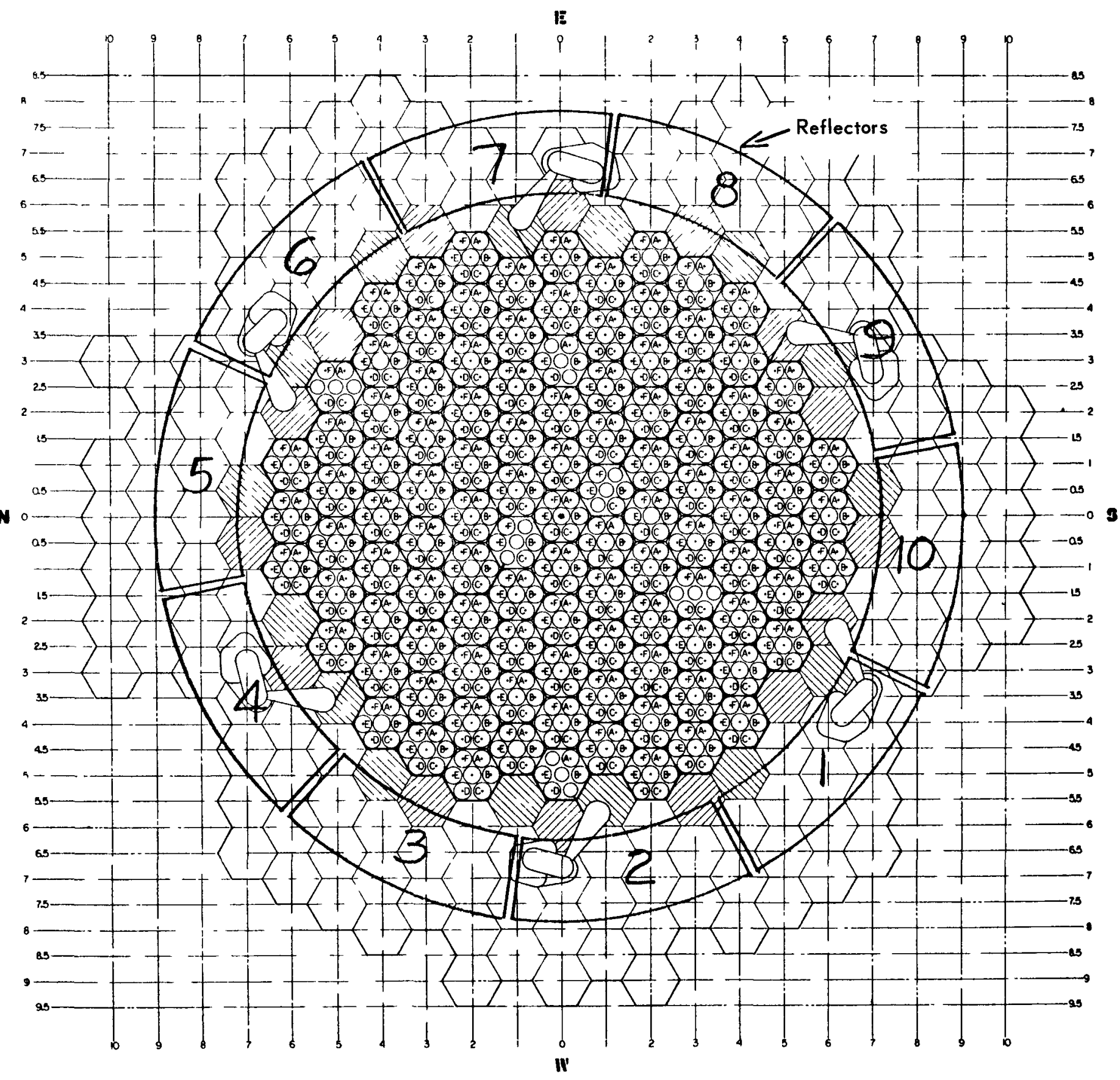

FIGURE 1-8. CORE LOADING LOCATIONS 


\section{MINIMUM CRITICAL CORE SIZE}

\subsection{PREDICTION OF THE MINIMUM CRITICAL SIZE}

\subsubsection{Calculated Results}

Calculations were performed prior to the initial SEFOR fuel loading to predict the minimum critical core size for the Southwest Experimental Fast Oxide Reactor (SEFOR). The predicted minimum critical loading was $519 \mathrm{PuO}_{2}-\mathrm{UO}_{2}$ fuel rods containing $285 \mathrm{~kg}$ of fissile $(\mathrm{Pu}-239+\mathrm{Pu}-241)$ plutonium, with one beryllium oxide tightener rod for each six fuel rods. The expected range of the minimum critical size was 265 to $307 \mathrm{~kg}$ (482 to 559 rods) corresponding to an estimated uncertainty of \pm 0.017 in reactivity. The actual minimum critical loading was equivalent to a core containing 518 standard fuel rods and the nominal 6-to-1 ratio of fuel-to-tightener rods.

The prediction was based on calculations which included a number of SEFOR core sizes ranging between approximately $65 \%$ and $100 \%$ of the fully loaded core, as well as the ZPR-3 Assembly 47 critical mockups $(1,2)$ of two SEFOR designs. One of these mockups was a one-fuel-segment design with no axial gaps between fuel pellets, while the other was the two-segment design used in the SEFOR reactor to decrease the reactivity effect of fuel axial expansion. 
The calculated results are shown in Table 2-1. The multiplication factors of the various reactor models are shown both before and after normalization to an average of the calculated values for the ZPR-3 oneand two-segment mockups. The multiplication factors were normalized by adding to the calculated values a constant chosen so that the average of the normalized multiplication factors for the one-and twosegment ZPR-3 Assembly 47 mockups were equal to unity. The predicted minimum critical core loading was then obtained by interpolation among the normalized multiplication factors.

Comparison of the normalized and calculated multiplication factors shown in the table indicates that the cross section data and methods used for these calculations are under-reactive by about $1 \%$. Hence, as indicated in the table, the predicted SEFOR minimum critical core size would have been 541 fuel rods (302 kg of fissile $\mathrm{Pu}$ ) if the calculations had not been normalized to the results for the ZPR-3 SEFOR mockups. Although the method of calculation for systems as complex as the SEFOR reactor and critical assembly mockups tends to obscure the amount of reactivity deficiency which may actually be present in the cross section data, the under-prediction of $k$ is consistent with other comparisons between calculation and experiment made

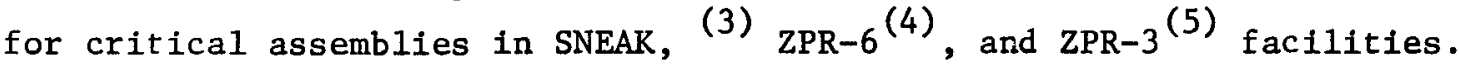

It is noted from a comparison of the ZPR-III one-segment and the ZPR-III two-segment values that the calculations appear to over-predict the negative reactivity due to the gap by about 0.01 . (A 0.007 overprediction of the negative gap effect was noted in the earlier calculations - see 2-dimensional results in Table 4-1 of Reference 2). The more highly negative gap effect in the present calculation may be due in part to the shift in the adjoint flux spectrum associated 
with the higher Pu-239 alpha in the current data, since there is an appreciable leakage of high energy neutrons from the core into the gap and a reverse leakage of low energy neutrons.

The curve of Figure $2-1$ is a plot of the normalized multiplication factors of Table 2-1 versus number of loaded fuel rods (648 rods are in the fully loaded core). The projected minimum critical configuration of 519 fuel rods is the point where the curve crosses $k=1.0$. The basis for the expected range of 265 to $307 \mathrm{Kg} \mathrm{Pu}$ is discussed in Section 2.1 .3 below.

The above calculated multiplication factors for the ZPR-3 mockups are in about the same range as those calculated earlier (see 2-dimensional, 4-group results in Table 4-1 of Reference 2). However, the $k$ values listed in Table 2-1 include about a $1 \%(0.01)$ reactivity increment as a transport theory correction for the diffusion theory over-estimate of leakage plus a correction for the ZPR-3 plate lattice heterogeneity effects (mainly the high energy selfmultiplication effect in the fuel plates, which is reduced by a smaller low energy "smooth" shielding effect and a small leakage effect, see Section 2.1.2); and no corrections were estimated for these effects in the earlier calculations. Thus, the cross section data used for the current calculations (Appendix I) are less reactive than those used for the earlier calculations by about 1\%. The higher Pu-239 alpha values in the present data (ORNL-RPI data) accounts for about a $1.4 \%$ reactivity loss; but this is partially compensated by a higher $\mathrm{Pu}-239$ fission cross section between 20 and $60 \mathrm{keV}$ in the present data. Several other differences in the data (See Appendix I) nearly cancel in their net reactivity effect. The difference in cross section 
GEAP-13588

TABLE 2-1

\section{CALCULATED $K$ FOR SEFOR AND ZPR-3 ASSEMBLY 47 MOCKUPS}

\section{Reactor Model}

Calculated $k^{(d)}$ $\underline{\text { Normalized } k^{(a)}}$
0.995
1.005
0.985
0.995

\begin{tabular}{|c|c|c|c|}
\hline SEFOR, & 419 Fuel Rods & 0.941 & 0.951 \\
\hline SEFOR, & 464 Fuel Rods & 0.966 & 0.976 \\
\hline SEFOR, & 512 Fuel Rods & 0.988 & 0.998 \\
\hline SEFOR, & 519 Fuel Rods $(\mathrm{b})$ & -- & $1.000^{(b)}$ \\
\hline SEFOR, & 541 Fuel Rods (c) & $1.000^{(c)}$ & -- \\
\hline SEFOR, & 554 Fuel Rods & 1.006 & 1.016 \\
\hline SEFOR, & 600 Fuel Rods & 1.022 & 1.032 \\
\hline SEFOR, & $\begin{array}{l}648 \text { Fuel Rods } \\
\text { (Ful1 Core) }\end{array}$ & 1.038 & 1.048 \\
\hline
\end{tabular}

(a). 0.01 added to calculated $k$ values to make the average $k$ of the ZPR-3 assembly 47 mockups equal to unity.

(b). SEFOR minimum critical core size predicted by interpolation.

(c). Minimum critical size that would have been predicted without normalization to the ZPR-3 Assembly 47 mockups.

(d). The correction factors of Table 2-3 are included. 


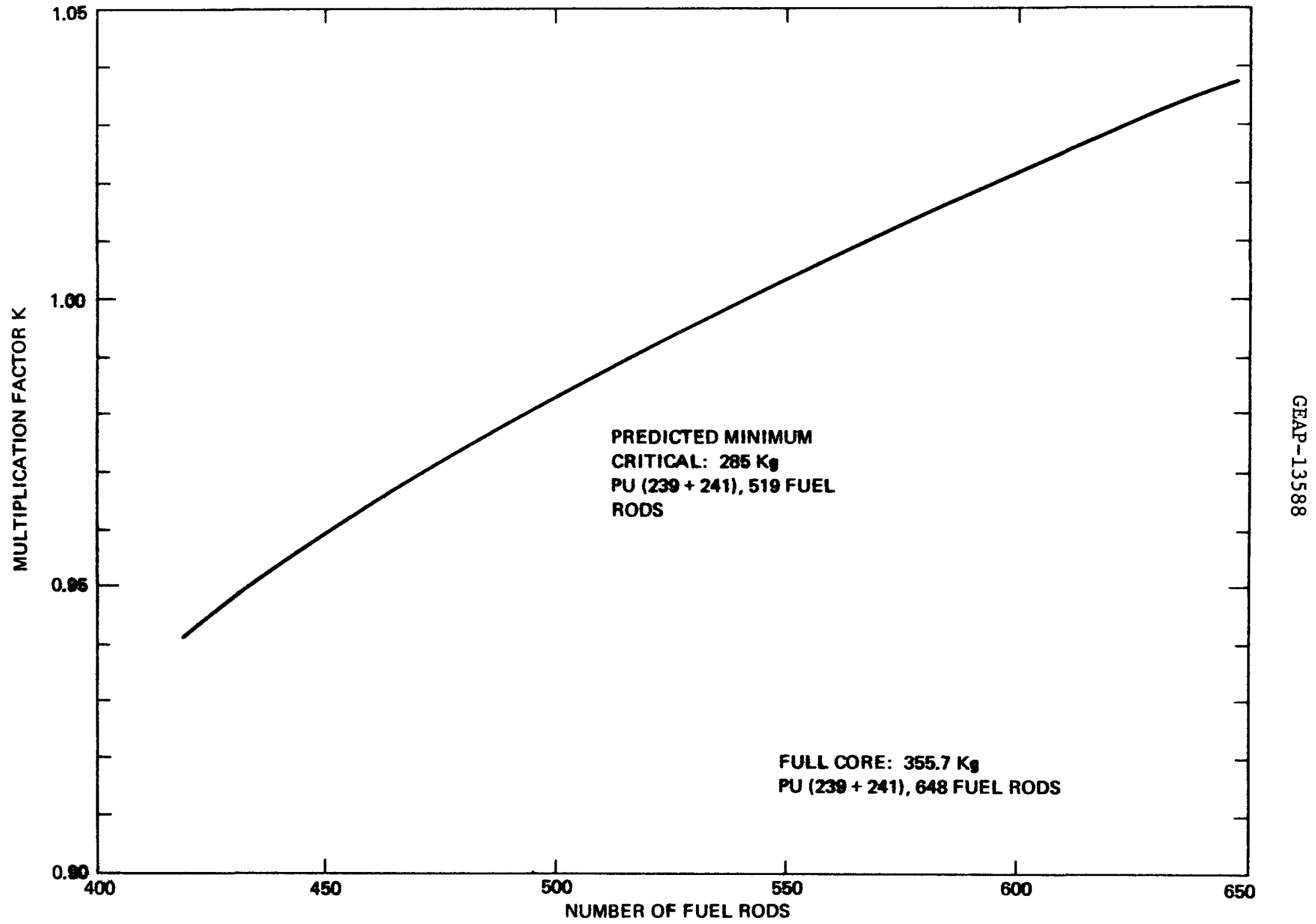

FIGURE 2-1. K VERSUS NUMBER OF LOADED FUEL RODS 
data used between the present and the earlier calculations might have a small effect on the critical mass prediction with respect to the contributions made by geometry or composition variations between the SEFOR reactor and the critical assembly mockup (e.g., the reactivity effect of the replacement of the BeO side rods with steel would be expected to be sensitive to the change in the $\mathrm{Pu}-239$ alpha).

\subsubsection{Calculational Methods}

The ZPR-3 and SEFOR reactor geometries were approximated by right circular cylinders of volumes equal to those of the reactors. The compositions of the different SEFOR core designs were assumed to be constant and the same as that of a standard fuel channel containing six fuel rods and one BeO tightener rod. The details of the ZPR-3 geometries are given in References 1 and 2, and a detailed description of the SEFOR geometry is given in Appendix $I$.

The cross sections used in the analysis were essentially those in the ENDF/B file, Version 1, distributed by Brookhaven National Laboratory in the summer of $1968,{ }^{(6)}$ with the exception of modifications to the fuel cross sections as noted in Appendix $I$.

The computational methods which were used included two-dimensional diffusion theory calculations ${ }^{(7)}$ with four and thirteen energy groups and two-dimensional synthesis calculations (8) that combined one-dimensional flux and adjoint solutions performed along the orthogonal coordinates. In addition, transport theory was used to obtain correction factors which were applied to the diffusion theory calculations. The results of the two-dimensional and synthesis 


\section{RESULTS OF SYNTHESIS AND DIFFUSION THEORY CALCULATIONS}

Reactor Mode1

ZPR-III, 1 Segment

ZPR-III, 2 Segment

SEFOR, 419 Fuel Rods

SEFOR, 464 Fuel Rods

SEFOR, 512 Fuel Rods

SEFOR, 554 Fuel Rods

SEFOR, 600 Fuel Rods

SEFOR, 648 Fuel Rods

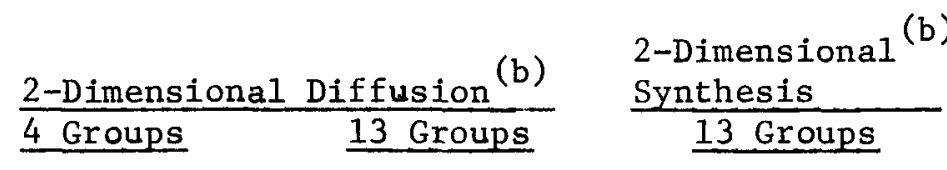
Normalized $k^{(a, b)}$

.989

.981
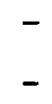

.988

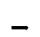

$-$

$-$

$$
.995
$$$$
.984
$$
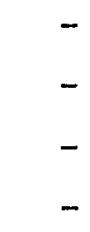

-
1.039

$$
.985
$$$$
.976
$$$$
.931
$$$$
.956
$$$$
.978
$$$$
.996
$$$$
1.012
$$

1.028
1.005

.995

.951

.976

.998

1.016

1.032

1.048

(a) Normalized so that the average of the multiplication factors for the one and two segment ZPR-3 Assembly 47 mockups is equal to unity.

(b) The correction factors listed in Table 2-3 are included. 
calculations are compared in Table 2--2. These multiplication factors listed in the table include the corrections of Table 2-3 which are discussed below.

The two-dimensiona1, 13-group diffusion theory results are the most reliable while the 4-group results are the most sensitive to approximations made to obtain the neutron spectra used for condensation of the group constants. The 13-group 2-dimensional synthesis consistently gave about a 0.01 lower multiplication factor than the 13-group direct 2-dimensional diffusion calculation. Because of this consistency, the 13-group synthesis results can be used to obtain differences in $k$ between the various SEFOR cases and the ZPR-III mockups, and only minor adjustments in these differences are required in order to give good agreement with similar differences calculated using the direct 13-group 2-dimensional computation. The "calculated $K^{\prime \prime}$ values of Table 2-1 were therefore obtained by using the results of synthesis calculations (including the corrections of Table 2-3) to interpolate to SEFOR core sizes for which a true two-dimensional calculation had not been performed.

The correction factors which were applied to the diffusion theory calculations are summarized in Table 2-3. The corrections are for the following effects:

a) Estimated over-prediction of core leakage by diffusion theory (based on comparisons between two-dimensional, 4-energy-group $\mathrm{S}_{4}$ transport calculations, and two-dimensional, 4-group diffusion calculations using the DOT2DB $(7)$ code).

The over-prediction of core leakage with diffusion theory was calculated for the ZPR-III 2-segment core using 4-group, 
TABLE 2-3

\section{CORRECTIONS TO DIFFUSION THEORY CALCULATIONS}

\begin{tabular}{lrrrr} 
Correction Factor & ZPR-III & ZPR-III & SEFOR & SEFOR \\
& $\underline{1-S e g m e n t}$ & $\underline{2-S e g m e n t}$ & $\underline{512 \text { Rods }}$ & \\
\hline
\end{tabular}

a) Transport Core Leakage

$+0.0086$

$+0.0089$

$+0.0097$

$+0.0089$

b) Ce11 Heterogeneity

High Energy
Low Energy
Leakage

$+0.0067+0.0067$

$+0.0042$

$+0.0042$

$-0.0017$

$-0.0017$

$-0.0004$

$-0.0004$

$-0.002$

$-0.002$

$-0.001$

$-0.001$

c) Excess Reactivity in ZPR-III Mockup Models

$-0.0073$

$-0.0042$

d) Non-cylindrical Outer Periphery

-

$-0.003$

$-0.003$

e) Doppler Effect

$\left(80 \rightarrow 350^{\circ} \mathrm{F}\right)$

$-$

$-0.003$

$-0.0033$

f) Overshielding Nickel Reflector

$+0.001$

$+0.001$

$+0.001$

$+0.001$

Total Correction

$+0.0053$

$+0.0087$

$+0.0075$

$+0.0064$ 
2-dimensional $\mathrm{S}_{4}$ transport calculations and 4-group, 2dimensional diffusion calculations with the DOT2DB $(7)$ code. The transport reactivity corrections for the full SEFOR core listed in Table 2-3 (+0.0089) was made the same as that calculated for the ZPR-III, 2-segment mockup. A slightly higher transport correction $(+0.0097)$ was calculated for the sma1ler (512 rod) core. Corrections for SEFOR cores containing other than 512 or 648 rods were obtained by interpolation. The calculated transport correction for the ZPR-III, 1-segment core $(+0.0086)$ was not significantly different than that of the two-segment core. It is noted that the above transport effects obtained with two-dimensional calculations are nearly twice as large as those which would be estimated from results of earlier transport $\mathrm{S}_{4}$ and diffusion calculations which used onedimensional spherical reactor models

b. High energy and low energy heterogeneity effects (over-andabove resonance self-shielding) of the ZPR-III plate lattice cells and the SEFOR rod lattice cell (based on one-dimensional, 24-group $\mathrm{S}_{16}$ transport cell calculations using the SNlD code, ${ }^{(10)}$ and confirmed using an independent analytical mode1). Also included are estimated negative reactivity effects due to increased leakage associated with the lattice heterogeneity.

Clumping of the fuel plates in the ZPR-III mockups produces a fuel flux advantage factor at high energies (the energy region of the fission source) which results in a significant positive reactivity. At lower energies, this heterogeneity in the ZPR-III lattice cells produces a flux disadvantage factor in the fuel plates which results in a negative reactivity with magnitude appreciably smaller than the positive high energy 
effect. (This low energy effect is in addition to the usual correction on the effective potential scattering cross section used to account for cell heterogeneity). The rodded SEFOR fuel has similar heterogeneity effects, even though all the uranium, plutonium and most of the oxygen is homogeneous, because of the large rod diameters and correspondingly large spaces of $\mathrm{Be} 0$, steel, and sodium between the rods.

For ZPR-III Assembly 48, one-dimensional cell transport calculations using up to 16 -angles ( $S_{16}$ method) with anisotropic scattering done at $\mathrm{PNL}{ }^{(11)^{6}}$ gave a positive reactivity of about t0.014 for the high energy effect and about -0.003 for the low energy effect. ZPR-III Assembly 47 the SEFOR mockup - has a much more complex lattice arrangement than did Assembly 48 - in fact there are several different lattice arrangements in Assembly 47 which were made necessary, in part, because of the use of the new mixed U-Pu plates in the central region of the core and the old Pu plates in the outer region. Previous studies of the ZPR-III Assembly 48 high energy heterogeneity effect by Wintzer ${ }^{(12)}$ yielded simplified mathematical relationships for estimating flux advantage factors which were found to give good agreement with actual cell transport calculations. The estimates of the high energy heterogeneity effect for the ZPR-III mockups and for the SEFOR rod cell based on Wintzer's analysis are given in Appendix II.

The results of cell transport theory calculation using 24 energy groups, 16 angles and anisotropic scattering to determine 
the heterogeneity effects of Table 2-3 are also described in Appendix II.

c. Reactivity reduction due to partially withdrawn control drawer or nickel reflector segment in the ZPR-III critical configurations. (1) Such withdrawn control elements were not taken into account in the calculational model.

d. Reactivity reduction due to the non-cylindrical outer periphery of the SEFOR full core and in the less predictable loading patterns during the approach to the minimum critical configuration.

The computations performed for this analysis were based on cylindrical approximations of the reactor geometry in which the core volume is preserved. The two ZPR-III mockups were loaded in a manner which simulates a cylinder, while the fully loaded SEFOR core has a highly irregular hexagonal boundary which departs considerably from a true cylinder. It was assumed that the minimum critical configuration in SEFOR would be approached in a sequence that would maintain as closely as possible a cylindrical surface; but considerable surface irregularities were expected to occur. Earlier calculations of the fully loaded SEFOR core using an equal volume cylinder resulted in multiplication factor which was 0.003 higher than that obtained with the outer-most radial fuel pins homogenized with material just outside the core. (13) The correct value is expected to lie between these two cases, probably closer to the model using the homogenized core sodium interface region for the fully loaded SEFOR core. The full 0.003 reduction was applied to the cylindrical equal-area model used for all the SEFOR reactor cases calculated, and no correction was applied to the ZPR-III critical assembly cases. 
e. SEFOR Doppler reactivity effect from $300^{\circ} \mathrm{K}$ to $350^{\circ} \mathrm{F}$. The Doppler broadened fuel material cross sections were computed at a temperature of $300^{\circ} \mathrm{K}$ because of limitations in the cross-section generation code. For this correction a value of -0.008 was used for the Doppler coefficient

$\mathrm{T} \frac{\mathrm{dk}}{\mathrm{dT}}$

f. The estimated effect caused by the overshielding of the nickel reflector cross sections. The radial reflector zones used in this analysis were dimensioned to include the movable nickel reflectors in a separate zone. Resonance self-shielding factors were determined for this nickel from tables in Bondarenko ${ }^{(14)}$ and from factors generated with the ENDRUN code. (15) A $\sigma_{\circ}$ value of 0.1 , estimated from the total cross sections of other materials in the zone, was used to compute the self-shielding factors. An additional surface effect will lessen the degree of selfshielding and improve the computed reflector worth. An estimated correction to the multiplication factor for this surface effect has been included in Table 2-3. 


\subsubsection{Uncertainty Estimates}

The predicted minimum critical configuration of $285 \mathrm{Kg} \mathrm{Pu}(239+241)$ (see Figure 2-1) had an expected range corresponding to \pm 0.017 in reactivity - which was considered to be one standard deviation. The \pm 0.017 reactivity range was calculated from the following estimated components :

a. Geometry defects in SEFOR computational model. $\quad+0.005$ The treatment of the departure of the outer core periphery from a cylindrical surface appears to be the main defect.

b. Uncertainty in effect of $B e O$ reduction. The $\pm 0.003$ ZPR-3 assemblies were mockups of SEFOR cores containing BeO side rods. These rods were replaced with stainless steel in the actual SEFOR core. The effect of this reduction on the multiplication factor was not measured in the $2 P R-3$ mockups.

c. Uncertainty in fissile weight of fabricated $\pm 0.002$ fuel. (The anticipated "grand average" fissile plutonium $(\mathrm{Pu}-239+\mathrm{Pu}-241)$ weight was $548.9 \pm 2$ grams per rod.

d. Uncertainty in effect of central FRED $\pm 0.003$ channel (not present in the ZPR-3 mockups) and in the spacing between fuel channels (believed to be $10 \mathrm{mils}$ in SEFOR). 
e. Uncertainty in lattice heterogeneity effect $\pm 0.004$ differences between the SEFOR rod system and the ZPR-III plate system. (This uncertainty has been appreciably reduced as a result of transport cell calculations - see Section 2.1.2).

f. Uncertainties in differential neutron leakage $\quad+0.006$ (and other gap effects) between SEFOR and the ZPR-3 two-segment mockup. (This uncertainty is accentuated by the persistent over-prediction of the negative reactivity of the fuel gap in going from the one-segment to the two-segment critical assembly - even with 2-dimensional transport theory calculations.)

g. Sensitivity of the difference in $\mathrm{k}_{\text {eff }}$ between \pm 0.005 the SEFOR cores and the ZPR-III critical assemblies to the specific multigroup calculation scheme used.

Correlating the three effects above dependent mainly on neutron leakageitems $a, d$, and $f$ - leads to a propagated uncertainty of \pm 0.017 .

Item $f$ above is one of the largest uncertainties and, as noted above, its magnitude is influenced by the apparent over-prediction of the negative reactivity effect of the fuel gap in the $\mathrm{ZPR}-3$ mockup. It is possible that the 2-dimensional, 4-group transport calculations used 
did not adequately reduce the difference in multiplication factor between the one-segment and the two-segment critical assemblies because of the inadequacy of a 4-energy group approximation for accurate treatment of the high energy leakage effects; or gap heterogeneity effects not properly taken into account in the calculational model may be responsible for a large part of the persistent over-prediction of the negative reactivity due to the fuel gap. (A 50\% reduction in the U-238 capture in the gap would account for only 0.003 of the 0.01 reactivity defect.) Nevertheless, the over-prediction remained substantial and was not accounted for. For that reason, it appeared that complete reliance for the prediction of $k$ in SEFOR should not be placed on normalization to only the ZPR-III, 2-segment experiment, which would assume that the calculation is entirely in error in its apparent over-prediction of the negative reactivity produced by the fuel gap. Rather it appeared highly possible that some other unidentified factors in the 1-segment and/or 2-segment mockups might not have been properly accounted for in the computational model; and, hence, the normalization of SEFOR $k$ values was made to both the 1-segment and the 2-segment critical assemblies.

\subsection{EXPERIMENTAL FUEL LOADING RESULTS}

\subsubsection{Initial Critical Core (Assembly I-A)}

Initial criticality in SEFOR was attained with a core loading of 550 fuel rods. The core arrangement for this loading (Assembly I-A) is shown in Figure 1-1. The excess reactivity of the system was $9.5 \mathrm{C}$ at a sodium temperature of $350^{\circ} \mathrm{F}$. Later investigations revealed that a 
number of the fuel rods in this core were low in reactivity worth as compared to a standard rod. After calibration of the reflector control system and performance of a few experiments, the low worth rods were removed and a minimum critical loading of 522 fuel rods and 100 tightener rods (Assembly I-C) was obtained. A description of this core is given in Section 1.3.

\subsubsection{Critical Approach}

The initial critical approach in SEFOR was performed in a conventional manner. Fuel was loaded in a roughly cylindrical pattern about the core center with the reflector control in the lowered leastreactive-position. Steady state count rates on two He-3 detectors locatea in the central channel and on two source range monitors (BF $_{3}$ detectors) located below the core were recorded. The reflectors were raised and the observed steady state count rates were recorded again. The data was used to estimate the critical size and to determine the next fuel loading increment. More fuel was then loaded, and the counting-estimating-loading process was repeated until criticality was attained with all reflectors in the raised (most reactive) position. Usually, each channel of the core was completely filled with six fuel rods and secured with a tightener rod prior to proceeding to the next channel of the core. However, after loading of a total of 504 fuel rods, single rods were placed in circumferential channels to maintain, as near as possible, cylindrical symmetry in the near-critical core.

A total of 19 incremental loading steps were used in the initial approach to critical. A total of 36 fuel rods and 6 tightener rods were loaded as a part of the first step and each of the Helium-3 detectors, preassembled in its individual tube, was then loaded into the center of the core. Due to the length of these tubes and the 
width of the fuel grapple head, six channels immediately surrounding the central channel were completely loaded with fuel prior to insertion of the detectors.

The data obtained during the 19 loading steps are summarized in Table 2-4. The tabulated count rate data include the dead time corrections described in Appendix III. The corrections for the count rates in the in-core detectors became quite large with the reflectors raised after approximately 520 rods had been loaded, and they were switched to the current mode of operation for loading step thirteen. The count rates on each in-core counting channel were repeated at least five times to accumulate a total of at least 10,000 counts, in order to obtain better than $1 \%$ statistical accuracy. The count rate data was statistically analyzed to obtain the standard deviations and probable error in order to establish the consistency of the data. Chisquared testing was also done to ensure the proper operation of the counting equipment throughout the fuel loading.

The count rate data adjusted for the dead time corrections discussed in Appendix III, is shown in Figures 2-2 through 2-4. The solid lines in Figures $2-3$ and 2-3 represent a best fit of a one energy group fundamental mode description (see Appendix IV) of the flux at the core center to the experimental count rate data observed on the centrally located in-core detectors. The upper curves describe the data obtained when all the reflectors were lowered, while the lower curves correspond to data obtained when the reflectors were in the raised (most reactive) position. Except for deviations at very small core loadings, the data indicated an essentially linear relationship 
TABLE 2-4

COUNT RATES ON START UP CHANNELS

\begin{tabular}{|c|c|c|c|c|c|c|c|}
\hline \multirow{2}{*}{$\begin{array}{l}\text { Loading Step } \\
\text { Number } \\
\end{array}$} & \multirow[b]{2}{*}{$\begin{array}{l}\text { Number of Fuel } \\
\text { Rods in Core } \\
\end{array}$} & \multicolumn{2}{|c|}{ Reflectors Down } & \multirow[b]{2}{*}{$\begin{array}{l}\text { Average SRM* } \\
\text { Count Rate } \\
\frac{(\text { counts/min })}{1}\end{array}$} & \multicolumn{3}{|c|}{ Reflectors Up } \\
\hline & & $\begin{array}{l}\text { In-core } \\
\text { Detector } \\
\text { No. } 1 \\
\text { (counts/sec) }\end{array}$ & $\begin{array}{l}\text { In-Core } \\
\text { Detector } \\
\text { No. } 2 \\
(\text { counts } / \text { sec })\end{array}$ & & $\begin{array}{l}\text { In-Core } \\
\text { Detector } \\
\text { No. } 1 \\
\text { (counts/sec) }\end{array}$ & $\begin{array}{l}\text { In-Core } \\
\text { Detector } \\
\text { No. } 2 \\
\text { (counts/sec. }\end{array}$ & $\begin{array}{l}\text { Average SRM* } \\
\frac{\text { Count Rate }}{\text { (counts/min) }} \\
\text {.) }\end{array}$ \\
\hline $1 \mathrm{a}$ & 36 & 113.4 & 134.0 & 18 & 138.8 & 164.6 & 24 \\
\hline $1 b$ & 108 & 347.5 & 418.4 & 73 & 394.3 & 471.5 & 103 \\
\hline 2 & 216 & 936.8 & 1131 & 202 & 1081 & 1302 & 316 \\
\hline 3 & 282 & 1442 & 1735 & 314 & 1742 & 2099 & 518 \\
\hline 4 & 348 & 2310 & 2788 & 498 & 3031 & 3655 & 903 \\
\hline 5 & 402 & 3210 & 3865 & 687 & 4684 & 5636 & 1396 \\
\hline 6 & 456 & 4676 & 5657 & 1005 & 8336 & 10070 & 2524 \\
\hline 7 & 486 & 5999 & 7275 & 1297 & 13400 & 16160 & 4052 \\
\hline 8 & 504 & 7212 & 8686 & 1530 & 20730 & 24870 & 6108 \\
\hline 9 & 516 & 8385 & 10080 & 1775 & 32080 & 38460 & 9361 \\
\hline 10 & 524 & 8997 & 10800 & 1896 & 41460 & 50100 & 12370 \\
\hline 11 & 531 & 9543 & 11390 & 2007 & -- & -- & 16480 \\
\hline 12 & 534 & 9742 & 11670 & 2054 & -- & -- & 18950 \\
\hline 13 & 540 & -- & -- & 2117 & -- & -- & 26870 \\
\hline 14 & 545 & -- & -- & 2316 & - & -- & 80660 \\
\hline 15 & 546 & -- & -- & 2337 & -- & -- & 97800 \\
\hline 16 & 547 & -- & -- & 2369 & -- & -- & 145600 \\
\hline 17 & 548 & -- & -- & 2340 & -- & -- & 276500 \\
\hline 18 & 549 & -- & -- & 2577 & -- & -- & 721900 \\
\hline 19 & 550 & -- & -- & -- & -- & -- & Critical \\
\hline
\end{tabular}




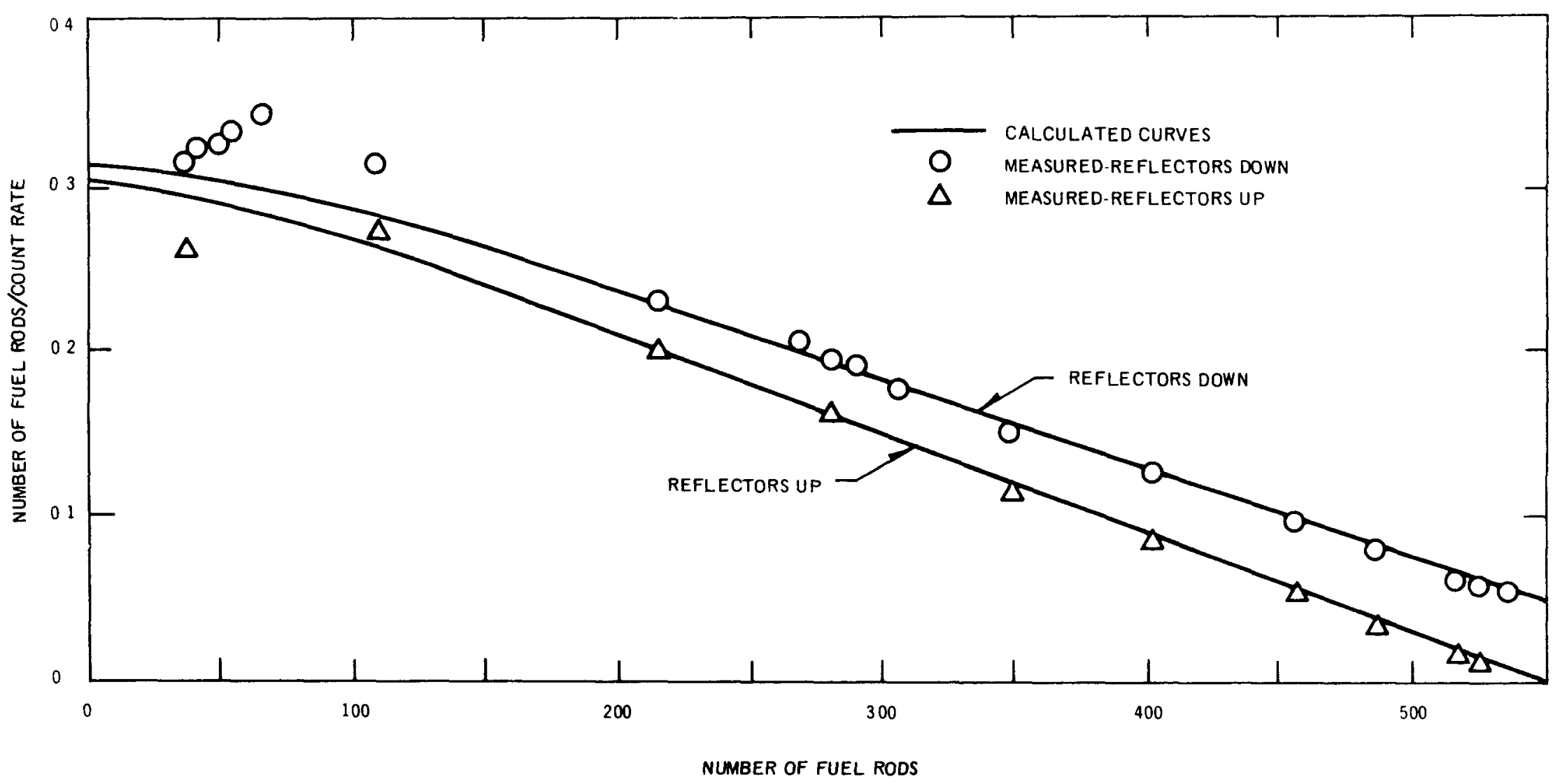

FIGURE 2-2. CRITICAL APPROACH USING IN-CORE DETECTOR NO. I 


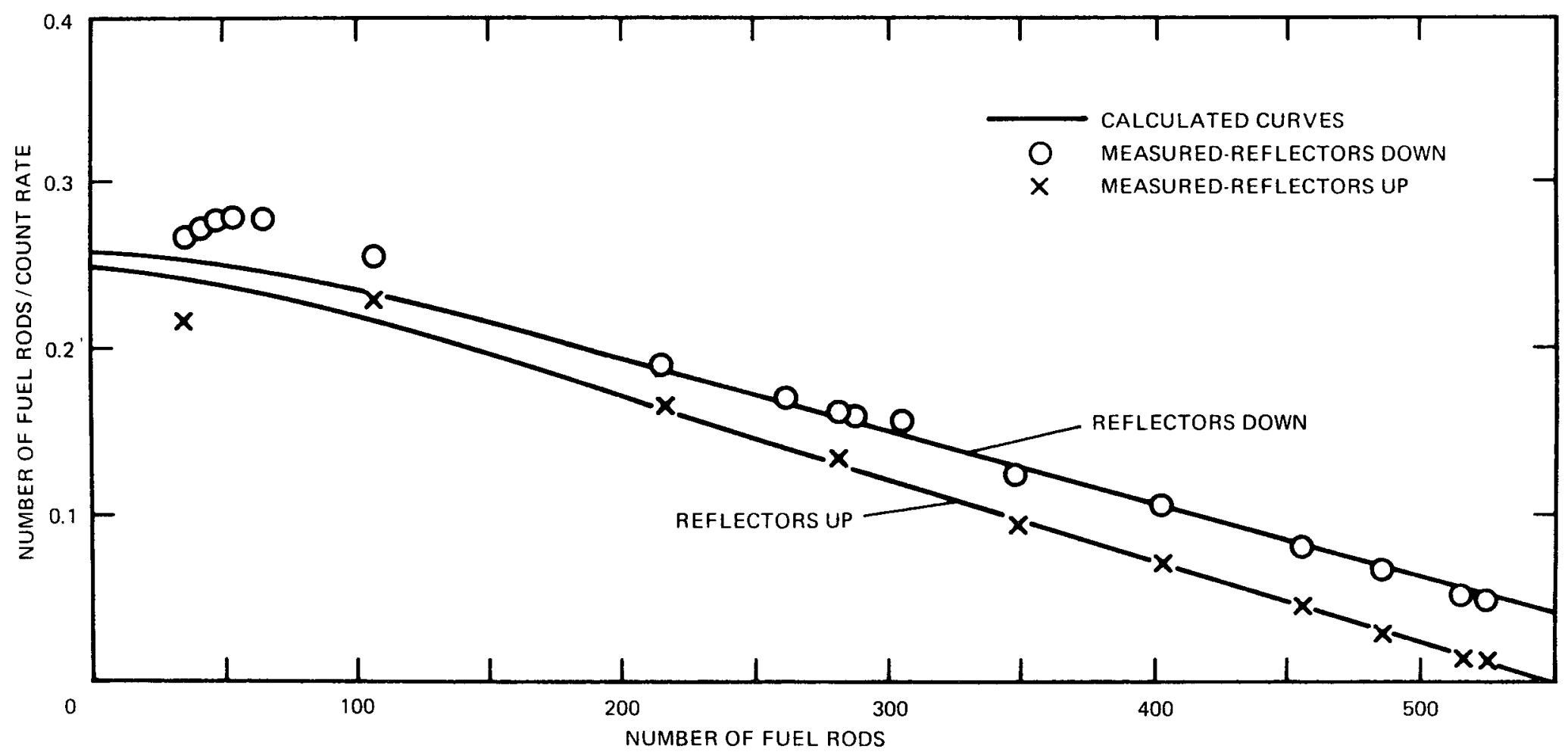

FIGURE 2-3. CRITICAL APPROACH USING IN-CORE DETECTOR NO. 2 


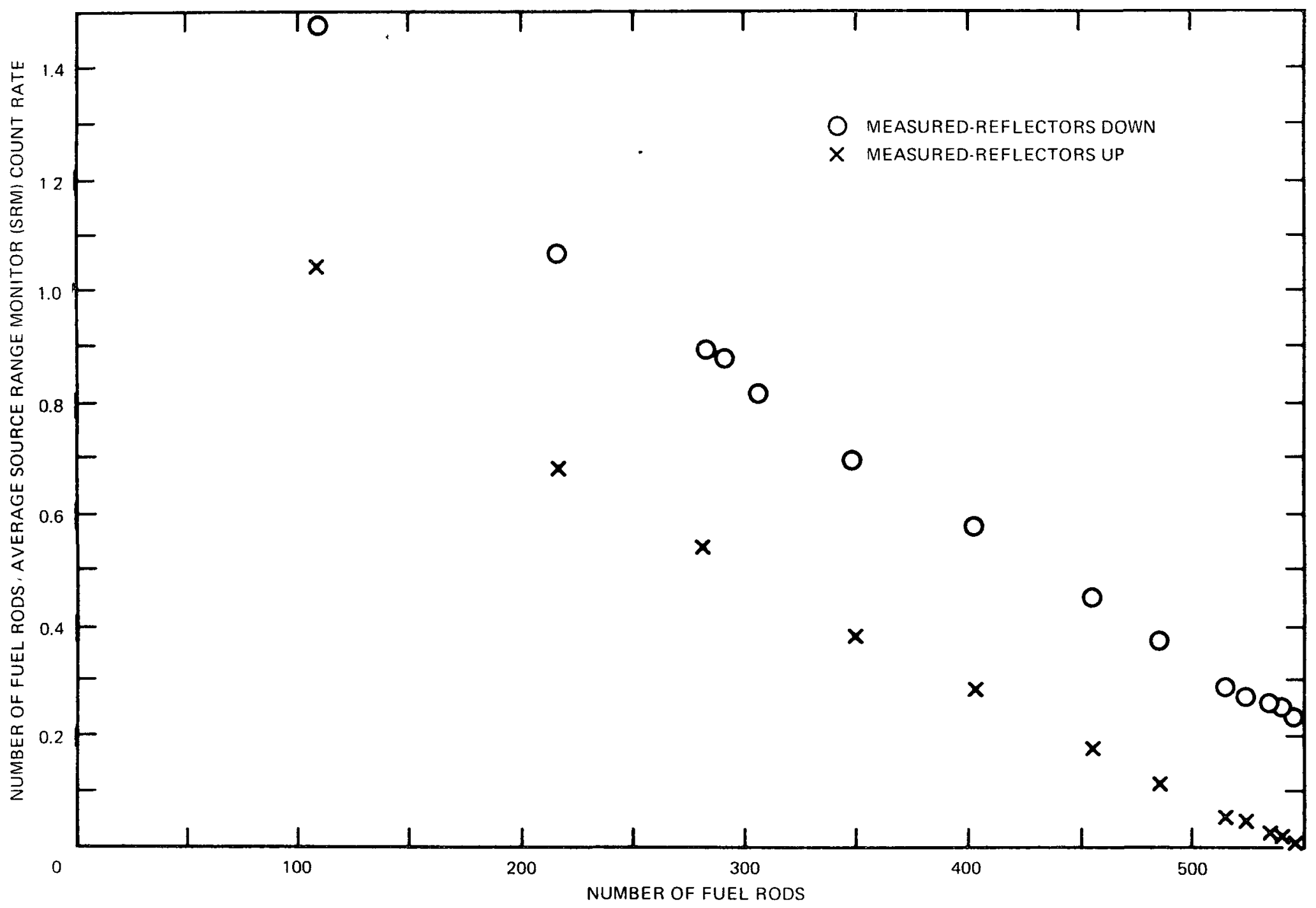

FIGURE 2-4. CRITICAL APPROACH USING THE AVERAGE COUNT RATES FROM TWO SOURCE RANGE MONITORS 
between: (1) the ratio of the number of fuel rods divided by the count rate, and (2) the number of fuel rods in the core. The agreement between experiment and calculation is better than might be expected in view of the inability of this simple model (Appendix IV) to account for spectral changes with core size and reflector position, the noncylindrical loading patterns, and the multidimensional spatial effects.

As Figures 2-2 through 2-4 indicate, it was thus clear, even before initial criticality was achieved, that the initial critical size would exceed the predicted value by some 30 fuel rods. The actual initial critical loading in SEFOR was 550 fuel rods. Subsequent investigations revealed that a number of the fuel rods in this core were as much as $40 \%$ low in reactivity worth when compared to a standard rod. The very low worth fuel rods were replaced and the core size was reduced by removing fuel from the core boundary.

\subsection{COMPARISON OF EXPERIMENTAL RESULTS WITH PREDICTION}

The actual SEFOR minimum critical core loading was $522 \mathrm{PuO}_{2}-\mathrm{UO}_{2}$ fuel rods and $100 \mathrm{BeO}$ tightener rods. The core arrangement for this loading is shown in Figure 1.3. The excess reactivity of this nearly cylindrically loaded assembly was approximately $0.9 \mathrm{c}$ with all reflectors raised at a sodium temperature of $350^{\circ} \mathrm{F}$.

In order to compare the experiment with prediction, the following two effects had to be accounted for:

\section{The experimental assembly contained 13 BeO tightener} rods over and above the standard fuel channel composition of one tightener rod for each six fuel rods. These extra tightener rods were not accounted for in the original prediction. 
GEAP-1 13588

2. The core cont ained approximately 50 fuel rods near the core center whose average reactivity worth was slightly lower ( $4 \%$ ) than that of the reference rods.

The estimated corrections to the minimum critical core size which could in principal have been made to of fet the effects noted above are summarized in Table 2-5. The addition of four fuel rods to compensate the postulated removal of the excess tightener rods is based on material reactivity worths in this assembly of $12 c$ for a peripheral fuel rod and $4 c$ for a peripheral BeO tightener rod. (The measured values of these worths agree with the calculated values.) The corresponding correction for the replacement of the slightly low worth rods by standard rods near the core center would be 8 fuel rods on the core periphery. The multiplication factor for the actual minimum critical core is thus equivalent to that of a core containing 518 standard fuel rods and the nominal 6-to-1 ratio of fuel-to-tightener rods.

Both the prediction based on results of a critical experiment mockup ( 519 rods), and the value which would have been predicted by calculation alone (541 rods) are in reasonable agreement with experimental results ( 518 rods). Although the correction in prediction caused by normalization to the critical assembly mockup was small (22 rods or about $1 \%$ in $k$ ) in this case, it was not insignificant. In view of their dissimilarities, it is highly encouraging, in fact, that such a close prediction can be made of the critical fuel loading for a rod-type core based on normalization of calculations to a platetype critical assembly mockup. 
TABLE 2-5

COMPARISON OF PREDICTED AND EXPERIMENTAL MINIMUM CRITICAL CORE

\author{
Predicted Core Size \\ 519 Fuel Rods \\ (6-to-1 ratio of fuel-to-tightener rods) \\ Experimental Core Loading \\ 522 Fuel Rods \\ (with 100 BeO tightener rods) \\ Correction for Excess Tightener Rods \\ (+4) Fue1 Rods \\ Correction for Low Worth Fuel \\ (-8) Fuel Rods \\ Equivalent Experimental Core Loading \\ 518 Fuel Rods \\ (with composition used in prediction)
}




\section{REFLECTOR CALIBRATIONS}

\subsection{CALCULATED REFLECTOR STRENGTH}

Total reflector control worth for the minimum critical core ${ }^{(1)}$ was calculated using 4-energy-group, 2-dimensional, $\mathrm{S}_{4}$ transport theory. These calculations were compared with the earlier prediction of the control worth ${ }^{(2)}$ which was based on diffusion theory calculations using modified boundary conditions to treat the voided region left when the reflectors are lowered. The latter calculation also relied on extrapolation of experimental results obtained from the single-rod and the quadrant-rod measurements done in the ZPR-III critical assembly mockup of the full core. (3) With transport theory the voided region with reflectors down was incorporated directly into the multigroup computational model, thereby providing a check of the earlier diffusion theory calculations by use of an appreciably different method.

The transport calculations gave a total reflector reactivity control worth of 0.036 for the minimum critical core. The calculation was performed for a core containing 512 fuel rods instead of the actual minimum critical core (see Section 2.3). The calculated results (Table 3-1) indicate that this difference should have an insignificant effect on the prediction. This is in very good agreement with the earlier predicted value of 0.035 (11\$).

Reflector-in and reflector-out 4-group cross section sets were obtained from a 60-group condensation, with one-dimensional diffusion calculations used to obtain the region-dependent spectra. The 60-group, reflector-out case used for the cross section condensation was approximated by reducing the reflector region density to only one-fourth of 
the reflector-in density. This permitted the use of diffusion theory to obtain the condensation spectrum. The DOT2DB code ${ }^{(4)}$ was used for the transport calculations.

The $0.036 \Delta \mathrm{k}$ includes a correction of -0.0015 since the control segments in the reflector-out calculational model were dropped to a position 4-inches below the bottom of the core, instead of 1-inch above the bottom of the core. The 0.0015 reduction was estimated from the curve of reflector worth versus axial position (figure 4-17 of Reference 5).

Table 3-1 lists several values of total reflector control worth calculated earlier for the full core using different diffusion theory approximations and extrapolation from the ZPR-III critical assembly measurements. (3) Also listed are the total reflector control worths for the minimum critical core calculated using modified-boundary diffusion theory (earlier calculation) and transport theory (present calculation). The calculated worths are all nearly the same. The calculations also indicate that the control worth does not change very much in going from the full core condition to the minimum critical (i.e., the higher leakage of the minimum critical core, and hence, its greater sensitivity to reflector effectiveness relative to that of the full core appears to compensate the decrease in the reflector control worth due to increasing the downcomer region thickness in going from the full core to the minimum critical).

The predicted total reflector reactivity control worth, based on the values listed in Table 3-1 and a consideration of the uncertainties in the calculations is $0.036 \pm 0.006(11.2 \$ \pm 1.8 \$)$. The \pm 0.006 is an 
TABLE 3-1

CALCULATED REFLECTOR CONTROL REACTIVITY WORTHS

\begin{tabular}{|c|c|c|c|c|}
\hline Case & $\begin{array}{l}\text { Reactor } \\
\text { Mode1 } \\
\end{array}$ & Method of Calculation & $\begin{array}{r}\text { Tot: } \\
\text { React } \\
\end{array}$ & $\begin{array}{l}1 \text { Control } \\
\text { Jity Worth }\end{array}$ \\
\hline 1 & $\begin{array}{l}\text { SEFOR full core } \\
(648 \text { fuel rods })\end{array}$ & $\begin{array}{l}\text { Extrapolation of ZPR-III } \\
\text { experimental results on } \\
\text { removal of nickel seg- } \\
\text { ments, using 4-group, } \\
\text { 2-dimensional diffusion } \\
\text { theory. }\end{array}$ & 0.036 & $(11.2 \$)$ \\
\hline 2 & $\begin{array}{l}\text { SEFOR full core } \\
(648 \text { fue1 rods })\end{array}$ & $\begin{array}{l}\text { 4-group, one-dimensional } \\
\text { diffusion theory with } \\
\text { modified boundary condition } \\
\text { to account for voided (region } \\
\text { with reflectors down. }\end{array}$ & 0.037 & $(11.6 \$)$ \\
\hline 3 & $\begin{array}{l}\text { SEFOR } 512 \text { fuel } \\
\text { rods }\end{array}$ & Same as Case 2 . & 0.035 & $(10.9 \$)$ \\
\hline 4 & $\begin{array}{l}\text { SEFOR } 512 \text { fuel } \\
\text { rods }\end{array}$ & $\begin{array}{l}\text { 4-group, 2-dimensional, } \\
\mathrm{S}_{4} \text { transport theory. }\end{array}$ & 0.036 & $(11.2 \$)$ \\
\hline
\end{tabular}

(a) See Reference 3, Sections 6.2 and 6.3 for details.

(b) It was possible to use diffusion theory to calculate the "nicke1-out" condition since a relatively large amount of steel and aluminum remained in the region after removal of the nickel.

(c) Conversion from $\Delta k$ to dollars is based on a $B$ of 0.0032 . 
estimated standard deviation arising from possible consistent errors in the different calculations indicated in Table 3-1.* These include uncertainties in the method used for condensation from the 60-group to the 4-group cross sections (see above); differences between the idealized cylindrical geometry of the computational model and that of the real reactor (and also some small composition differences); uncertainties in the treatment of nickel self-shielding (including the surface effect); and possible nuclear data errors (due to data uncertainties) that may be sensitive to the difference in spectrum between the reflector-in and the reflector-out conditions.

The full core reflector worth was also predicted to be $0.036 \pm 0.006$. The 0.036 value is about twice the amount of calculated control required for operation.

*The method of extrapolation of the ZPR-III experimental results is subject to many of the same potential errors as the other methods indicated in Table 3-1. This is because the nickel was removed from only one-tenth of the ZPR-3 reflector (and also one-fourth in the ZPR-III one-segment critical assembly) and fairly elaborate diffusion theory calculations were required to extrapolate from the measured values in the critical assembly environment to the total reflector worth in SEFOR. 


\subsection{MEASURED TOTAL REFLECTOR STRENGTH}

The total strength of the entire reflector system (i.e. - the reactivity worth of simultaneously moving all the reflectors from the completely raised to the completely lowered position) is estimated to be $3 \% \Delta \mathrm{k} / \mathrm{k}$ or $\$ 10$, for both the partially loaded and the fully loaded critical cores. The estimated value for the 550 rod core Assembly I-A is based on the normalized one group model for the critical loading that is discussed in Appendix IV and the calculated radial leakage for the critical assembly, while the extrapolation to other core sizes is based on the calculations described above which indicated that the total reflector strength is relatively insensitive to core sizes in the range between the minimum critical and the full size core.

For the model described in Appendix IV, the initial loading data described in Section 2.2.2 indicates that the fundamental mode buckling of the 550 rod core with reflectors lowered is $10.7 \%$ larger than the corresponding (critical) buckling with reflectors raised. (i.e. the data indicates that the leakage is increased by $10.7 \%$ when the reflectors are lowered.) Multigroup, two-dimensional synthesis calculations indicate that in the 550 rod core the radial leakage from the core and that portion of the axial reflectors within the height of the radial reflectors is $29 \%$. Based on these two results the worth of the ten reflector segments is then $(0.107)(.29)=.031 \Delta \mathrm{K} / \mathrm{K}$, or $\$ 9.7$. This compares with the predicted ${ }^{(1)}$ value of $\$ 11.2 \pm \$ 1.8$ discussed in Section 3.1 above. Although the maximum upper limit for the worth of the total system (i.e., the change in reactivity when all ten segments are lowered simultaneously) is ten times the 
average value per segment in Assembly $I-B$, or $\$ 12.7$, it is known from the experimental results described below that the worth of an individual reflector is less when its immediate neighbors are lowered. The total strength of the system is therefore less than this maximum value.

\subsection{REFLECTOR CALIBRATIONS}

\subsubsection{Summary of Experimental Results}

Reflectors have been calibrated for four different core loadings; the 563 rod partially loaded core - Assembly I-B, and three fully loaded cores - Assemblies I-D, I-E, and I-F. In Assembly I-E the reflectors were calibrated with the reactor at a temperature of $350^{\circ} \mathrm{F}$, and again with the reactor at $650^{\circ} \mathrm{F}$. Calibrations on the other cores were performed only at $350^{\circ} \mathrm{F}$. In each case, with the exception of Assembly I-F where only fine reflector $k^{8}$ was calibrated, the two fine reflectors ( $\$ 3$ and $\# 8$ ) were calibrated in increments by means of period measurements with approximately $1 \%$ accuracy (see below) and the worth of each of the eight coarse reflectors was obtained by the rod-swap technique discussed below. As will be shown below, the worth of a reflector is influenced ("shadowed") by the position of its neighbors. Since the fine reflectors are used to determine the reactivity effects associated with changes in temperature, core loading, etc. the details of the calibrations and the associated reflector configurations are described in some detail below.

The "shadowing effects" appear to be localized, and the worth of 
a reflector is nearly independent of the position of non-adjacent reflectors provided the immediately adjacent reflectors are up. As indicated below, however, the worth of a reflector may be influenced (by up to $\sim 4 \%$ ) by the position of a neighbor which is only two reflectors removed; and the worth is strongly dependent on the position of immediately adjacent reflectors. The results show that the fine reflectors which are used to determine feedback effects should be calibrated with both adjacent reflectors completely raised and, insofar as practical, they should be calibrated with a coarse reflector configuration similar to that which will be used during the experimental program at power.

\subsubsection{Calibration Procedures}

The coarse reflector worths were determined in the following manner: A critical reflector configuration was attained with the coarse reflector to be calibrated completely raised; all other coarse reflectors either completely raised or completely iowered - not at intermediate positions; fine reflector number 3 completely lowered; and fine reflector $\# 8$ at an intermediate position as required for criticality. A second critical configuration was attained with fine reflector \#3 completely raised, the coarse reflector to be calibrated completely lowered, the other coarse reflectors in their original positions, and fine reflector $\$ 8$ at an intermediate position as required for criticality. The worth of the coarse reflector was then determined from the worth of the reflector (\#3) for which it was "swapped" and the change in position of reflector \#8. 
The fine reflector calibrations are performed in the following manner: The reactor was brought to critical with the fine reflector to be calibrated in the completely lowered position and the other fine reflector completely raised. A coarse reflector configuration was selected to maintain criticality and to minimize the influence of a lowered coarse reflector on the fine reflector calibration (i.e., the coarse reflectors immediately adjacent to the fine reflectors were maintained in the completely raised position.). The reflector to be calibrated was raised a few centimeters to produce a period of the order of 100 seconds, the period was measured, and the other fine reflector was then lowered to bring the reactor back to critical at the original flux level. This process was repeated until the entire length of a fine reflector had been calibrated.

In Assemblies I-B and I-D the reactor was critical at $350^{\circ} \mathrm{F}$ with slightly more than one reflector lowered. The fine reflectors were thus calibrated in these assemblies with one coarse reflector( $\$ 10)$ in a partially raised position. Since Assembly I-E was critical at $350^{\circ} \mathrm{F}$ with $21 / 2$ reflectors lowered, fine reflector $\$ 3$ was calibrated with reflector $\# 5$ lowered, $\# 10$ raised $40 \%$, and the other coarse reflectors completely raised, while $\# 8$ was calibrated with $\|_{10}$ down and \#5 raised $35 \%$. At $650^{\circ} \mathrm{F}$ the reactor was critical with slightly more than one reflector lowered and $\# 3$ was calibrated with $\# 10$ raised $85 \%$ while 非 8 was calibrated with 15 raised $75 \%$. The calibration of reflector \#8 in Assembly I-F at $350^{\circ} \mathrm{F}$ was performed with coarse reflector $\# 5$ and \#10 completely lowered and with \#6 nearly down.

The delayed neutron parameters which were used in the in-hour equation to convert measured periods to reactivities in units of cents were taken from Keepin's ${ }^{(6)}$ data and are listed for convenience along with the calculated effective delayed neutron fractions in Appendix $V$. 


\subsubsection{Calibration Results}

The worths of the two fine reflectors (非 and \#8) are shown as a function of reflector position for different assemblies in Figures 3-1 through 3-8, and the values for all the measurements are tabulated in Appendix VI. These curves have the expected "S" shape, and the total worth of each of the fine reflectors is in the expected range. The values of the total worth of each reflector (coarse as well as fine reflector segments) are summarized in Tables 3-2 and 3-3. Other than as indicated in the tables, the measurements were performed with all reflectors raised.

The data shows that the worth of fine reflector number 8 is nearly the same as the worth of number 3 in Assembly I-B as well as in I-D. In addition, the fine reflector worths are essentially the same in both cores. In Assembly I-E, however, there is a difference of about 10 percent in the worths of the two fine reflectors at $350^{\circ} \mathrm{F}$, even though the total combined worth of the two reflectors is the same as in AssembIy I-B and I-D (about \$2.52). The difference in worths, combined with an inspection of the core loadings in the different assemblies (Figures 1-2, 1-4, and 1-5) indicates that the $\mathrm{B}_{4} \mathrm{C}$ rod and guinea-pig rod distribution in Assembly I-E may have caused an asymmetrical flux distribution with an increase toward the W-side of the core relative to the E-side (see Figure 1-8 for a diagram of the core). The loading in Assembly I-D, for example, appears to be more uniform, although the N-E section of the core in Assembly $I-D$ may be somewhat deficient in $\mathrm{B}_{4} \mathrm{C}$ relative to the remainder of the core. 


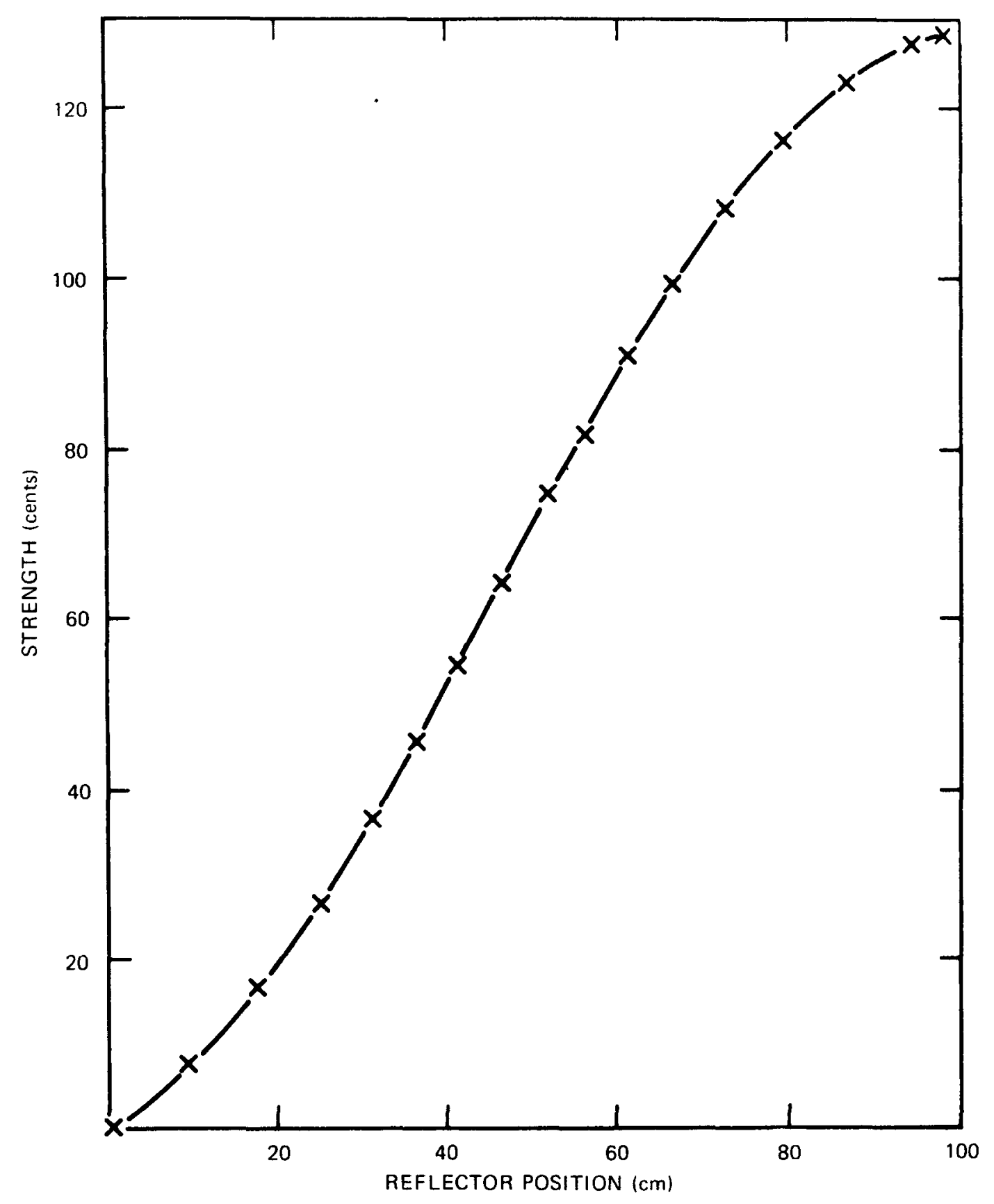

FIGURE 3-1. FINE REFLECTOR NO. 3 CALIBRATION CURVE (ASSEMBLY I-B) 


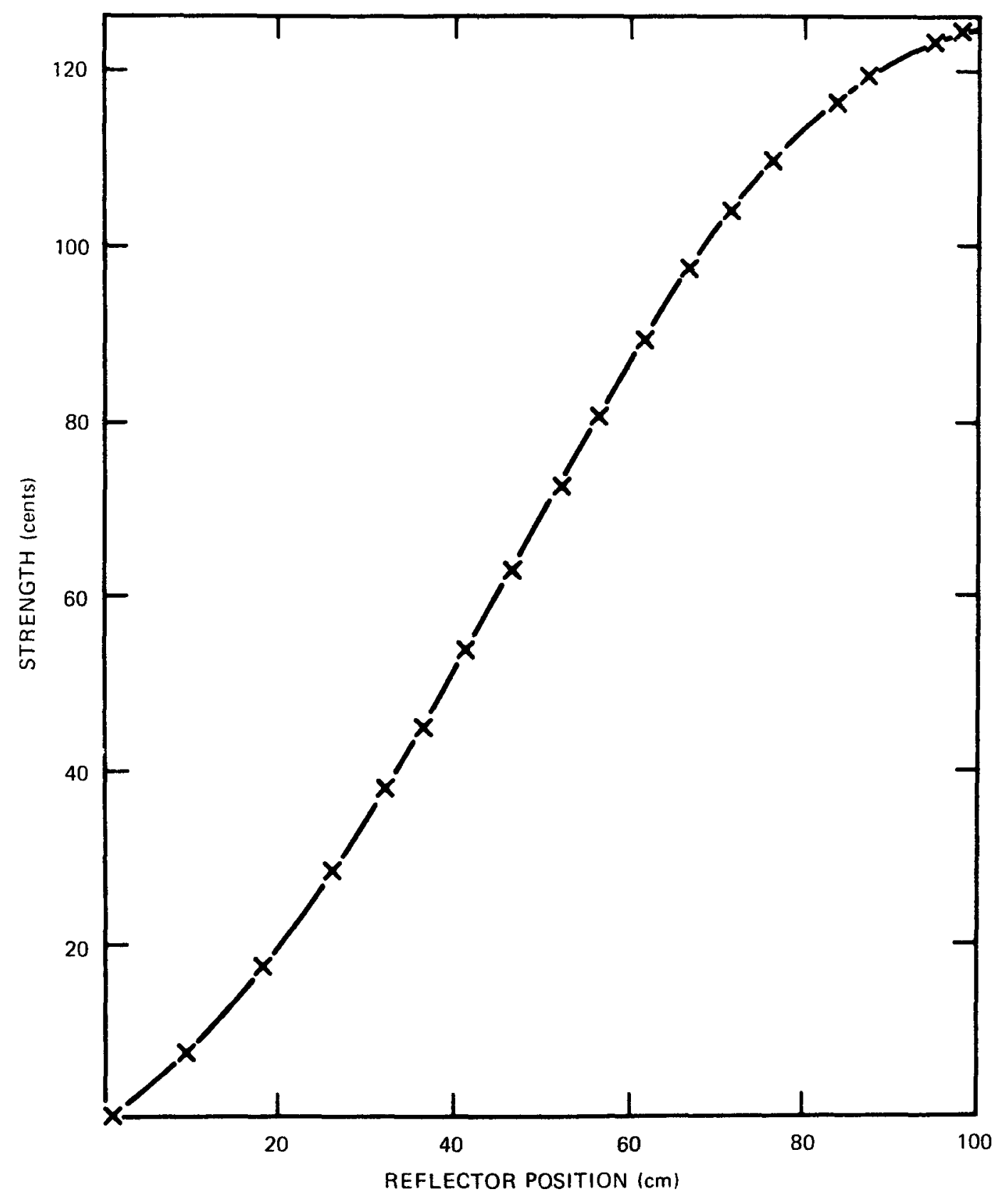

FIGURE 3-2. FINE REFLECTOR NO. 8 CALIBRATION CURVE (ASSEMBLY I-B) 


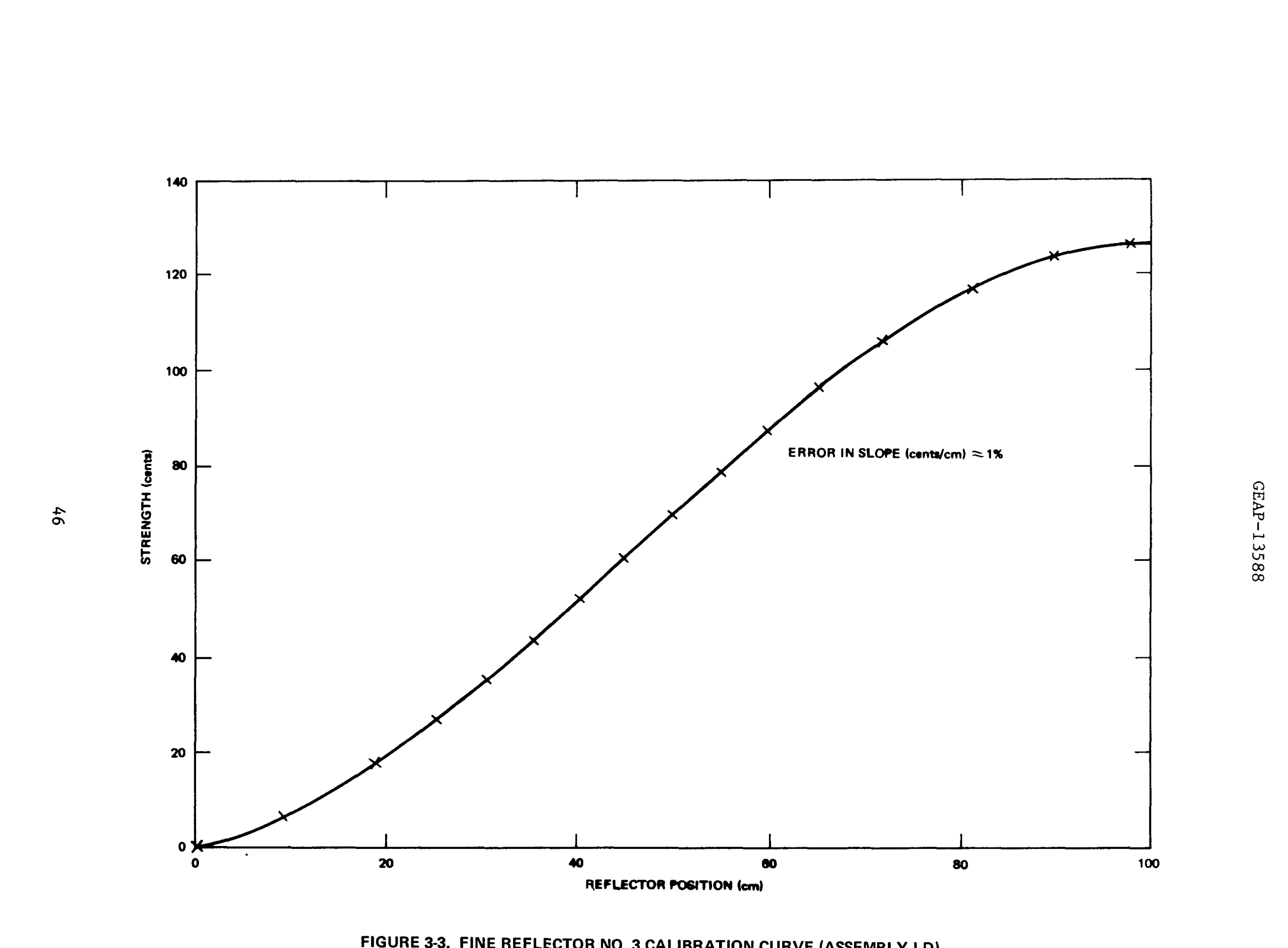




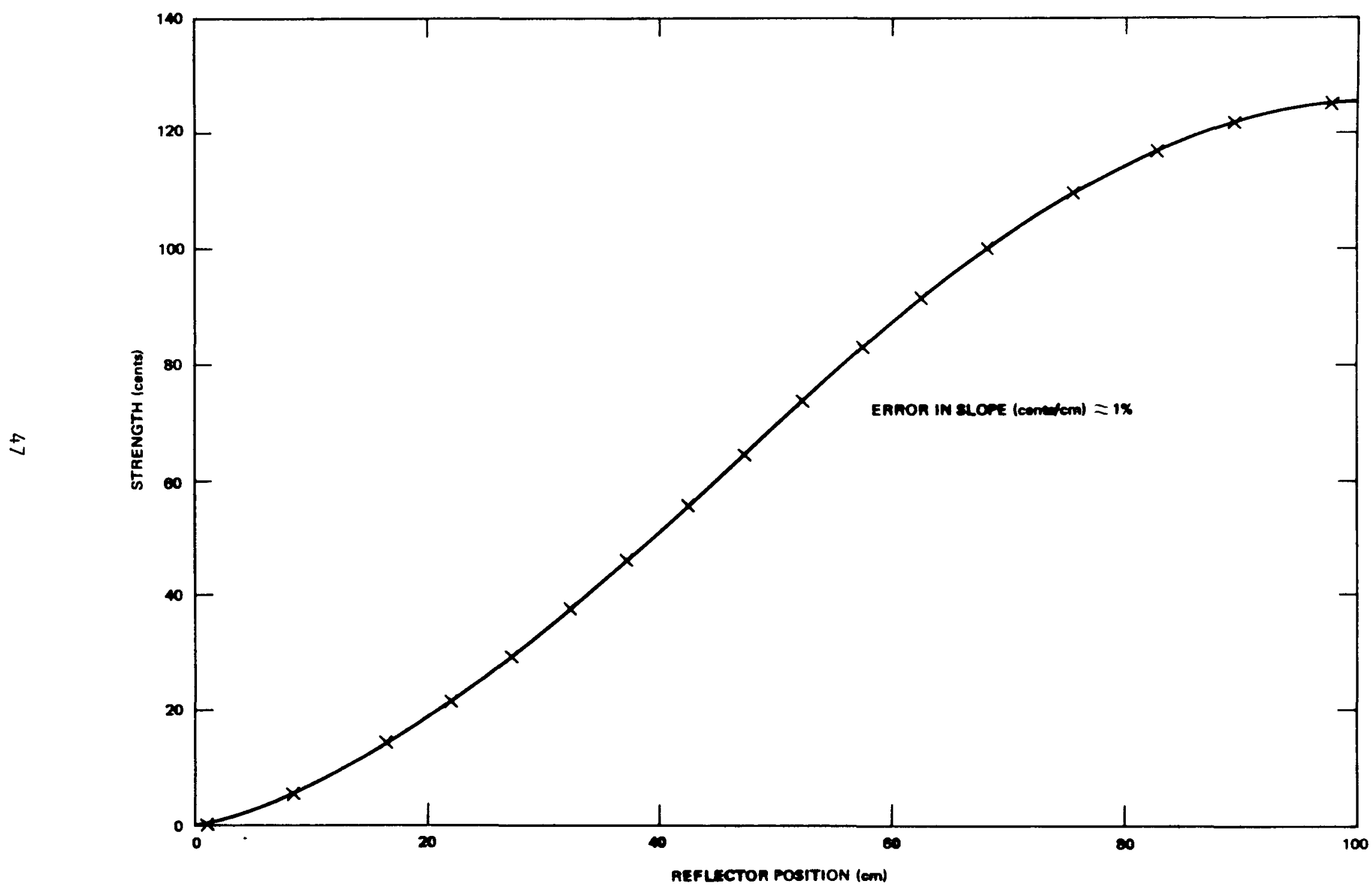

FIGURE 3-4. FINE REFLECTOR NO. 8 CALIBRATION CURVE (ASSEMBLY ID) 


$$
E
$$




$$
=
$$




$$
E
$$




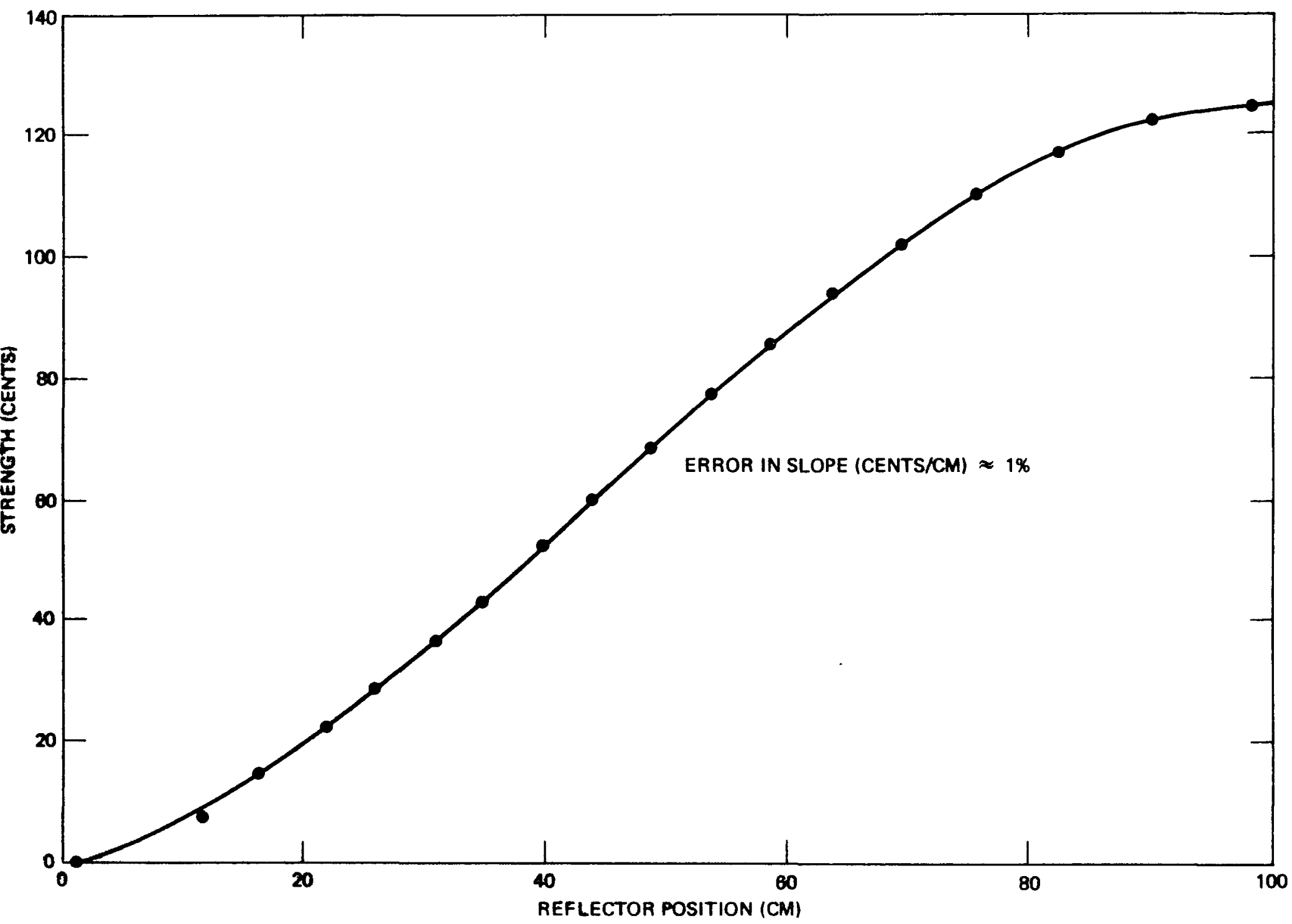

FIGURE 3-8. FINE REFLECTOR NO. 8 CALIBRATION AT 650\% (ASSEMBLY I-E) 
REFLECTOR WORTHS FOR ASSEMBLIES I-B and I-D

Worth (do1lars)*

\section{Reflector Number}

N
Assemb1y I-B

(swapped with \#3)
$($ il at $285 \mathrm{~cm}) * * *$
$(\# 10$ at $\sim 90 \mathrm{~cm}) * * *$

Assembly I-D

Set 1

(swapped with 非)

(\#8 at $250 \mathrm{~cm}) * * *$

1.25

1.28

$1.27 * *$

1.24

1.25

1.28

1.14

$1.25 * *$

1.09

1.26
Set 2

(swapped with \#8)

(\#3 at $\sim 50 \mathrm{~cm}) * * *$

1.02

0.99

1.20

1.29

$1.25 * *$

1.20

1.28

1.24

*The estimated standard deviation in the difference between two values for the same assembly is \pm 0.01 dollars. - Measurements were made with all reflectors, other than those indicated, in the raised position.

**Worths obtained from period measurements.

$\star \star *$ Completely raised position is about $98 \mathrm{~cm}$. 
TABLE $3-3$

REFLECTOR WORTHS IN ASSEMBLY I-E

\begin{tabular}{|c|c|c|c|c|c|}
\hline \multirow[t]{2}{*}{ Reflector Number } & \multicolumn{2}{|c|}{$\begin{array}{l}\text { Calibration at } 350^{\circ} \mathrm{F} \\
\text { (reflector } 5 \text { down) }\end{array}$} & \multicolumn{3}{|c|}{ Calibration at $650^{\circ} \mathrm{F}$} \\
\hline & (swapped with $\# 3$ ) & $(\mathrm{cm})$ & (swapped with 非) & $(\mathrm{cm})$ & \\
\hline 1 & 1.42 & 44 & 1.39 & 84 & \\
\hline 2 & 1.44 & 45 & 1.43 & 88 & \\
\hline 3 & $1.32 *$ & 39 & $1.38 *$ & 82 & \\
\hline 4 & 1.00 & 17 & 1.30 & 75 & \\
\hline 5 & $1.23 * *$ & 40 & 1.27 & 71 & 3 \\
\hline 6 & 0.87 & 2 & 1.24 & 70 & $\stackrel{1}{\leftarrow}$ \\
\hline 7 & 0.88 & 3 & 1.16 & 64 & $\underset{\propto}{\infty}$ \\
\hline 8 & $1.20 *$ & -- & $1.25 *$ & -- & \\
\hline 9 & 1.00 & 17 & 1.18 & 66 & \\
\hline 10 & 1.34 & 40 & 1.33 & 78 & \\
\hline
\end{tabular}

*Worth obtained from period measurements

** Worth measured with reflector $\# 10$ lowered.

+ Position of reflector 非 8 when the indicated reflector was lowered.

+ The estimated standard deviation in the difference between two values at the same temperature is \pm 0.01 dollars 
In addition to demonstrating the asymmetry in worth that is congruous with an asymmetric core loading, the tabulated worths for both* assemblies I-D and I-E show that the worth of a reflector is influenced by the position of its neighbors. In particular, the total worth of a reflector is less when an adjacent reflector is lowered, or partially lowered, than when both adjacent reflectors are completely raised. For example, in the first set of measurements (Set 1 of Table 3-2) for Assembly I-D, fine reflector 非 was swapped with the coarse reflector to be calibrated, while fine reflector $\|^{8}$ was adjusted to maintain criticality. For these measurements, reflector \#8 was only partially raised (approximately halfway) during the "swap". The reflectors adjacent to number eight ("⿰ 7 and \#19) are consequent1y lower in worth than the others. In the second set of measurements in Table 3-2, the functions of the two fine reflectors were interchanged. This caused a decrease in the worth of Reflector \#2 and \#4. Similarly, the data in Table 3-3 for Assembly I-E denonstrates this "shadowing" effect. For the measurements at $350^{\circ} \mathrm{F}$, reflector $\left.\right|^{5}$ was lowered and 非 8 was either partially or almost completely lowered. The worths of reflectors $\# 6$ and $\# 7$ are thus considerably less in this configuration than the worths of the other reflectors. The worths of \#4 and \#9 demonstrate the same "shadowing" effect, although to a lesser extent, since their worths were determined with only one completely lowered neighboring reflector.

*The results for Assembly I-B also demonstrate this effect, although to a smaller extent, in that reflector $\$$ | 9 has a slightly smaller worth than the other reflectors (and also a slightly smaller worth than the worth of $\equiv^{9}$ in Assembly I-D) due to its two slightly lowered neighbors. 
A comparison of the Assembly I-E calibrations at $650^{\circ} \mathrm{F}$, which were performed with all coarse reflectors raised, with those at $350^{\circ} \mathrm{F}$ clearly demonstrates the influence of the lowered reflector $\$ 5$ and partially lowered reflector $\|^{8}$ on other reflector worths. The worths of reflectors \#1, 非, and \#10 are essentially unchanged and 5 is only slightly changed, while the worths of \#4, \#6, \#7, and \#9 are from 18 to $43 \%$ larger at $650^{\circ} \mathrm{F}$ where 5 is completely raised and $\$$ is raised more than at $350^{\circ} \mathrm{F}$. The worths of 33 and of $\# 8$ are both about $4 \%$ larger at $650^{\circ} \mathrm{F}$ than at $350^{\circ} \mathrm{F}$. This is probably due to the influence of reflector $\# 5$ on the calibration of $\# 3$ and the influence of reflector \#10 on the calibration of \#8 (see above).

The "shadowing effects" thus appear to be somewhat localized although the worth of a reflector may be influenced by as much as $4 \%$ by the position of a neighbor which is only two reflectors removed.

\subsubsection{Calibration Accuracy}

The accuracy of the calibrations for measurements of the finereflector period is indicated by the data in Tables $3-4$ and $3-5$. The reactivity values under the second column of the tables were calculated with the in-hour equation using periods obtained from visual observation of flux changes and doubling-time measurements made with a stop watch. The values in the third column were calculated on-line from the neutronflux signal input to a computer. These data provide two independent checks on the calibration and are in very good agreement. With the small reactivity values (large periods) excepted, the mean-squared deviation is approximately 0.9 percent for reactivity increments of the order of 9 cents. Similar deviations also occur in six repeated 
TABLE 3-4

FINE REFLECTOR \#8 CALIBRATION IN ASSEMBLY I-D

\begin{tabular}{|c|c|c|c|}
\hline \multirow[b]{2}{*}{ Step No. } & \multicolumn{2}{|c|}{ Reactivity } & \multirow[b]{2}{*}{$\%$ Deviation } \\
\hline & $\begin{array}{l}\text { Doub ing-time } \\
\text { Measurement (cents) }\end{array}$ & $\begin{array}{l}\text { Un-Iine Reactivity } \\
\text { Meter (cents) } \\
\end{array}$ & \\
\hline 1 & 5.58 & 5.65 & -1.3 \\
\hline 2 & 8.46 & 8.5 & -0.5 \\
\hline 3 & 7.66 & 7.75 & -1.2 \\
\hline 4 & 7.57 & 7.5 & 0.9 \\
\hline 5 & 8.59 & 8.6 & -0.1 \\
\hline 6 & 8.68 & 8.7 & -0.2 \\
\hline 7 & 9.10 & 9.1 & 0.0 \\
\hline $8 *$ & 9.41 & 9.45 & -0.4 \\
\hline $8 A^{*}$ & 9.40 & 9.3 & 1.1 \\
\hline $8 \mathrm{~B} *$ & 9.35 & 9.3 & 0.5 \\
\hline $8 C *$ & 9.46 & 9.3 & 1.7 \\
\hline $8 D^{*}$ & 9.38 & 9.3 & 0.9 \\
\hline $8 \mathrm{E} *$ & 9.12 & 9.2 & -0.9 \\
\hline 9 & 9.24 & 9.25 & -0.1 \\
\hline 10 & 9.33 & 9.2 & 1.4 \\
\hline 11 & 7.88 & 7.9 & -0.3 \\
\hline 12 & 8.55 & 8.6 & -0.6 \\
\hline 13 & 9.84 & 9.75 & 0.9 \\
\hline 14 & 6.87 & 6.95 & -1.2 \\
\hline 15 & 5.16 & 5.3 & -2.7 \\
\hline 16 & 3.36 & 3.5 & -4.2 \\
\hline
\end{tabular}

*Repeated measurements of the reactivity associated with the movement of reflector $\$$ 淁 between $42.10 \mathrm{~cm}$ and $47.14 \mathrm{~cm}$. 
GEAP- 13588

TABLE $3-5$

PORTION OF FINE REFLECTOR \#3 CALIBRATION

IN ASSEMBLY I-D

Reactivity

Doubling-time Measurement (cents)

8.72

8.60

9.24

8.51

8.97

9.04

9.56

13

14

15
10.75

6.45

2.87
On-1ine reactivity

Meter (cents) \%Deviation

$\begin{array}{rr}8.65 & 0.8 \\ 8.5 & 1.1 \\ 9.2 & 0.4 \\ 8.5 & 0.1 \\ 8.8 & 1.9 \\ 9.1 & -0.7 \\ 9.6 & -0.4 \\ 10.7 & 0.5 \\ 6.5 & -0.8 \\ 3 & -4.5\end{array}$


GEAP-13588

measurements (Step No. 8 through Step No. 8E) listed in Table 3-4.

Thus a \pm 1 percent uncertainty is assigned to the slope of the reflectorworth calibration curve (see Figures 3-1 through 3-8). The effects of these deviations on measured reactivity changes are discussed in Section 4.4 . 


\section{SECTION IV}

\section{MATERIAL REACTIVITY WORTH MEASUREMENTS}

\subsection{SUMMARY OF RESULTS FOR ASSEMBLIES I-B AND I-D}

The reactivity worth of numerous materials, such as fuel, $\mathrm{B}_{4} \mathrm{C}$, depleted $\mathrm{UO}_{2}, \mathrm{BeO}$, etc. were measured at different locations in the core of the 563 rod partially loaded core Assembly I-B and in the fully loaded core Assembly I-D. All materials were in rods which were identical, except for identification markings, to normal fuel rods, or in the case of BeO to tightener rods. The compositions of the various rods are given in Appendix I.

Generally acceptable agreement between experimental and calculated material reactivity worths was obtained. However, the consistent over-estimate (by 10 to $15 \%$ ) of material worths in the center of Assembly I-D, (see Section 4.3) combined with the reaction rate discrepancies discussed in Section $V$, indicates that the spatial dependence of the flux is flatter than predicted, and analysis (Section 4.3) indicates that the calculations are sensitive to the axial flux shapes near the radial core boundaries. Comparison of two-dimensional S-4 transport and diffusion theory calculations in four energy groups indicated only a small effect due to the underprediction of core leakage by diffusion theory calculations. Generally better agreement between calculated and measured values can be obtained for both Assemblies I-B and I-D by increasing the calculated effective delayed neutron fraction, $\beta$, which is approximately $90 \%$ of the true delayed neutron fraction, by 6 to 10 percent. 


\subsection{WORTH MEASUREMENTS IN ASSEMBLY I-B}

The reactivity worth of fuel $(18.7 \%$ fissile $\mathrm{Pu}), \mathrm{B}_{4} \mathrm{C}$, and stainless steel rods were measured at four different radial core locations in the 563 rod partially loaded core Assembly I-B as part of the planned experimental program. In addition, the reactivity worth of four BeO tightener rods on the core periphery were measured. During the measurements a fuel rod that was substantially low (approximately $40 \%$ ) in worth was found and an extensive investigation was undertaken to determine the extent of the problem. The investigation, which is reported in Reference 1 , showed that a number of rods were low in worth. As discussed in Section 2.2, the very low worth rods were removed after completion of the experiments on Assembly I-B. The results of the originally planned measurements are given here. The results of the additional reactivity worth measurements performed during the investigation of the low worth rods are given in Reference 1 .

The reactivity worth of fuel, $\mathrm{B}_{4} \mathrm{C}$, and stainless steel rods at a given location were measured by recording the reactor temperature and the critical reflector positions with the following core arrangements; the core loading with the original fuel rod in place; the original fuel rod removed - the fuel rod location thus being filled with liquid sodium; the original fuel rod replaced by the reference fuel rod, the $\mathrm{B}_{4} \mathrm{C}$ rod, or the stainless steel rod; and finally the core with the original rod re-inserted. The worth of the peripheral Be0 tightener rods in Assembly I-B was determined from the critical reflector configurations occurring before and after insertion of four rods into sodium filled tightener rod locations. 
GEAP- 13588

The positions within the core at which measurements were made are illustrated in Figure 4-1, and measured results are shown in Figures 4-2 through 4-4 along with the curves obtained using perturbation calculations of 13 group two-dimensional synthesis solutions, and the calculated effective delayed neutron fraction, $\beta$, for this assembly of 0.00323 . The measured results are also tabulated in Table 4-1 along with the calculated values.

It is evident that the worth of fuel rod No. 874 is considerably less than the worth of the reference rod No. 781. The relatively large discrepancy between calculated and measured fuel rod worths at location W1.0 - S2.0-B (in measurement set number 3) may be the result of a number of very low worth rods in this region which were not taken into account in the calculation. A portion of this disparity may also be attributable to an over-estimate or rod worths near the core center by the two-dimensional synthesis calculations, as evidenced by the disparities in Assembly I-D (see below). The apparent close agreement between calculated and measured fuel (if not $\mathrm{B}_{4} \mathrm{C}$ ) rod worths at location N1.0 - N2.0-B would appear to refute the latter explanation; however, it is possible that the very low worth rods in the vicinity of W1.0 S2.0-B may have caused an increase in measured worth on the opposite side of the core near location E1.0 - N2.0-B to bring closer agreement between measurement and calculation at this point than would otherwise have occurred.

It is worthy of note that better agreement between the experimental and calculated values is obtained by increasing the calculated effective delayed neutron fraction $(\beta)$ by $6 \%$ so that the calculated worths, in cents, are decreased by $6 \%$. 


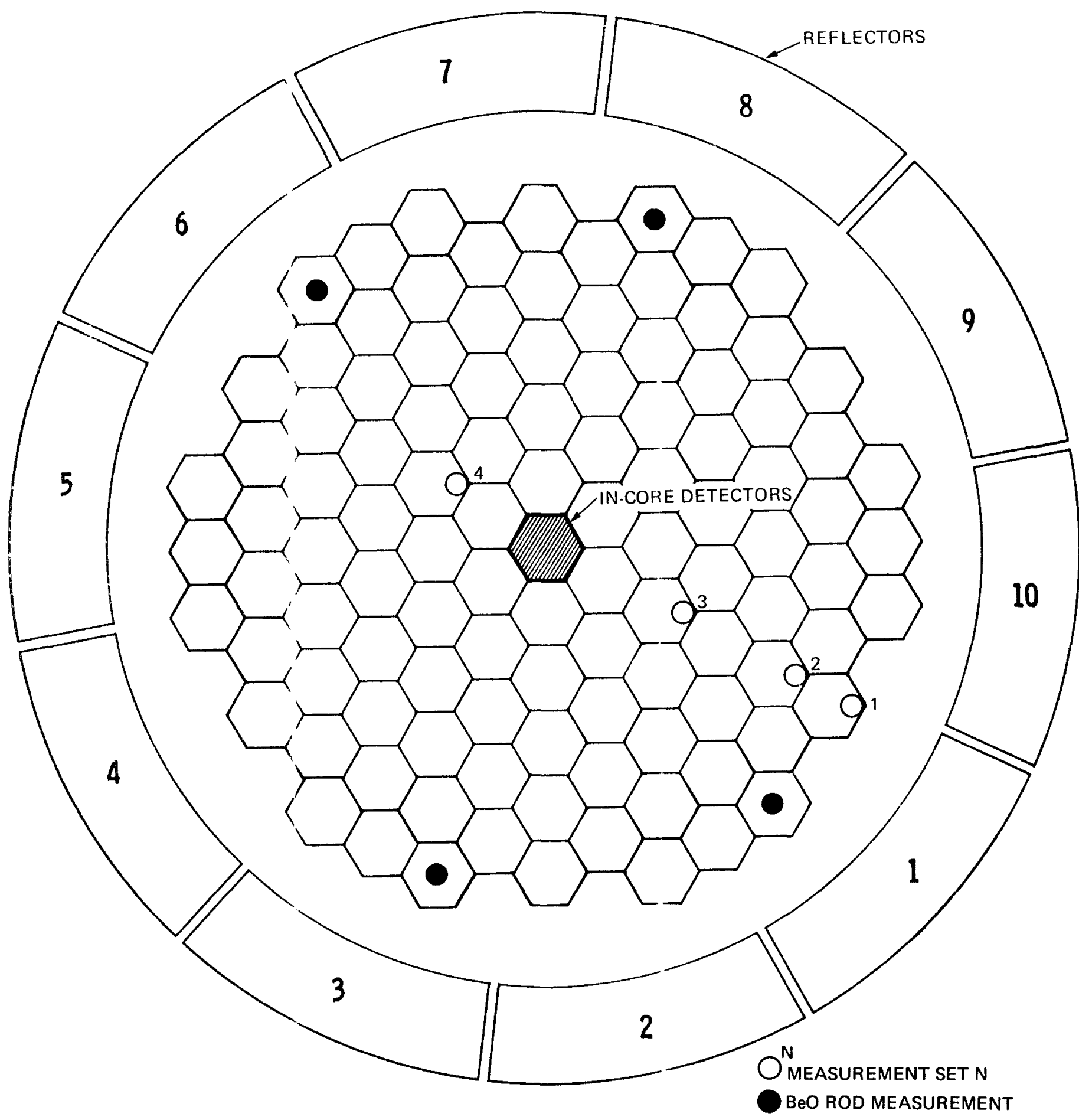

FIGURE 4-1. LOCATION OF MATERIAL WORTH MEASUREMENTS IN ASSEMBLY I-B 


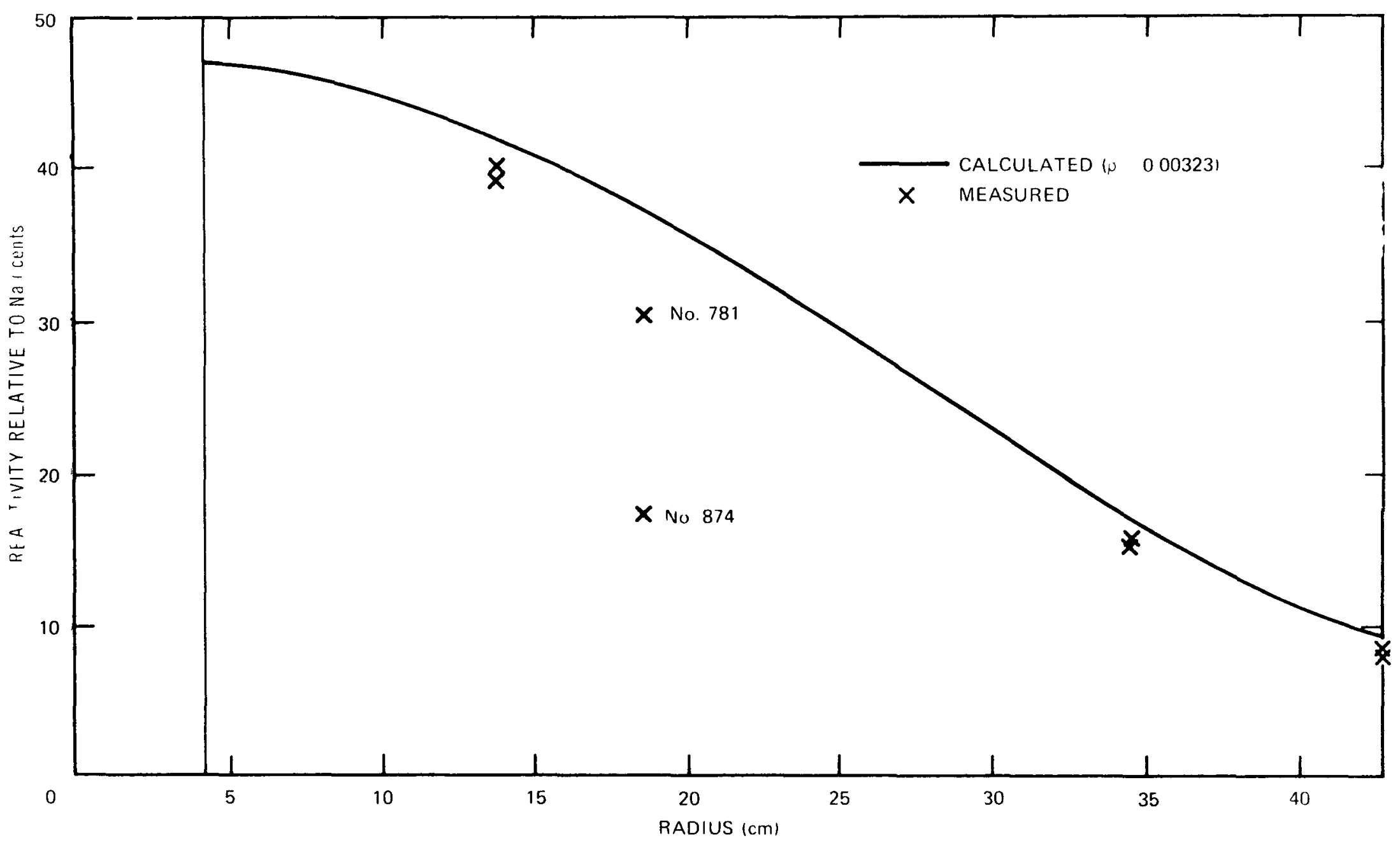




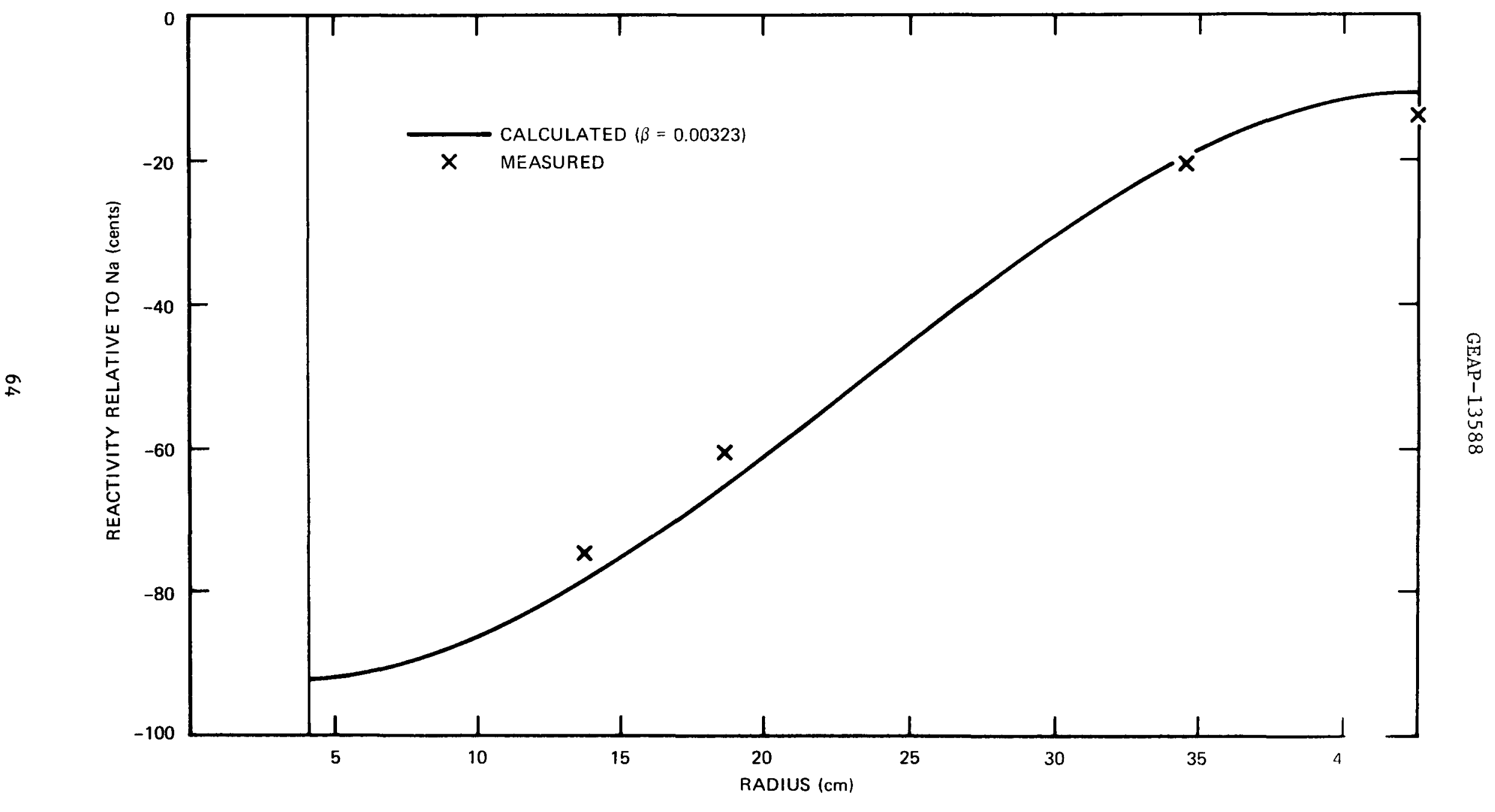

FIGURE 4-3. RADIAL DEPENDENCE OF $\mathrm{B}_{4}$ C ROD WORTH (ASSEMBLY I-B) 


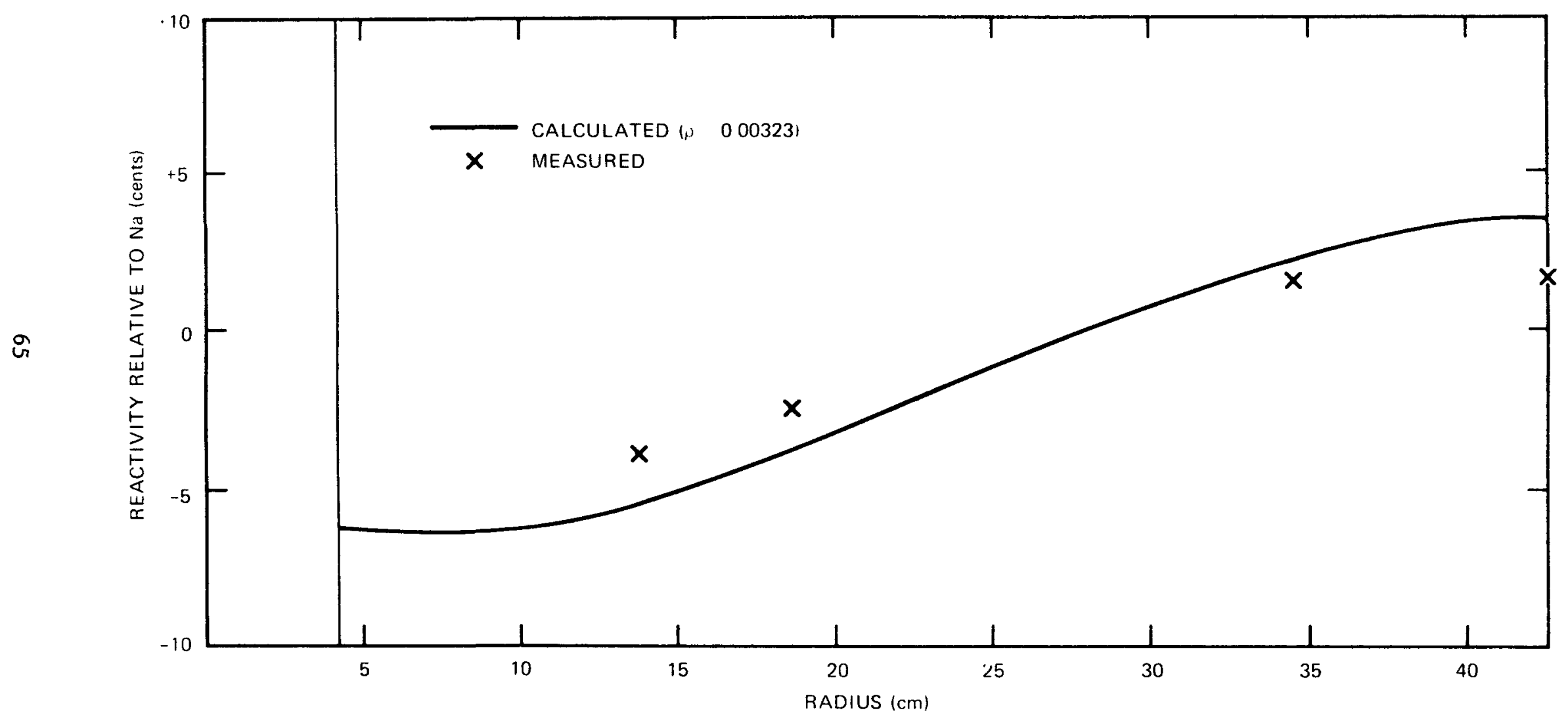


TABLE 4-1

MATERIAL REACTIVITY WORTH MEASUREMENTS

(ASSEMBLY I-B)

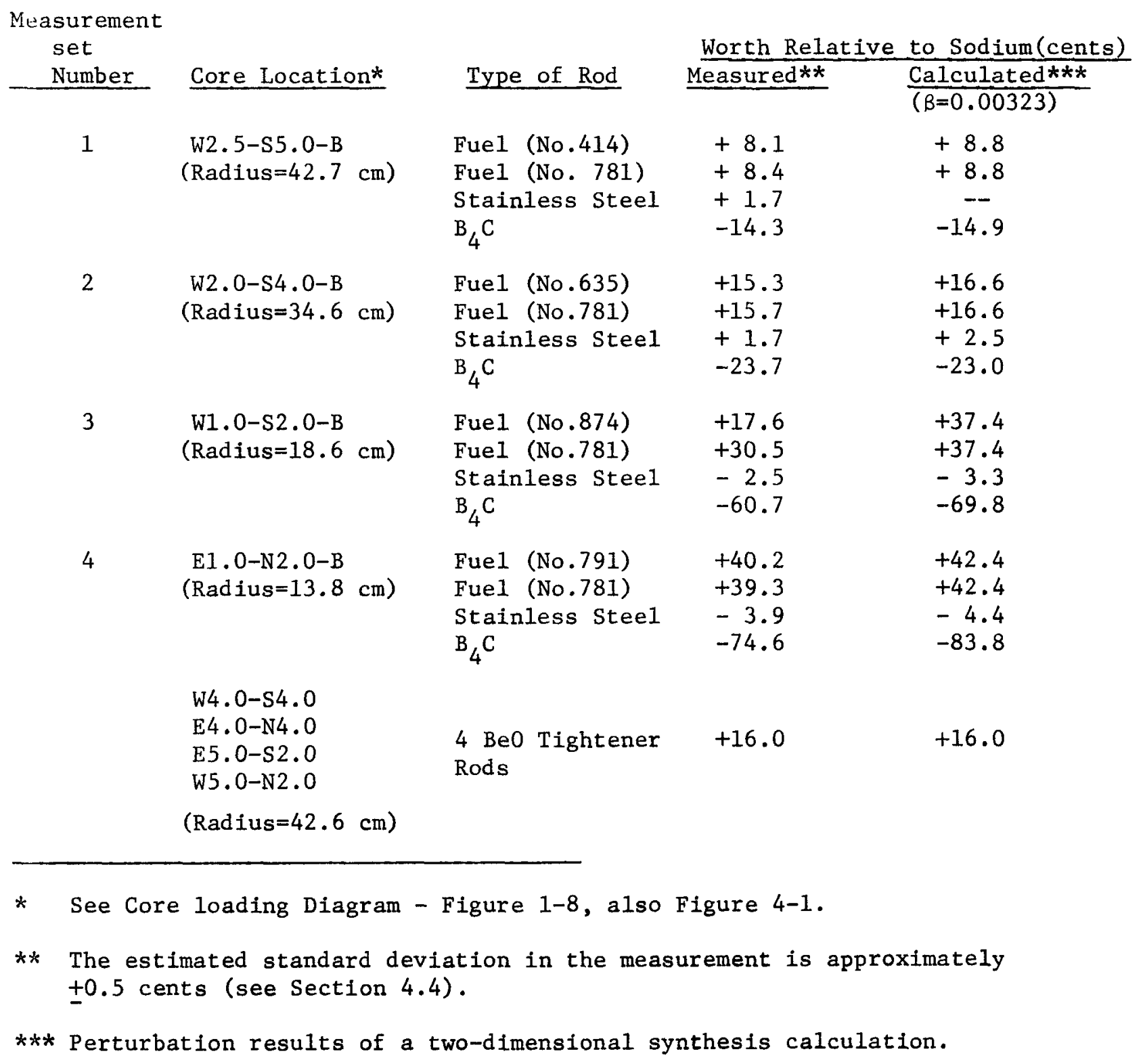




\subsection{WORTH MEASUREMENTS IN ASSEMBLY I-D}

The reactivity worth of fuel ( $18.7 \%$ fissile $\mathrm{Pu}), \mathrm{B}_{4} \mathrm{C}$, stainless steel, guinea pig ( $25 \%$ fissile $\mathrm{Pu}$ ), depleted $\mathrm{UO}_{2}$, and $\mathrm{BeO}$ tightener rods were measured at several locations in Assembly I-D. The measurements were performed in the same manner, which is described above, as in Assembly I-B, with the addition that a guinea pig and a depleted $\mathrm{UO}_{2}$ rod were substituted for the original fuel rod during the sequence of measurements. The worth of the BeO tightener rods in Assembly I-D were determined at four radial locations by replacing the original Be0 rods in these locations with special stainless steel tightener rods. The positions within the core at which measurements were made are illustrated in Figure 4-5. The compositions of the various rods are discussed in Appendix I.

The measured values of fuel, $\mathrm{B}_{4} \mathrm{C}, \mathrm{UO}_{2}$, and guinea pig rods are illustrated in Figures 4-6 through 4-9 along with calculated results, and measured values for all materials are tabulated in Tables 4-2 through 4-4. The data indicates that the measured worth of a fuel rod is higher at location E1.5 - N3.0-B (a radius of $21.8 \mathrm{~cm}$ ) than at location $\mathrm{W} 2.5$ - N1.0-B (a radius of $20.6 \mathrm{~cm}$ ). This may be due to the proximity of three $\mathrm{B}_{4} \mathrm{C}$ rods at the latter location and the deficiency of $\mathrm{B}_{4} \mathrm{C}$ rods in the $\mathrm{N}-\mathrm{E}$ portion of the core (see Figure 4-5). However, a comparison of the measurement at E1.0 - N2.0-B with that at E1.0 - S2.0-D indicates that the proximity of $a_{4} B_{4}$ rod has little influence on fuel rod worth, and it is more probable that the indicated difference is a result of experimental variations.

The reactivity worths of the different materials were calculated from perturbations of one-dimensional diffusion and two-dimensional 
LOCATION OF IN-CORE B ${ }_{4}$ C RODS

$\bigoplus$ FUEL, $\mathrm{B}_{4} \mathrm{C}, \mathrm{UO}_{2}$, AND STEEL ROD WORTH MEASUREMENTS

FfUEL AND GUINEA PIG ROD WORTH MEASUREMENTS

FUEL ROD WORTH MEASUREMENTS

QBeO TIGHTENER ROD WORTH MEASUREMENTS

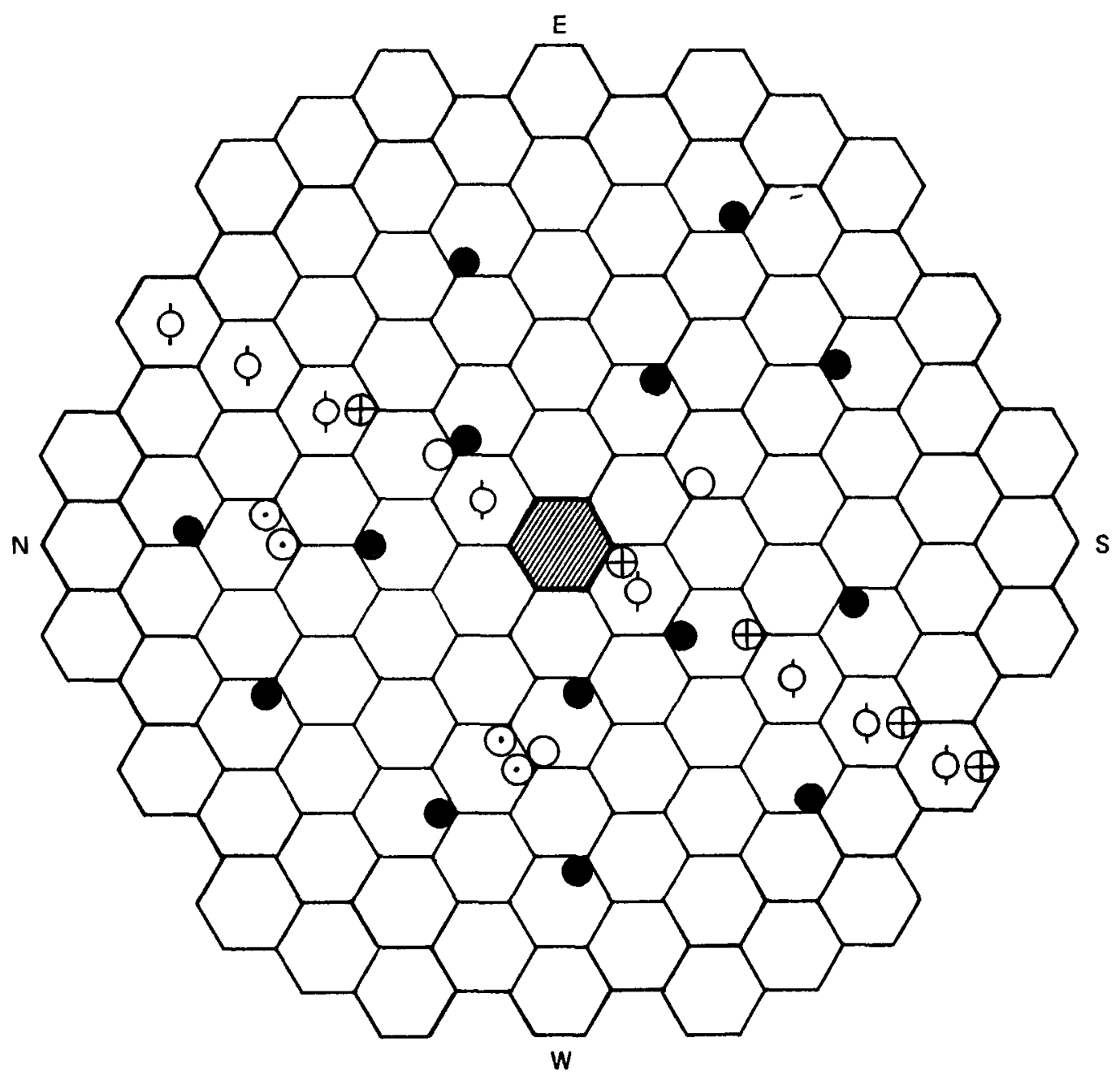

FIGURE 4.5. LOCATIONS OF MATERIAL WORTH MEASUREMENTS IN ASSEMBLY I-D 


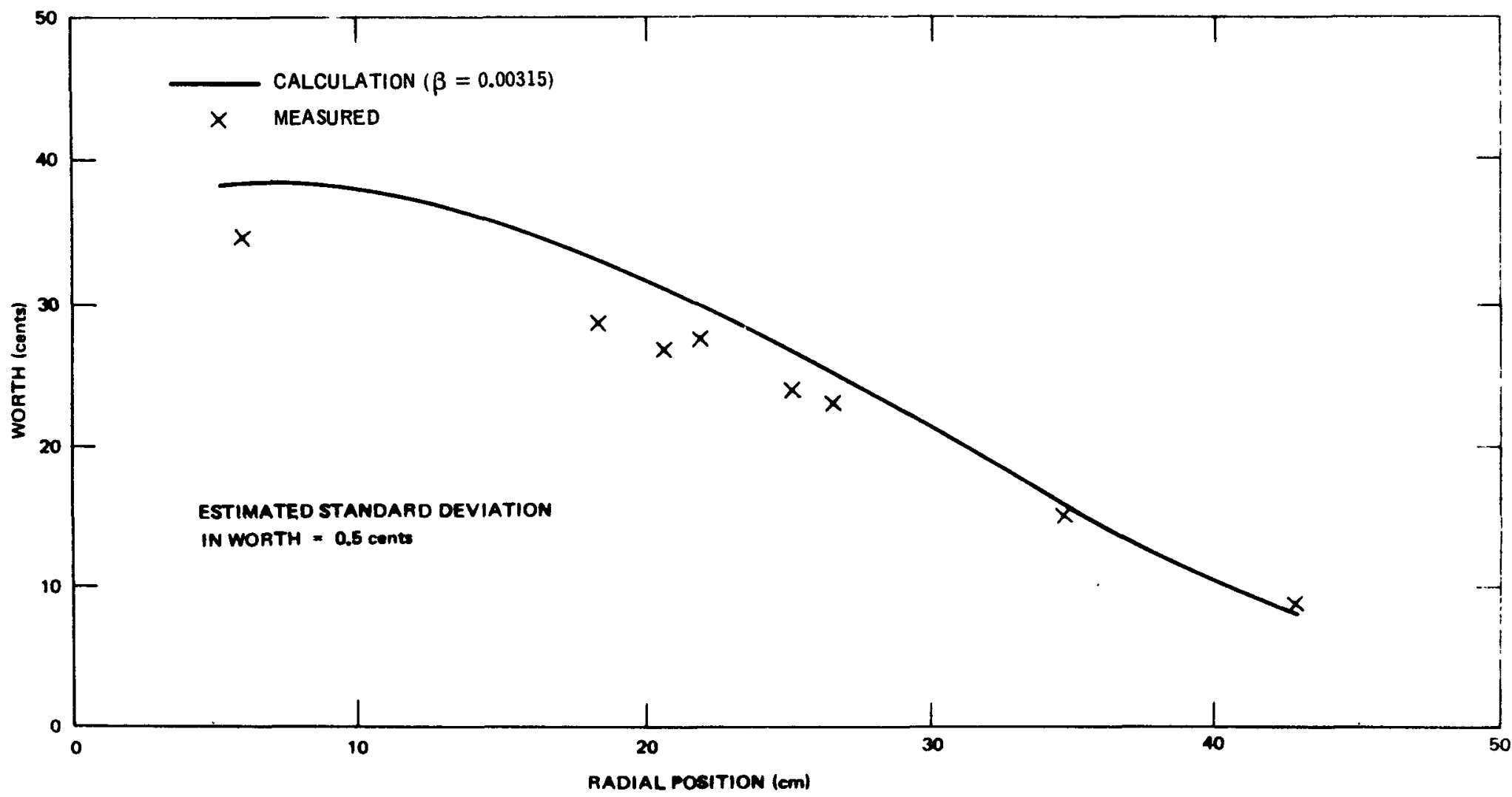

FIGURE 4-6. RADIAL DEPENDENCE OF FUEL ROD WORTH (ASSEMBLY I-D) 


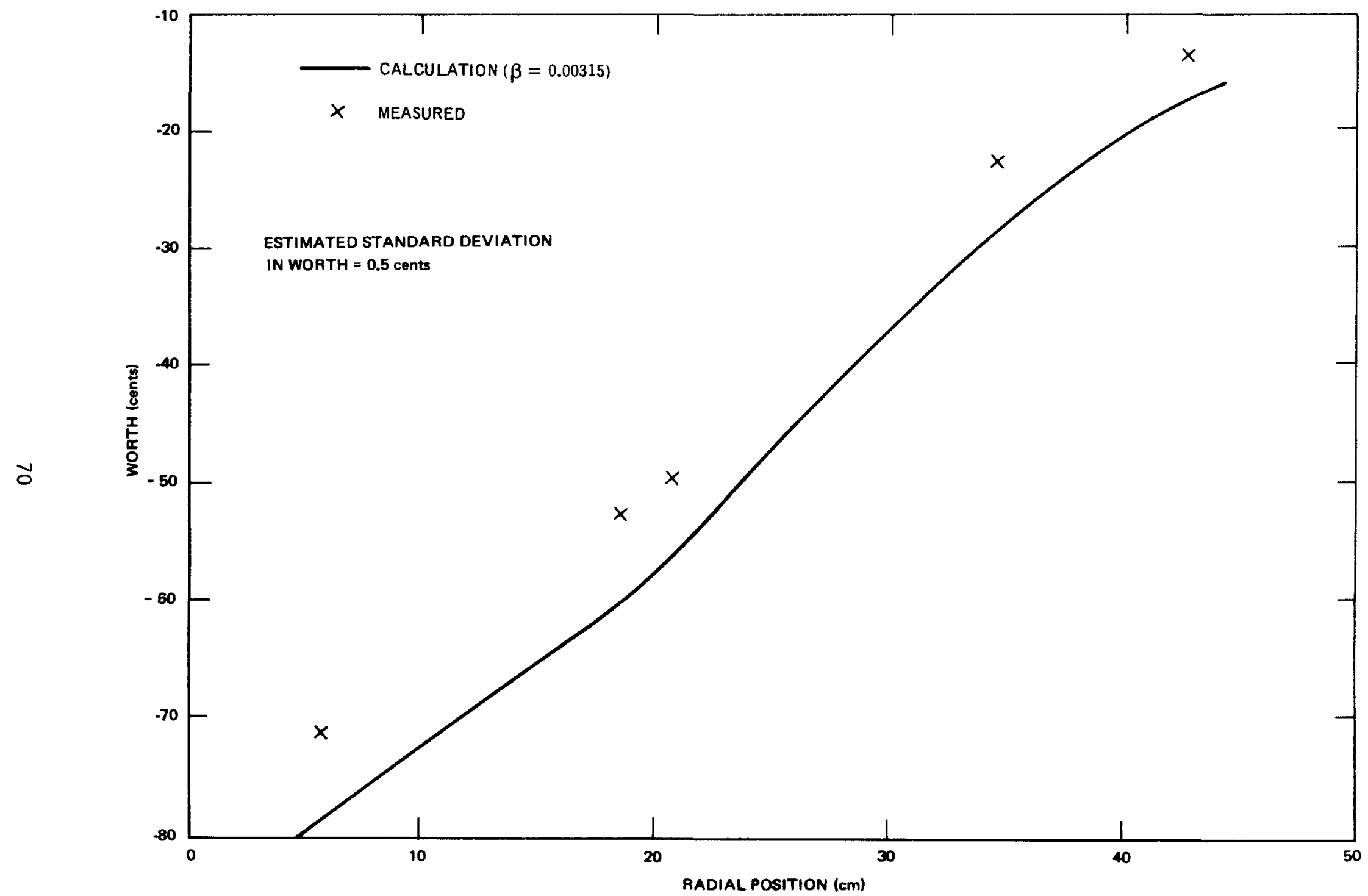




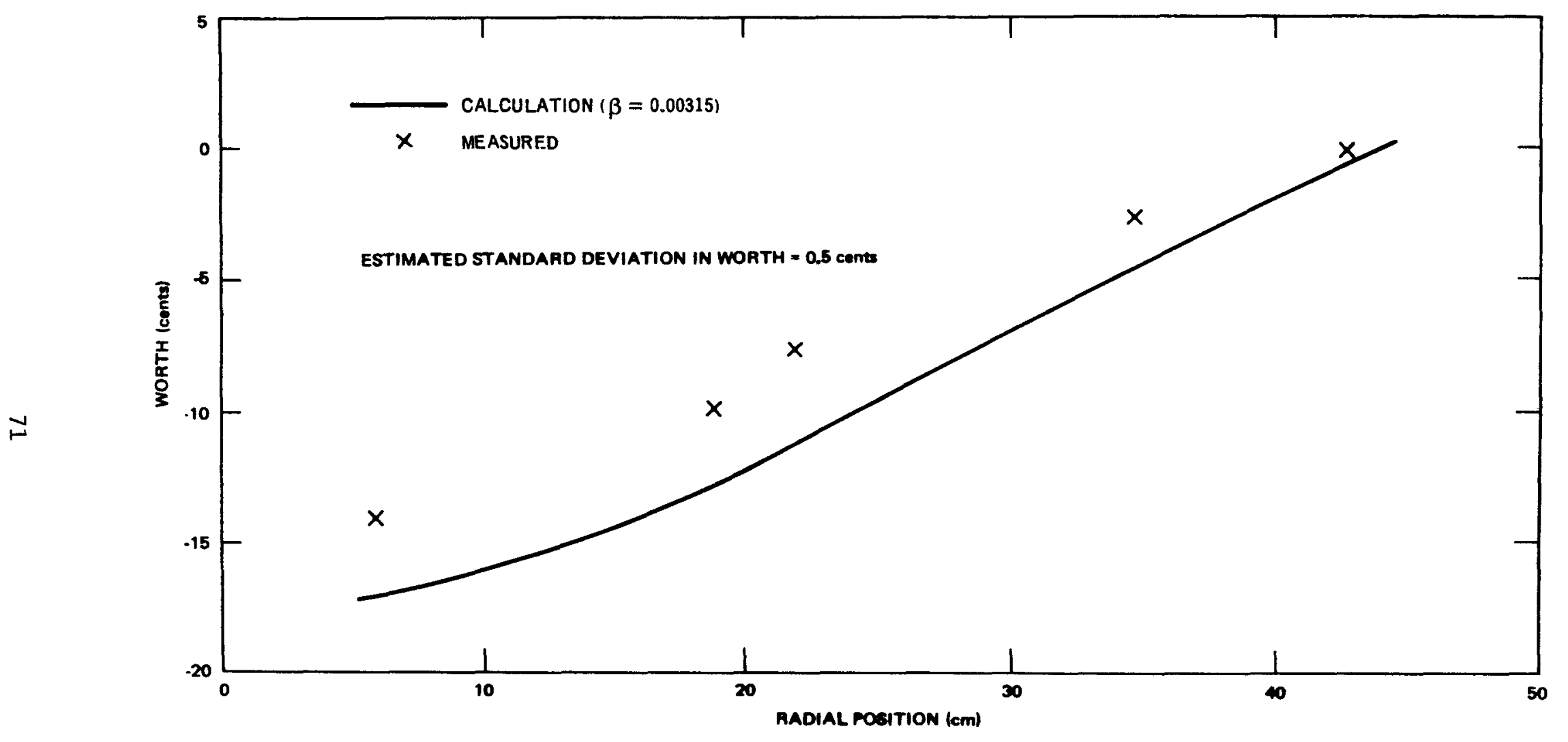

0
P
Pu
1
$\omega$
$\omega$
$\infty$
$\infty$
$\infty$

FIGURE 4-8. RADIAL DEPENDENCE OF DEPLETED UO ${ }_{2}$ ROD WORTH (ASSEMBLY I-D) 


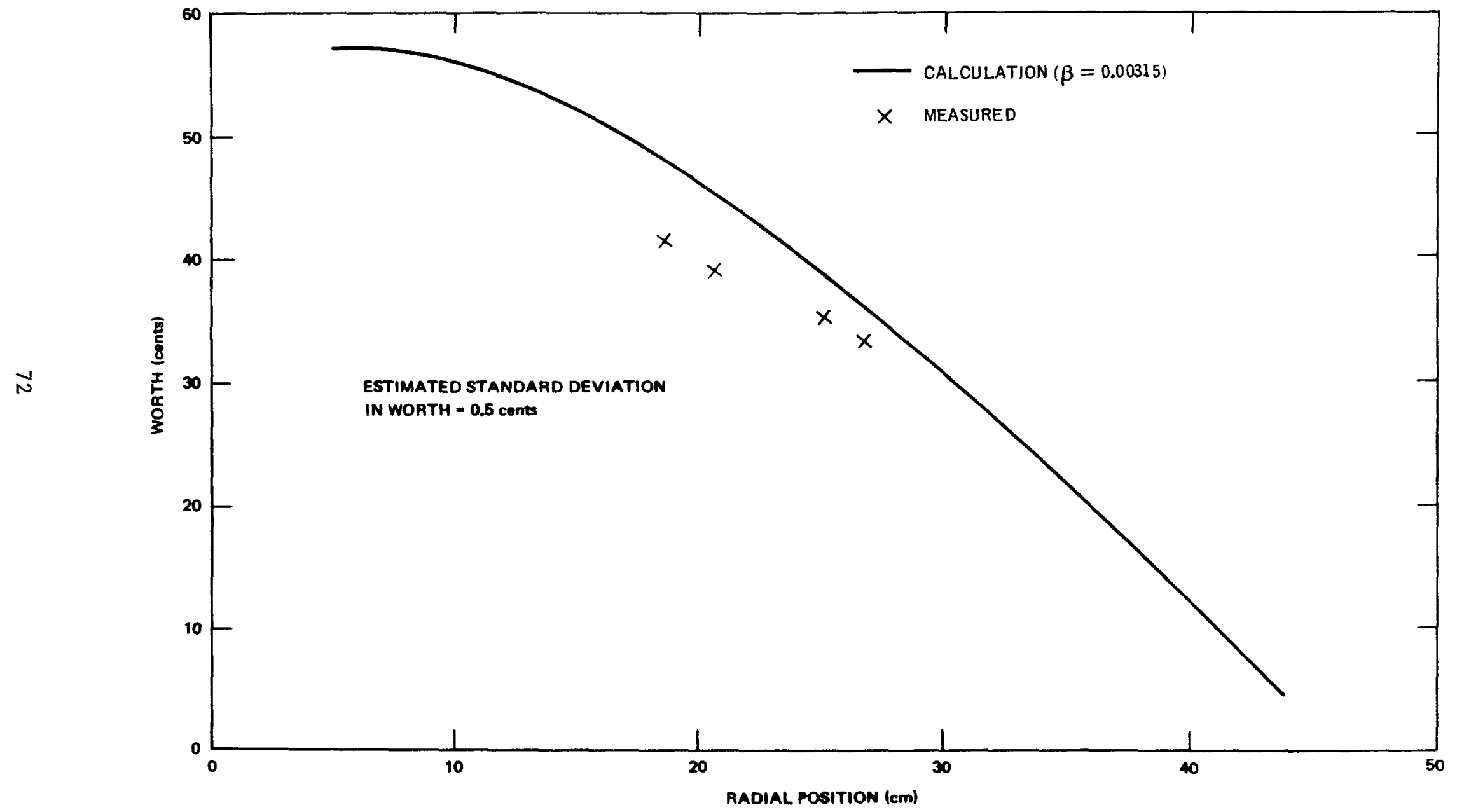

FIGURE 4-9. RADIAL DEPENDENCE OF GUINEA PIG ROD WORTH (ASSEMBLY I-D) 
synthesis calculations and in addition, material worths were calculated using a reactor model in which a portion of the original fuel rods in a thin angular ring were replaced with sodium or one of the test rods and the reactivity effect associated with this replacement was determined. The latter effects were calculated at a few locations using a true two-dimensional diffusion ${ }^{(2)}$ program. The results of these calculations are compared with experiment in Table 4-5.

The two-dimensional calculations of fuel rod worth were in agreement with the experiment (see Table 4-5). Calculated results at the core periphery were essentially the same as experimental values, while the calculated fuel rod worth near the center was approximately $10 \%$ higher than the experimental value. The corresponding $\mathrm{B}_{4} \mathrm{C}$ worth near the core center was over-predicted by about 15\%. The perturbation calculations of the two-dimensional synthesis ${ }^{(3)}$ solutions over-estimated the magnitude of the worth for all materials by about 15 to $20 \%$. The discrepancies were the largest near the core center. This implies, in agreement with the discrepancies in measured and calculated reaction rates near the core boundaries (see Section V), that the calculated synthesis flux distributions are not as flat as they should be.

Perturbation results of radial one-dimensional diffusion theory calculations have shown that the calculated worths and radial flux distribution in SEFOR, which has a high radial leakage, are strongly influenced by the perpendicular bucklings which are used in the radial regions outside the core. For a one-dimensional calculation which provided reasonable agreement with experiment, (see Tables 4-2 through 4-4), the effect of the fuel gap on the non-core bucklings was eliminated by using non-core bucklings obtained from calculations of the one-segment 


\section{Core Location* Type of Rod}

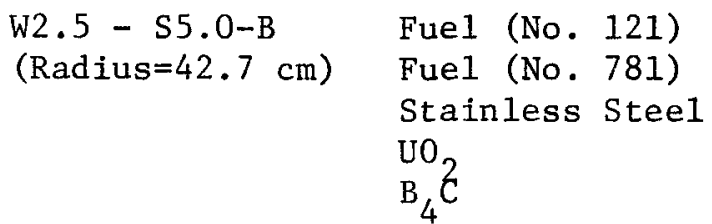

Worth Relative to Sodium (cents) Measured** $\frac{\text { Calculation } * * *}{(\beta=0.00315)}$

$+8.7$

$+9.2$

$+8.5$

$+2.1$

$+8.5$

0.0

$+0.8$

$-13.0$

$-1.1$

$-17.5$

$+14.6$

$+16.2$

$+15.4$

$+16.2$

$-0.4$

$-1.3$

-2.7
-22.1

- 4.6

$-22.1$

$-28.5$

$+27.8$

$+29.6$

$+27.6$

$+29.6$

$-1.6$

$-5.0$

$-11.4$

$-7.6$

$-53.7$

$+28.4$

$+32.7$

$+28.8$

$+32.7$

$-2.8$

$-6.0$

$-9.8$

$-12.9$

$-52.3$

$-59.8$

$+34.5$

$+38.7$

$-3.6$

$-7.3$

$-13.0$

$-17.2$

$-70.9$

* See Core Loading Diagram Figure 1-8, also Figure 4-5.

** The estimated standard deviation in the measurements is approximately \pm 0.5 cents (see Section 4.4 ).

*** Perturbation Results of a one-dimensional diffusion calculation. 
GUINEA PIG AND ADDITIONAL FUEL ROD WORTH MEASUREMENTS (ASSEMBLY I-D)

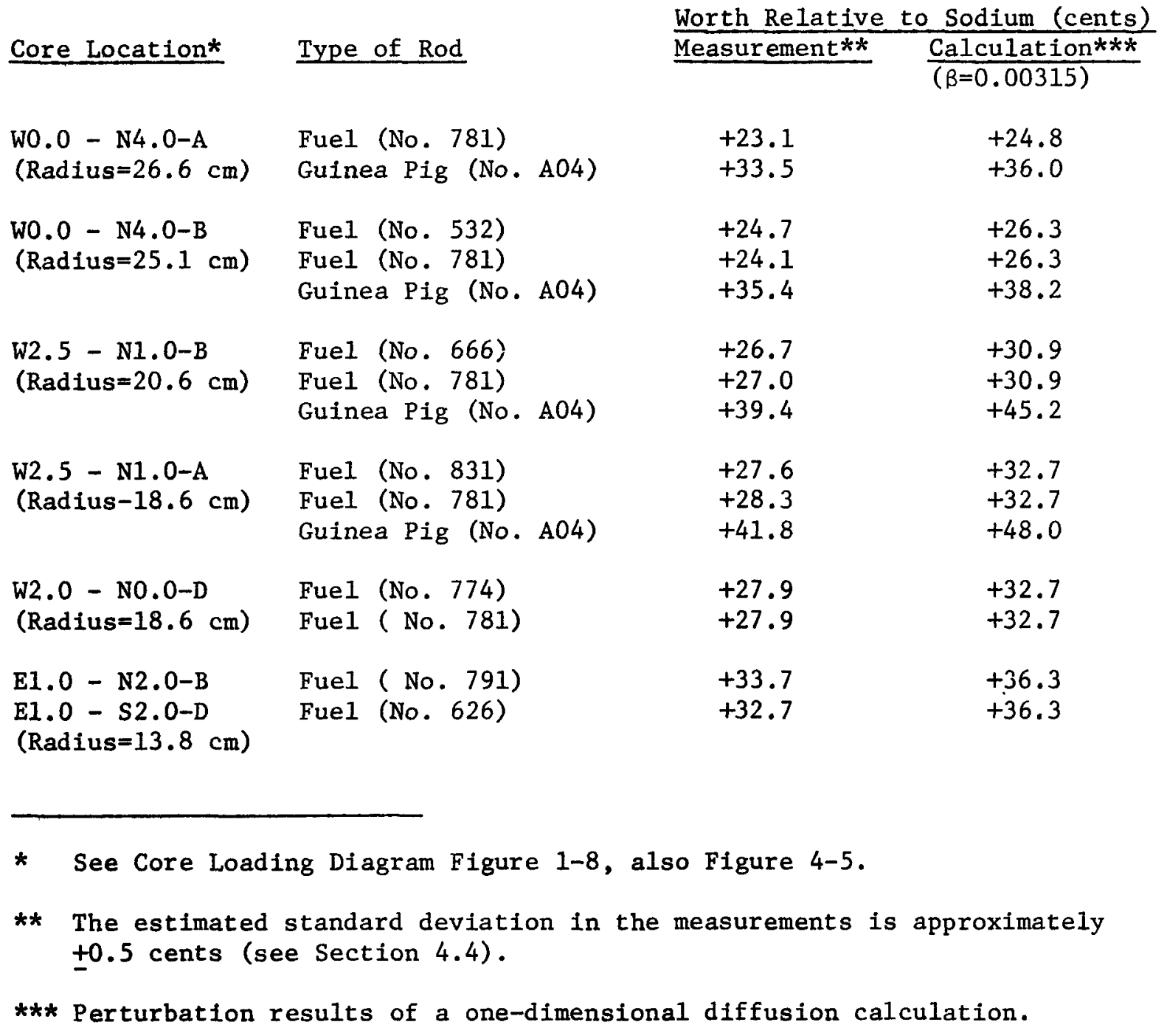


TABLE $4-4$

\section{TIGHTENER ROD REACTIVITY WORTH MEASUREMENTS}

(ASSEMBLY I-D)

\section{Core Location* Type of Rod}

Worth Relative to Stainless Steel (cents)

Measurement** $\quad \frac{\text { Calculation } * * *}{(\beta=0.00315)}$

$W 2.5-\mathrm{S} 5.0$
E2.5 - N5.0

(Radius $=40.3 \mathrm{~cm}$ )

$\mathrm{BeO}$

$\mathrm{BeO}$

4.6

5.4

$\mathrm{W} 2.0-\mathrm{S} 4.0$

$\mathrm{E} 2.0-\mathrm{N} 4.0$

(Radius $=32.2 \mathrm{~cm})$

$\mathrm{Be} 0$ ?

$\mathrm{Be} 0\}$

5.7

5.0

$\mathrm{W} 1.5-\mathrm{S} 3.0$

$\mathrm{E} 1.5-\mathrm{N} 3.0$

(Radius $=24.2 \mathrm{~cm}$ )

$\mathrm{BeO}$

$\mathrm{BeO}$

6.1

5.2

W0.5 - S1.0

BeO

E0.5 - N1.0

(Radius $=8.0 \mathrm{~cm}$ )

BeO

4.5

6.0

* See Core Loading Diagram Figure 1-8, also Figure 4-5.

** The worth of substituting two rods simultaneously. The estimated standard deviation in the measurements is t0.5 cents (see Section 4.4).

*** Perturbation results of a one-dimensional diffusion calculation. 
Fuel Rod Worth radius $=9.4 \mathrm{~cm}$ radius $=40.4 \mathrm{~cm}$

$\mathrm{B}_{4} \mathrm{C}$ Rod Worth radius $=9.4 \mathrm{~cm}$ radius $=40.4 \mathrm{~cm}$

$\mathrm{UO}_{2}$ Rod Worth radius $=9.4 \mathrm{~cm}$ radius $=40.4 \mathrm{~cm}$

Guinea Pig Rod Worth radius $=19 \mathrm{~cm}$ radius $=26 \mathrm{~cm}$
Worth from

Synthesis

perturbation

calculation

(c)

$$
43.0
$$

12.0

$-83.0$

$-19.5$

$-16.0$

$-1.4$

50.5

39.5

\begin{tabular}{l} 
Worth from \\
one-dimensional \\
perturbation \\
calculation \\
\hline
\end{tabular}

(द)

39.2

10.5

$-74.0$

$-20.0$

$-16.3$

$-1.4$

47.5

37.0
Worth from

two-dimensional

diffusion

calculation

(c)

perimental Worth*

(c)

$36.0 *$

$10.5 *$
$-66.5 *$

$-15.5 *$

$-$

$$
\begin{aligned}
& -15.5 * \\
& -12.5 * \\
& -0.5 *
\end{aligned}
$$

41.5*

$34.5 *$

*The experiments were actually performed at other radii (see Tables 4-2 and 4-3). The values shown here were obtained by interpolation among the measured values. 
mockup in ZPR-3 Assembly 47. The differences between the calculated axial flux distributions in the core and the axial distributions in the radial region outside the core near the fuel gap are illustrated in Figures 4-10 through 4-13. These curves show the axial distribution of four of the energy groups from a thirteen energy group twodimensional calculation. For illustrative purposes the magnitude of the fluxes were normalized to unity at the axial location of the peak power in the core. The curves illustrate that the axial distributions outside of the core rapidly (within a very few centimeters) lose the two-segment gap characteristic of the core and assume a flatter shape which is more akin to a one-segment core. The effect of the gap in the outer radial non-fuel regions of the reactor is automatically eliminated in the two-dimensional calculations, where the agreement between experiment and calculation is in the 10 to $15 \%$ range. In the synthesis calculations however, the core axial flux shapes were extended out through the radial reflector region, and the resulting discrepancy between experiment and theory were of the order of $20 \%$ near the core center.

As was true with the results for Assembly I-B discussed in the previous section, generally better agreement between experiment and calculation would be obtained if the value of the calculated effective delayed neutron fraction $(\beta=0.00315$ for Assembly I-D) were increased by 6 to $10 \%$. 


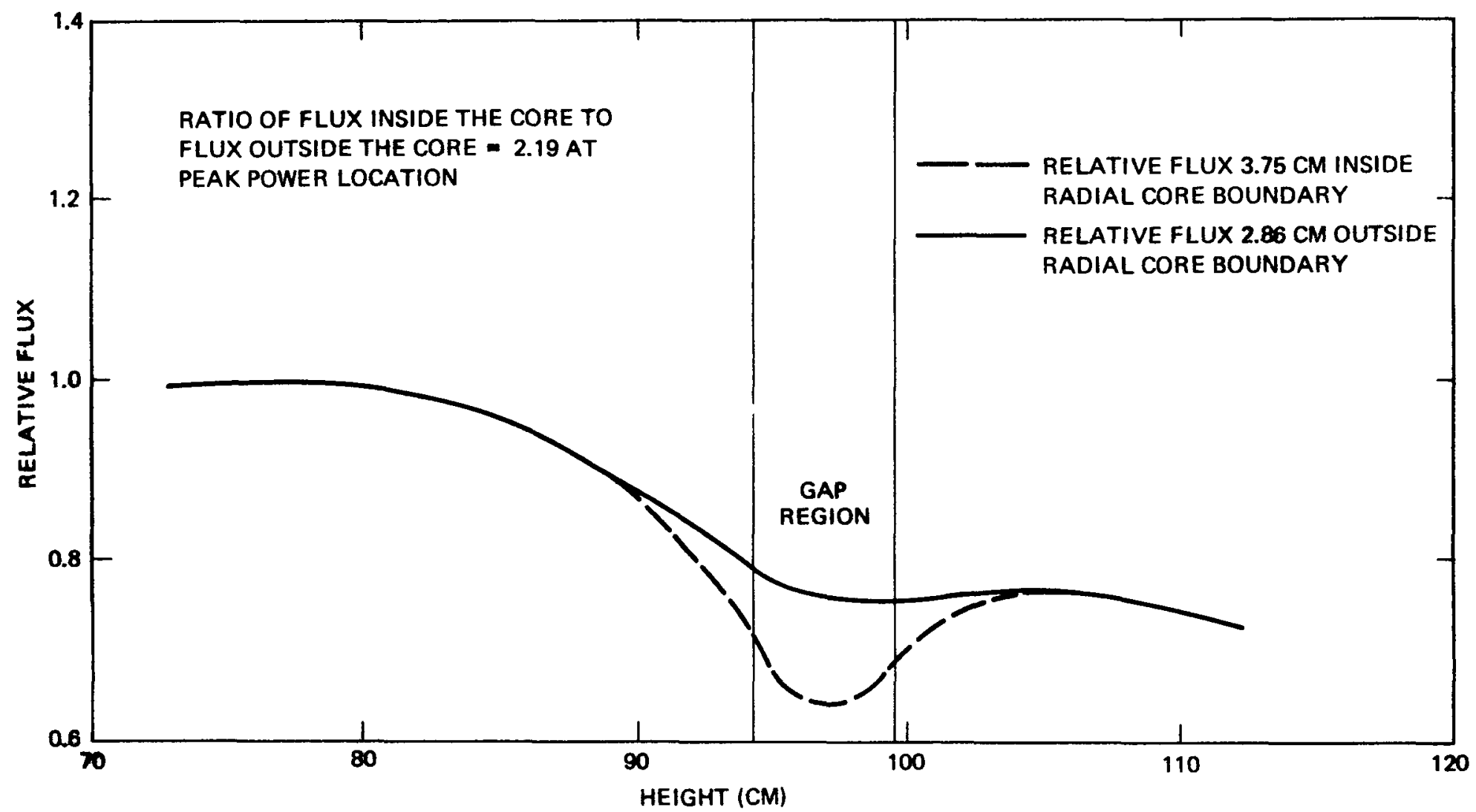




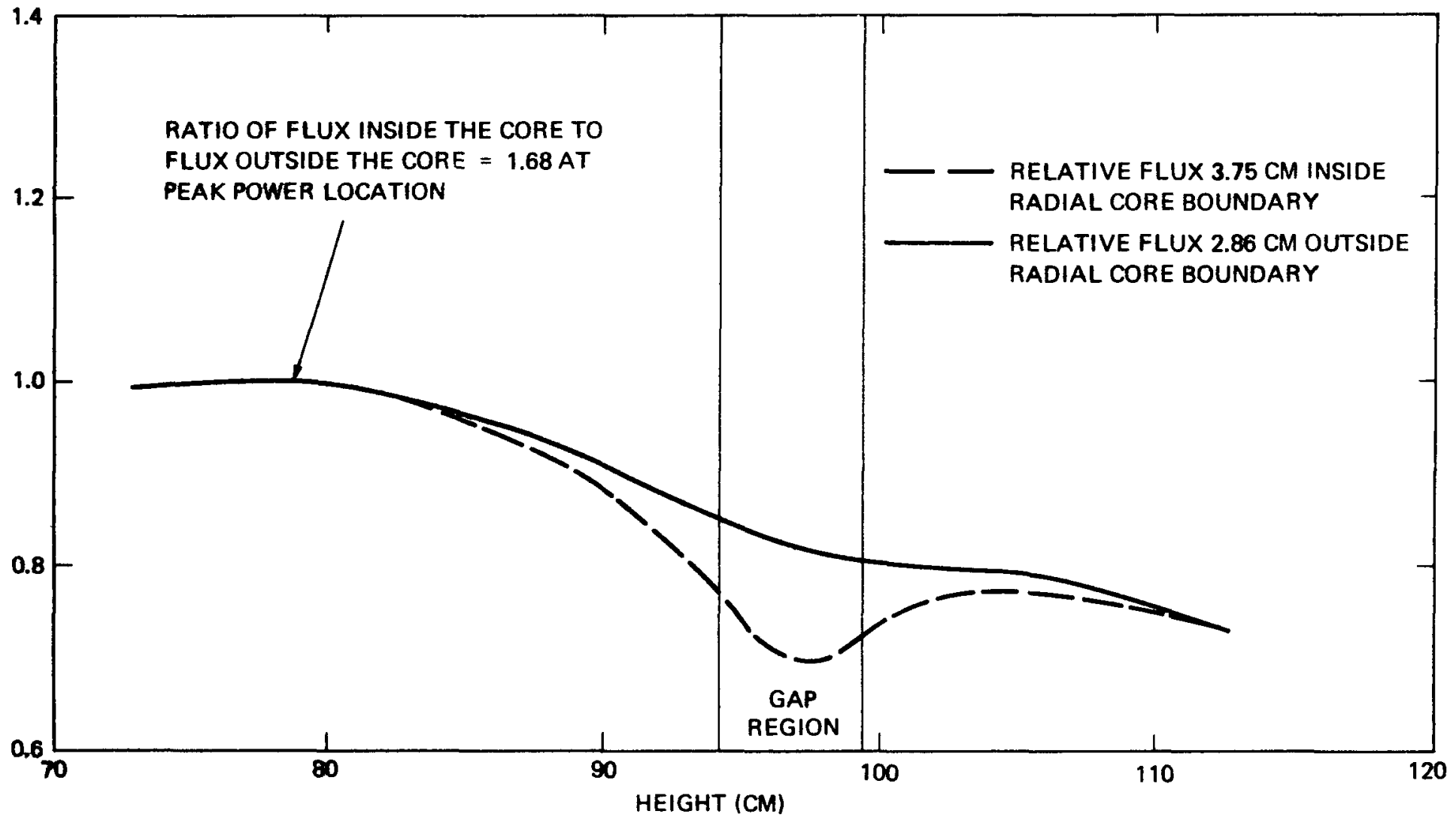




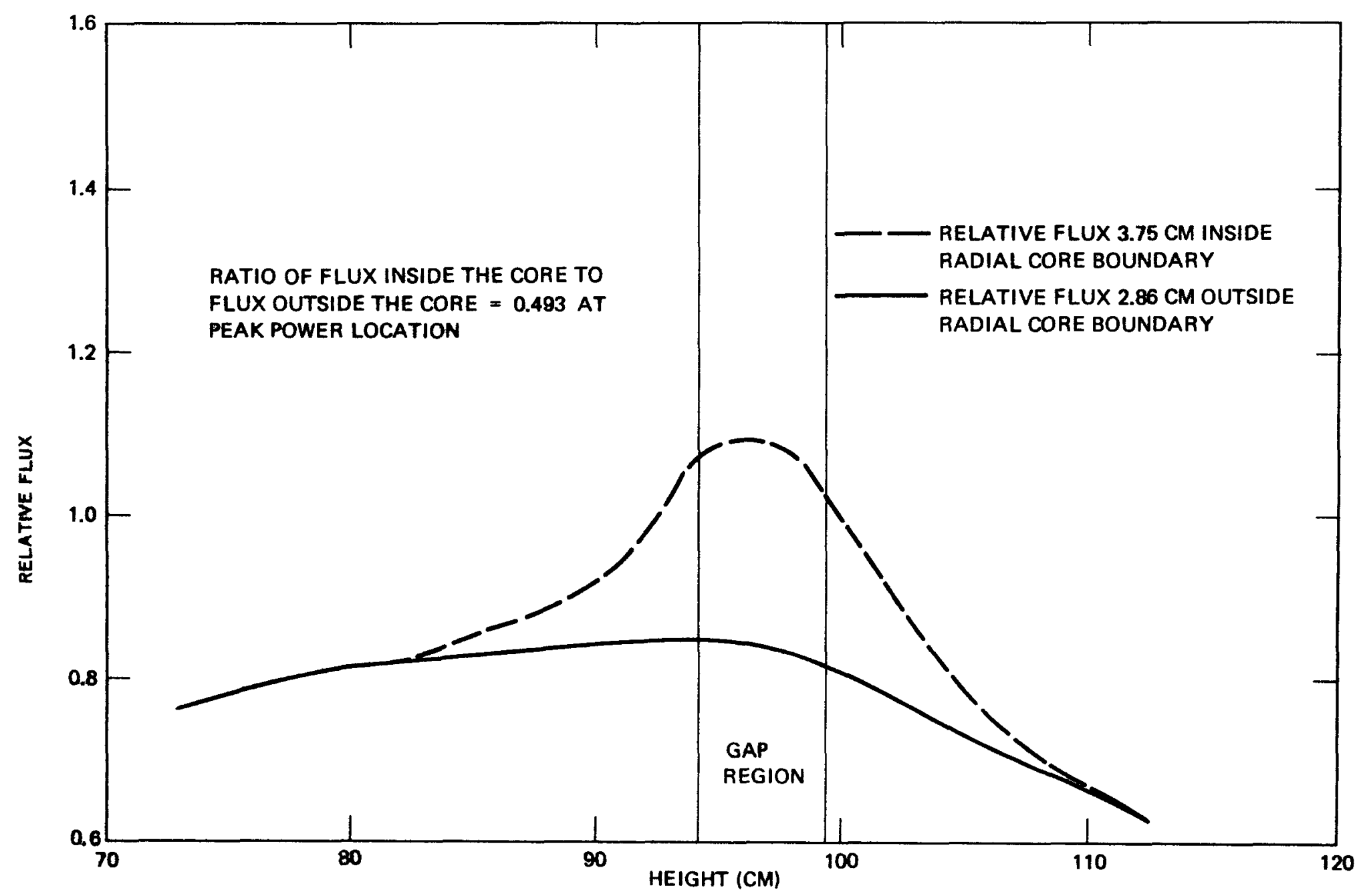

FIGURE 4-12. AXIAL FLUX DISTRIBUTION FOR GROUP TWELVE (310 TO $91 \mathrm{eV}$ ) 


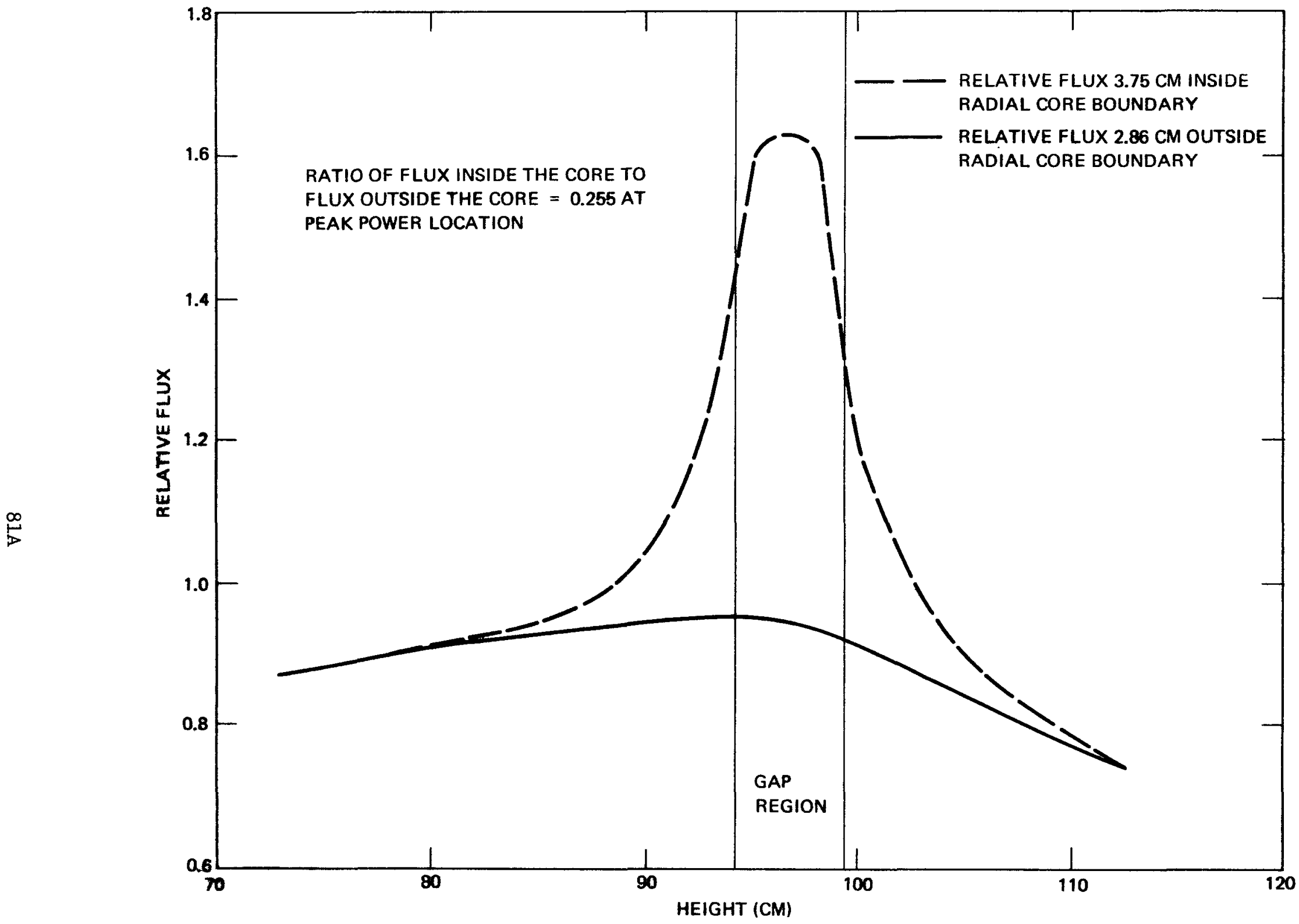

FIGURE 4-13. AXIAL FLUX DISTRIBUTION FOR GROUP THIRTEEN (LESS THAN $91 \mathrm{eV}$ ) 


\subsection{UNCERTAINTIES IN REACTIVITY MEASUREMENTS}

Due to small variations in system temperatures, instrumentation, relative reflector-core configurations, etc., the measurement of the critical point (the system conditions for which the reactor is exactly critical) is inexact, and different measurements of the same point show small variations. Evidence for this variation is shown by the two sets of data in Tables 4-6 and 4-7, obtained from repeated measurements on two slightly different core configurations. (The core loading was changed slightly between the critical measurements on September 12 and September 13.) Although the mean reactivity is different for the two sets of data, because of the different core loadings, the individual deviation appears to be random. The estimated standard deviation, which is essentially the same for both cases, appears to be unaffected by changes in reactor configuration.

Based on the above measurements, the estimated standard deviation in a single measurement of a small reactivity change, calculated from the difference between two measurements of the critical point, is $0.37 \sqrt{2}$ cents, or 0.5 cents.

Since the variations noted in Tables 4-6 and 4-7 appear to be random in nature, and, as noted in Section 3.3.4, the uncertainty due to reflector calibration errors in a 9 cent increment is (0.009) X 9 cents, or 0.08 cents, the estimated calibration uncertainty in a 90 cent reactivity change associated with movement of the reflector over ten consecutive increments, which were measured to be worth 9 cents each, would be expected to be $\sim 0.08 \sqrt{10}$ cents, or 0.25 cents. Similarly, 
the calibration uncertainty in any reactivity change of magnitude $\Delta \mathrm{k}$ cents would be expected to be approximately $0.08 \sqrt{\Delta \mathrm{k} / 9}$ cents, and the total uncertainty in any reactivity change would thus be $\left[2(0.37)^{2}+(0.08)^{2} \Delta \mathrm{k} / 9\right]^{1 / 2}$. This relation is probably reasonable for reactivity changes thich are of the order of 30 cents or less. For larger changes the reflector configuration changes considerably, and the reflector interaction effects noted in Section 3.3 may increase the uncertainties. 
TABLE 4-6

SEFOR CRITICAL CHECKS

(September 1 to September 12)

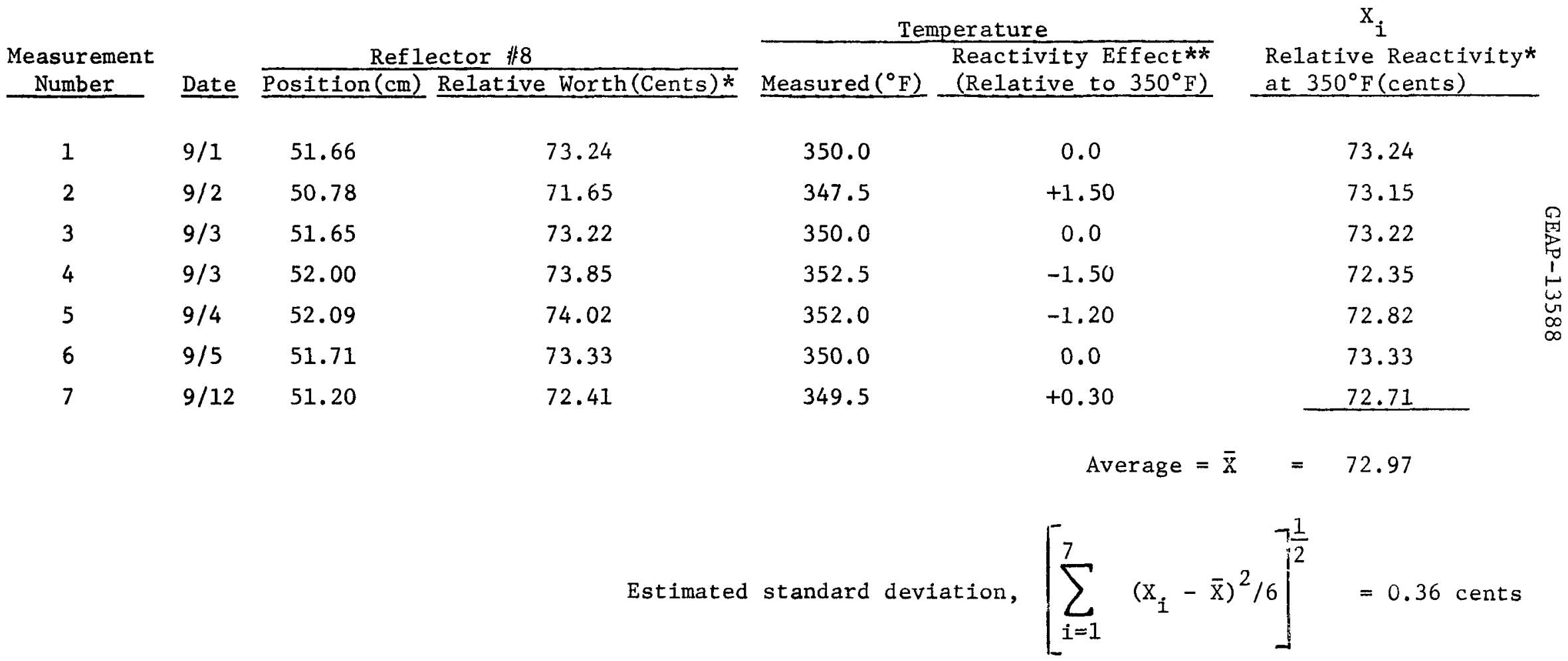

* Relative to the worth with the reflector lowered.

** Using a temperature coefficient at $350^{\circ} \mathrm{F}$ of -0.60 cents $/{ }^{\circ} \mathrm{F}$. 
TABLE 4-7

SEFOR CRITICAL CHECKS

(September 13 to October 7)

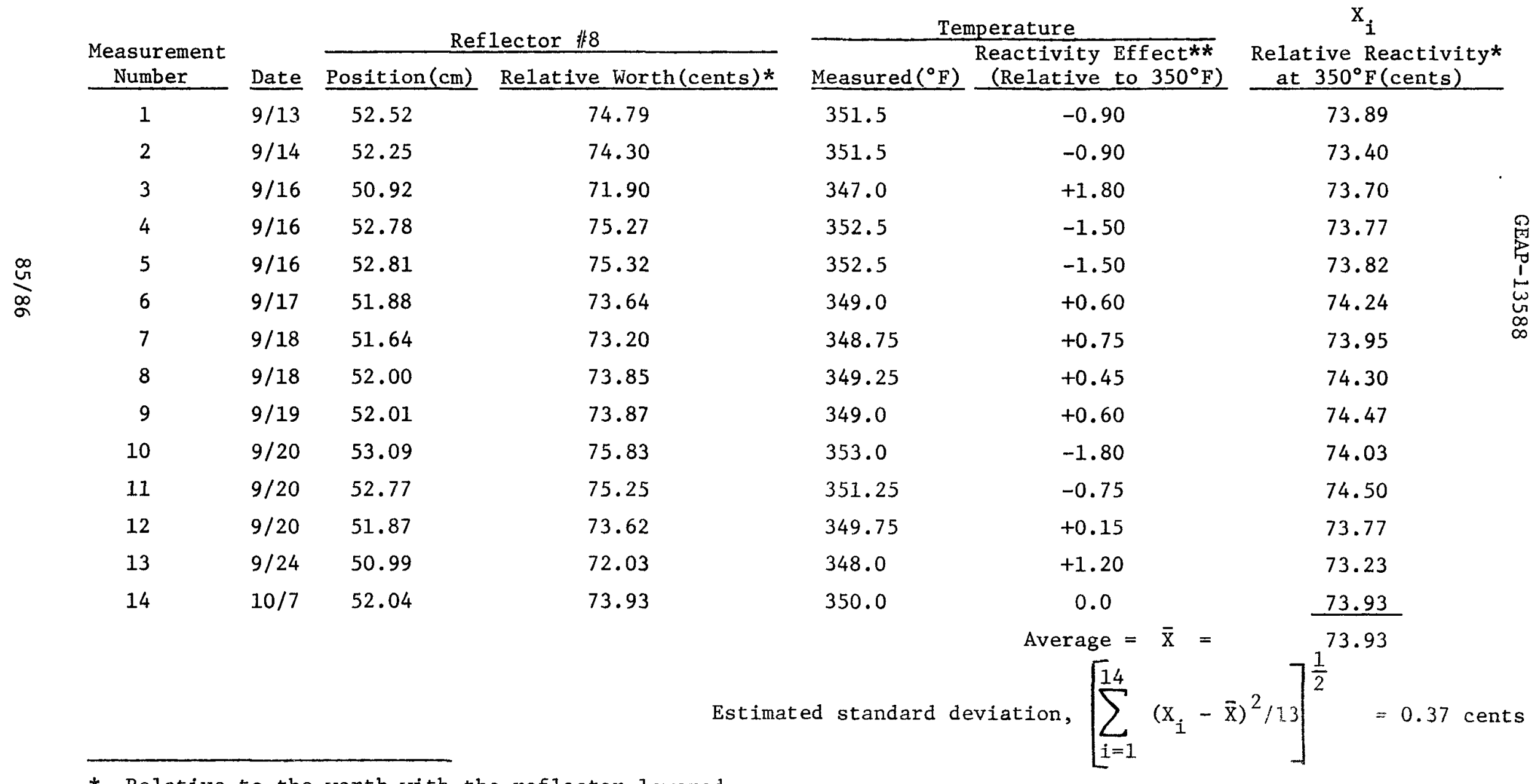

* Relative to the worth with the reflector lowered.

** Using a temperature coefficient at $350^{\circ} \mathrm{F}$ of -0.60 cents $/{ }^{\circ} \mathrm{F}$. 


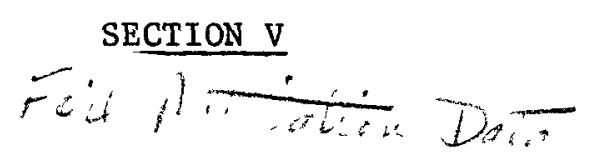

$\underline{\text { F }}$

The spatial distrf

sotopes

$\mathrm{Pu}-239, \mathrm{U}-238$, and $\mathrm{U}-2$ :

can be

used to estimate the $p$

of an

absolute fission rate

me avail-

able, to provide an at

in, the

isotopic fission rati،

from

relative activities o

\subsection{DESCRIPTION ANI}

\section{1 .1 Fission Rate}

Foils of three

selected axial posit

were inserted into wa ..

for approximately 1 hour at a nominal reactor powe _ _. kw. After removal from the core, the fission product gamma activity of each foil was obtained with a Na-I crystal scintillation counter. The energy window for the counting of all foils was the same, and covered the range between 430 and $730 \mathrm{keV}$. This region included several gamma peaks which are composites of fission product peaks.

The specified isotopic compositions of the thin cylindrical foils are 1isted in Table 5-1. The weight of the uranium foils was of the order of 120 milligrams, while that of the Al-clad Pu foils (a Pu-Al alloy of $99.01 \% \mathrm{Pu}$ ) was about 23 milligrams. 
GEAP-13588

TABLE 5-1

FOIL ISOTOPIC COMPOSITIONS

Foil Type

Enriched

Uranium

Depleted

Uranium

Plutonium
Isotopic Composition Isotope

Percent

$\mathrm{U}-235$

93.15

$\mathrm{U}-238$

6.85

$\mathrm{U}-235$

0.19

$\mathrm{U}-238$

99.81

$\mathrm{Pu}-238$

$\mathrm{Pu}-239$

$\mathrm{Pu}-240$

$\mathrm{Pu}-241$

$\mathrm{Pu}-242$

0.036

92.905

6.444

0.582

0.033 
The fissionable foils were placed in cylindrical Al "cans" that were 0.27 inches in height with an outer diameter of 0.475 inches. The fissionable foils within a given can were separated from each other and from the ends of the can by Al foils. The cans were positioned vertically within the special foil holder rod, (see Figure 5-1) by Al spacers*. The position of the cans and spacers within a foil holder rod is indicated in Table 5-2. The axial position of the foils above the bottom of the core (not including the lower uranium insulator pellet) is also shown in the table. In calculating the axial foil positions, it was assumed that all foils were 0.098 inches above the bottom of the foil can. In some instances the foil can was replaced with a 1/4" Al spacer. The effect on axial foil position of this slight difference in thickness (0.02 inches) was neglected.

Six of the standard fuel rods in core loading Assembly I-D were replaced by the special foil holder rods. Their location within the core is shown in Figure 5-2. With this core configuration the reactor was critical with reflector 非, which is close to the position of foil holder rod $\mathrm{FE}$, at an intermediate height (at a position of $\sim 47 \mathrm{~cm}$ relative to a completely raised position of $\sim 98 \mathrm{~cm}$ ) and all other reflectors were completely raised.

The measured specific activities for all the foils are tabulated in Tables 5-3 through 5-5. The corrections for background gamma events in the foils, small differences in foil weight, and activity decay during the counting process are included. The background corrections for $\mathrm{U}-238$ and $\mathrm{Pu}-239$ were about $5 \%$ of the observed count rate in the irradiated foils of lowest activity. Background corrections for the U-235 were negligible. The corrections for the time decay of the activity were determined from the measured time dependence of the specific activity

\footnotetext{
*These were of two thicknesses: $1 / 4$ " and 1 ".
} 


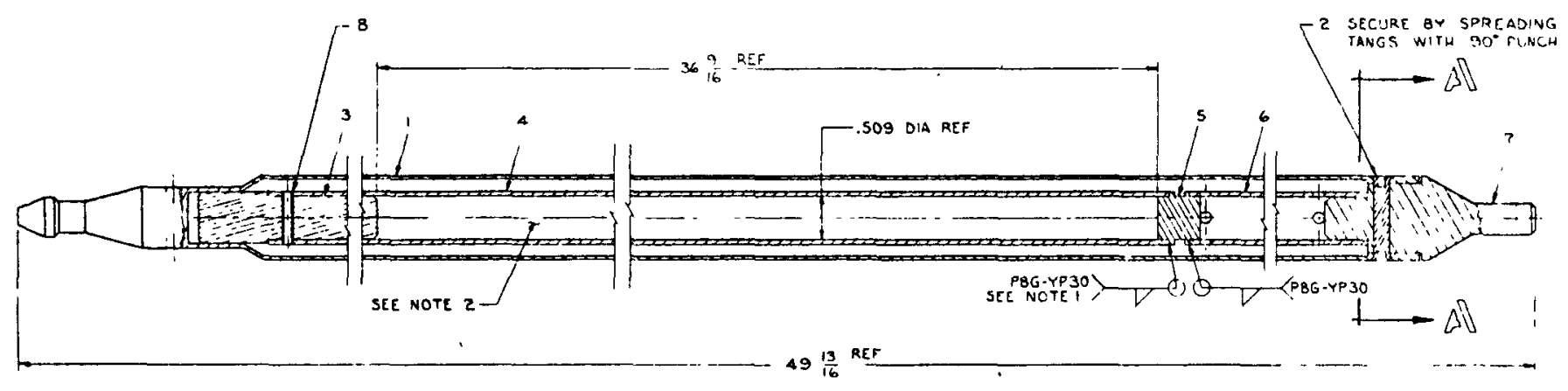




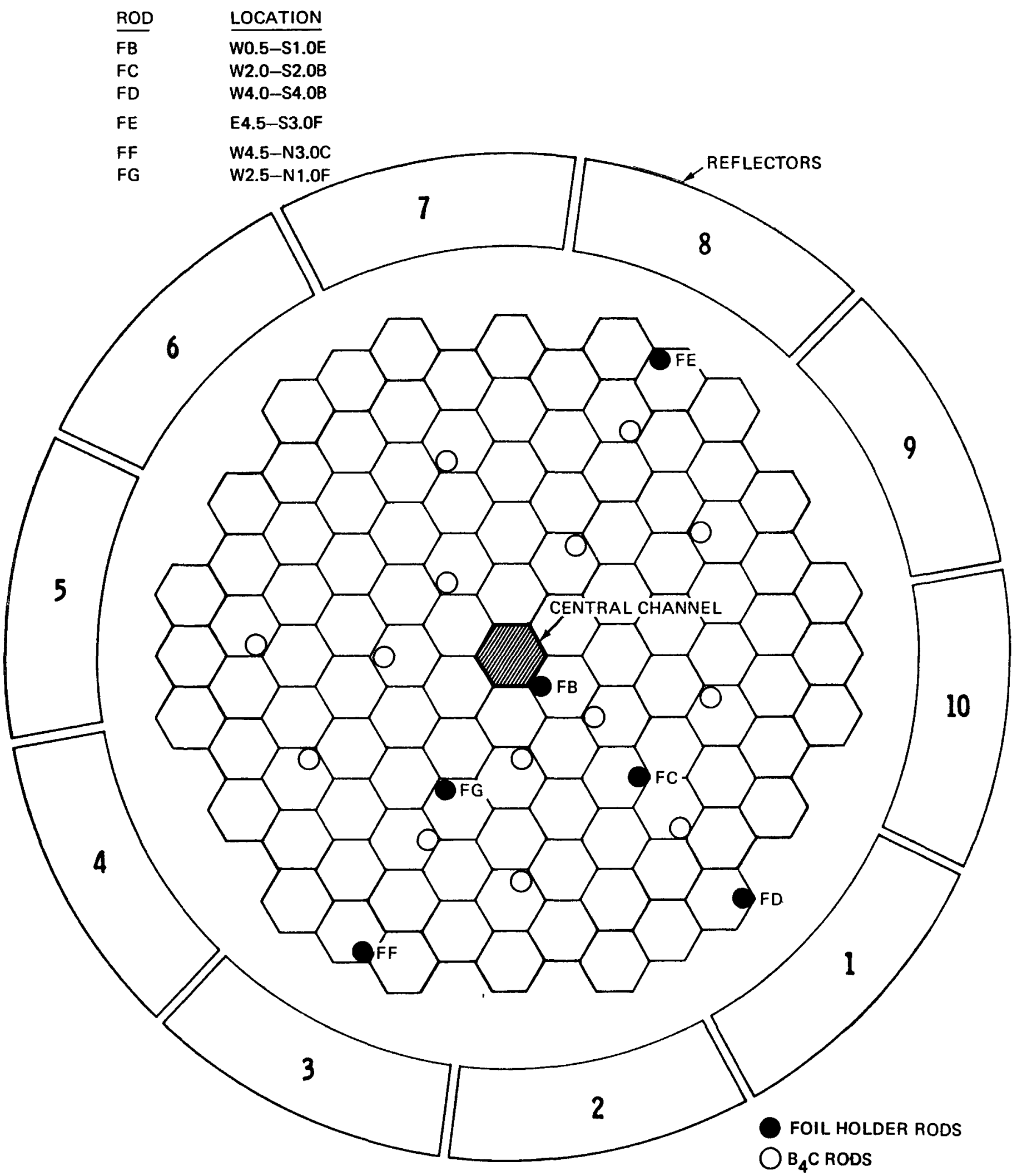

FIGURE 5-2. FOIL HOLDER ROD LOCATIONS (ASSEMBLY I-D) 


\section{TABLE $5-2$}

FOIL POSITIONS IN FOIL HOLDER RODS

\begin{tabular}{cccc}
$\begin{array}{l}\text { Position } \\
\text { Number }\end{array}$ & $\begin{array}{l}\text { Height of A1 } \\
\text { Spacers Below } \\
\text { Can at } 70^{\circ} \mathrm{F} \\
\text { (inches) }\end{array}$ & $\begin{array}{l}\text { Can Width* } \\
\text { at } 70^{\circ} \mathrm{F} \\
\text { (inches) }\end{array}$ & $\begin{array}{c}\text { Foil Height** } \\
\text { above bottom } \\
\text { of core at } 350^{\circ} \mathrm{F} \\
\text { (cm) }\end{array}$ \\
\hline $\begin{array}{c}0.75 \\
2\end{array}$ & 9.50 & 0.27 & 1.2 \\
3 & 4.00 & 0.27 & 26.1 \\
4 & 6.00 & 0.27 & 37.0 \\
5 & 0.50 & 0.27 & 53.0 \\
6 & 1.00 & 0.27 & 54.9 \\
7 & 5.75 & 0.27 & 58.2 \\
8 & 6.50 & 0.27 & 73.5
\end{tabular}

* In some rods a few cans were replaced with $1 / 4$ inch spacers.

** Foils located 0.098 inches (at $70^{\circ} \mathrm{F}$ ) above bottom of can. The bottom of the first can is $3 / 8$ inches above the bottom of the core. A linear expansion coefficient of $1.3 \times 10^{-5} /{ }^{\circ} \mathrm{F}$ was used for the aluminum. The core height at $350^{\circ} \mathrm{F}$ is $91.2 \mathrm{~cm}$. 
for each type of foil. These corrections were $3 \%$ or less for foils within the same rod but ranged up to $223 \%$ for foils in different rods.

\subsubsection{Determination of Approximate Fission Ratios}

In addition to the data described in the previous section, supplementary count rate data has been taken on the three foils near the core center (can number 3, rod FB) to determine approximate foil fission ratios. The $1.6 \mathrm{Mev}$ La-140 fission product emission was counted for the depleted uranium, enriched uranium and plutonium foils in this can. The enriched uranium and plutonium foils were counted for one hour twenty minutes and the depleted uranium foil was counted for fifteen hours thirty seven minutes. The data was recorded on a multi-channel analyzer and the area under the total energy peak of the 1.6 gamma ray was integrated for each foil.

The area under the total energy peak consists of the $1.6 \mathrm{Mev}$ events from the decay of La-140 plus background from other fission products. The background was assumed to have the same shape and magnitude as the spectrum just above the $1.6 \mathrm{Mev}$ peak. This background was subtracted from the area of the total energy peak and the resulting count rate was then normalized to the foil weight to obtain the specific "La-140" activity for each type of foil.

No normalization was made for differences in counting time. The counts were treated as if they had been taken in the middle of the counting interval and the three count intervals were assumed to be at the same time after shutdown. The first assumption results in less than one percent error (Reference 1 p.49), while the second assumption results in 1 ess than $2 \%$ error as can be seen by using the daughter product relation 


$$
\begin{aligned}
& \text { Activity of La }\left(\lambda_{\mathrm{La}} \mathrm{N}_{\mathrm{La}}\right)= \\
& \mathrm{N}_{\mathrm{La}, 0} \frac{\lambda_{\mathrm{Ba}}{ }^{\lambda} \mathrm{La}}{\lambda_{\mathrm{La}}-\lambda_{\mathrm{Ba}}} \quad\left(\mathrm{e}^{-{ }^{\lambda} \mathrm{Ba} \mathrm{t}^{\mathrm{t}}}-\mathrm{e}^{\left.-{ }^{\lambda} \mathrm{La}{ }^{\mathrm{t}}\right)}\right.
\end{aligned}
$$

for the times in question.

The foil fission ratios are as follows after accounting for count length, mass and yield

$$
\begin{aligned}
& \frac{\sigma \text { Depleted } U}{\sigma \text { Enriched } U}=0.0290 \\
& \frac{\sigma \text { Pu Mixture }}{\sigma \text { Enriched U }}=0.9215
\end{aligned}
$$

The actual isotopic fission ratios that were determined from these ratios are shown in the next section.

The estimated outside error limit $(\sim 2 \sigma)$ on these ratios is about $10 \%$. This limit is due to a combination of uncertainties in La-140 yield, counting statistics, background subtraction, weigh normalization and counting geometry reproducibility. 
GEAP-1 3588

TABLE 5-3

FISSION RATE MEASUREMENTS FOR PU FOILS

(Relative Values)

Rod Number

FB

FG

FC

FF

FE

FD

Radial

Distance* $(\mathrm{cm})$

5.8

19.6

23.2

43.3

43.3

44.5

\section{Axial Position}

No. Distance**

$\begin{array}{rrllllll}8 & 90.8 & 0.6013 & - & - & - & - & - \\ 7 & 73.5 & 0.7388 & - & - & - & - & - \\ 6 & 58.2 & 0.9198 & - & - & - & - & - \\ 5 & 54.9 & 0.9396 & - & - & 0.5769 & - & 0.5871 \\ 4 & 53.0 & 0.9423 & - & - & - & - & - \\ 3 & 37.0 & 1.0000^{+} & 0.8564 & 0.8111 & 0.5543 & - & 0.5747 \\ 2 & 26.1 & 0.9419 & - & - & - & - & - \\ 1 & 1.2 & 0.6901 & - & - & - & - & -\end{array}$

*Distance from core center

** Distance above bottom of core - core height $=91.2 \mathrm{~cm}$

+ The specific activity at this point was 6398.3 counts/min/mg. 


\section{$\underline{\text { TABLE } \quad 5-4}$}

FISSION RATE MEASUREMENTS FOR ENRICHED URANIUM FOILS

(Relative Values)

\begin{tabular}{|c|c|c|c|c|c|c|c|}
\hline \multicolumn{2}{|c|}{ Rod Number } & $\mathrm{FB}$ & FG & FC & FF & $\mathrm{FE}$ & FD \\
\hline \multicolumn{8}{|c|}{ Radial } \\
\hline \multicolumn{8}{|c|}{ Axial Position } \\
\hline No. & $\frac{\text { Distan }}{(\mathrm{cm})}$ & & & & & & \\
\hline 8 & 90.8 & 0.6240 & 0.5418 & 0.5018 & - & - & - \\
\hline 7 & 73.5 & 0.7778 & 0.6629 & 0.6184 & 0.4311 & & 0.4747 \\
\hline 6 & 58.2 & 0.9515 & 0.8222 & 0.7807 & 0.5673 & & 0.6055 \\
\hline 5 & 54.9 & 0.9750 & 0.8679 & 0.8093 & 0.5979 & 0.5003 & 0.6114 \\
\hline 4 & 53.0 & 0.9932 & 0.8806 & 0.7949 & 0.5953 & - & 0.6001 \\
\hline 3 & 37.0 & $1.0000^{+}$ & 0.8599 & 0.8154 & 0.5703 & 0.5450 & 0.5782 \\
\hline 2 & 26.1 & 0.9633 & 0.8524 & 0.7742 & 0.5275 & - & 0.5523 \\
\hline 1 & 1.2 & 0.7191 & 0.6114 & 0.5739 & - & - & - \\
\hline
\end{tabular}

*Distance from core center.

** Distance above bottom of core - core height $=91.2 \mathrm{~cm}$.

+ The specific activity at this point was 6410.2 counts/min/mg. 


\section{TABLE 5-5}

FISSION RATE MEASUREMENTS

FOR DEPLETED URANIUM FOILS

(Relative Values)

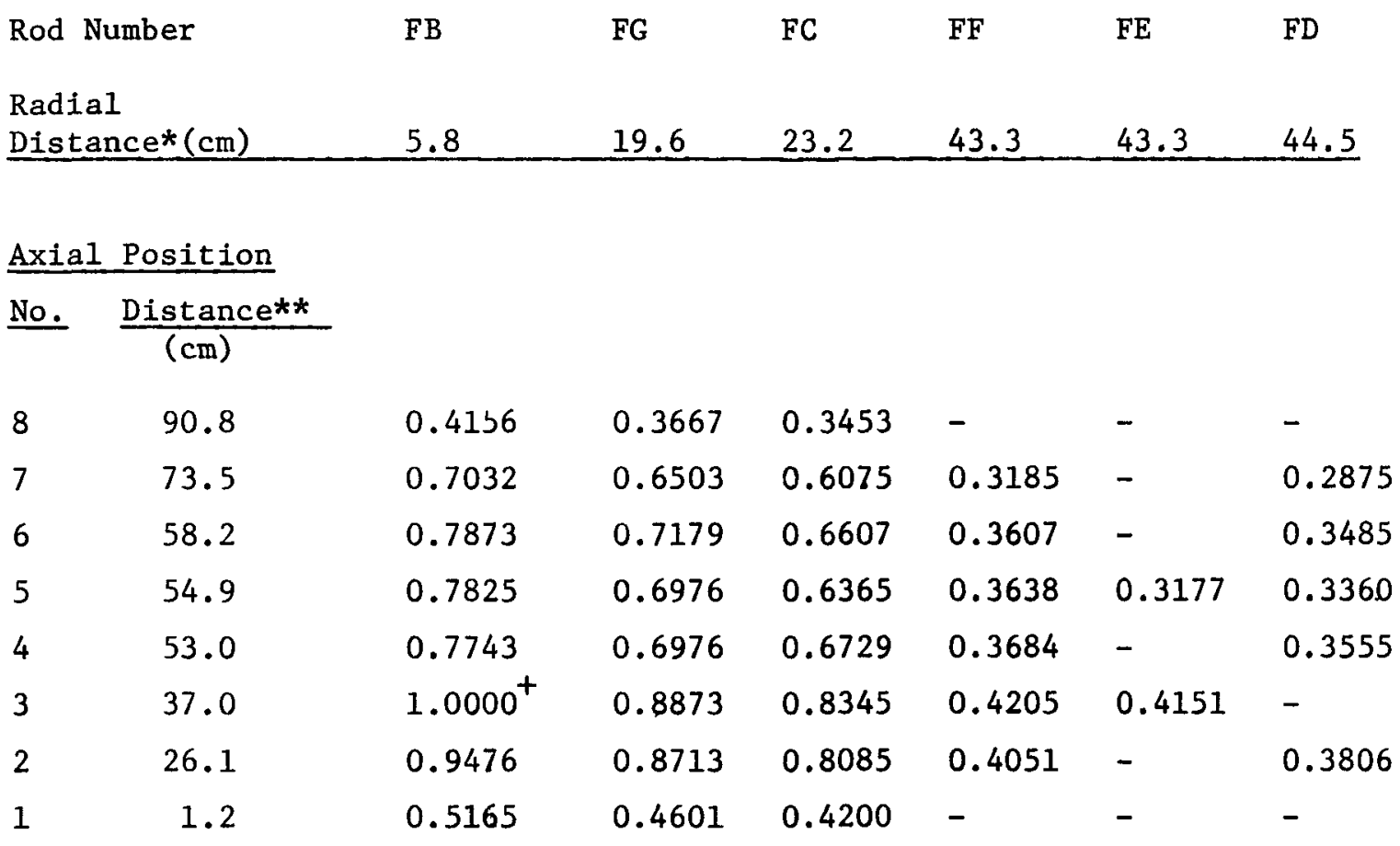

*Distance from core center

** Distance above bottom of core - core height $=91.2 \mathrm{~cm}$.

+ The specific activity at this point was 230.8 counts/min/mg. 


\subsection{COMPARISON OF EXPERIMENTAL AND CALCULATED RESULTS}

\subsubsection{Comparison of Fission Rate Distributions}

The calculated and measured fission rate distributions in a number of rods are compared in Figures 5-3 through 5-10. The estimated uncertainty in the measured values is $\pm 5 \%$ for the axial profiles and $\pm 10 \%$ for the radial profiles. The agreement between the calculations, which are discussed in more detail below, and the experiment is well within the experimental uncertainties throughout the major portion of the core, but differences of the order of $20 \%$ occur near the core boundaries. Possible explanations for these discrepancies are discussed below. In general, however, it appears that the actual fission rate, and thus the power, distribution may be slightly flatter than calculated.

The calculations were performed with a core model for Assembly I-D that had six radial core zones. The first (central dry well) core zone is described in Appendix I. The second, fourth, and sixth calculational zones contained 36, 108, and 288 fuel rods respectively. The third zone contained 67 fuel and $5 \mathrm{~B}_{4} \mathrm{C}$ rods, while the fifth zone contained 135 fuel rods and $9 \mathrm{~B}_{4} \mathrm{C}$ rods. The tightener rods, core structare, and sodium were distributed uniformly as described in Appendix $I$. The fuel and $B_{4} C$ were assumed to be uniformly distributed within their respective zones.

Calculations using the above model were performed in 13 energy groups using two-dimensional synthesis, ${ }^{(2)}$ as well as true two-dimensional diffusion (3) programs. There were no significant differences between the reaction rate distributions calculated with the two methods. Generally, however the reaction rate profiles obtained from the true 2-D calculations were somewhat flatter than those calculated with the synthesis program. Infinitely dilute cross sections were used to calculate the fission rate distributions. The results of the true two-dimensional calculations as shown in Figures 5-3 through 5-10. The apparent effect of the lowered reflector $\# 8$ on the axial uranium profile in rod FE is clearly demonstrated. 


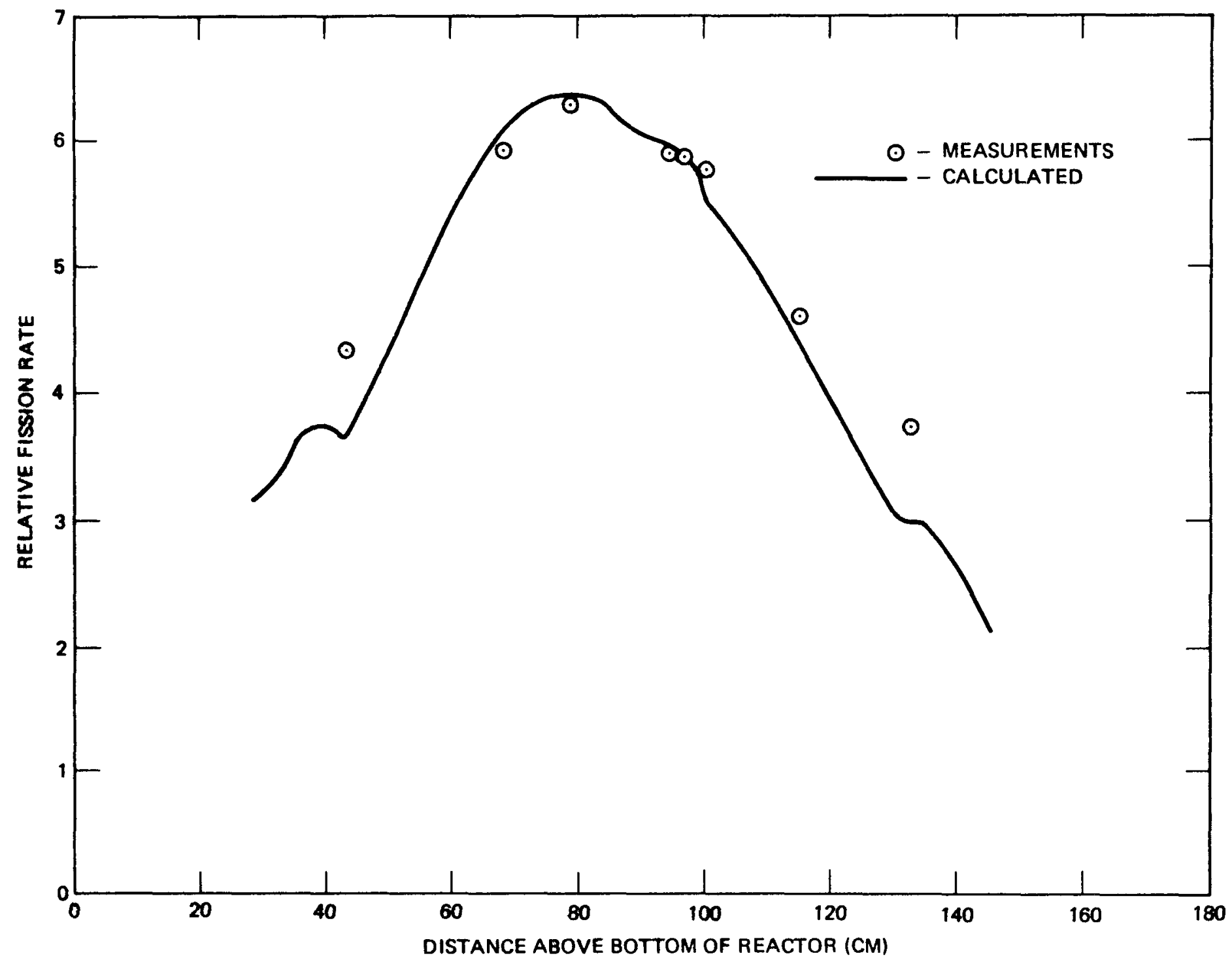




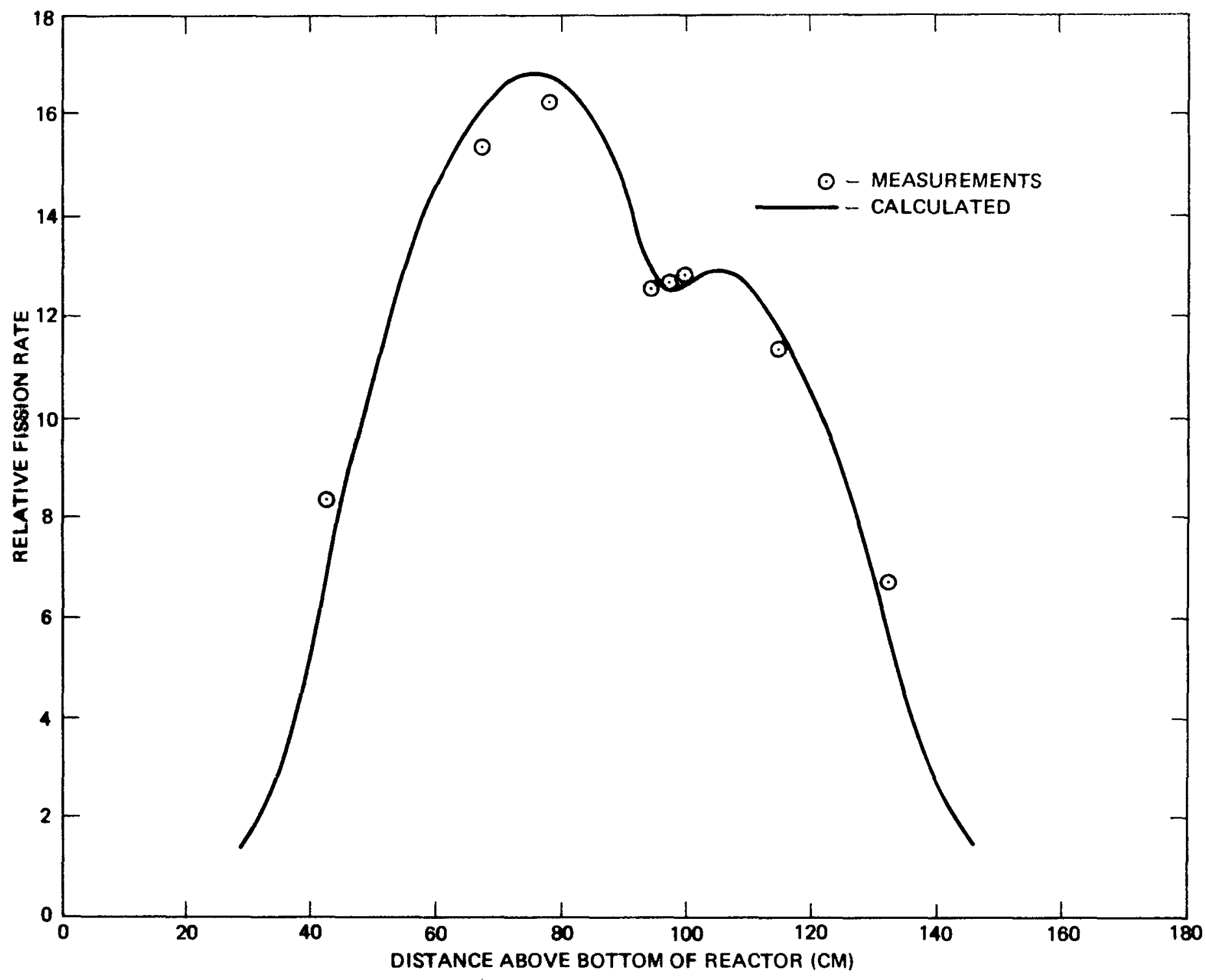




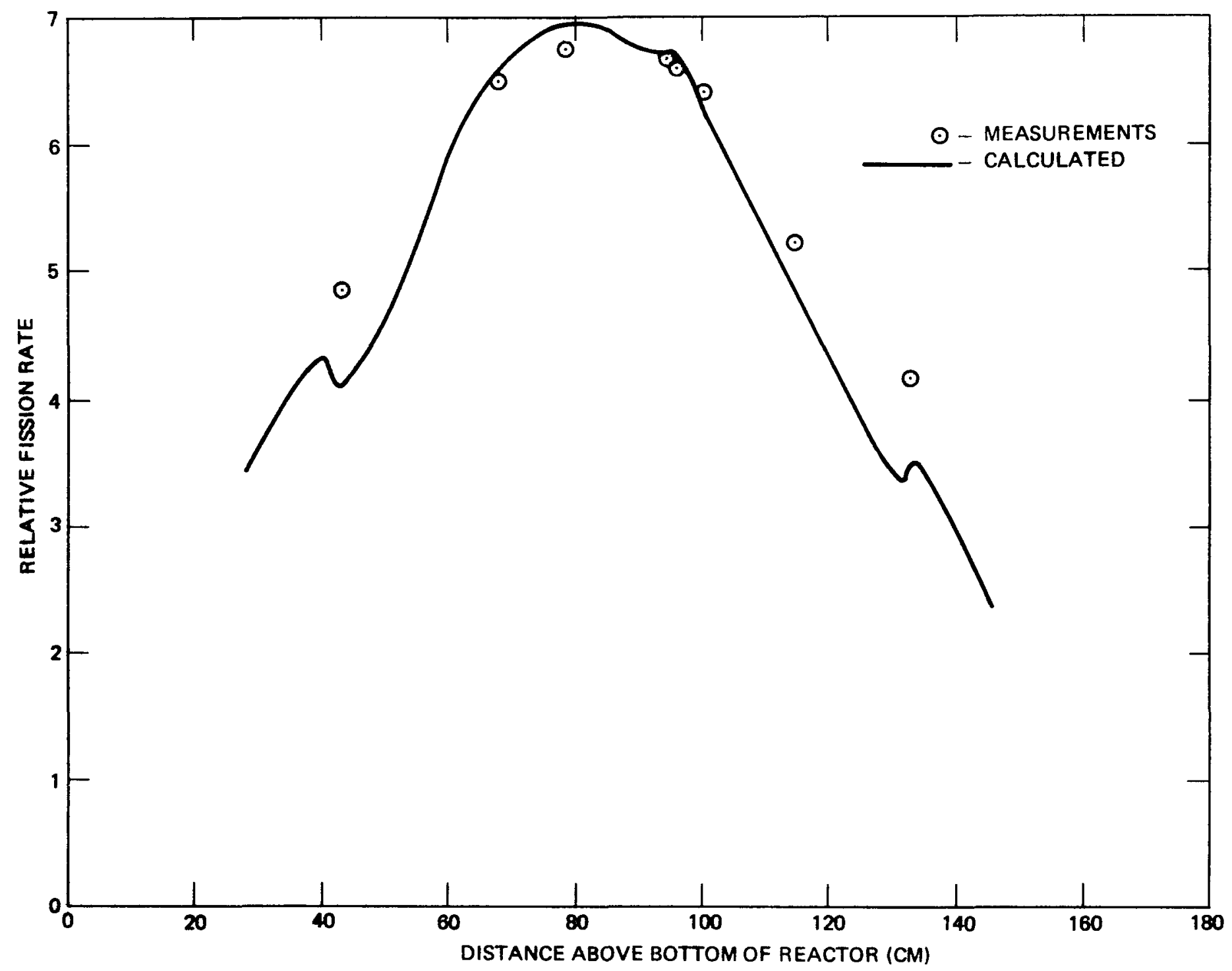




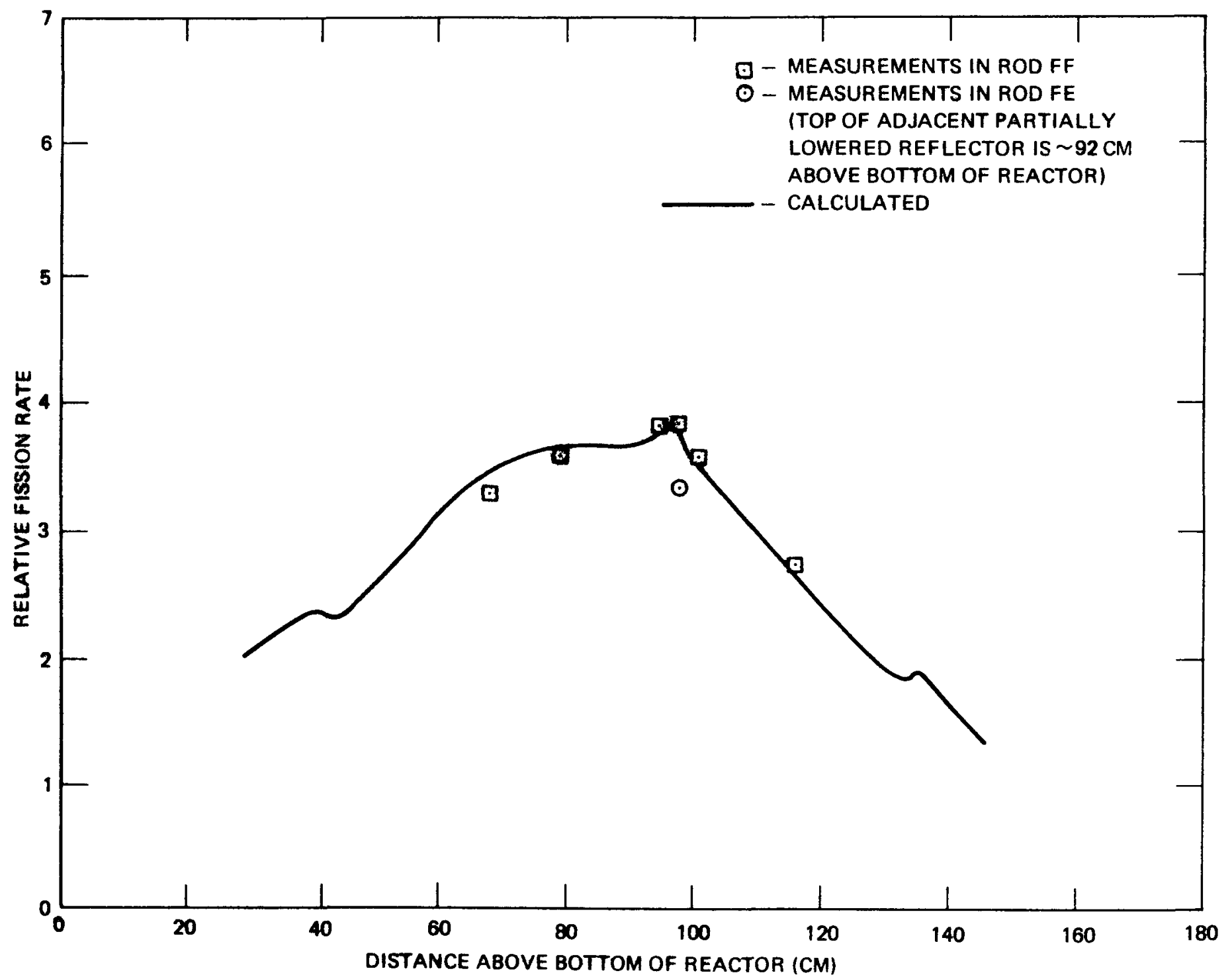




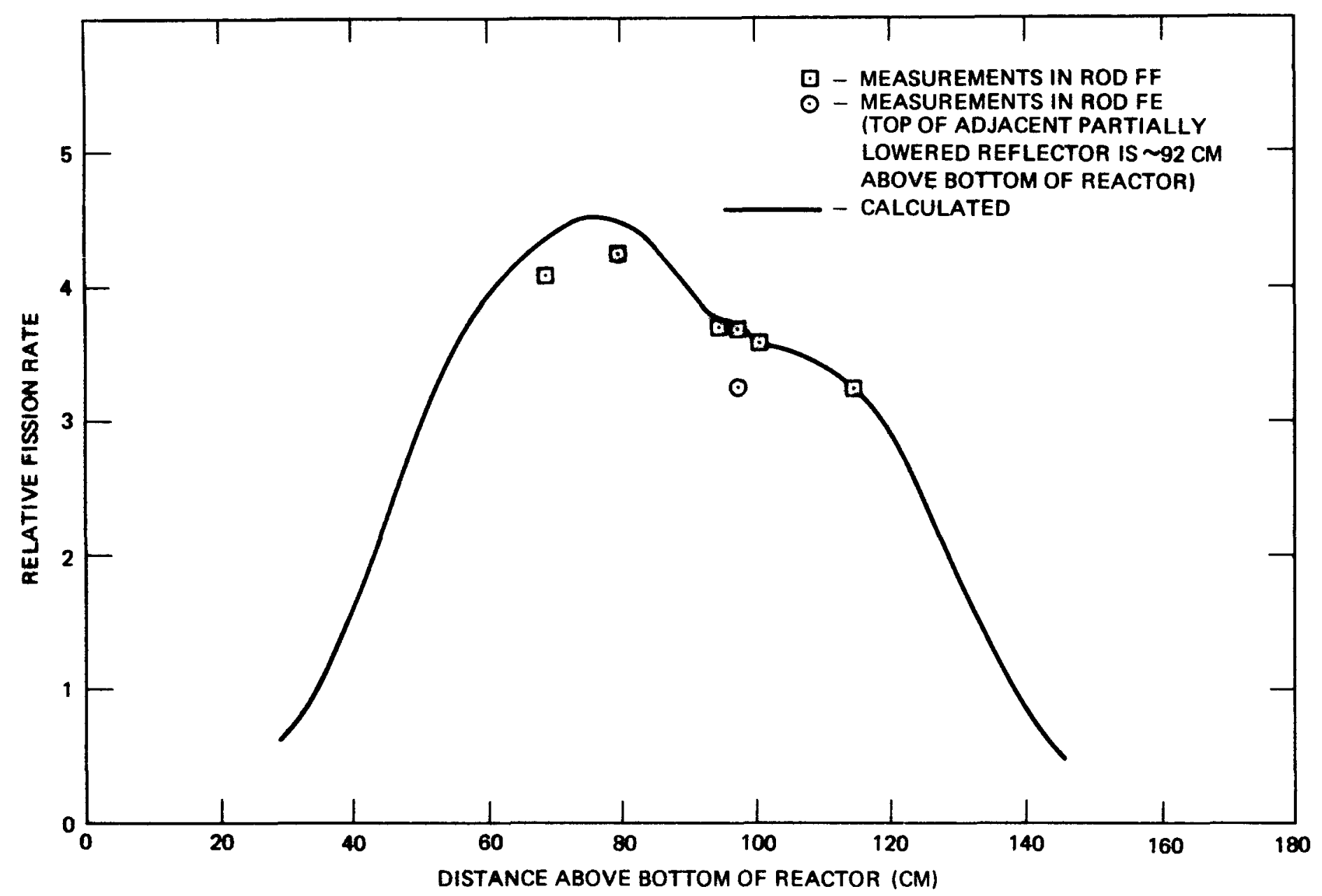

FIGURE 5-7. U-238 AXIAL FISSION DISTRIBUTION AT CORE RADIAL BOUNDARY 


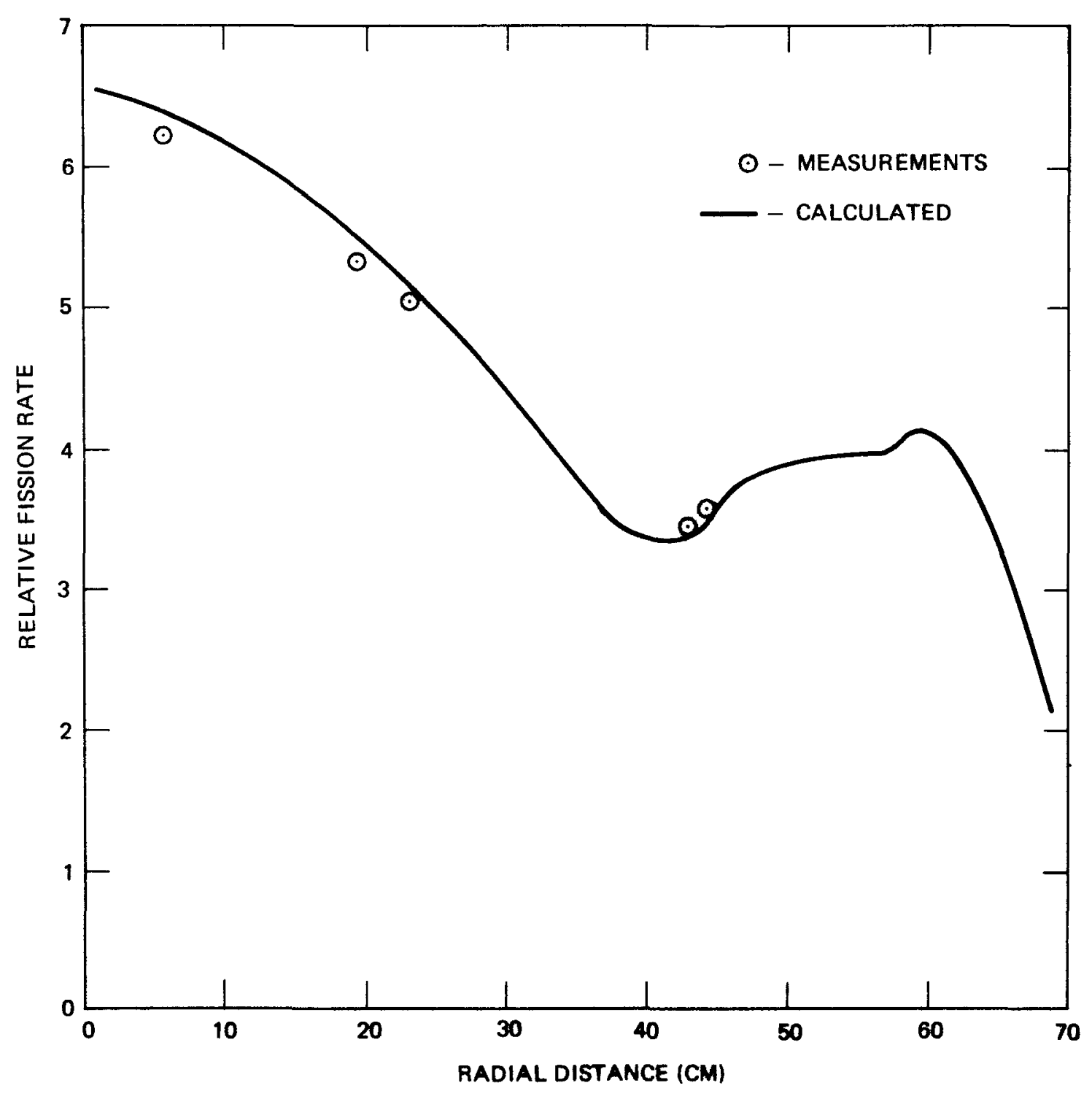

FIGURE 5-8. PU-239 RADIAL FISSION DISTRIBUTION AT AXIAL POSITION 3 
GEAP-13588

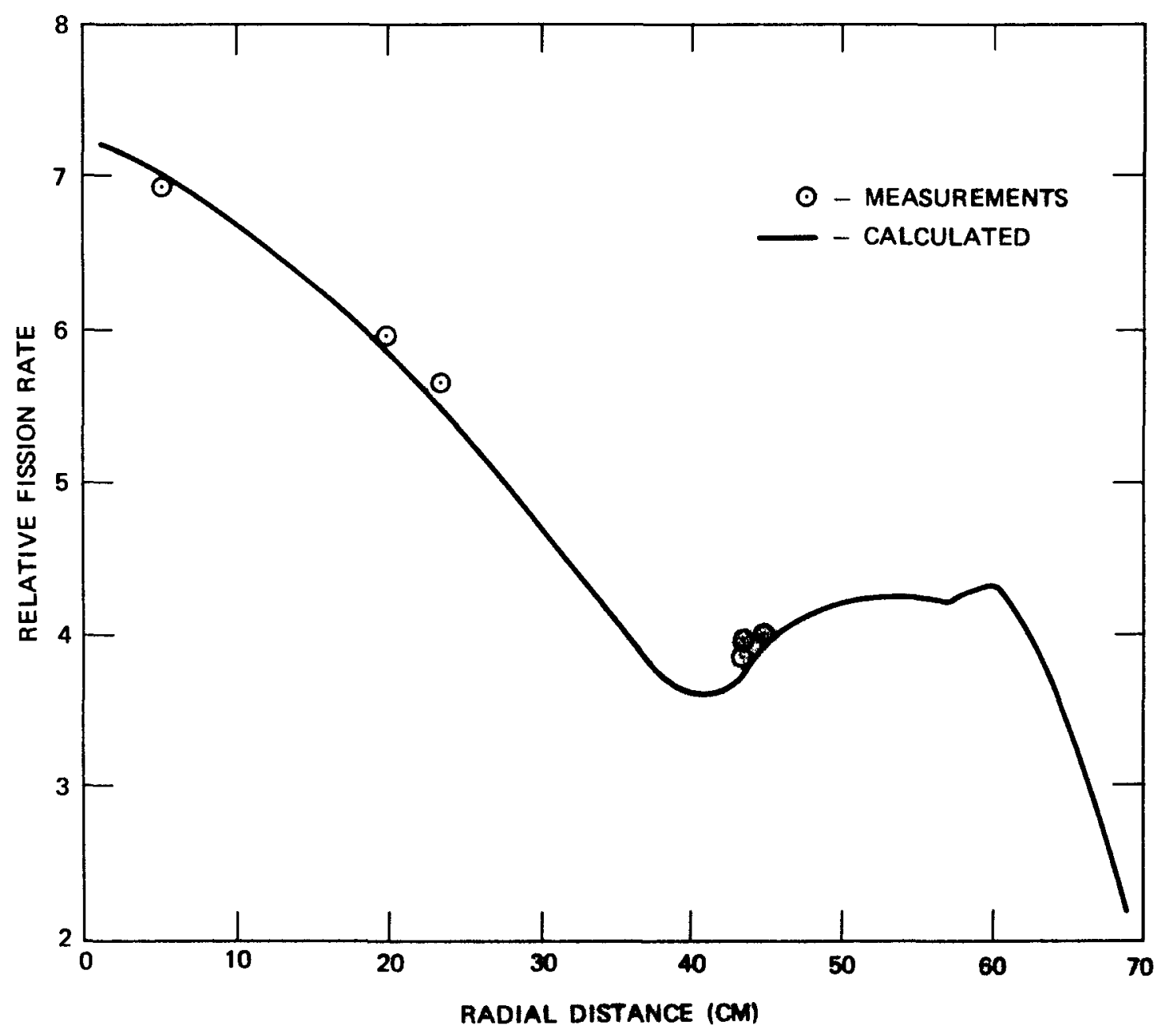

FIGURE 5-9. U-235 RADIAL FISSION DISTRIBUTION AT AXIAL POSITION 3 


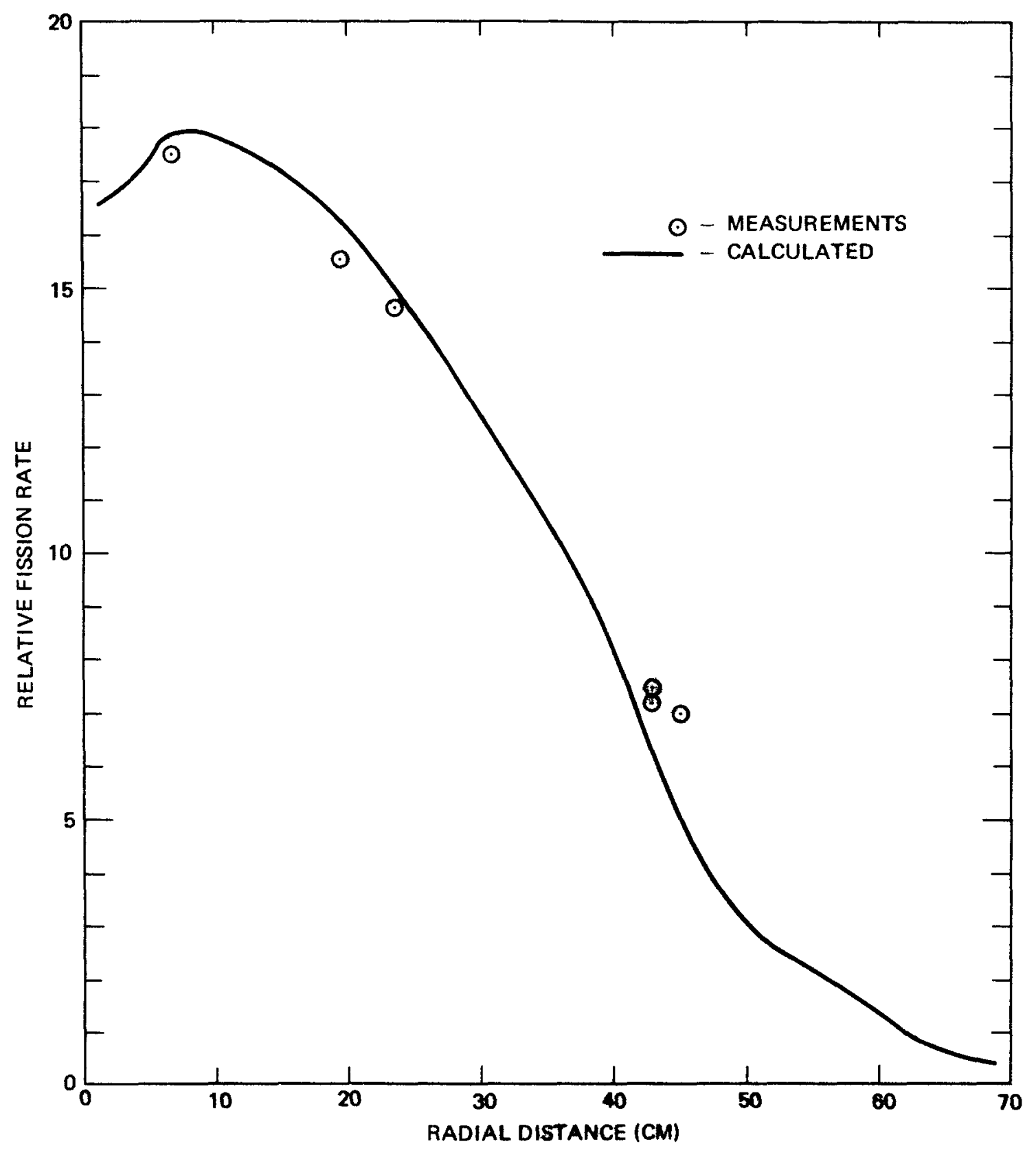

FIGURE 5-10. U-238 RADIAL FISSION DISTRIBUTION AT AXIAL POSITION 3 
The calculations indicated that the U-238 fission rate within the Al filled foil-holder rods may be about 5\% lower (except in the gap region) than in the adjacent fuel rods and they also indicated that the axial profile within the foil holder rod is significantly less depressed through the fuel gap region than is the U-238 fission distribution within the fuel rods. This effect is apparently caused by the sharp decrease in the high energy flux (and $\mathrm{U}-238$ fissions) in those core regions, such as the fuel gap, central channel, foil holder rods, etc., that contain no fission source. The rapid change in high energy flux shape in and around the gap region is shown in Figures 4-10 and 4-11 of Section 4. In addition, the difference between the shape of the calculated axial U-238 fission distribution at a radius of $3.17 \mathrm{~cm}$ (in the calculational model this is in a sodium steel central channel region and is $\sim I \mathrm{~cm}$. from the inner radius of the fuel zone) and at $5.97 \mathrm{~cm}$ (or $21.7 \mathrm{~cm}$ within the fuel zone) is indicated by the fission rate ratios shown in Figure 5-11. The calculations Indicate that this difference in axial shape occurs within a distance of about $1 \mathrm{~cm}$ into the central channel and undergoes little additional change at further distances into the channel. Since the shortest distance between fuel rod centers is $22.8 \mathrm{~cm}$, these calculations indicate that corrections should be applied to the calculations of the U-238 fission distribution to account for the absence of a fission source in the foil holder rods. Such corrections were applied by using the curve in Figure 5-11 to obtain the calculated curves in Figure 5-5 and 5-7. Although a cell calculation, perhaps with transport theory, may provide better correction terms and closer agreement, the measured $U-238$ axial profiles agree fairly well with the presently calculated profiles. Calculations indicated that no corrections of this nature were required for the U-235 and $\mathrm{Pu}-239$ distributions. Fission in these isotopes are predominantly the result of lower (<iMev) energy neutrons which are not so directly influenced by the lack of an in-rod fission source. 


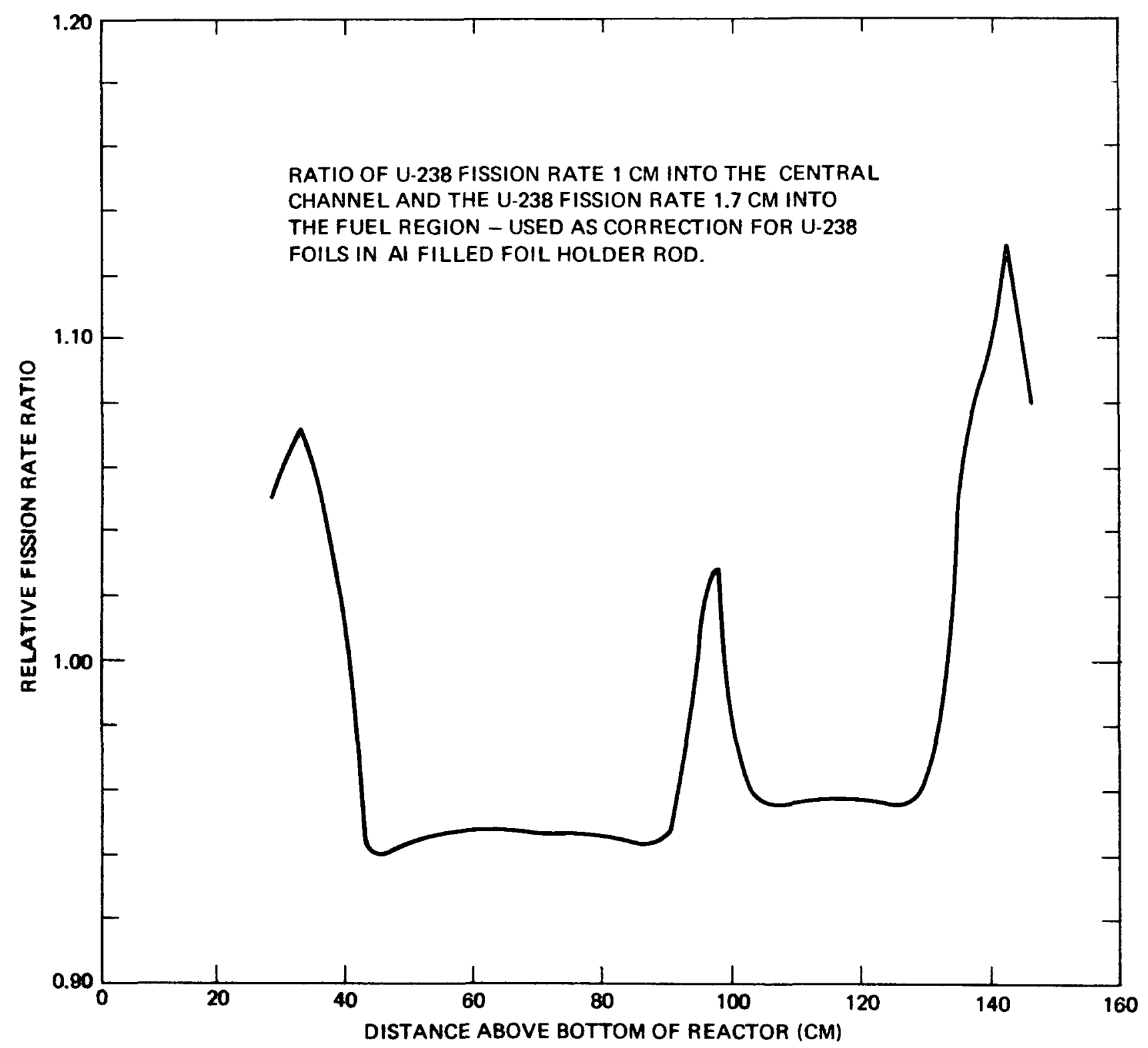


The measured relative radial fission rates near the core midplane are shown in Figures 5-8 through 5-10, and the axial distributions in the uranium near the radial core boundary are shown in Figures 5-6 and 5-7. The fission rates in these regions near the edge of the core are difficult to calculate because of the unusual geometry. The cylindrical model in which the volume of the core was preserved cioes not provide sufficient detail to accurately represent the geometry in and around the three foil holder rods on the edge of the core. With this model, for example, one of the foil holder rods (FD) is located at a radius $(44.5 \mathrm{~cm})$ outside the periphery $(44.1 \mathrm{~cm})$ of the core. In addition to geometrical deficiencies in the model, diffusion theory results in a more isotropic angular flux distribution than would be expected in such a region.

The measured values of the reaction rates in all the foils are higher, relative to the rates in the center, than the calculated values near the core reflector interfaces at the upper and lower boundaries of the core. Preliminary comparisons of two dimensional transport $\left(\mathrm{S}_{4}\right)$ and diffusion theory calculations indicate that corrections for transport effects would decrease these disparity by no more than $\sim 3 \%$.

The general agreement between the calculated and measured reaction rate profiles throughout most of the core and the apparent (see above) underprediction of the reaction rates near the core boundaries indicate that the power (and thus fuel temperature) distribution may be somewhat flatter than calculated. Even if additional calculations do not remove the disparities, previous calculations $(5,6)$ have indicated that the Doppler effect is relatively insensitive to the shape of the flux and temperature distributions and it is expected that the observed disparities in the power distribution will have only a small effect $(\preccurlyeq 3 \%)$ effect on the calculated reactivity coefficients. 


\subsubsection{Comparison of Calculated and Measured Fission Ratios}

The measured fission ratios in the foils at the core center were discussed in Section 5.1.2. The calculated fission ratios for all the fissionable isotopes were previously calculated and reported in reference 4. The measured (from La-140 decay) foil fission ratios of the previous section can be combined with the foil isotopic content given in Table 5-1 to obtain isotopic fission cross section ratios. These "measured" values are listed along with the previously calculated values in Table 5-6. The "measured" U-238 to U-235 fission ratio in Table 5-6 is obtained directly from the measured foil fission ratios and the isotopic composition in Table 5-1. The "measured" Pu-239 to U-235 ratio of Table 5-6 was obtained from the measured foil ratios by treating the small amount of $\mathrm{Pu}-241$ (see Table 5-1) as if it were $\mathrm{Pu}-239$, and by treating the other isotopes as Pu-240. In addition the calculated ${ }^{(4)} \mathrm{Pu}-240$ to U-235 fission ratio of 0.206 was used to obtain a correction of 0.013 in the value of 0.905 in Table 5-6.

The measured and calculated fission cross section ratios are in very good agreement. Even if the measured U-238 to U-235 ratio is increased by approximately 5\% to account for the apparent high energy flux depression in the foil holder rods (see Figure 5-11 and the discussion in the previous section) the agreement is still within $4 \%$. In view of estimated uncertainty $(\sim 10 \%)$ in the measurement, it is possible however that the true fission ratios are not calculated with the same accuracy as indicated by the table. It is expected that a more accurate measurement can be obtained from the proposed fission tracketch measurement. 
GEAP-13588

TABLE 5-6

FISSION CROSS SECTION RATIOS NEAR CORE CENTER

Ratio

$\sigma_{f}^{238} / \sigma_{f}^{235}$

$\sigma_{f}^{239} / \sigma_{f} 235$
Measured

0.0252

0.905

0.894 


\section{SECTION VI}

\section{ANALYSIS AND RESULTS OF NOISE MEASUREMENTS}

The primary purpose of the Noise Measurement was to determine the ratio $(l / \beta)$ of the neutron lifetime to the delayed neutron fraction. This ratio will be used in the interpretation of the super-prompt critical transients. In addition, the experiment provides a means of determining the reactor power, independently of the detector efficiency, by using a calculated value for the delayed neutron fraction. Conversely, if the reactor power is accurately known, the effective delayed neutron fraction can be determined.

\subsection{DESCRIPTION OF THE EXPERIMENT}

\subsubsection{Experimental Method and Instrumentation}

In order to obtain a high efficiency for the detection of neutrons, the neutron noise was measured with two sensitive He-3 detectors* located in the central channel of the core. They were operated as ionization chambers (operating voltage: 300V). The fluctuating components of the chamber currents were amplified, digitized with a sampling frequency of $10^{4}$ samples/sec, and recorded on magnetic tape using the data acquisition system. Since this system accepts only positive signals, batteries were used to provide a constant positive bias voltage so that the negative portion of the fluctuating signal could be recorded on the magnetic tape. The mean value of the current from each detector was measured with a pico ammeter. A high pass filter and

Texas Nuclear, Model 9321

Filling pressure 6 atm., outer diameter 1.0 inch. Active length 6 inches. 


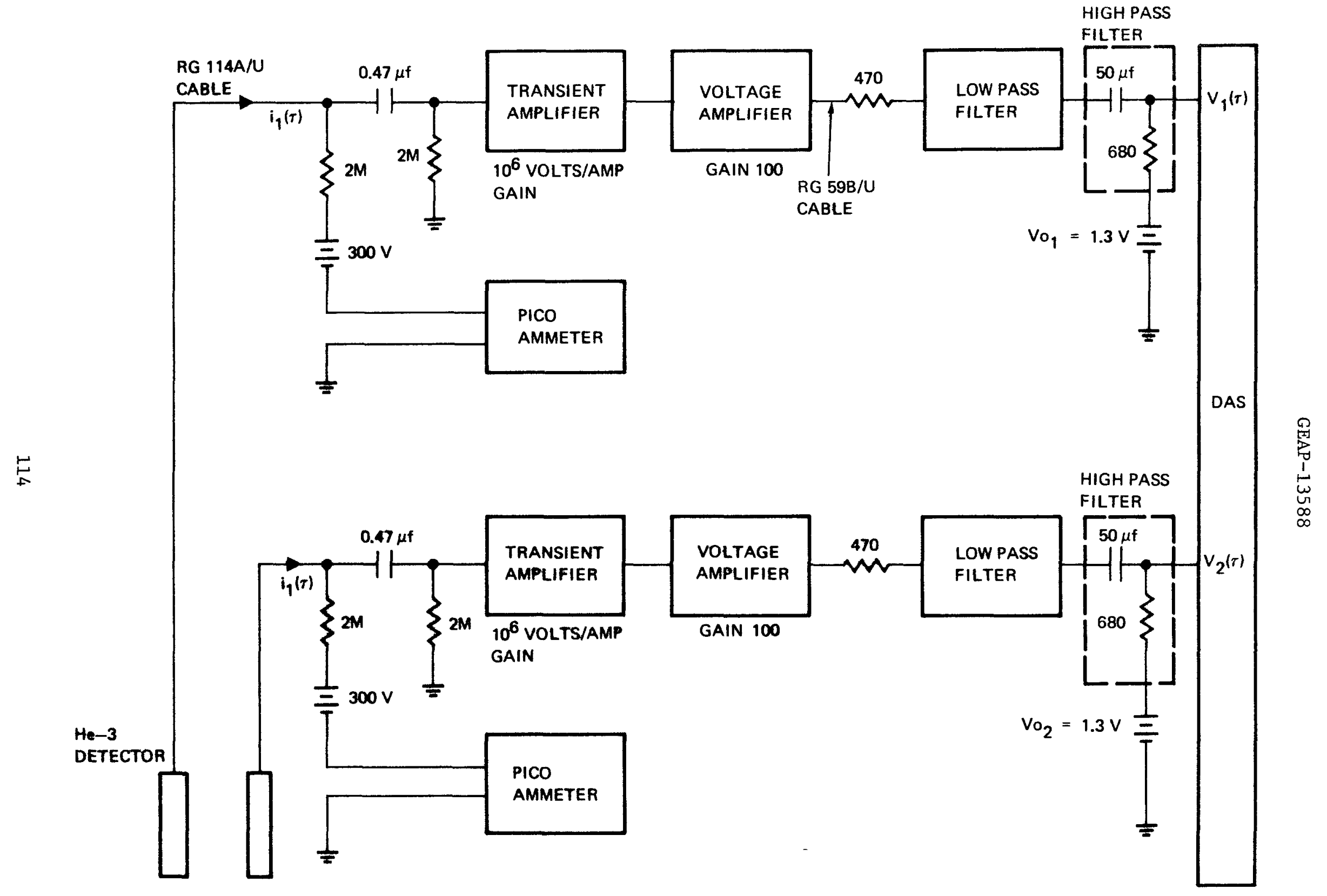

FIGURE 6-1. EXPERIMENTAL SET-UP FOR NOISE RECORDING 
and low pass filter were included to avoid aliasing and to eliminate low frequency induced noise respectively. Figure 6-1 shows a block diagram of the experimental setup.

In order to determine the finite band width of the measuring channel (ionization chamber plus amplifier), the frequency response of the whole detection system, except for the He-3 chambers, was measured with a sine wave generator. The results are plotted in Figure 6-2. Measurements were also performed to determine the frequency response of the He-3 chambers. Previously, satisfactory measurements to determine the response of similar detectors had been performed in the SEFOR mockup in ZPR-III ${ }^{(1)}$ using "white" neutron noise. Because of the difficulties in obtaining a "white" neutron source, the response of the detectors was determined with the "white" noise of a 20 Curie $\mathrm{Co}^{60}$ source. These measurements indicated a cut-off frequency for the detectors above $5 \mathrm{kH}$. Unfortunately, these measurements may not provide an adequate description of the ionic component of the chamber current produced by neutrons, because the gamma radiation is mainly detected by electron release in the walls of the chamber, while the neutron detections occur as a result of the $n-p$ reaction in $\mathrm{He}-3$.

\subsection{ANALYSIS AND CORRECTIONS}

The analysis of the data has mainly been performed in the time domain. A digital computer was used to calculate the auto correlation functions $\psi_{11}(\tau)$ and $\psi_{22}(\tau)$ and the cross correlation of function $\psi_{12}(\tau)$ from the digitized and amplified fluctuating components of the two detector signals $V_{1}(\tau)$ and $V_{2}(\tau)$ that were recorded on magnetic tape. These correlation functions are defined as follows:

$$
\psi_{j j}(\tau)=\frac{1}{T} \int_{0}^{T} v_{j}(t) v_{j}(t+\tau) d t-\bar{v}_{j}^{L} \quad j=1,2
$$




$$
\psi_{12}(\tau)=\frac{1}{T} \int_{0}^{T} v_{1}(t) V_{2}(t+\tau) d t-\bar{V}_{1} \bar{V}_{2}
$$

where:

$$
\begin{aligned}
& V_{1}(\tau)=\left(I_{1}(\tau)-\bar{I}_{1}\right) y_{1}+\bar{V}_{1} \\
& V_{2}(\tau)=\left(I_{2}(\tau)-\bar{I}_{2}\right) y_{2}+\bar{V}_{2} \\
& I_{j}=\text { time dependent current in chamber } j \\
& \bar{I}_{j}=\text { average current in chamber } j \\
& y_{j}=\text { total gain of channel } j \\
& \bar{V}_{j}=\text { average (battery) voltage for channel } j
\end{aligned}
$$

The theoretical expression for the correlation functions as obtained from the point reactor kinetics model can be written ${ }^{(2)}$ as follows:

$$
\begin{aligned}
& \psi_{j j}(\tau)=\bar{I}_{j} y_{j} \frac{\bar{q}^{2}}{\bar{q}} \delta(\tau)+\bar{I}_{j}^{2} y_{j}^{2} \frac{x}{2 \alpha F \Lambda^{2}} e^{-\alpha \tau} \\
& \psi_{12}(\tau)=\bar{I}_{1} \bar{I}_{2 y_{1}} y_{2} \frac{x}{2 \alpha F \Lambda^{2}} e^{-\alpha \tau}
\end{aligned}
$$

with

$$
\begin{aligned}
& \overline{\mathrm{q}}=\text { average charge collected for one neutron in He-3 chamber } \\
& \overline{v(v-1)} \\
& X=\frac{\nu(\nu-1) p}{\bar{v}^{2}}=0.815(1-\beta)^{2}-\text { see reference }(3) \text {. } \\
& v=\text { average number of neutrons produced per fission } \\
& \Lambda=\frac{\ell}{\mathrm{k}} \text { - prompt neutron generation time } \\
& k=\text { effective multiplication factor } \\
& F=\text { total fission rate in the reactor } \\
& \alpha=\frac{1-k(1-\beta)}{\ell} \quad(=\beta / \ell \text { for a critical reactor })
\end{aligned}
$$


The value for $B / \ell$ was determined from semi-logarithmic plots of the correlation functions. To obtain statistical independent results, each measurement of about 2.5 minutes total recording time was divided into series of $20 \mathrm{sec}$ intervals and each interval was analyzed separately. From these results, the averages and standard deviations were calculated to obtain the best experimental results and estimates for the error.

A value $F$, which is proportional to the total reactor power, was calculated with the following expression from the average detector currents $\overline{\mathrm{I}}$, and $\overline{\mathrm{I}}_{2}$, and the total gain of all amplifiers by using the values of $\psi_{12}$ (o) and $\beta / \ell$ obtained from the cross correlation function and calculated values for $\beta$ and $\chi$.

$$
F=\bar{I}_{1} \overline{\mathrm{I}}_{2 \mathrm{y}_{1} \mathrm{y}_{2}} \frac{x \beta / \ell}{2 \beta^{2} \psi_{12}(0)}
$$

If an absolute and independent power calibration, either by fission track counting or some other means, becomes available, it may be possible to use the above relation to check the calculated value of $\beta$.

As a test of the recorded data, the amplitude distributions of the measured ionization current fluctuations were checked. The total range of the voltages between 0 and 2.5 volts was divided into 100 intervals and the number of values of the digitized voltage occurring within each interval was counted. This distribution was compared with a calculated Gaussian distribution for which the mean value $m$ and the variance $\sigma^{2}$ were taken from the measured auto correlation functions $\left(m_{j}=\bar{v}_{j}\right.$ and $\left.\sigma_{j}^{2}=\psi_{j j}(0)\right)$. In all cases a good agreement was observed. There were some small deviations from a Gaussian distribution near the mean values of the actually observed distributions however. These may be due to an induced background. 
The induced background was determined separately before and after each noise-record by measuring the current obtained without the high voltage supply for the He-3 chambers. In some cases corrections were made for this background.

To all correlation functions, corrections for the finite band width of the recording system have been applied. These corrections were calculated from the system frequency response $H_{1}(w)$ and $H_{2}(w)$, for channel 1 and 2 which were obtained from the measurements with a sinewave generator. If the reactor spectral density is denoted by $\psi_{0}(w)$, the measured spectral density $\psi(w)$ would be

$$
\psi(w)=H_{1}(w) H_{2}(w) \phi_{0}(w)=(1+\psi(w)) \quad \psi_{0}(w)
$$

which is related to the measured correlation function $\psi(\tau)$ by a Fourier transform as follows:

$$
\psi(\tau)=\psi_{0}(\tau) \int_{-\infty}^{+\infty} \phi_{0}(w) \quad \psi(w) e^{i w \tau} d w
$$

The integral in the preceding relation is the correction for the finite band width which was subtracted from $\psi(\tau)$ to obtain the corrected values $\psi_{0}(\tau)$. These corrections were normally small and never larger than $5 \%$.

The effect of delayed neutrons on the correlation function was estimated. The effect at the frequency range of interest is sma11 and can be neglected.

As the He-3 detectors were used in the current mode, a discrimination against gamma rays was not possible. Prompt fission gamas and gammas from neutron capture and inelastic scattering are directly correlated with prompt neutrons and should increase the total detector efficiency without inducing systematic errors. The effect of completely uncorrelated 
gammas from fission products, which contribute only $15 \%$ to the total gamma energy, were eliminated by using the cross correlation technique and by using longer delay times $\tau$ for evaluating $\beta / \ell$ from the auto correlation function. However, since the detection of gammas from short lived fission products might interfere with correlated neutron noise, if their lifetimes are of the same order of magnitude as the prompt neutron lifetime, their contribution to the total detector current was estimated from a current measurement with a $\mathrm{Co}^{60}$ gamma source and from an estimated gamma flux in the reactor. This effect was also found to be negligible.

\subsection{EXPERIMENTAL RESULTS}

Four measurements have been made in the full size core (Assembly I-D) at different power levels (i.e. at different subcritical reactivities) between 0.2 and 6000 watts. The background level due to induced noise was relatively high for the measurement at the lowest power level of 0.2 watts and no reasonable information could be obtained from this measurement. The results of the other three measurements are listed in Table 6-1.

The wide range monitor readings, given in column one are proportioned to the reactor power. The reactivities were obtained from the calibrated reflector readings and the different power levels were calculated from equation (6-7i). Except for the highest level of 6180.0 watts, this power calibration is in good agreement with the calibration obtained from the subcritical measurements using the theoretical value for the inherent neutron source (see Appendix VII). The values of $\psi(0)$ and $l / \beta$ in Table $6-1$ are average values, determined by the method described above, and the errors are the estimated standard deviations.

The difference between the values of $\ell / \beta$ measured at the two higher 
power levels is probably due to saturation effects. The non-linearity of the average detector currents $\overline{\mathrm{I}}$ with the WRM readings indicates saturation in the in-core He-3 detectors for power levels $P \geq 1 \mathrm{kw}$, presumably caused by charge build-up in the He-3 tubes. Thus, the value for measurement number three is probably invalid. The difference in $l / \beta$ between measurements number 1 and 2 is about $10 \%$ larger than expected from the corresponding changes in the reactivity. Although the reason for this difference is not clearly defined, it may be the result of signal distortion or saturation, of a lower than anticipated cut off frequency, and of a higher than expected detector efficiency. As examples, the variances of the detector signals $\sigma_{1}^{2}=\psi_{11}(0)$ and $\sigma_{2}{ }^{2}=\psi_{22}(0)$ are not proportional to the WRM values as they should be, and the ratio of the second to the first term in equation (6-5) due to correlated and uncorrelated events are much larger than calculated by using the estimated detector efficiency of $3 \times 10^{-5}$ counts/fission. (The calculated value does not include any contribution from gamma radiation).

There is no indication of a peak in the auto correlation function caused by uncorrelated events (see Figure 6-4). However, a comparison $b \in t w e e n$ the auto and cross corfelation functions shows that a relatively small contribution from uncorrelated events may be smeared out over the time interval of approximately $0<\tau<300 \mu \mathrm{sec}$. This would be explained if the detector efficiency is larger than $3 \times 10^{-5}$ counts/fission and if the cut off frequency of the detector tubes is lower than $5 \mathrm{kH}$. The first effect might be due to a relatively higher gamma sensitivity compared to the neutron sensitivity of the He-3 chambers, caused perhaps by partial saturation for neutron detection because of the longer collection time and therefore higher recombination probability for ions.

A lower cut off frequency of the He-3 tubes would not agree with the results of Morrell ${ }^{(1)}$. Also, the difference in gas pressure (6 atm.) 
of the detectors used in SEFOR and those used by Morrell for the SEFOR mockup in ZPR-III (10 atm.), should increase rather than decrease the cut off frequency (4). A lower cut off frequency would explain some of the differences observed in SEFOR however, and if the tubes had a lower cut off frequency, which would only be caused by the ionic component, and if partial saturation occurred at $\overline{\mathrm{I}} \sim 5 \mu \mathrm{amp}$, the results from the measurements No. 2 and 3 would be erroneous.

For more detailed investigations of these questions an analysis was also made in the frequency domain. These investigations led to the same suggestions. These investigations included the calculation of the stochastic coherence function (5) (this is the ratio of the cross power spectral density and the square root of the product of the autospectral densities) to circumvent the problem of an unknown detector frequency response. This is independent of the detector frequency response and in principle it should be possible to evaluate $\ell / \beta$ from this function without the knowledge of the detector frequency response. (5) Unfortunately in the case of a relatively low cut-off frequency and a high detector efficiency, as is indicated for the SEFOR data, the method does not provide increased accuracy in the determination of $\ell / B$.

Because of the apparent low cut-off frequency and high detector efficiency, the measurements No. 2 and 3 at higher power levels should be treated as invalid and measurement No. 1, made at the lowest power level, must be regarded as the most reliable. Even for this measurement however, the possibility of systematical errors cannot be completely excluded, and clear answer can only be obtalned by checking the chamber characteristics, including the frequency response, in a "white" neutron field of adequate intensity. 


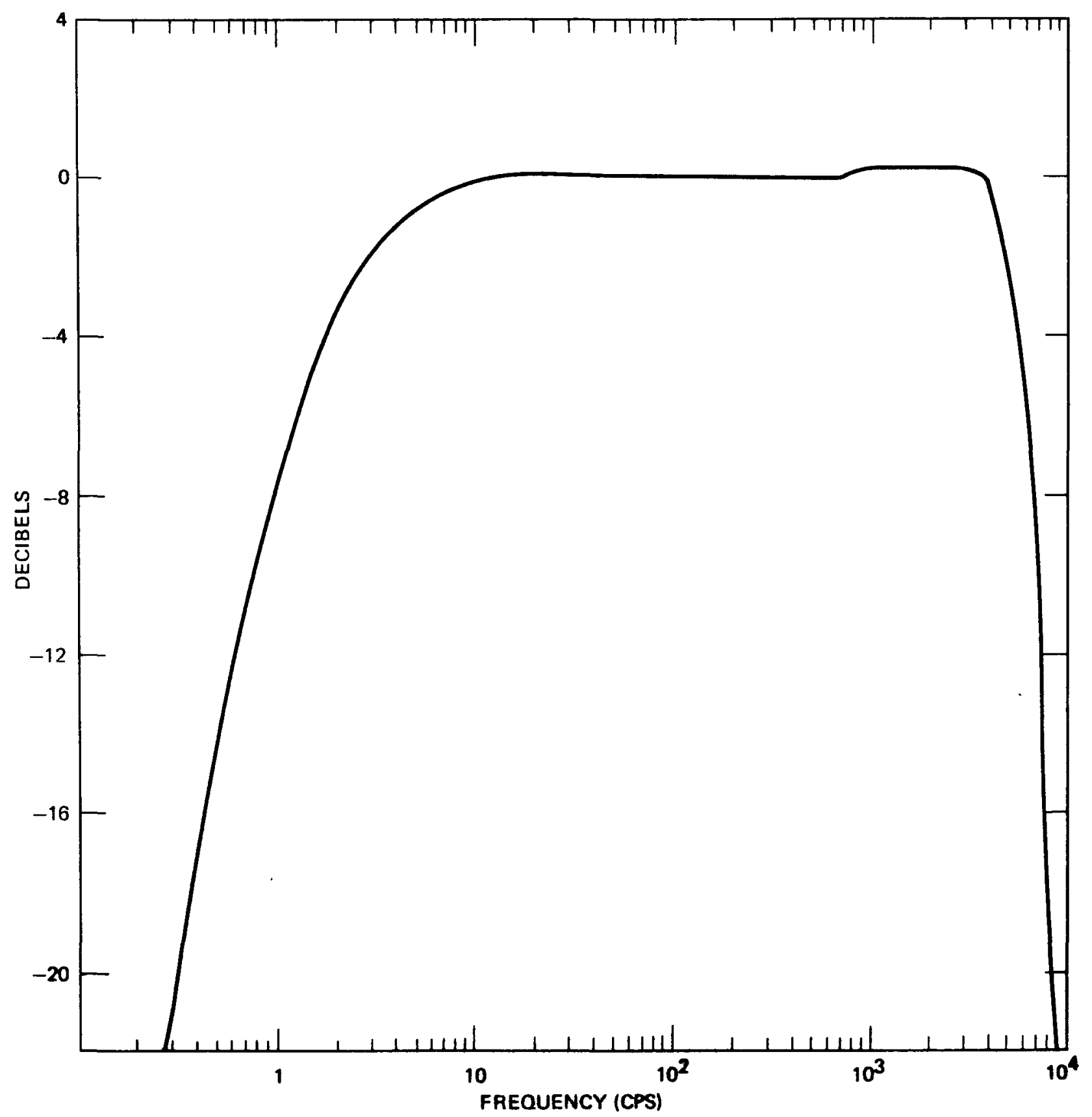

FIGURE 6-2. FREQUENCY RESPONSE FOR CHANNEL 1 


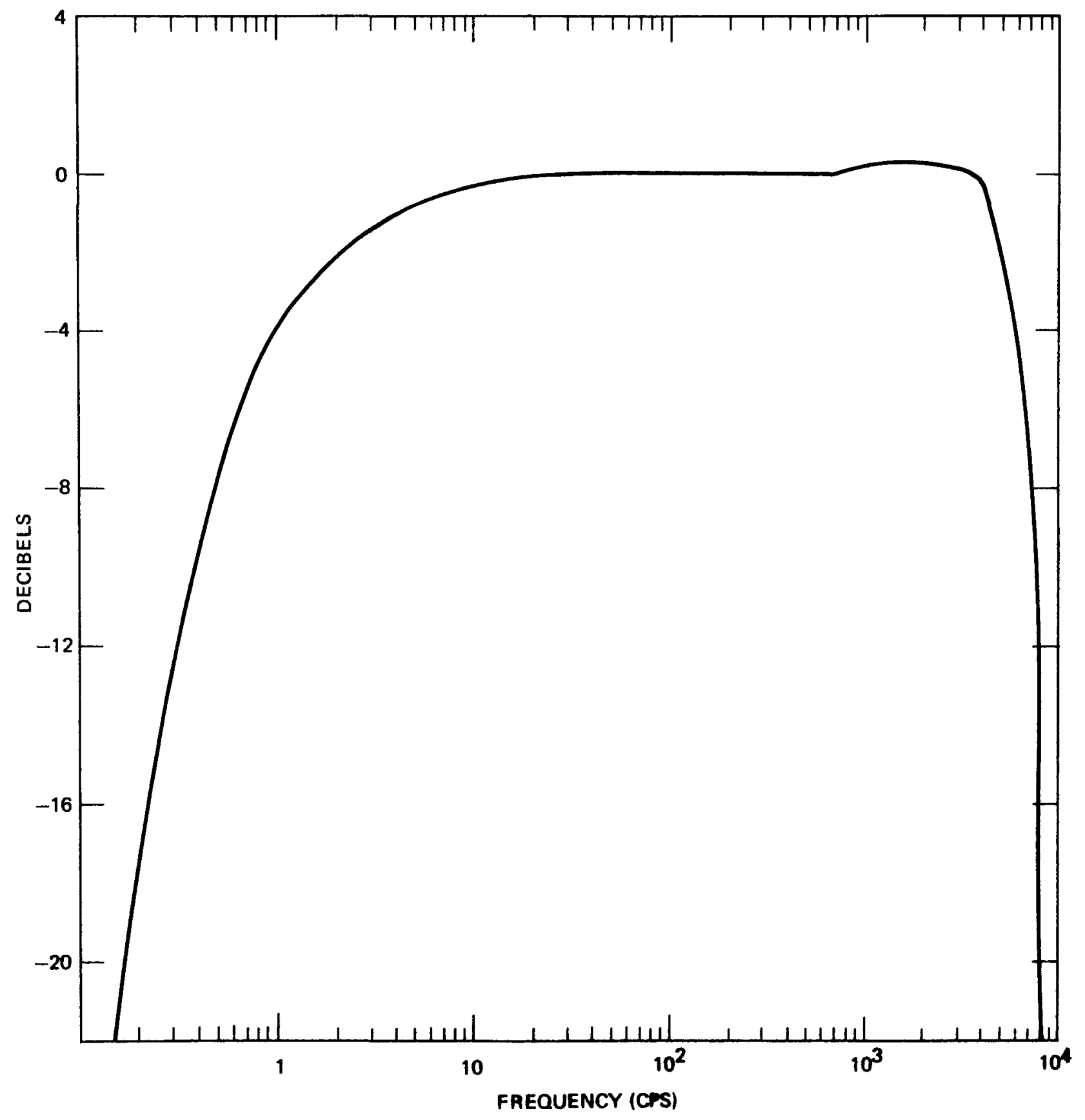

FIGURE 6-3. FREQUENCY RESPONSE FOR CHANNEL 2 
$\lambda$

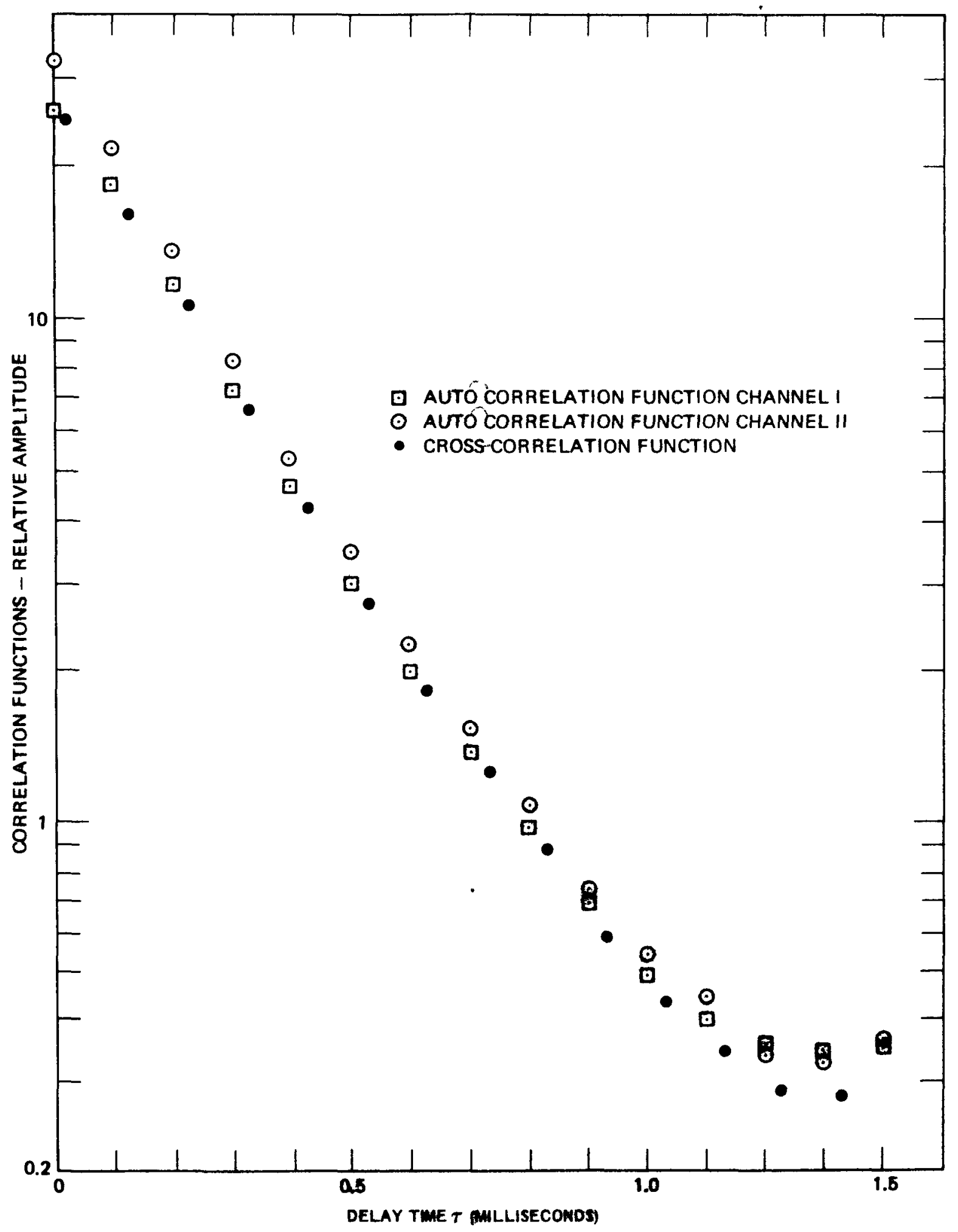

FIGURE 6-4. CORRELATION FUNCTIONS FROM MEASUREMENT NO. 2 


\subsection{CALCULATION OF $\ell / B$ AND COMPARISON WITH EXPERIMENT}

The effective delayed neutron fraction $\beta$ was calculated as described in Appendix V. The lifetime $\ell$ was calculated with a twodimensional synthesis and with a two-dimensional diffusion program from the reactivity effects resulting from the introduction of a $1 / \mathrm{v}$ absorber. The results for $\ell / B$ are given in Table 6-1. In the synthesis method, relatively high uncertainties are expected due to difficulties of getting accurate axial flux distributions in the radial reflector regions. Therefore, the result of the two-dimensional diffusion calculation must be regarded as the best theoretical value. The influence of heterogeneity and transport effects on the lifetime calculations were estimated from one-dimensional homogeneous and heterogeneous cell calculations, as well as from a comparison of two-dimensional diffusion $\mathrm{S}_{4}$ transport calculations (with 4 energy groups). Both effects turned out to be small $(0.7 \%$ and $0.2 \%$ respectively).

It is possible that the point reactor kinetics model does not provide an adequate description of a fast reflected system such as SEFOR. Such a possibility is indicated by the analysis of the pulsed measurements with the ZPR-III SEFOR mockup ${ }^{(6)}$. More sophisticated methods for neutron lifetime calculations, such as modal or nodal analyses might clarify this point.

A comparison between the best experimental and theoretical values indicates that the measured prompt neutron lifetime is $11 \%$ bigger than calculated. Although more detailed calculation or additional measurements may decrease this difference, it is in agreement with previous comparison of calculation ${ }^{(7)}$ and experiment in the SEFOR tockup in ZPR-3. 


\section{TABLE $6-1$}

\section{RESULTS OF NOISE ANALYSIS}

\begin{tabular}{|c|c|c|c|c|c|c|c|c|c|}
\hline $\begin{array}{c}\text { Measurement } \\
\text { Number }\end{array}$ & $\begin{array}{c}\text { Wide Range } \\
\text { Monitor }\end{array}$ & $\begin{array}{l}\text { Power obtained } \\
\text { from Noise } \\
\text { Analysis } \\
\text { (watts) }\end{array}$ & $\begin{array}{l}\text { Reactivity } \\
\text { (c) }\end{array}$ & $\begin{array}{l}\overline{\mathrm{I}}_{1} \\
\text { pamp. }\end{array}$ & $\begin{array}{l}\overline{\mathrm{I}}_{2} \\
\mu \text { amp. }\end{array}$ & $\begin{array}{r}\psi_{12}(0) \\
\text { (volt) } \\
\end{array}$ & $\begin{array}{r}\psi_{11}(0 \\
(\operatorname{volt})\end{array}$ & $\begin{array}{r}1 \\
0) \\
\psi_{<2}(0) \\
2(\operatorname{volt})^{2} \\
\end{array}$ & $\begin{array}{l}\ell / \mathrm{p}(\mathrm{sec}) \\
\text { measurement* }\end{array}$ \\
\hline 1 & $12 \times 10^{-6}$ & 22.28 & $-1.2 \pm 0.5$ & 0.101 & 0.114 & 0.0108 & 0.0105 & 0.0120 & $0.205 \times 10^{-3}$ \\
\hline 2 & $50 \times 10^{-5}$ & 1036 . & 0.0 & 4.0 & 4.2 & 0.305 & 0.286 & 0.352 & $0.232 \times 10^{-3}$ \\
\hline The estin & d uncertaj & in the meas & ts is $+1 \%$. & & & & & & $\begin{array}{l}0 \\
\text { Pि } \\
\text { P } \\
1 \\
\omega \\
\omega \\
\infty \\
\infty \\
\infty\end{array}$ \\
\hline
\end{tabular}

Calculated results:

2-dimensional synthesis program $\ell / \beta=0.214 \times 10^{-3}$ seç.

True 2-dimensional diffusion program $l / \beta=0.184 \times 10^{-3^{\circ}} \mathrm{sec}$. 


\section{SECTION VII \\ ZERO POWER REACTIVITY COEFFICIENT MEASUREMENTS}

\subsection{FLOW AND PRESSURE COEFFICIENTS OF REACTIVITY}

The flow and pressure coefficients of reactivity in SEFOR are essentially zero. The reactivity effects that are associated with changes over the normal operating range of reactor vessel hydraulic pressure and primary coolant flow are of the order of the standard deviation $(0.5 c)$ in reactivity difference measurements (see section 4.4). These results are in agreement with expectations. (1)

In order to enable the ultimate determination of the Doppler reactivity coefficient, a number of experiments are performed in SEFOR to determine the relationship, if any, between reactivity (reflector position) and plant variables such as fuel temperature, reflector temperature, core inlet temperature, etc. The experiments discussed here were performed to determine the relationship between reactivity and coolant flow, and between reactivity and reactor vessel hydraulic pressure. In these experiments, the flow and the vessel cover gas pressure were separately and independently changed in increments between minimum and maximum values while the reflector position was adjusted to maintain a constant flux level. The variation in reactor temperature during these measurements was held to $20^{\circ} \mathrm{F}$ or less.

The data are tabulated in the sequential order of data collection in Tables 7-1 through $7-3$ and the relative reactivity after corrections for the temperature variations are plotted versus the pressure in 
Figure 7-1, and versus flow in Figures 7-2 and 7-3. Two sets of flow coefficient measurements were performed on two different core loadings, Assemblies I-E, and I-I. The first of these data sets was limited by operational difficulties to flows of $4000 \mathrm{gpm}$ or less. Flow rates up to $\sim 100 \%$ flow ( $5000 \mathrm{gpm}$ ) were obtained in the measurements in Assembly I-I. The reflector calibration curve for Assemb1y I-F (which is similar to Assembly I-I) was used to determine the relative reactivity data in Assembly I-I. The slight differences, if any, in reflector calibrations will not affect the results.

The data indicates little or no correlation between flow and reactivity, or between pressure and reactivity. For example, even though Figure 7-1 indicates that there may perhaps be a loss in reactivity of 0.5 to $1.0 \mathrm{c}$ when the pressure is lowered from 5 psig to 0 psig, (the normal operating pressure is 20 psig), the maximum difference between any of the reactivity values in Figure 7-1 or Table 7-1 is $1.15 c$, while the maximum deviation from the mean of these values is $0.82 \mathrm{c}$. These deviations are all of the same order of magnitude as the estimated standard deviation ( $(0.5 c$ - see Section 4.4) in the reactivity measurements.

Similarly, the first set of flow-reactivity data, shown in Figure 7-2 and Table 7-2, appears to be uncorrelated. The second set of data; shown in Figure 7-3 and Table 7-3 indicates that there may be a loss in reactivity of the order of one cent as the flow is increased from $500 \mathrm{gpm}$ to $3500 \mathrm{gpm}$ and that this reactivity is regained as the flow is increased to $4000 \mathrm{gpm}$. In view of the small magnitude of this apparent change, the relatively large temperature changes $\left(\sim 20^{\circ} \mathrm{F}\right)$ which occurred during the second set of measurements, and the 
GEAP-13588

evident lack of any such correlation in the first set, it appears that there is no appreciable correlation between flow and reactivity.

The data thus indicates that any reactivity effects which may accompany changes in flow or pressure are of the same order of magnitude as the $0.5 c$ estimated standard deviation in reactivity measurements. Any effects of flow and pressure on reactivity are therefore negligible and can be neglected. 
TABLE 7-1

PRESSURE-REACTIVITY MEASUREMENTS

(Assembly I-E)

\begin{tabular}{|c|c|c|c|c|c|}
\hline \multirow{3}{*}{$\begin{array}{l}\text { Cover Gas } \\
\text { Pressure } \\
\text { (psig) }\end{array}$} & \multirow[b]{2}{*}{ Reflector } & \multirow[b]{2}{*}{$\# 8$} & \multicolumn{3}{|c|}{ Relative System } \\
\hline & & & Temperature & $\begin{array}{l}\text { Reactivity at } \\
350^{\circ} \mathrm{F}^{* *}\end{array}$ & $\begin{array}{l}\text { Deviation From } \\
\text { Mean Reactivit }\end{array}$ \\
\hline & $\frac{\text { Position }}{(c)}$ & $\frac{\text { Worth* }}{(c)}$ & $\left({ }^{\circ} \mathrm{F}\right)$ & $(c)$ & $(c)$ \\
\hline 20 & 38.85 & 72.71 & 348.75 & 71.86 & +0.17 \\
\hline 15 & 38.85 & 72.71 & 348.75 & 71.86 & +0.17 \\
\hline 0 & 39.36 & 71.83 & 349.0 & 71.15 & -0.54 \\
\hline 20 & 39.03 & 72.40 & 349.25 & 71.89 & +0.20 \\
\hline 15 & 39.14 & 72.21 & 349.5 & 71.87 & +0.18 \\
\hline 10 & 39.13 & 72.23 & 349.5 & 71.89 & +0.20 \\
\hline 5 & 39.13 & 72.23 & 349.5 & 71.89 & +0.20 \\
\hline 0 & 39.21 & 72.09 & 349.0 & 71.41 & -0.28 \\
\hline 20 & 38.66 & 73.04 & 348.5 & 72.02 & +0.33 \\
\hline 0 & 39.23 & 72.06 & 348.25 & 70.87 & -0.82 \\
\hline 20 & 38.67 & 73.03 & 348.25 & 71.84 & +0.15 \\
\hline
\end{tabular}

*Relative to worth in the completely raised position $(\sim 98 \mathrm{~cm})$ $* *$ Using a temperature coefficient at $350^{\circ} \mathrm{F}$ of $-0.68 \mathrm{c} /{ }^{\circ} \mathrm{F}$. $* * *$ Estimated standard deviation in measurements is $\pm 0.5 \mathrm{c}$. 
TABLE $\quad 7-2$

\section{FLOW-REACTIVITY MEASUREMENTS}

(Assembly I-E)

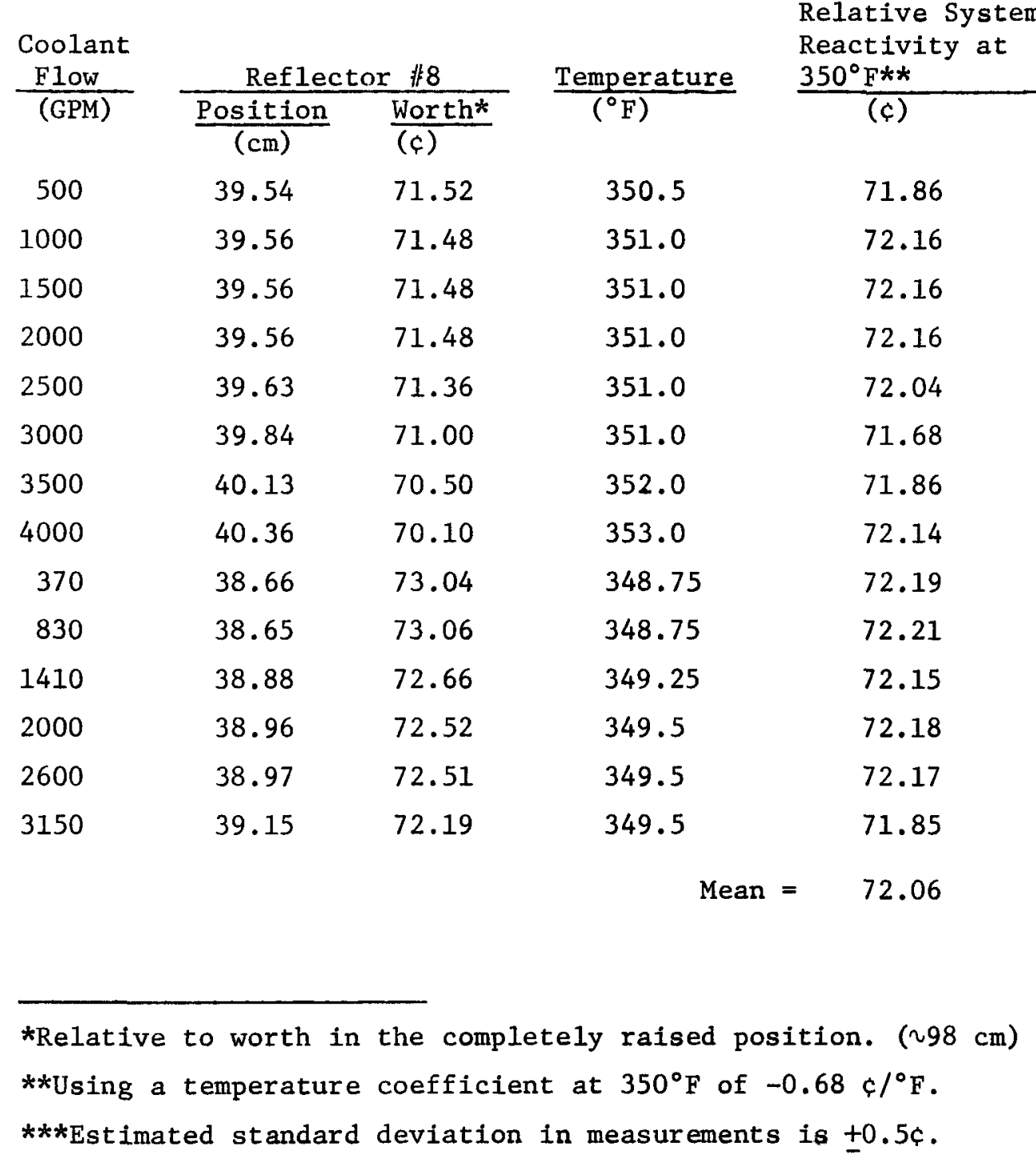




\section{$\underline{\text { TABLE } \quad 7-3}$}

FLOW-REACTIVITY MEASUREMENTS

(Assembly I-I)

\begin{tabular}{|c|c|c|c|c|c|}
\hline $\begin{array}{l}\text { Coolant } \\
\text { Flow }\end{array}$ & Reflec & $\leq$ 非 8 & Temperature & $\begin{array}{l}\text { Reactivity at } \\
390^{\circ} \mathrm{F}^{* *}\end{array}$ & $\begin{array}{l}\text { Deviation from } * * * \\
\text { Mean Reactivity }\end{array}$ \\
\hline (GPM) & $\frac{\text { Position }}{(\mathrm{cm})}$ & $\frac{\text { Worth* }}{(c)}$ & $\left({ }^{\circ} \mathrm{F}\right)$ & $(c)$ & $(c)$ \\
\hline 500 & $54.09-$ & 46.99 & 389.0 & 46.31 & +0.33 \\
\hline 500 & 53.89 & 47.32 & 388.25 & 46.13 & +0.15 \\
\hline 500 & 53.68 & 47.67 & 387.75 & 46.14 & +0.16 \\
\hline 1000 & 53.55 & 47.89 & 387.0 & 45.85 & -0.13 \\
\hline 1000 & 53.15 & 48.55 & 386.25 & 46.00 & +0.02 \\
\hline 1000 & 52.90 & 48.97 & 385.5 & 45.91 & -0.07 \\
\hline 1500 & 52.76 & 49.20 & 385.0 & 45.80 & -0.18 \\
\hline 1500 & 52.55 & 49.55 & 384.5 & 45.81 & -0.17 \\
\hline 1500 & 52.38 & 49.84 & 384.0 & 45.76 & -0.22 \\
\hline 2000 & 52.31 & 49.96 & 383.75 & 45.71 & -0.27 \\
\hline 2000 & 52.15 & 50.22 & 383.25 & 45.63 & -0.35 \\
\hline 2000 & 52.01 & 50.46 & 383.0 & 45.70 & -0.28 \\
\hline 3000 & 51.93 & 50.59 & 382.5 & 45.49 & -0.49 \\
\hline 3000 & 52.09 & 50.32 & 382.75 & 45.39 & -0.59 \\
\hline 3000 & 52.22 & 50.11 & 383.0 & 45.35 & -0.63 \\
\hline 3500 & 52.19 & 50.16 & 382.75 & 45.23 & -0.75 \\
\hline 3500 & 52.25 & 50.06 & 382.75 & 45.13 & -0.85 \\
\hline 3500 & 52.15 & 50.22 & 382.5 & 45.12 & -0.86 \\
\hline
\end{tabular}

*Relative to worth in the completely raised position ( $298 \mathrm{~cm}$ ) - using the reflector calibration curve for Assembly I-F.

**Using a temperature coefficient at $390^{\circ} \mathrm{F}$ of $-0.68 \mathrm{c} /{ }^{\circ} \mathrm{F}$. $* * *$ Estimated standard deviation in measurements is $\pm 0.5 \mathrm{c}$. 
$\underline{\text { TABLE 2-3 (Continued) }}$

\section{FLOW-REACTIVITY MEASUREMENTS}

(AssembIy I-I)

Coolant

$$
\text { Elow }
$$$$
\text { ( } 3 P M)
$$$$
\frac{\text { Reflect }}{\frac{\text { Position }}{(\mathrm{cm})}}
$$

$$
58.71
$$

58.74

58.57

58.55

58.68

58.84

58.86

58.93

59.37

59.49

59.78

59.77

57.69

$57.52^{\circ}$

$57.35^{\prime}$

57.35
39.31

39.26

39.54

39.57

39.36

39.10

39.06

38.95

38.23

38.04

37.57

37.58

40.98

41.26

41.55

41.55
Relative System

Reactivity at

Temperature

$\left({ }^{\circ} \mathrm{F}\right)$ $390^{\circ} \mathrm{F} * *$

(c)

Deviation from*** Mean Reactivity

(c)

$\begin{array}{ll}46.11 & +0.13 \\ 46.06 & +0.08 \\ 46.34 & +0.36 \\ 46.20 & +0.22 \\ 46.16 & +0.18 \\ 46.07 & +0.09 \\ 46.20 & +0.22 \\ 46.09 & +0.11 \\ 46.05 & +0.07 \\ 46.20 & +0.22 \\ 46.07 & +0.09 \\ 46.25 & +0.27 \\ 47.27 & +1.29 \\ 46.70 & +0.72 \\ 46.48 & +0.50 \\ 46.48 & +0.50\end{array}$

Average $=45.98$

*Relative to worth in the completely raised position $(\sim 98 \mathrm{~cm})-$ using the reflector calibration curve for Assembly I-F.

**Using a temperature coefficient at $390^{\circ} \mathrm{F}$ of $-0.68 \mathrm{c} /{ }^{\circ} \mathrm{F}$.

***Estimated standard deviation in measurements is $\pm 0.5 \mathrm{c}$. 


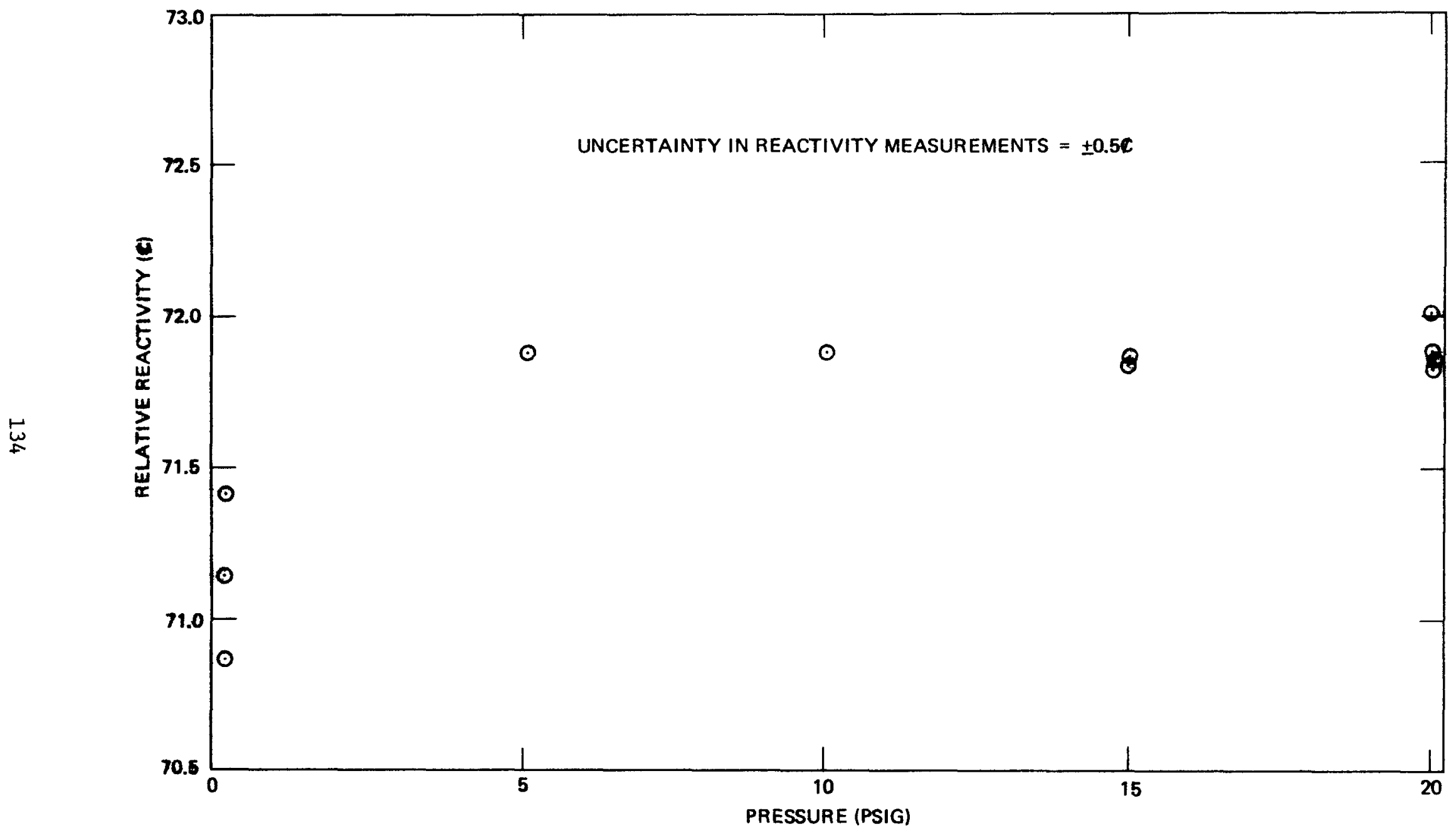




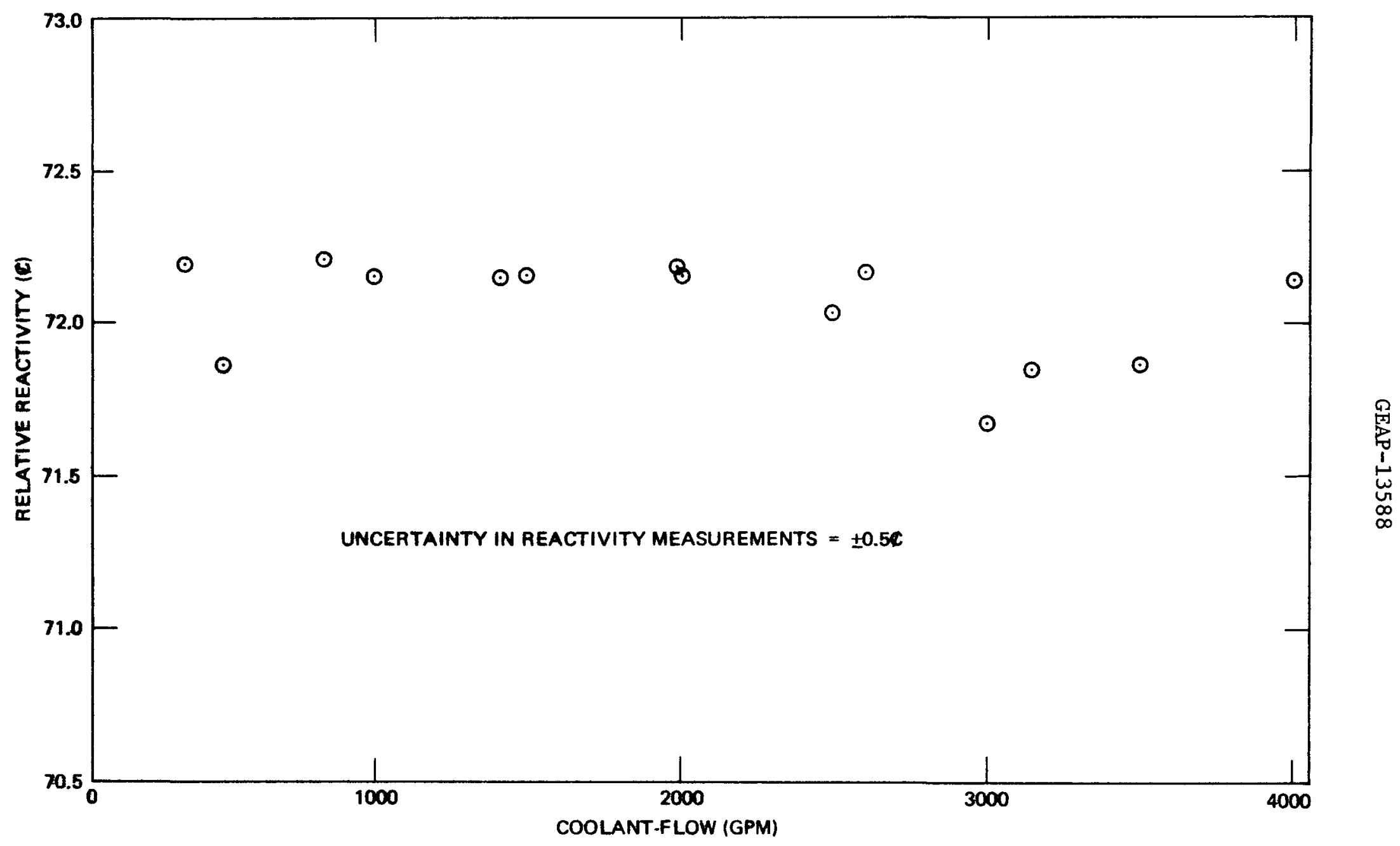

FIGURE 7-2. FLOW REACTIVITY MEASUREMENTS (ASSEMBLY I-E) 


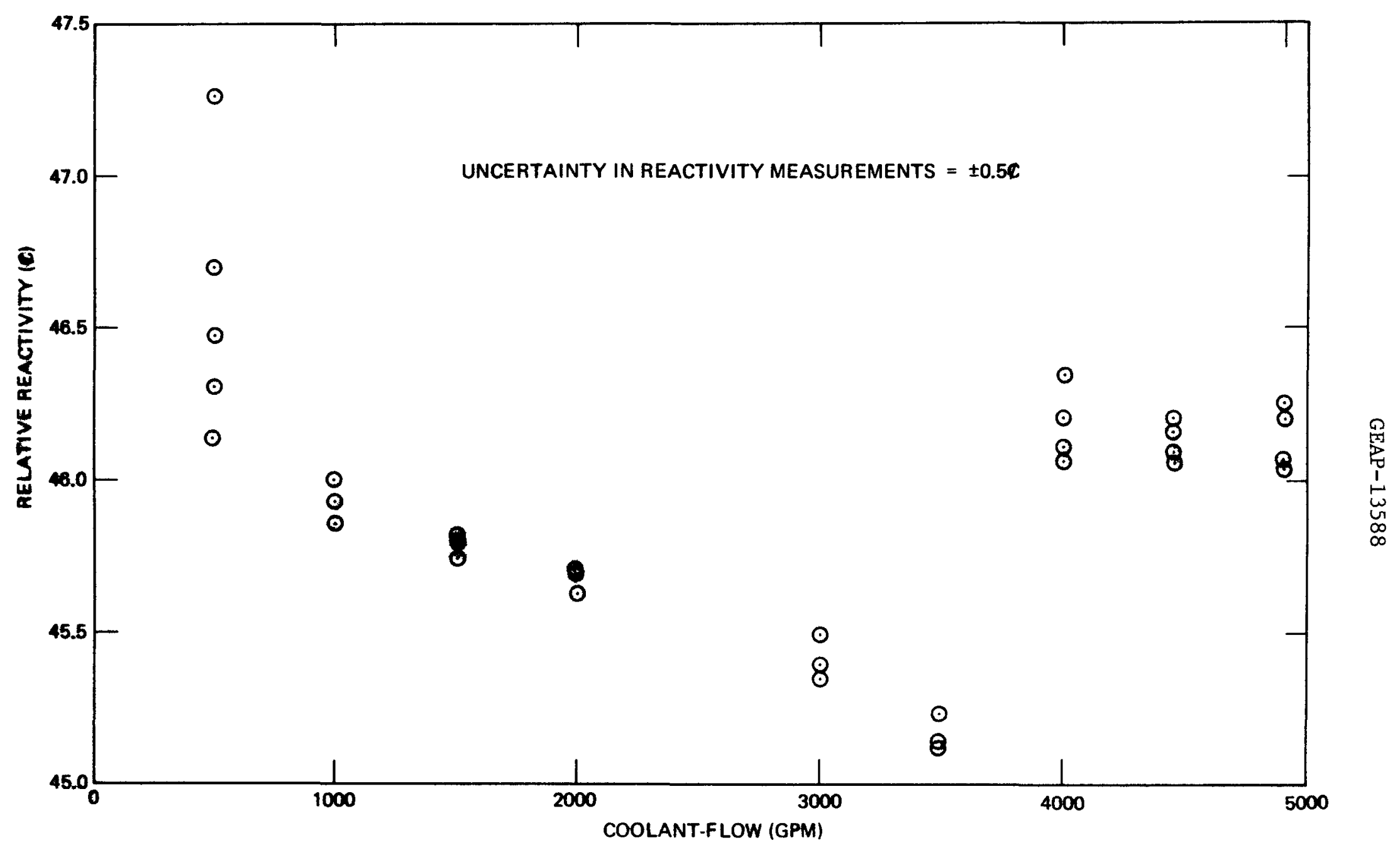

FIGURE 7-3. FLOW REACTIVITY MEASUREMENTS (ASSEMBLY $\mid-1$ ) 


\subsection{CALCULATION OF THE UNIFORM TEMPERATURE REACTIVITY COEFFICIENTS}

The major components of the temperature dependent reactivity feedback coefficients for the fully loaded SEFOR core were calculated, and the influence of core $B_{4} C$ content on these coefficients was investigated. In addition, the reactivity coefficients were also calculated for the minimum critical core loading. Both of these calculations were performed prior $(2,3)$ to the actual $(4,5)$ temperature coefficient measurements. The calculated average Doppler coefficient $\left(\mathrm{T} \mathrm{dk} / \mathrm{dT}\right.$ ) between fuel temperatures of $300^{\circ} \mathrm{K}$ and $1400^{\circ} \mathrm{K}$ was -0.0082 for a fully loaded core containing 19 uniformly distributed $\mathrm{B}_{4} \mathrm{C}$ rods, while the expansion coefficient was $-0.36 \mathrm{c} /{ }^{\circ} \mathrm{F}$. The magnitudes of the Doppler and expansion coefficients were increased by only $5 \%$ and $3 \%$, respectively, for a core containing 12 uniformly distributed $\mathrm{B}_{4} \mathrm{C}$ rods instead of 19. Since the coefficients are relatively insensitive to $\mathrm{B}_{4} \mathrm{C}$ content, the values quoted here should be representative of the feedback coefficients for any SEFOR full size core loading. The corresponding Doppler $\mathrm{T} \frac{\mathrm{dk}}{\mathrm{dT}}$ and total expansion coefficient for the minimum critical core were -0.0086 and $-0.44 \zeta /{ }^{\circ} \mathrm{F}$, respectively.

The total calculated ${ }^{(3)}$ feedback coefficient for the fully loaded core, including Doppler, is $-0.68 \mathrm{c} /{ }^{\circ} \mathrm{F}$ at $350^{\circ} \mathrm{F}$ and $-0.58 \mathrm{c} /{ }^{\circ} \mathrm{F}$ at $700^{\circ} \mathrm{F}$. The corresponding total feedback coefficient for the minimum critical core ${ }^{(2)}$ is $-0.77 \mathrm{c} /{ }^{\circ} \mathrm{F}$ at $350^{\circ} \mathrm{F}$. The calculated Doppler coefficient for the fully loaded core is in good agreement with previously calculated values for the full size ${ }^{(6)}$ core and is only $5 \%$ lower for the fully loaded core containing 19 uniformly distributed $\mathrm{B}_{4} \mathrm{C}$ rods than for the minimum critical partially loaded core. The expansion coefficient is $220 \%$ lower in the full size core than for the minimum 
critical core, primarily because of the decreased sodium density effect between the core and vessel due to the smaller amount of sodium between the core and reflectors in the fully loaded core.

Calculations were performed for two fully loaded SEFOR cores; one containing 629 fuel rods and $19 \mathrm{~B}_{4} \mathrm{C}$ rods distributed uniformly throughout the core and the other containing 636 fuel rods and $12 \mathrm{~B}_{4} \mathrm{C}$ rods. In addition, calculations were performed for a partially loaded core containing 512 fuel rods and no $\mathrm{B}_{4} \mathrm{C}$ rods. The calculational models, cross sections, and energy group structures are described in Appendix I.

The calculation for the 512 rod core was performed to provide a basis for correcting any reactivity measurements in a partially loaded core for undesired temperature variations. No temperature coefficient measurements were actually performed on a partially loaded core, but the close agreement between calculation and experiment for the fully loaded core allows the results for the partially loaded core to be used with a reasonable degree of confidence. A core model with 512 rods was used in the initial critical prediction, and was used for the reactivity coefficient calculations prior to the initial loading because it was nearly the size of the predicted minimum critical core.

\subsubsection{Doppler Coefficient Calculations}

The U-238 contribution to the Doppler coefficient was calculated using temperature dependent cross sections at $300^{\circ} \mathrm{K}, 700^{\circ} \mathrm{K}$ and $1400^{\circ} \mathrm{K}$ for the fully loaded core that were obtalned from a cross section fitting routine. Similar temperature dependent cross sections at $300^{\circ} \mathrm{K}$ and $700^{\circ} \mathrm{K}$ were used in the 512 rod core. Results for the fully loaded cores 
containing $\mathrm{B}_{4} \mathrm{C}$ were calculated for a uniform fuel temperature change using 13 group cross sections and the two-dimensional synthesis code BISYN $^{(7)}$. The results are summarized in Table 7-4. The Doppler reactivity effect for the partially loaded core was calculated by perturbation of a 60 energy group, one-dimensional radial diffusion theory calculation. In addition, the Doppler coefficient for this core was also evaluated from calculations using 13 energy groups and a two-dimensional synthesis program (7). The results of the two methods of calculation are in good agreement as indicated in Table 7-4. The calculations indicate that for the fully loaded core the quantity defined as $\mathrm{T} d \mathrm{~d} / \mathrm{dT}$ can be treated as a constant (within $\sim \pm 5 \%$ ) over the temperature range between $300^{\circ} \mathrm{K}$ and $1400^{\circ} \mathrm{K}$. The predicted Doppler $\mathrm{T} \mathrm{dk/dT}$ is -0.0082 for a fully loaded core containing 19 uniformly distributed $\mathrm{B}_{4} \mathrm{C}$ rods and -0.0086 for a partially loaded core containing 512 fuel rods and no $\mathrm{B}_{4} \mathrm{C}$ rods. These values are composed of the U-238 contributions listed in Table 7-4 and a previously calculated ${ }^{(6)}$ value of -0.0003 for the Pu-240 contribution. It was assumed that the Pu-239 contribution to the Doppler effect is zero. The predicted Doppler $\mathrm{T} \mathrm{dk} / \mathrm{dT}$ for a fully loaded core containing $12 \mathrm{~B}_{4} \mathrm{C}$ rods (including a contribution from Pu-240 of -0.0003) is -0.0086 . 
GEAP-13588

TABLE $\quad 7-4$

\section{U-238 DOPPLER CALCULATIONS}

Number of $\mathrm{B}_{4} \mathrm{C}$ rods

in Fully Loaded Core

19

12
Reactivity Effects for Fully Loaded Core

(using 13 energy groups and synthesis (7) calculation) $300^{\circ} \mathrm{K}$ to $700^{\circ} \mathrm{K} \quad 700^{\circ} \mathrm{K}$ to $1400^{\circ} \mathrm{K}$ Average $\mathrm{T} \mathrm{dk} / \mathrm{dT}$ $\Delta \mathrm{k}$ $\Delta \mathrm{k}$ $\left(300^{\circ} \mathrm{K}\right.$ to $\left.1400^{\circ} \mathrm{K}\right)$

$\begin{array}{lll}-0.00695 & -0.00518 & -0.0079 \\ -0.00726 & -0.00541 & -0.0083\end{array}$

Method of Calculation

Perturbation of a 60-group radial problem

Change in Feptivity from synthesis calculations
Reactivity Effects for 512 Rod Partially Loaded Core $300^{\circ} \mathrm{K}$ to $700^{\circ} \mathrm{K}$ $\Delta \mathrm{k}$

Doppler $T \frac{\mathrm{dk}}{\mathrm{T}}$
$300^{\circ} \mathrm{K}$ to $700^{\circ} \mathrm{KF}$

$\begin{array}{lll}-0.00707 & -0.00835 \\ -0.00692 \text { Average }= & \frac{-0.00817}{-0.0083}\end{array}$




\subsubsection{Definition and Calculation of Expansion Coefficients}

The expansion coefficients for SEFOR have been previously defined in Reference 6, but are repeated here for convenience of the reader.

1. Axial Fuel Expansion: The reactivity effect due to increasing the length of the fuel segments with a corresponding reduction in fuel density and size of the gap.

2. Axial Fuel Clad Expansion: The reactivity effect due to axial expansion of the fuel clad. Most of this reactivity effect is due to the upper fuel segment moving with the fuel clad and there is a smaller contribution due to the reduction in clad density.

3. Be0 Axial Expansion: The reactivity effect due to extending the length of the $\mathrm{BeO}$ in the tightener rods with a corresponding reduction in BeO density.

4. Structure Axial Expansion: The reactivity effect due to extending the length of the channels, steel side rods, tightener rod cladding, tightener sleeve, axial reflectors, and the inner vessel wall with a corresponding reduction in the respective material densities.

5. Structure Radial Expansion: The reactivity effect caused by radial expansion of the channels. Since the structure temperature change is accompanied by the same change in fuel and BeO clad temperatures, core volume fractions remain unchanged during radial expansion. Displacement of sodium surrounding the core is included in this effect. Change of sodium density is not included; this appears in a separate coefficient. 
GEAP-13588

6. Sodium Density Effect in Core and Axial Reflectors: The reactivity effect due to a change of sodium density in the core and axial reflectors.

7. Sodium Density Effect Between Core and Vessel: The reactivity effect due to a change of sodium density in the region between the core and the vessel wall.

8. $\mathrm{B}_{4} \mathrm{C}$ Axial Expansion: The reactivity effect due to extending the length of the $\mathrm{B}_{4} \mathrm{C}$ rods with a corresponding reduction in $\mathrm{B}_{4} \mathrm{C}$ density.

The coefficients for fuel axial expansion and fuel clad axial expansion were taken directly from Reference 6. Al1 other expansion coefficients were calculated from the results of a series of 13 group BISYN $^{(7)}$ problems. All expansion reactivity effects are assumed to vary linearly with respect to the dominating variable, i.e. change in height, radius, etc. The expansion reactivity coefficients obtained from the BISYN calculations are summarized in Tables 7-5 and 7-6.

The total expansion coefficient for the fully loaded core in Table 7-5 is $\sim 20 \%$ lower than the expansion coefficient for the minimum critical core given in Table 7-6. The primary reason for this is the decreased volume of sodium between the core and radial reflector in the fully loaded core. Because of the smaller amount of sodium, the sodium density effect in this region is reduced from -0.122 to -0.056 . Another effect, although of smaller magnitude, is the decreased magnitude of the core sodium density coefficient in the fully loaded core. 
GEAP-13588

TABLE $\quad 7-5$

EXPANSION REACTIVITY COEFFICIENTS FOR FULLY LOADED SEFOR CORE

Effect

Percentage Change** per degree

Reactivity Effects*

Fahrenheit $\left(\% /{ }^{\circ} \mathrm{F}\right)$

for Core with 19

Eefect

Fuel Axial Expansion

$+0.000461$

$\mathrm{B}_{4} \mathrm{C}$ Rods $\left(\mathrm{C} /{ }^{\circ} \mathrm{F}\right)$

Fuel Clad Axial Expansion

$+0.000980$

$-0.009^{+}$

Be0 Axial Expansion

$+0.000580$

$-0.072^{+}$

Structure Axial Expansion

$+0.000980$

$-0.003$

Structure Radial Expansion

$+0.000980$

$-0.014$

Sodium Density in Core

and Axial Reflector

$-0.015789$

$-0.135$

Sodium Density Between

Core and Vessel

$-0.015789$

$-0.072(-0.076)$

$\mathrm{B}_{4} \mathrm{C}$ Axial Expansion

$+0.000250$

$-0.056(-0.059)$

$+0.002(+0.001)$

$-0.359(-0.367)$

\footnotetext{
*If different, the reactivity effect for a core containing $12 \mathrm{~B}_{4} \mathrm{C}$ rods is enclosed in parenthesis.

**This represents the percentage change in length, density, etc.

+Based on the calculated coefficients in Reference 2 of $-19.27 \mathrm{c} / \% \Delta \mathrm{h} / \mathrm{h}$ for fuel axial expansion and $-73.31 \% / \% \Delta \mathrm{h} / \mathrm{h}$ for fuel clad axial expansion
} 
GEAP-13588

TABLE $\quad 7-6$

EXPANSION REACTIVITY COEFFICIENTS FOR 512 ROD CORE

\section{Effect}

Fuel Axial Expansion

Fuel Clad Axial Expansion

Be0 Axial Expansion

Structure Axial Expansion

Structure Radial Expansion

Sodium Density in Core and Axial Reflector

Sodium Density Between

Core and Vessel

$\mathrm{B}_{4} \mathrm{C}$ Axial Expansion
Percentage change** per degree

Fahrenheit $\left(\% /{ }^{\circ} \mathrm{F}\right)$

$+0.000461$

$+0.000980$

$+0.000580$

$+0.000980$

$+0.000980$

$-0.015789$

$-0.015789$

$+0.000250$
Reactivity Effect $\left(\mathrm{c} /{ }^{\circ} \mathrm{F}\right)$

$-0.009 *$

$-0.072 *$

$-0.004$

$-0.014$

$-0.130$

$-0.093$

$-0.122$

0.0

$-0.444$

*Based on the calculated coefficients in Reference 2 of $-19.27 \mathrm{c} / \% \Delta \mathrm{h} / \mathrm{h}$ for fuel axial expansion and $-73.31 \mathrm{c} / \% \Delta \mathrm{h} / \mathrm{h}$ for fuel clad axial expansion **This represents the percentage change in length, density, etc. 


\subsection{TEMPERATURE COEFFICIENT MEASUREMENTS}

\subsubsection{Temperature Coefficient Measurement in Assembly I-D}

A preliminary measurement of the temperature coefficient was performed in a fully loaded core Assembly I-D (see Figure 1-4) in order to determine an appropriate fuel loading for the normal operating temperature $\left(760^{\circ} \mathrm{F}\right)$, and to obtain a preliminary value for use in correcting other zero power reactivity test data for undesired changes in temperature.

The primary sodium was heated from $350^{\circ} \mathrm{F}$ to $400^{\circ} \mathrm{F}$ by the primary loop trace heating system. The temperature was maintained at $400^{\circ} \mathrm{F}$ for about two hours and the primary system was then cooled down to $350^{\circ} \mathrm{F}$. This process was repeated to establish the reproducibility of the data. The reactor was shut down during the actual heating and cooling periods, but steady state critical reflector positions were recorded at both temperature extremes.

The data obtained during the experiment are shown in Table 7-7. A least squares fit of a straight line to the data in the table gives a value of $-0.59 \pm 0.01 \mathrm{c} /{ }^{\circ} \mathrm{F}$ for the temperature coefficient. 


\section{TABLE 7-7}

TEMPERATURE COEFFICIENT MEASUREMENTS IN ASSEMBLY I-D

\begin{tabular}{|c|c|c|c|c|c|}
\hline \multirow[b]{2}{*}{$\begin{array}{l}\text { Temperature } \\
\left({ }^{\circ} \mathrm{F}\right) \\
\end{array}$} & \multicolumn{2}{|c|}{ Reflector 非3 } & \multicolumn{2}{|c|}{ Reflector 非 } & \multirow{2}{*}{$\begin{array}{l}\text { Reactivity Change } \\
\text { Relative to } 350^{\circ} \mathrm{F} \\
\text { (c) }\end{array}$} \\
\hline & $\begin{array}{c}\text { Position } \\
\quad(\mathrm{cm}) \\
\end{array}$ & $\begin{array}{l}\text { Worth* } \\
(c)\end{array}$ & $\begin{array}{l}\text { Position } \\
\quad(\mathrm{cm}) \\
\end{array}$ & $\begin{array}{l}\text { Worth* } \\
\text { (c) }\end{array}$ & \\
\hline 352.0 & 0.75 & 0.19 & 52.09 & 74.02 & -0.88 \\
\hline 398.5 & 0.75 & 0.19 & 69.07 & 101.60 & -28.46 \\
\hline 397.5 & 0.75 & 0.19 & 68.88 & 101.33 & -28.19 \\
\hline 397.0 & 0.75 & 0.19 & 68.67 & 101.03 & -27.89 \\
\hline 350.0 & 0.44 & 0.00 & 51.71 & 73.33 & 0.00 \\
\hline 398.25 & 0.44 & 0.00 & 69.27 & 101.88 & -28.55 \\
\hline 398.25 & 0.44 & 0.00 & 69.27 & 101.88 & -28.55 \\
\hline 398.25 & 0.44 & 0.00 & 69.15 & 101.71 & -28.38 \\
\hline 398.25 & 0.44 & 0.00 & 69.15 & 101.71 & -28.38 \\
\hline
\end{tabular}

*Relative to the worth with the reflector lowered. 


\subsubsection{Temperature Coefficient Measurements in Assembly I-E}

In order to determine the temperature coefficient of reactivity in Assembly I-E (see Figure 1-5), the reactor was heated from $350^{\circ} \mathrm{F}$ to $760^{\circ} \mathrm{F}$ with the primary loop trace heating system, cooled to about $700^{\circ} \mathrm{F}$ and then reheated to $760^{\circ} \mathrm{F}$. The reactor power level was held constant at about 600 watts throughout the heating and cooling periods by adjusting the reflector positions to compensate the reactivity feedback effects. Resistance-Temperature Detectors (RTD's) were used to monitor the main and, over the last portion of the experiment, the auxilary primary reactor inlet and outlet temperature. In addition, the temperatures indicated by a thermocouple located inside the reactor vessel were recorded. The RTD readings had an estimated uncertainty at any point of $\pm 2.5^{\circ} \mathrm{F}$, while the estimated uncertainty in the thermocouple reading at any point was $\pm 0.25^{\circ} \mathrm{F}$.

The temperatures and reflector positions were recorded approximately every 15 minutes. The primary sodium temperature was stabilized for two to three hours at temperatures of approximately $450^{\circ} \mathrm{F}, 550^{\circ} \mathrm{F}$, $650^{\circ} \mathrm{F}$, and $760^{\circ} \mathrm{F}$ to ensure that both thermal and nuclear equilibrium were attained at these points. The time dependent behavior of the temperatures are shown in Figures 7-4 through 7-10 and the reactivity feedback as a function of temperature indicated by the thermocouple is shown in Figure 7-11.

Although the indicated auxilary primary inlet temperature is somewhat erratic, the thermocouple and the main primary RTD's show a nearly constant difference of about $15^{\circ} \mathrm{F}$ (which can be corrected by recalibration), and the indicated changes in temperature are nearly 
identical. The data indicates that the relationship between reactivity and temperature is independent of the heating rate, for rates of about $20^{\circ} \mathrm{F}$ per hour or less. This demonstrates that the reactivity feedback contains no major components with long time constants and that reactivity transient effects are insignificant for heating rates up to $\sim 20^{\circ} \mathrm{F} /$ hour.

The close agreement between the experimental reactivity feedback and the feedback calculated using the predicted values of -0.0082 for the Doppler $\mathrm{T} \frac{\mathrm{dk}}{\mathrm{dT}}$, and $-0.36 \mathrm{c} /{ }^{\circ} \mathrm{F}$ for the combined expansion - sodium density coefficient is shown in Figure 7-11. The actual data taken during the experiment are tabulated in Appendix VII. 


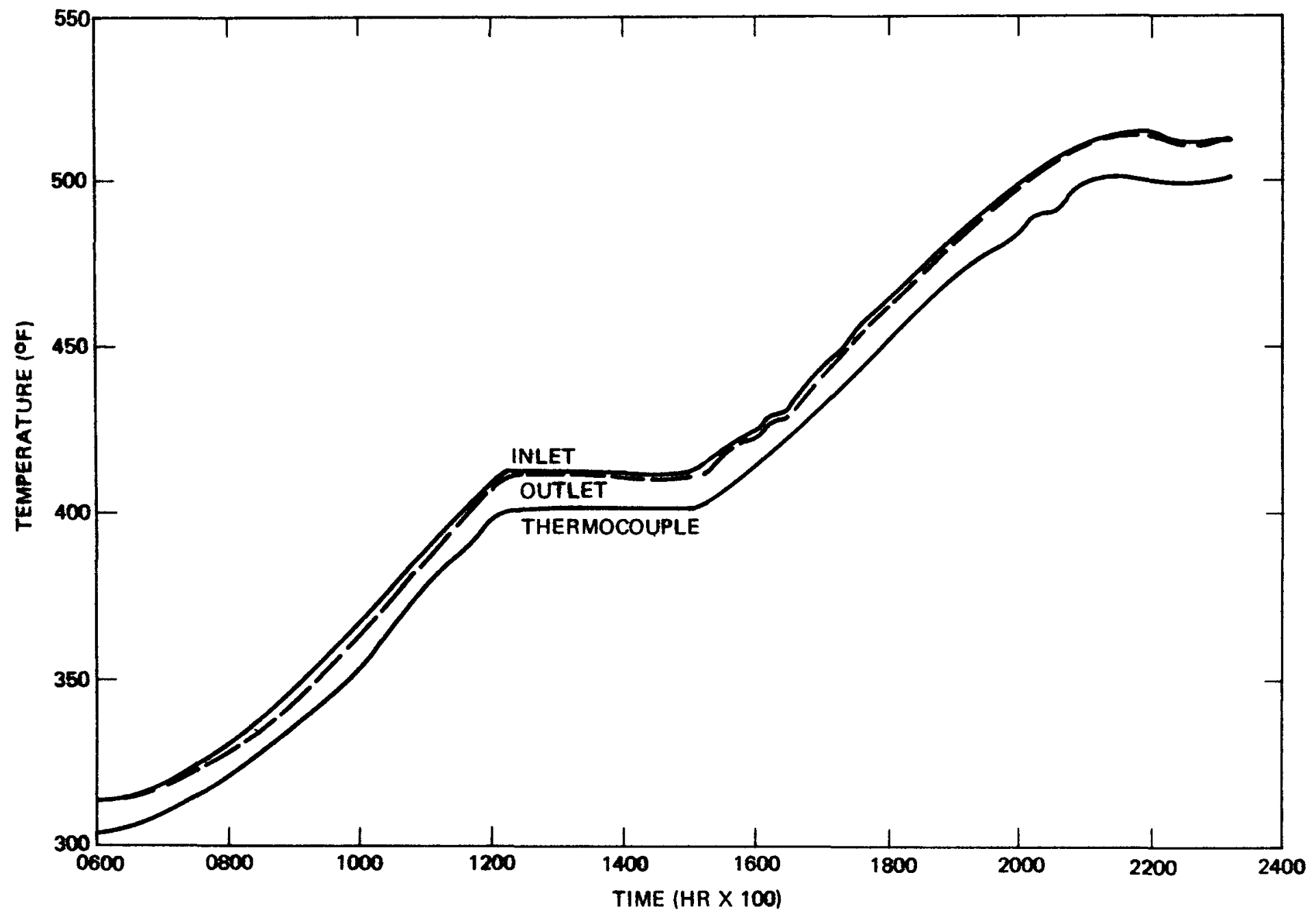




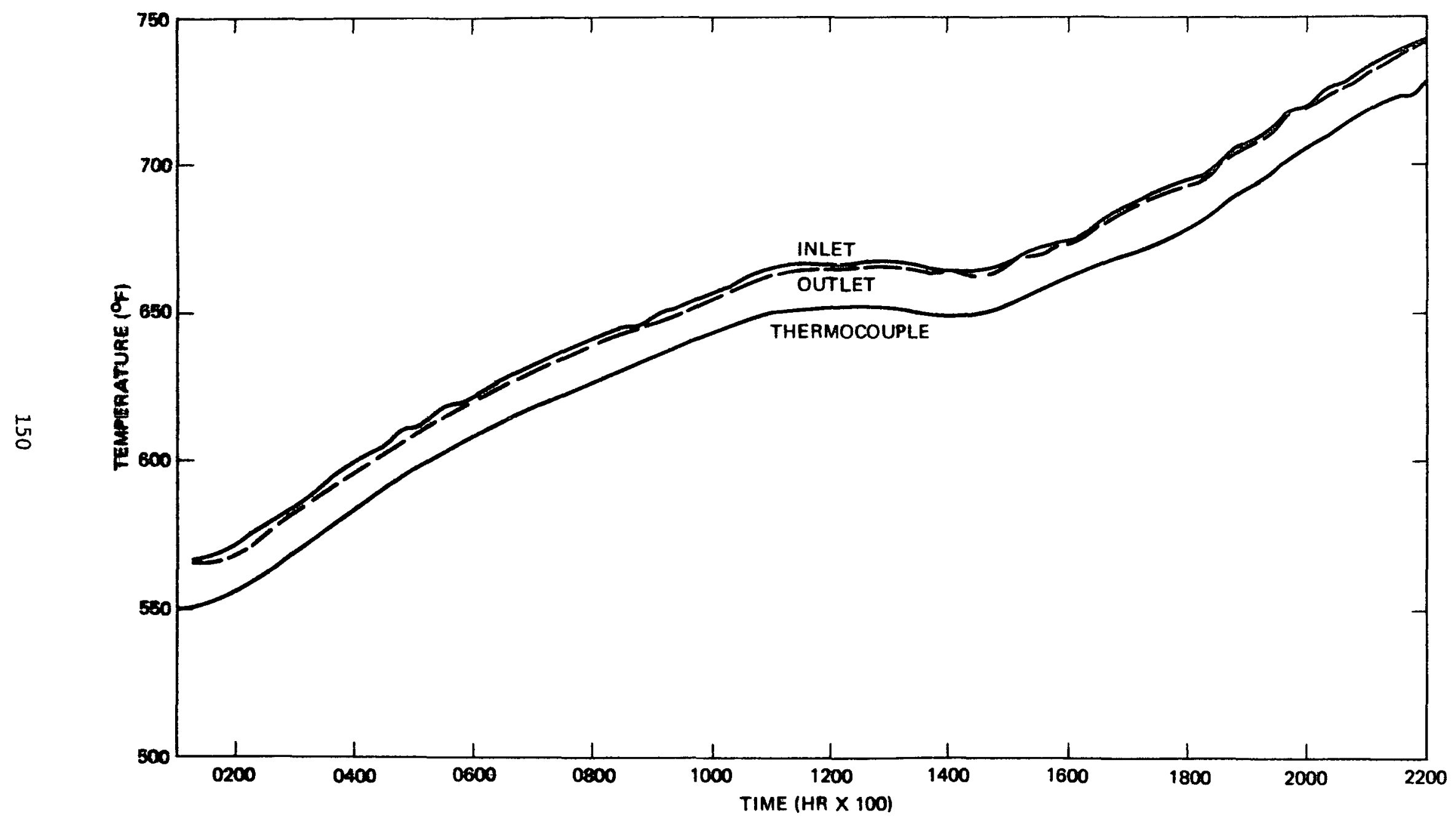




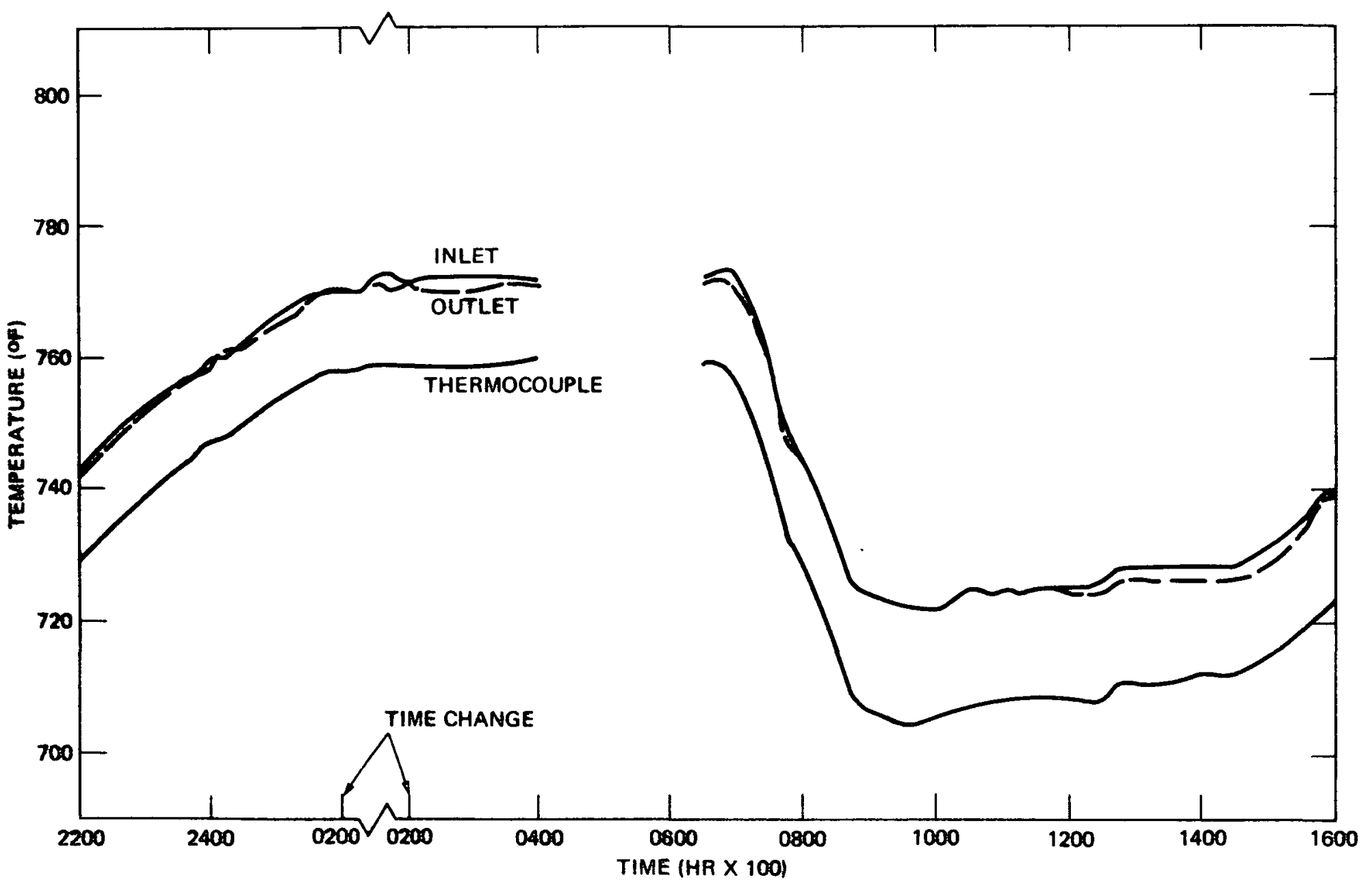




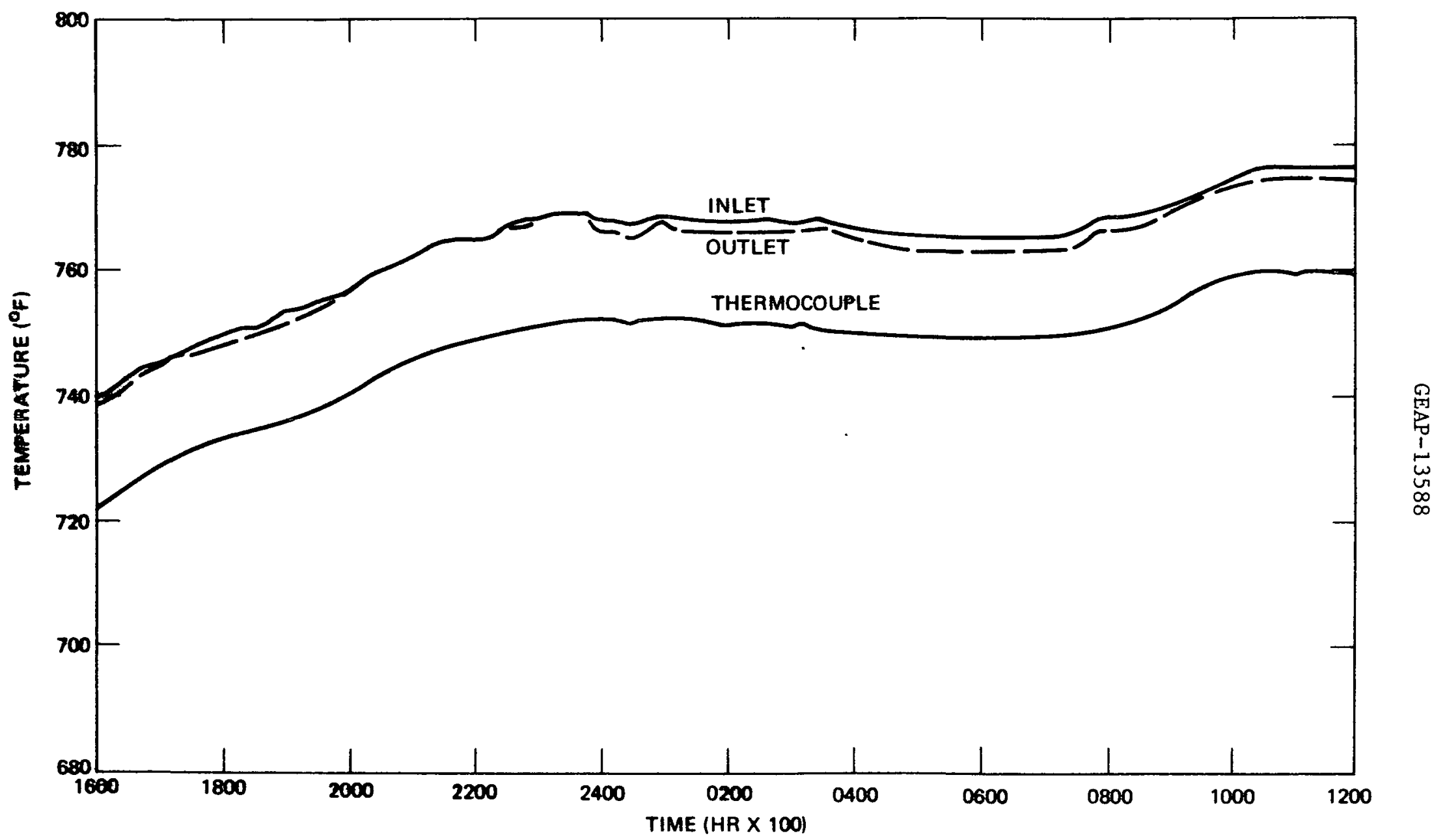

FIGURE 7-7. IN CORE THERMOCOUPLE AND MAIN PRIMARY RTD'S (10/26/69 - 10/27/69) 


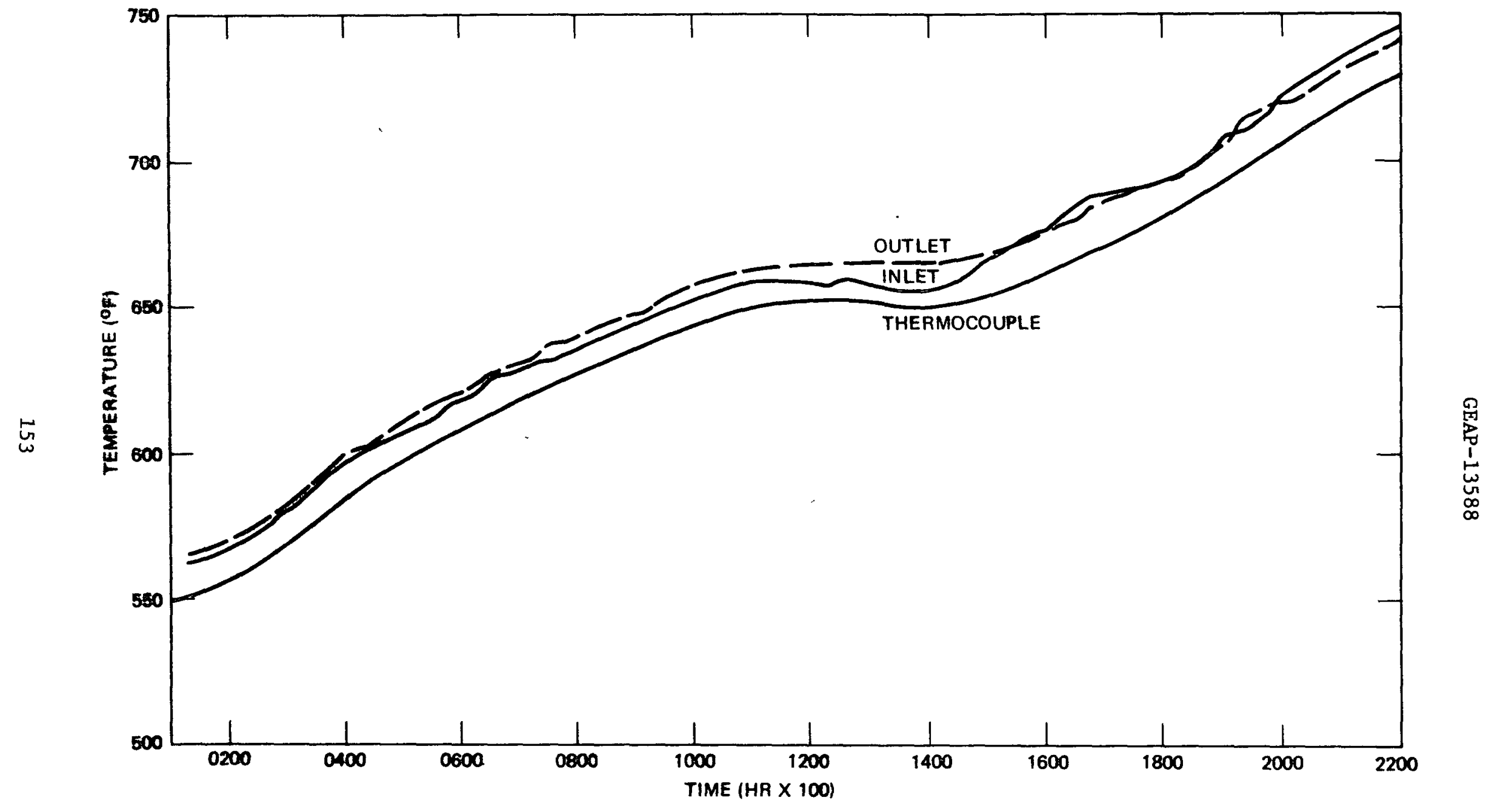

FIGURE 7-8. IN CORE THERMOCOUPLE AND AUXILIARY PRIMARY RTD'S (10/25/69) 


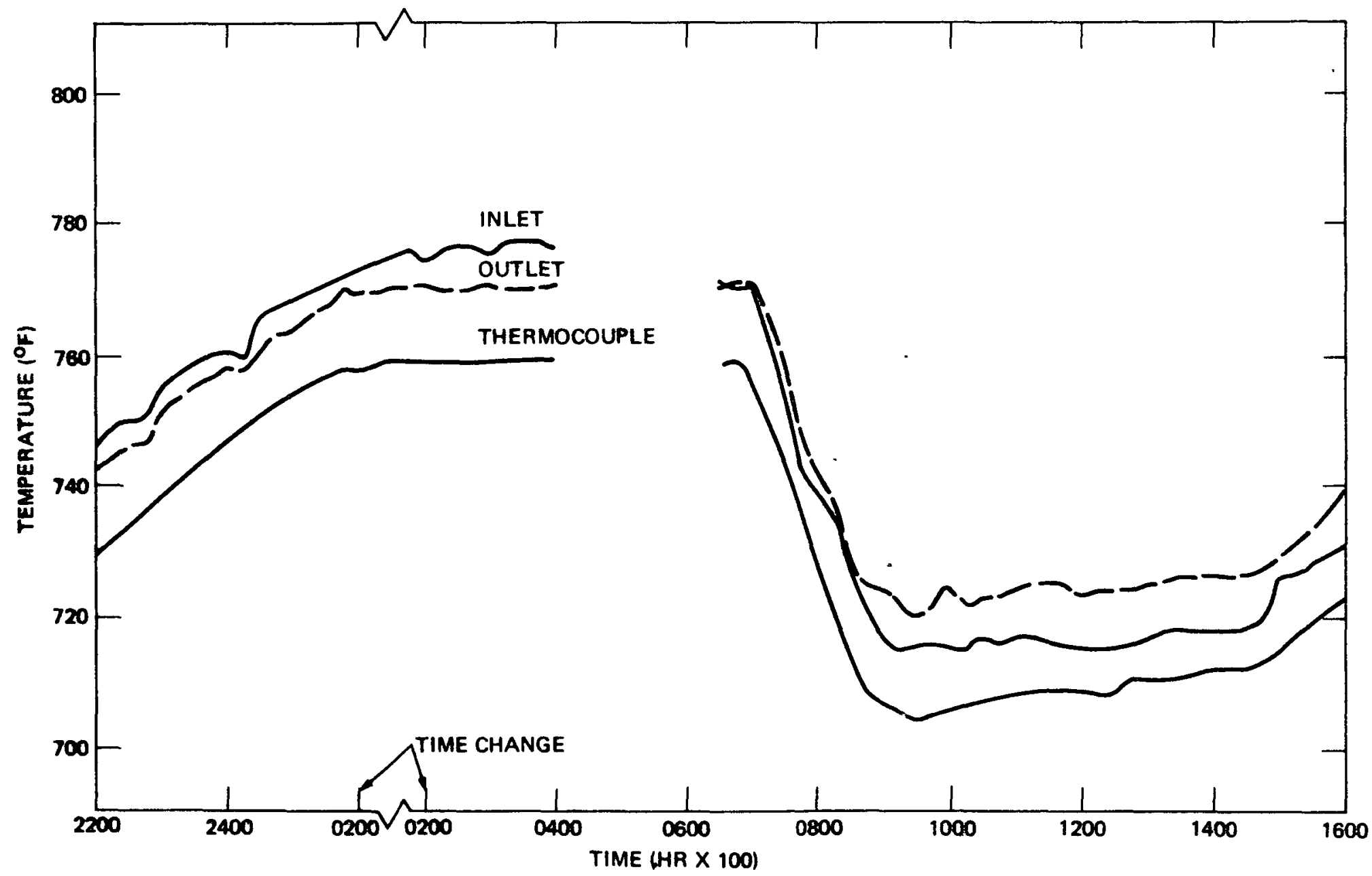




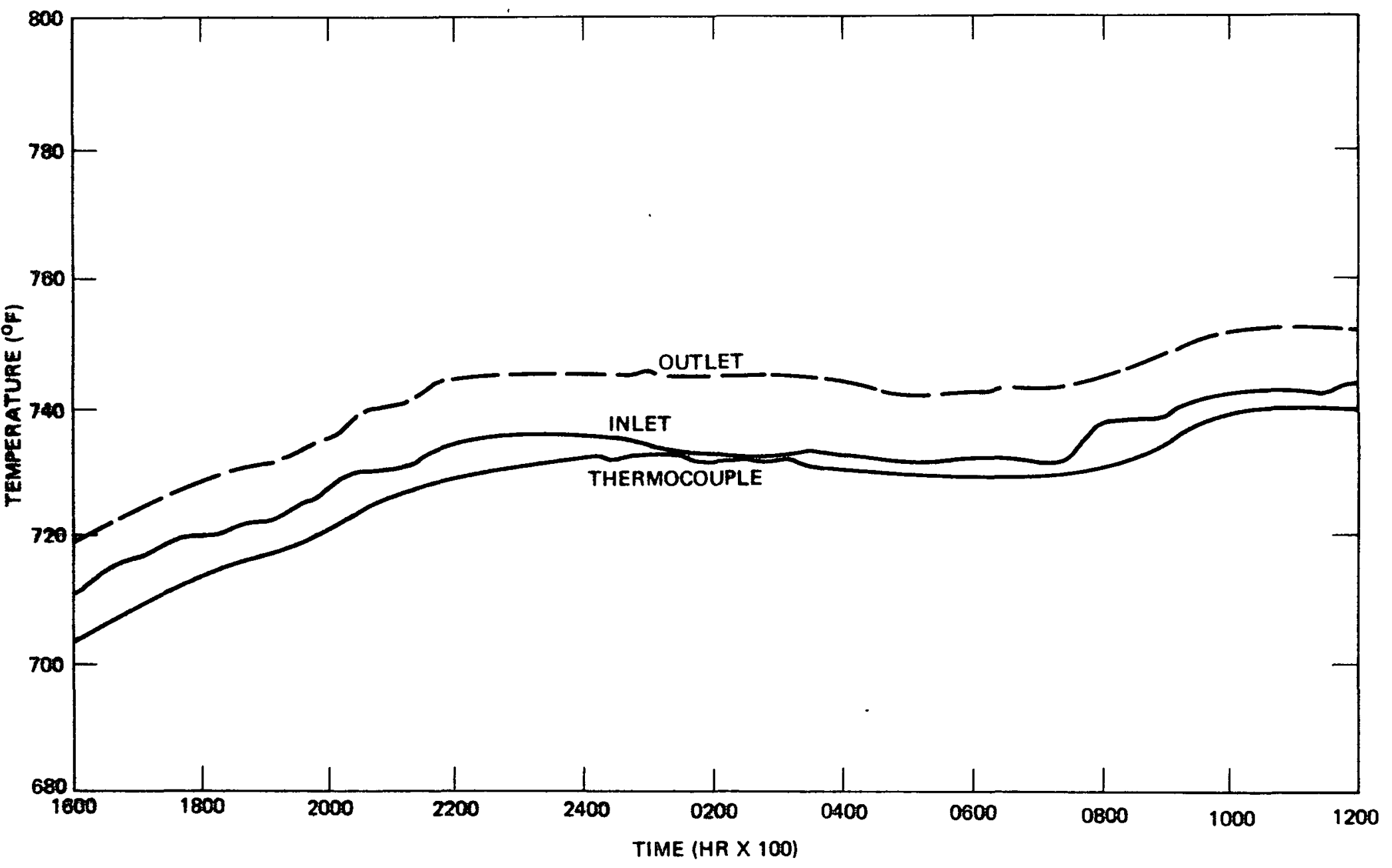




\subsection{COMPARISON OF EXPERIMENTAL AND CALCULATED RESULTS}

The flow and the pressure coefficients of reactivity are essentially zero (see Section 7.1). The reactivity effects, if any, that occur as a result of changes within their normal operating ranges in reactor vessel hydraulic pressure or primary coolant flow are of the order of the $\pm 0.5 c$ standard deviation in reactivity difference measurements. This is in agreement with expectations ${ }^{(1)}$.

Figure 7-11 illustrates the excellent agreement between the predicted $^{(3)}$ temperature dependent reactivity feedback, and the experimentally determined reactivity feedback for Assembly I-E. This agreement is further illustrated in Table 7-8 where the reactivity coefficients calculated from the previously predicted (4) total expansion coefficient of $-0.36 \mathrm{c} /{ }^{\circ} \mathrm{F}$ and the predicted Doppler $\mathrm{T} \frac{\mathrm{dk}}{\mathrm{dT}}$ of -0.0082 is compared with the coefficients determined from a least squares fit of a parabola to the experiuental data in Appendix VII. Since the prediction was based (see Section 7.2) on a reactor model containing $19 \mathrm{~B}_{4} \mathrm{C}$ rods, while Assembly I-E contained $14 \mathrm{~B}_{4} \mathrm{C}$ rods, the calculated values should be modified to reflect this difference. Using the ca1culated results in Section 7.2 as a basis for extrapolating to a core with $14 \mathrm{~B}_{4} \mathrm{C}$ rods results in about a $4 \%$ increase in the calculated total coefficient. This in turn results in approximately a $6 \%$ difference between the calculated and measured uniform temperature coefficient, rather than the $22 \%$ difference in Table 7-8. Regardless of which calculated coefficients are used, the agreement between calculation and experiment is quite good.

The approximately $12 \%$ difference the reactivity coefficient of $-0.59 \mathrm{c} /{ }^{\circ} \mathrm{F}$ (in the range $350^{\circ} \mathrm{F}$ to $400^{\circ} \mathrm{F}$ ) that was measured in Assembly 
$I-D$, and the corresponding value of $-0.67 \mathrm{C}$ that was measured in Assembly I-E is unexplained. Although the core loadings, and thus the reflector arrangements, were different in the two cases, two-dimensional synthesis calculations which were performed to estimate the influence of reflector density on the temperature coefficients of reactivity indicate that only a one or two percent change in the total coefficient might be expected between the two assemblies*. Because of the large amount of data obtained in Assembly I-E versus the rather limited data in Assembly I-D, and the calculated small influence* of the reflectors on the temperature feedback, the results obtained in Assembly I-E are considered to be the most reliable. The estimated uncertainties in the measured reactivity changes are estimated to be $\pm 0.5 c$ (see section 4.4 ) or $\pm 4 \%$ (due to "shadowing" - see Appendix VIII), whichever is larger.

The rather limited range of these measurements, in terms of absolute temperature, does not provide for a good experimental separation of the Doppler from the expansion effects. However, since the Doppler effect contributes about $40 \%$ of the calculated uniform temperature coefficient in the $350^{\circ} \mathrm{F}$ to $760^{\circ} \mathrm{F}$ temperature range, the close agree= ment between the calculated and measured total temperature coefficient is an indication that the Doppler effect is not drastically different from its predicted value.

\footnotetext{
*Preliminary analysis of recent measurements in Assembly I-I, which has yet a third core loading and reflector configuration, substantiate the results obtained in Assembly I-E.
} 


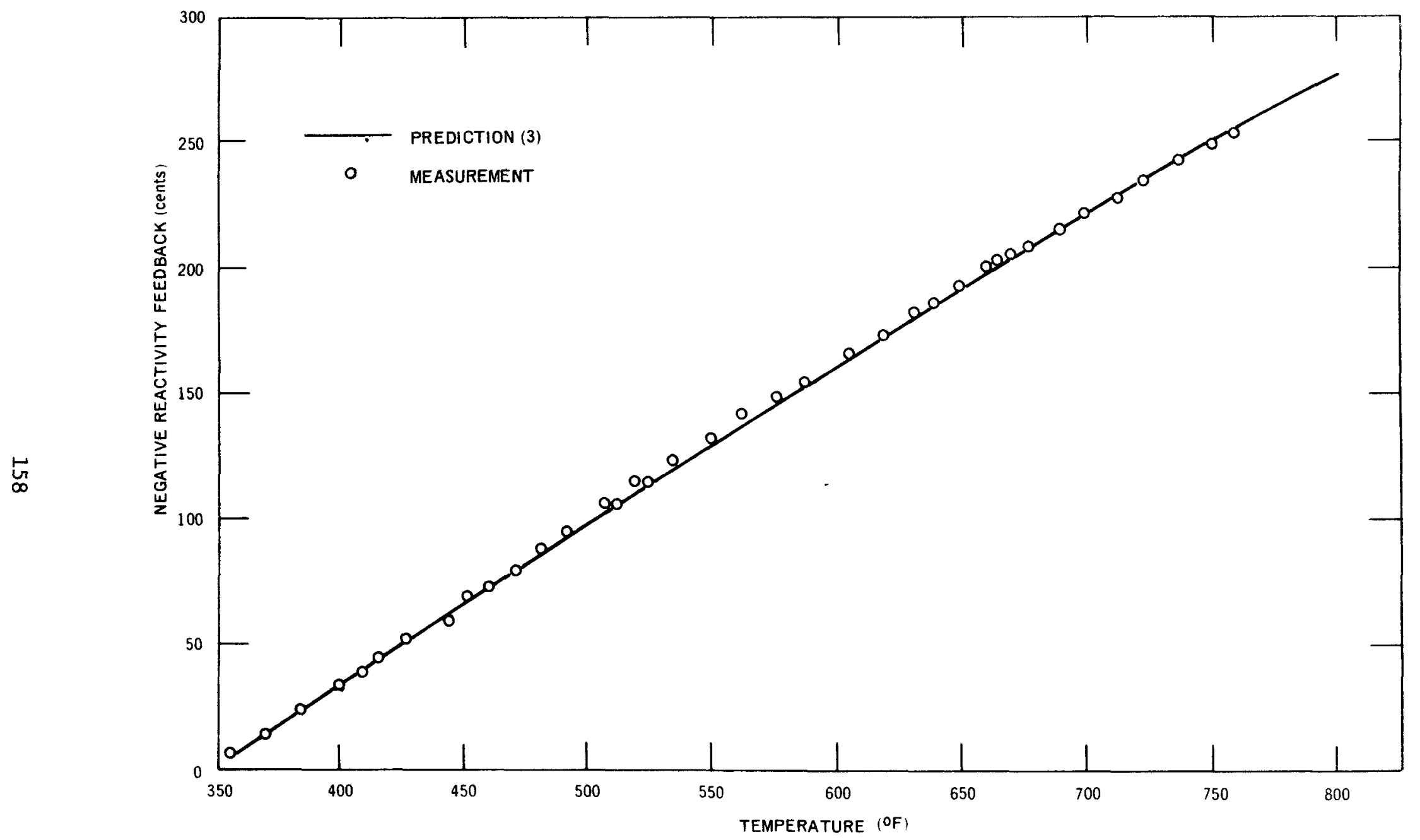

FIGURE 7-11. TEMPERATURE REACTIVITY FEEDBACK (ASSEMBLY I-E) 
Temperature Range

$\left({ }^{\circ} \mathrm{F}\right)$
Average Temperature Reactivity Coefficient in indicated Temperature Range $\left(c /{ }^{\circ} \mathrm{F}\right)$

Measured**

$-0.67$

$-0.66$

350 to 450

$-0.64$

$-0.63$

$-0.60$

$-0.61$

550 to 650

$-0.57$

$-0.58$

*The expression ${ }^{(3)}$ for the coefficient at a given temperature $\mathrm{T}$ (in degrees Rankin) is $-(0.36+260 / \mathrm{T}) \mathrm{c} /{ }^{\circ} \mathrm{F}$. (see discussion and Section 7.2 for the influence of $\mathrm{B}_{4} \mathrm{C}$ content on the calculated coefficients).

**A fit to the experimental data yields a coefficient at a given temperature $T$ (in degreees Fahrenheit) of the form $[0.692-0.000357(\mathrm{~T}-350)] \mathrm{c} /{ }^{\circ} \mathrm{F}$. 
GEAP-13588

\section{APPENDIX I \\ SEFOR CALCULATIONAL MODEL AND CROSS SECTION DATA}

\section{CALCULATIONAL MODEL}

A typical cross section of a SEFOR fuel channel is shown in Figure I-1, and the SEFOR two-segment fuel design is illustrated in Figure I-2. A calculational model for the core was obtained by homogenizing all materials within a unit cell containing a fuel channel and additional sodium associated with a spacing between channels of 0.010 inches.

Because of the construction of the core and the fuel and tightener rods, the core was divided into four compositionally different regions which are labled in Figure $I-3$ as lower core, core, gap, and central channel. The combined length of the lower core, core, and gap is equal to the height of the fuel $\left(\mathrm{P}_{\mathrm{u}} \mathrm{O}_{2}-\mathrm{UO}_{2}\right)$ pellet column (exclusive of the $\mathrm{UO}_{2}$ insulator pellets at each end of the fuel column - these are homogenized into the axial reflectors) within the fuel rods. The gap region includes the actual physical gap (void), as well as the springs, spacers, and $\mathrm{UO}_{2}$ insulator pellets on each side of the gap. The length of the lower core region is determined by the length of the low-Be0 portion of the tightener rods. The centıal channel contained He-3 detectors during the critical approach and will contain a dry well for operation at higher power levels.

The radial dimensions of the core were chosen to yield right circular cylinders of volumes equal to those of the varfous core regions.

The homogenized composition of the vartous rods which are inserted into the core from time to time are summarized in Table I-1 and the 
composition of the unit cells and the over-all reactor model given in Tables I-2 through I-3. The materia1 densities corresponding to this reactor model are given in Table $\mathrm{I}-4$.

During the initial critical loading the outer radial region of the core contained only sodium and the steel from the channels and side rods, and from the tightener sleeve. A homogenized composition for this region is readily obtained from Table I-3 by replacing all fuel, $\mathrm{BeO}$ and SS-316 in Composition 1 with sodium. The height of this region (which contains $13.11 \% \mathrm{SS}-304$ and $86.89 \% \mathrm{Na}$ ) is the same as that of a fuel rod. (i.e., it extends through both axial reflectors.) The composition of any core loading can be obtained in a straight forward manner from the data in Tables I-1 through I-4.

Most of the calculations were performed with either thirteen or four energy groups. These group structures were selected according to the recipe in reference 1 and are shown in Table $I-5$. The group cross sections were obtained from a condensation of 60 group onedimensional diffusion calculations which used perpendicular bucklings obtained from previous calculations ${ }^{(2)}$. The sources of the cross sections for the 60 group calculations are discussed below.

Self-shielding calculations for the fuel isotopes were performed (in the sixty group structure mentioned above) using a cross section fitting routine with a Bell(3) approximation for resonance region heterogeneity. In addition, the cross sections for the movable nickel segments in the radial reflector zones were self-shielded using tables in Bondarenko ${ }^{(4)}$ and factors generated with the ENDRUN code ${ }^{(5)}$. 


\section{CROSS SECTION DATA}

\section{Data Sources}

The cross section values which were used are essentially those in the ENDF/B file, Version 1, distributed by Brookhaven National Laboratory in the summer of $1968^{(6)}$ with the exception of the following changes:

a) Pu-239. The $\bar{v}$ values were increased by $0.77 \%$ (to 2.89 at low energy) to agree more with current evaluations. The fission cross section between 20 and $100 \mathrm{keV}$ was increased to ignore the dip in the White data. (7) Below $15 \mathrm{keV}$ the fission cross section was lowered to be consistent with higher alpha values used at these energies, while a slight decrease was made in $\sigma_{f}$ above $2 \mathrm{MeV}$. The alpha value below $15 \mathrm{keV}$ was increased to agree with the measured values of ORNL-RPI, ${ }^{(8)}$ and the infinitely dilute cross sections computed on the basis of an analysis which accounts for rapid energy variations in both the strength function and the fission width. (9)

b) U-238. The capture cross section was lowered by about $4 \%$ over the energy range at the peak of the neutron flux ( $200 \mathrm{keV}$ ), and from 5 to 10 percent between 4 and $20 \mathrm{keV}$. This resulted in values which agree with the Garg data, (10) plus some additional p-wave contribution around $1 \mathrm{keV}$, in the resolved resonance range; Pönitz's values ${ }^{(11)}$ from 3 to about $100 \mathrm{keV}$; and a compromise between Barry, Bunce and White values ${ }^{(12)}$ and the much lower Pönitz data above $100 \mathrm{keV}$. The fission cross section above $2 \mathrm{MeV}$ was also slightly decreased. 
c) $\mathrm{Pu}-240$. The fission cross section at energies below several hundred keV was modified to agree with the Petrel results. (13) The primary difference from ENDF/B is an increase to about 0.3 barns at $1 \mathrm{keV}$. Capture cross sections were reduced at all energies to account for lower values of $\Gamma_{\gamma}$, as indicated by the analysis of Pitterle. (14) The reduction factor was a constant 0.83 , corresponding to a decrease in $\Gamma_{\gamma}$ from 0.030 to $0.025 \mathrm{eV}$.

\section{Indicated Further Data Adjustments}

In Section 2.1 it was seen that the directly computed multiplication factor for the ZPR-III and SEFOR minimum critical assemblies was from 0.5 to 1.5 percent low. Cross section changes which could account for these low values and are most probable from differential measurements are:

a) decreases in $\sigma_{c}$ and inelastic scattering for U-238, and b) an increase in $\sigma_{f}$ for $\mathrm{Pu}-239$. Studies by Pitterle, (14) Küsters, (15) Kato, (16) Hummel, ${ }^{(17)}$ and Zolotar ${ }^{(18)}$ show that similar substantial changes from Version 1 ENDF/B data are required to obtain good agreement between calculated and measured integral quantities. Although the cross sections used for this analysis have already been adjusted in some of these directions, additional changes could be made and still be consistent with differential data.

The value of $\sigma_{c}$ for U-238 from 20 to several hundred $\mathrm{keV}$ is uncertain. Independent absolute measurements disagree by as much as $30 \%$. Below $20 \mathrm{keV}$ there is weak indication from results obtained by Glass, et.a1 that $\Gamma_{\gamma}$ is $20 \%$ lower than obtained by Garg ${ }^{(10)}$. Zolatar's ${ }^{(18)}$ calculations show variations of several percent in the multiplication factors 
of fast assemblies due to the inelestic scattering cross section. A large uncertainty in $\sigma_{f}$ of $\mathrm{Pu}-239$ results from normalization of the experimental results. Hummel $(17)$ shows a variation of $5 \%$ in the multiplication factor of ZPR-III, Assembly 48 due to this difference in normalization. Thus, a reasonable increase in the values used for the current calculations could also increase $k$ on the order of 1 percent.

\section{Differences from Data Used in Earlier Design Calculations}

A comparison of the nuclear data used for these calculations and that used for the original SEFOR computations shows the following major differences.

a) Pu-239. There have been two major changes in Pu-239 nuclear data since the generation of the original SEFOR values. These are: 1) the identification of extremely broad fission resonances, associated with the $J=0$ spin state; and 2) differential measurements indicating that the alpha value below $15 \mathrm{keV}$ is from 30 to 70 percent higher than that assumed earlier. These two changes result in group constants for $\mathrm{Pu}-239$ which have a 30 to 50 percent higher alpha value below $10 \mathrm{keV}$, but one which decreases with self-shielding of the Pu-239.

The fission cross sections used in both the earlier and present calculations are based on the measurements of White ${ }^{(7)}$ above $10 \mathrm{keV}$. However, the dip in White's data between 20 and $100 \mathrm{keV}$ has been smoothed out in the new set, making the present data as much as $8 \%$ higher than the old SEFOR values in this range. Below $10 \mathrm{keV}$ the new values tend to be somewhat lower than the original data set, as a result of the recent analysis of the $\mathrm{Pu}-239$ alnha value, although both are close to James' values. (20) 
b) U-238. In the energy range above $40 \mathrm{keV}$, the capture cross section has been reduced below the values of Barry, Bunce and White ${ }^{(12)}$ used origina1ly due to more recent measurements by Pönitz, ${ }^{(11)}$ and others. Between 10 and $40 \mathrm{keV}$, the present values are significantly higher than the old SEFOR values. The resolved resonance data of Garg ${ }^{(10)}$, used previously, have been augmented by a p-wave contribution, which increases the capture cross section, but is still significantly lower than that of the ENDF/B file. ${ }^{(6)}$

Ineleastic scattering by U-238 is increased, and produces a much softer spectrum of secondary neutrons in the current file. This is a result of level data measured by Barnard, et a1. (21)

c) Pu-240. The major change in Pu-240 cross sections is a substantial reduction in the capture cross section. Between 20 and $200 \mathrm{keV}$ the reduction has been about 50 percent, while it is somewhat less at lower energies. The inclusion of non-zero $\sigma_{f}$ values at sub-threshold energies is also a difference.

d) Other Materials. There have been no significant changes in the basic cross sections of $\mathrm{Be}, \mathrm{Na}, 0, \mathrm{Fe}, \mathrm{Cr}$, and $\mathrm{Ni}$. 
FUEL PELLET $0.875 \pm 0.001$ DIA.

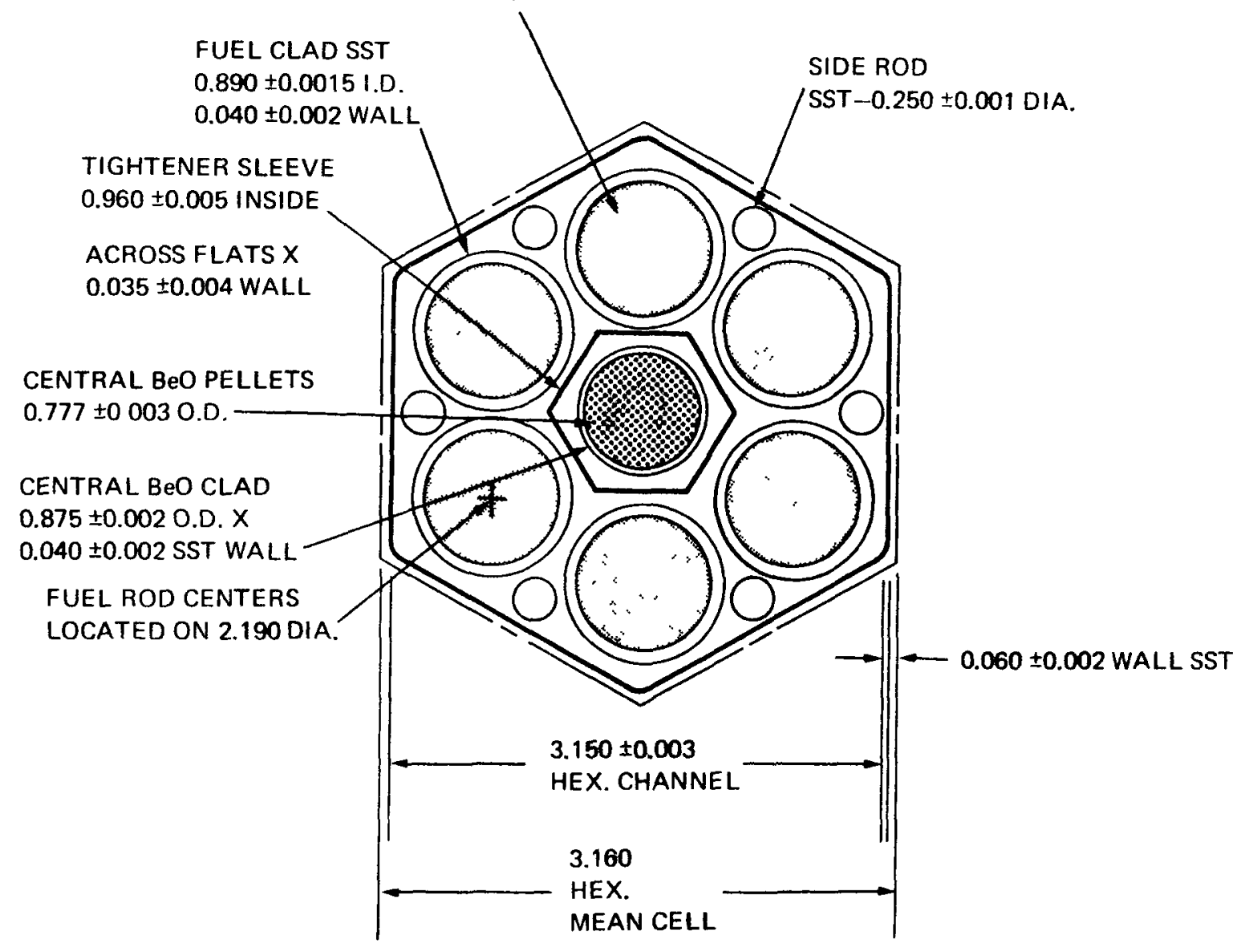

FIGURE 1-1. SEFOR FUEL CHANNEL 


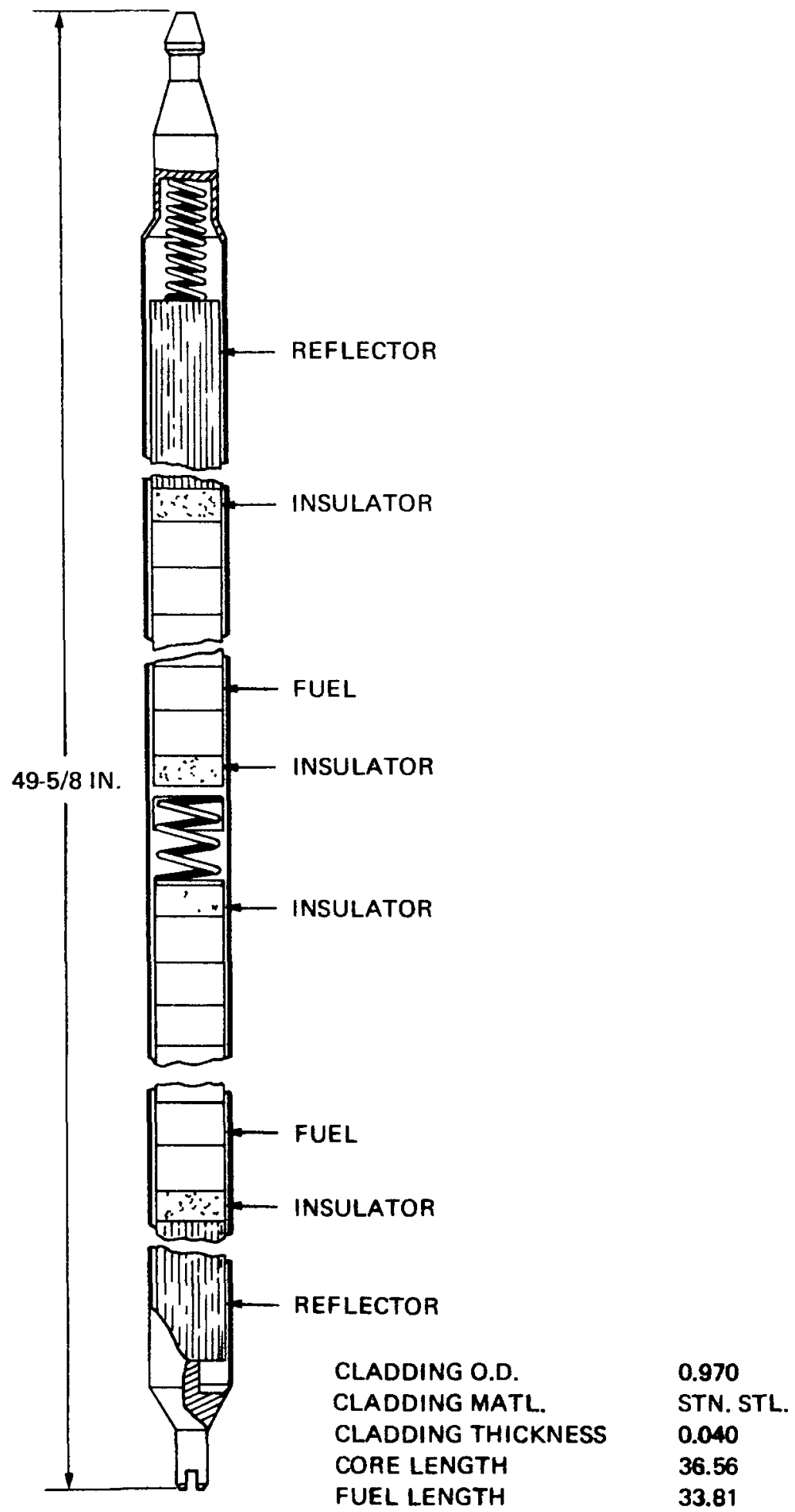

FIGURE 1-2. SEFOR FUEL ROD 


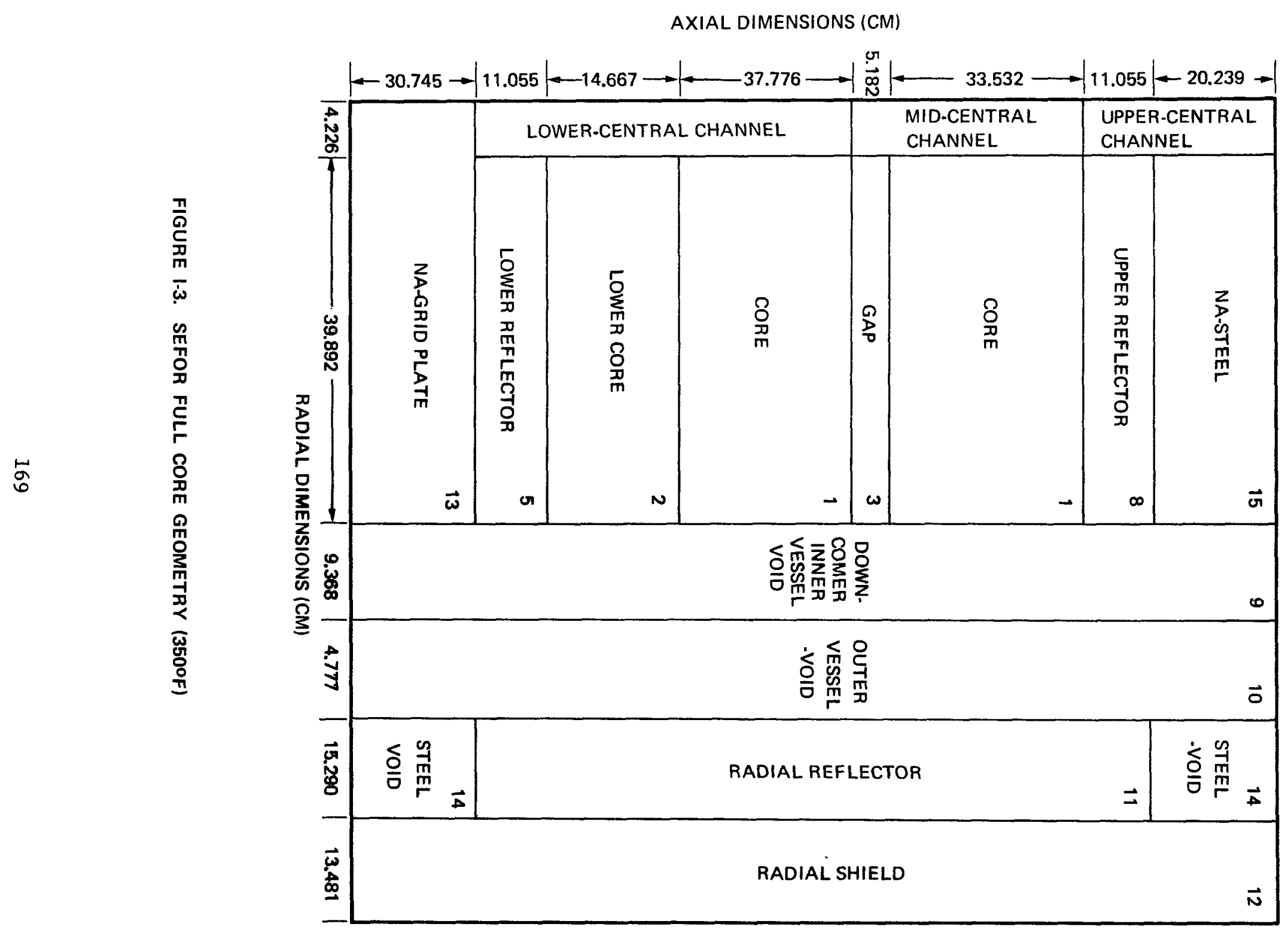


TABLE I-1

ROD COMPOSITIONS

\section{Material}

Fuel (1)

$\mathrm{UO}_{2}$

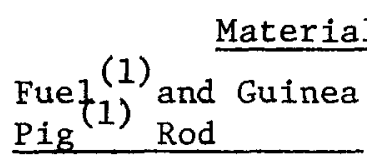

$$
0.8384^{(2)}
$$

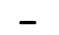

0.1616

$-$

$-$

$-$

$-$
Material Volume Fractions in the Core Region of the Reactor

Upper Pightener Rods $(4)$
Portion Lower Portion Core Poison Stainless
of Core

$2^{\operatorname{Rod}}$

$\mathrm{Be} 0$

SS-304 (in Stee1 Rod)

Void

Central Shaft(SS-304)

inside Poison Rod

-
-
0.1745
0.8255
-
-
-

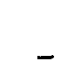

(1) $(\mathrm{Pu}-239+\mathrm{Pu}-241) /(\mathrm{U}+\mathrm{Pu})=\left\{\begin{array}{l}\mathrm{u} .187 \text { for standard fuel rod } \\ 0.250 \text { for guinea pig rods }\end{array}\right.$

(2) Exclusive of gap regions where the fuel is replaced by a smeared composition of $37.5 \%$ UO 2 , $3.1 \%$ inconel, $15.1 \% \mathrm{SS}-304$, and $44.3 \%$ void.

(3) Includes additional ss-316 inside the cladding.

(4) In the special tightener rods used for material reactivity worth measurements the Be0 and void was replaced with SS-304 at a smeared density of $7 \mathrm{~g} / \mathrm{cc}$. 
TABLE I-1 (Continued)

ROD COMPOS ITIONS

Material

$\mathrm{UO}_{2}$

$\mathrm{Ni}$

SS-316

$\mathrm{Be} 0$

Void

Central Shaft(SS-304)

inside Poison Rod

SS-304 (in Stee1 Rod)
Material Volume Fractions in the Axial Reflector Regions of the Reactor

Fue $f^{(1)}$ and Guinea
Pig

$\frac{\text { Tightener Rod }}{\text { Upper Lower }}$

Core Poison Rod

Upper

Lower

Stainless $\mathrm{UO}_{2}$ Rod Reflector Reflector

Reflector Reflector

Stee1 Rod

$2^{\text {Rod }}$

0.0725

0.7659

$-$

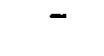

$$
0.4223
$$

0.4730

0.1609

0.1873

0.0710

0.0507

0.3458

0.2890

$-$

$-$

-
0.8128
0.1616

0.7897

0.1616

$-$

0.0487

0.0256
0.0725

0.7659

$-$

0.1616

0.0281

$-$

0.8103

(1) $\quad(\mathrm{Pu}-239+\mathrm{Pu}-241) /(\mathrm{U}+\mathrm{Pu})=\left\{\begin{array}{l}0.187 \text { for standard fuel rods } \\ 0.250 \text { for guinea pig rods }\end{array}\right\}, \quad \mathrm{Pu}-240 / \mathrm{Pu}=0.0824$ 
TABLE I-2

UNIT CELL COMPOSITION

\begin{tabular}{lccc} 
Composition & \multicolumn{3}{c}{ Ce11 Volume Fraction } \\
\cline { 2 - 4 } & $\begin{array}{c}\text { Standard Core } \\
\text { Unit Cel1 }\end{array}$ & $\begin{array}{c}\text { Unit Ce11 } \\
\text { in 1ower } \\
\text { portion of Core }\end{array}$ & $\begin{array}{l}\text { Gap Region } \\
\text { in Core }\end{array}$ \\
\hline Fue1 / U0 2 & 0.4316 & 0.4316 & 0.1619 \\
Be0 & 0.0574 & 0.0408 & 0.0574 \\
Fuel Clad(SS-316) & 0.0832 & 0.0832 & 0.0832 \\
Be0 Clad(SS-316) & 0.0121 & $0.0224 *$ & 0.0121 \\
Tightener Sleeve(SS-304) & 0.0178 & 0.0178 & 0.0178 \\
Channel and Side & 0.1133 & 0.1133 & $0.1784 * *$ \\
Rods (SS-304) & & & 0.2846 \\
Sodium & 0.2846 & 0.2846 & 0.0133 \\
Inconel & - & - & 0.1913 \\
Void & - & 0.0063 &
\end{tabular}

* Includes extra cladding around BeO

** Includes extra SS-304 in the gap portion of six fuel rods. 
TABLE I-3

SEFOR FULL-CORE (648 FUEL ROD) VOLUME FRACTIONS

Volume Fraction by Region

\begin{tabular}{|c|c|c|c|c|c|c|c|c|}
\hline Composition & 1 & 2 & 3 & 4 & 5 & 6 & 7 & 8 \\
\hline Fuel & 0.4316 & 0.4316 & - & - & - & - & - & - \\
\hline $\mathrm{UO}_{2}$ & - & - & 0.1619 & - & 0.0373 & - & - & 0.0373 \\
\hline SS -316 & 0.0953 & 0.1056 & 0.0953 & - & 0.0962 & - & - & 0.0944 \\
\hline SS-304 & 0.1311 & 0.1311 & 0.1962 & 0.3056 & 0.1215 & 0.1177 & 0.1812 & 0.1383 \\
\hline Incone1 & - & - & 0.0133 & - & - & - & - & - \\
\hline $\mathrm{Be} 0$ & 0.0574 & 0.0408 & 0.0574 & - & 0.0035 & - & - & 0.0049 \\
\hline Sodium & 0.2846 & 0.2846 & 0.2846 & 0.6944 & 0.2908 & 0.6944 & 0.6944 & 0.2871 \\
\hline Ni (Fuel Rod) & - & - & - & - & 0.3943 & - & - & 0.3943 \\
\hline Ni (Tightener Rod) & - & - & - & - & 0.0330 & - & - & 0.0294 \\
\hline Void & - & 0.0063 & 0.1913 & - & 0.0236 & 0.1879 & 0.1244 & 0.0145 \\
\hline
\end{tabular}


TABLE I-3 (Continued)

SEFOR FULL-CORE (648 FUEL ROD) VOLUME FRACTIONS

Volume Fraction by Region

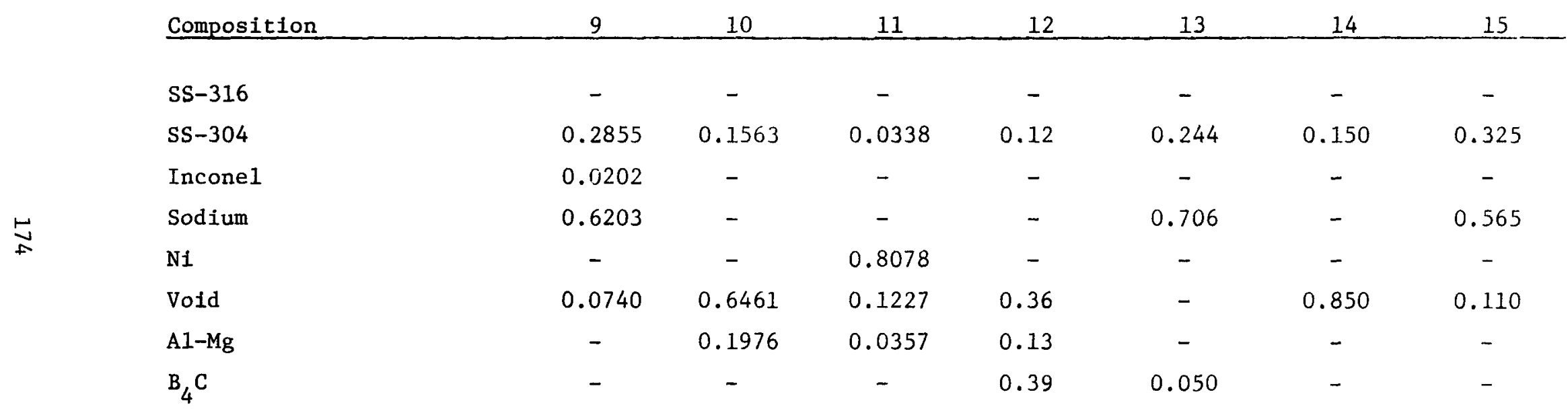


GEAP-13588

TABLE I-4

\section{SEFOR MATERIAL DENSITIES \& $350^{\circ} \mathrm{F}$}

\section{Material}

Fuel - Pu - U Oxide

Oxygen $/$ meta $1=1.99$

$(\mathrm{Pu}-239+\mathrm{Pu}-241) /(\mathrm{Pu}+\mathrm{U})=0.1870$

$\mathrm{Pu}-240 / \mathrm{Pu}=0.0824$

$\mathrm{U}-235 / \mathrm{U}=0.0022$

Uranium in insulator pe]lets

ard special $\mathrm{UC}_{2}$ rod

. Oxygen $/$ metal $=2.01$ )

Stainless Steel 316 and 304

Incone1

$\mathrm{Be} 0$

$\mathrm{Na}$

$\mathrm{B}_{4} \mathrm{C}$ in special poison core rod

$\mathrm{B}-10 / \mathrm{B}=0.199$

$\mathrm{B}_{4} \mathrm{C}$ in radial shield

$\mathrm{Ni}$ in radial reflector

$\mathrm{Ni}$ in axial reflector

$\mathrm{Al}-\mathrm{Mg}(96 \% \mathrm{Al}, 4 \% \mathrm{Mg})$ $\underline{\text { Density* }(g / c c)}$

9.587

9.786

7.961

8.288

2.731

0.9131

1.415

1.600

8.833

8.433

2.669

*Some of these densities are "smeared" to include void regions and should be used only with the volume fractions indicated in Tables I-1 through $\mathrm{I}-3$. 
TABLE I-5

SEFOR THIRTEEN AND FOUR GROUP STRUCTURE

\section{Group Structure}

\begin{tabular}{rcl} 
Group Number & Lethargy Interval & $\begin{array}{l}\text { Lower Energy } \\
\text { of Group }\end{array}$ \\
\hline 1 & 1.500 & $2.23 \mathrm{MeV}$ \\
2 & 1.000 & $0.821 \mathrm{MeV}$ \\
3 & 0.500 & $0.498 \mathrm{MeV}$ \\
4 & 0.500 & $0.302 \mathrm{MeV}$ \\
5 & 0.500 & $0.183 \mathrm{MeV}$ \\
6 & 0.600 & $0.101 \mathrm{MeV}$ \\
7 & 0.800 & $45.2 \mathrm{KeV}$ \\
8 & 1.100 & $15.0 \mathrm{KeV}$ \\
9 & 1.333 & $3.96 \mathrm{KeV}$ \\
10 & 1.367 & $1.01 \mathrm{KeV}$ \\
11 & 1.167 & $315 \mathrm{eV}$ \\
12 & 1.233 & $91.7 \mathrm{eV}$ \\
13 & - & thermal
\end{tabular}

\section{Group Structure}

$\begin{array}{lcl}1 & 3.000 & 0.498 \mathrm{MeV} \\ 2 & 1.300 & 0.136 \mathrm{MeV} \\ 3 & 2.533 & 10.8 \mathrm{KeV} \\ 4 & - & \text { thermal }\end{array}$




\section{APPENDIX II}

Heterogeneity effects on reactivity may be decomposed into four contributions:

1. High Energy Heterogeneity Effect

This effect is caused by an increased fission probability of fission neutrons in the fuel plates or rods, which may be described by a fuel flux peak in the spatial distribution of high energy neutrons. The high energy heterogeneity effect is the most important one in the reactor considered and will be estimated below.

2. Heterogeneity Effect on Resonance Self-shielding This effect is caused by flux depressions in the fuel at resonance energies. It was taken into account in calculating the self-shielding factors by applying Bell's (3) approximation, which assumes a flat flux distribution throughout the cell between resonances.

3. "Smooth Shielding" of Fuel Cross Sections in the Lattice Cell This is caused by low energy fuel flux depression between resonances, and is not taken into account by using Bell's (3) approximation for self-shielding factors. 


\section{Heterogeneity Effects on Leakage}

They are caused by the relatively large mean free neutron paths in certain regions of the lattice cell and generally result in increased effective diffusion coefficients for the lattice.

Results of estimation of the effects 1,3 , and 4 for SEFOR and ZPR-III, Assembly 47 are 1isted in the following table:

\begin{tabular}{llllll} 
& $\begin{array}{c}\text { High Energy } \\
\text { Effect }\end{array}$ & $\begin{array}{c}\text { "Smooth" } \\
\text { Shielding } \\
\text { Effect }\end{array}$ & $\begin{array}{l}\text { Leakage } \\
\text { Effect }\end{array}$ & Total \\
\cline { 2 - 2 } & & & & & \\
ZPR-TII, Assembly 47 & +0.008 & & -0.002 & -0.002 & +0.004 \\
SEFOR & +0.006 & -0.002 & -0.001 & +0.003
\end{tabular}

The estimates are based on calculated and measured effects in ZPR-III, Assembly 48 and SNEAK, Assembly $3 \mathrm{~A}-1$ and $3 \mathrm{~A}-2$. Extrapolation to SEFOR and ZPR-III, Assembly 47 was done by use of two-region models for the cells and simple transport models.

The model used for comparative estimation of the dominating high energy heterogeneity effects was based on the following considerations:

a) The contributions to the high energy effects (roughly above $0.5 \mathrm{MeV}$ ) are energy dependent, but the energy dependence is similar in the considered reactors.

b) The main contributions stem from the energy region around 2 $\mathrm{MeV}$. The neutron optical parameters of the lattice cell should be compared at that energy. 
c) For a given energy group, the contribution to the increased reactivity is roughly proportional to the relative change in the flux weighted fuel cross sections, compared to the homogeneous case:

$$
\frac{\Delta k_{\text {eff }}}{k_{\text {eff }}} \sim \frac{\sum_{\text {fuel }} \frac{\left(\phi_{\text {fuel }}\right.}{\Sigma_{\text {fuel }}}-\bar{\phi} v_{\text {fuel }}}{\text { fuel }}=\frac{\phi_{\text {fuel }}-\bar{\phi}}{\bar{\phi}}
$$

$\bar{\phi}$ is the average cell flux, which is assumed to be the same as in the homogeneous case. $V_{\text {fuel }}$ is the Volume of the fuel material.

d) Multiple collison probability equations, using Wigner's rational approximation for single collision probabilities, yie1d :

$$
\frac{\phi_{\text {fuel }}}{\bar{\phi}} \approx \frac{1+\frac{V_{\text {fuel }}}{V_{s}}}{1+\frac{V_{\text {fuel }}}{V_{\text {s }}} \frac{1+\Sigma_{\text {rem,fuel }} L_{\text {fuel }} Q_{s} /\left(Q_{\text {fuel }}+Q_{s}\right)}{1+\Sigma_{\text {rem, }} L_{s} Q_{\text {fuel }} /\left(Q_{\text {fuel }}+Q_{s}\right)}}
$$

Subscript $s$ denotes the second region of the cell (structural and coolant material), $L$ is a symbol for the average chord length of the respective region, and $Q$ is a symbol for the source strength (fission sources plus downscattering sources). Subscript rem denotes removal. 
e) The sources $Q$ are usually concentrated in the fuel region of the two-medium cell; an approximation that takes into account downscattering sources in the non-fuel region is:

$$
\frac{Q_{\text {fuel }}}{Q_{\text {fuel }}+Q_{s}}=\frac{1}{1+c \frac{\left(\Sigma_{\text {rem,s }}-\Sigma_{a, s}\right) V_{s}}{\left(\Sigma_{\text {rem,fuel }}-\Sigma_{a, f u e l}\right) V_{\text {fuel }}}}
$$

Subscript a denotes absorption.

The parameter $C$ may be adjusted to reproduce results of multigroup cell calculations.

The estimation of the smooth shielding effect at low energies was done by use of the same formula for $\phi_{\text {fuel }} / \bar{\phi}$, which was used for the high energy heterogeneity effect. The source ratio $\mathrm{Q}_{\mathrm{fuel}} / \mathrm{Q}_{\mathrm{s}}$ was assumed to be proportional to $\Sigma_{\text {rem,fuel }} \mathrm{V}_{\text {fuel }}$ ' $\Sigma_{\text {rem, } s} V_{s}$. (At low energies, $Q_{\text {fuel }} / Q_{s}$ is close to 0 instead of close to 1 as at high energies.) The effect of differences in the global form of the spectrum of the reactor was neglected.

The estimation of heterogeneity effects on leakage was based on a single formula for a correction of the diffusion coefficients at high energies:

$$
\frac{D_{\text {het }}-D_{\text {hom }}}{D_{\text {hom }}} \approx\left[1+\frac{1}{\Sigma_{\text {fuel }} L_{\text {fuel }}}+\frac{1}{\Sigma_{s} L_{s}}\right]^{-1} \times \frac{\frac{\Sigma_{\text {fuel }}}{\Sigma_{s}}+\frac{\Sigma_{s}}{\Sigma_{\text {fuel }}}-2}{\frac{L_{\text {fuel }}}{L_{s}}+\frac{L_{s}}{L_{\text {fuel }}}+2}
$$


This formula was derived from Benoist's (22) expression for the diffusion coefficient in a two medium cell:

$$
3 \mathrm{D}_{\text {het }}\left(\mathrm{V}_{1}+\mathrm{V}_{2}\right)=\phi_{1} \mathrm{~V}_{1}\left(\frac{\mathrm{P}_{11}}{\Sigma_{1}}+\frac{\mathrm{P}_{12}}{\Sigma_{2}}\right)+\phi_{2} \mathrm{~V}_{2}\left(\frac{\mathrm{P}_{21}}{\Sigma_{1}}+\frac{\mathrm{P}_{22}}{\Sigma_{2}}\right)
$$

Again, Wigner's rational approximation was used for calculating the collision probabilities $P_{i k}$. Differences between $\phi_{1}$ and $\phi_{2}$ were neglected.

Cell transport theory calculations were done using the onedimensional SN1D code ${ }^{(23)}$ with 24-energy groups, 16 angles and anisotropic scattering. Table II-1 shows results for the ZPR-III Assembly 47 plate lattices and for the SEFOR rod lattice based on analysis of the cell transport calculations. It is seen that the overall high energy and low energy "smooth shielding" heterogeneity effects deduced from the txansport calculations are in good agreement with estimates based on the formulas described above. The largest difference between the values obtained using the formulas and those deduced from the transport calculations is an appreciably smaller low energy "smooth shielding" effect for SEFOR obtained from the transport calculations. This may be explained because the above formulas do not take into account the spectral difference between the SEFOR minimum critical configuration and the ZPR-III critical assembly mockup, with the latter having a somewhat softer spectrum because of a higher Be 0 content and a lower leakage. 
TABLE II-1

HETEROGENEITY EFFECTS ON REACTIVITY FOR SEFOR \& ZPR-III (ASSEMBLY 47), BASED ON SNID ${ }^{(23)}-$ RESULTS

\begin{tabular}{|c|c|c|c|}
\hline \multirow[b]{2}{*}{ LATTICE PROBLEM } & \multirow[b]{2}{*}{ SEFOR } & \multicolumn{2}{|c|}{ ZPR-III, ASSEMBLY 47} \\
\hline & & INNER CORE ZONE & OUTER CORE ZONE \\
\hline $\begin{array}{l}\text { High Energy Heterogeneity } \\
\text { Effect }(a)\end{array}$ & +0.005 & +0.0056 & +0.0171 \\
\hline $\begin{array}{l}\text { "Smooth" Low Energy (a) } \\
\text { Heterogeneity Effect }\end{array}$ & -0.0004 & -0.0015 & -0.0041 \\
\hline Sum & +0.0047 & +0.0041 & +0.0130 \\
\hline $\begin{array}{l}\text { Statistical Weight of }(b) \\
\text { the Lattice Zone }\end{array}$ & 0.82 & 0.64 & 0.18 \\
\hline $\begin{array}{l}\text { Weighted Reactivity } \\
\text { Contribution }\end{array}$ & +0.0038 & +0.0026 & +0.0024 \\
\hline Sum for the Reactor & +0.0038 & +0.0 & 50 \\
\hline
\end{tabular}

(a) For the corresponding unreflected critical lattice.

(b) The statistical weight of the total core is not one because the lattice does not extend to the extrapolated boundary (core dimension plus reflector savings). 
GEAP- 13588

APPENDIX III

\section{COUNTING RATE CORRECTIONS AND EFFECTS OF DETECTOR LOCATION}

\section{COUNT RATE CORRECTIONS}

The count rate data obtained during the initial approach to critical are summarized in Tables III-1 through III-3. The count rates on each in-core counting channel were generally repeated at least five times to accumulate a total of 10,000 counts, in order to obtain better than $1 \%$ statistical accuracy. As discussed in Section 2.2.1, the fuel was loaded with the reflectors completely lowered. Count rates were taken with the reflectors lowered; a specified number of fuel rods were loaded, the reflectors were raised, and count rates were recorded again. The counting rates were monitored throughout the fuel loading however, and some of the count rates obtained during a loading increment are shown in Tables III-1 and III-2. As discussed in Section 2.2.1, the first loading increment was broken into two steps 1 (a) and 1(b) to allow insertion of the in-core detectors. The corrections for the count rates on the in-core detectors became quite large with the reflector raised after approximately 520 rods had been loaded, and they were switched to the current mode of operation for loading step number thirteen.

As the initial SEFOR loading approached the critical size, the count rates on the He-3 in-core detectors became very high, (see Table III- I for example) and two indications of a need for dead time correction were observed. One, the ratio of the observed count rates on the two He-3 detectors did not remain constant, but instead exhibited a definite trend with increasing count rate. This is demonstrated in Figure III-1 
and can be observed from the uncorrected count rate data in Tables III-1 and III-2. Two, the ratio of the count rates in the He-3 detectors to the count rates in the source range monitors (SRM's) also exhibited a definite trend with increasing count rate (see Figure III-2 which was obtained from the data in the tables).

Because of the relatively low count rates in the source range monitors, it was felt that no dead time corrections were required for these detectors. This assumption appears to be born out by the data shown in Figure III-3 and Table III-3. Although there is some scatter, the ratio of the count rates in the two source range monitors appears to be independent of the absolute counting rate and no definite trend with increasing count rate is indicated.

In order to estimate the appropriate dead time corrections for the two He-3 detectors, a paralyzable type ${ }^{(24)}$ relationship between the observed He-3 counting rate $y$ and the true He-3 counting rate $x$ of the form

$$
y=x \exp (-\tau x)
$$

was assumed, where $\tau$ is the dead time. In addition, it was assumed that with the reflectors raised* the ratio of the true He- 3 counting rate $x$ to the true average SRM count rate $z$ is, at lease on the average, constant; i.e.,

$$
\mathrm{x} / \mathrm{z}=\mathrm{C}=\text { constant }
$$

*The data obtained with the reflectors in the raised, rather than lowered, position was used in order to emphasize the difference between the "true" and "observed" counting rates and thus the effect of the dead time correction. 
Although this latter assumption simplifies the analysis and provides for a reasonable correlation of results, it is not a unique choice and other, perhaps equally valid, assumptions could be postulated.

From these two assumptions, an expression of the form

$$
\ln (y / z)=\ln C-(\tau C) z
$$

was used to determine the parameters " $1 n C$ " and " $\tau$ C", and thus the dead time $\tau$ from a least squares $f$ it to the observed values of in $(y / z)$. The experimental values, as well as the fitted curves, are shown in Figure III-2.

The dead times obtained from the fit were $12.23 \mu-\mathrm{sec}$ for detector $\#_{1} 1$ and $7.91 \mu-\mathrm{sec}$ for detector $\# 2$. These dead times were used with the expression for the paralyzable type (24) system to obtain estimates of the true He-3 counting rates. The corrected ratio of count rates between the two He-3 detectors is shown in Figure III-1 along with the uncorrected ratio. As would be expected for the true counting rate ratio, the corrected ratio appears to be essentially constant and does not exhibit the previously noted trend demonstrated by the raw data. The fitted dead times thus appear to provide for an adequate description of the true counting rates. The corrected count rates are tabulated in Tables III-1 and III 2 .

\section{EFFECT OF DETECTOR LOCATION}

When the reflectors were raised, the counting rates on the two source range monitors located below the core increased by a larger factor than did the counting rates on the two in-core detectors. This effect is demonstrated by the data in Figure III-4. Although the 
corrected data shows a much smaller change than the raw data, the ratio of the reflector up to reflector down count rates in the SRM's divided by the corresponding ratio for the He-3 detectors increases slightly with increasing core size to a value of $\sim 1.4$ for the critical core.

The fact that the reflector up-to-down count rate ratio is different for detectors located in different positions and that this ratio is a function of core size should not be surprising. Even the simple one group model described in Appendix IV shows both of these effects when reflector-up-to-reflector down flux ratios at the center are compared to the corresponding flux ratios at different radial locations. This effect, although interesting, does not, of course, influence reflector calibrations by period measurements, power calibrations, etc. 
$\underline{\text { TABLE III-1 }}$

COUNT RATES ON IN-CORE He-3 DETECTOR \#1

\begin{tabular}{|c|c|c|c|c|c|}
\hline \multirow{3}{*}{$\begin{array}{l}\text { Loading Step } \\
\text { Number }\end{array}$} & \multirow{3}{*}{$\begin{array}{l}\text { Number of Fue } \\
\text { Rods in Core }\end{array}$} & \multicolumn{4}{|c|}{ Average Count Rate (counts/sec.) } \\
\hline & & \multicolumn{2}{|c|}{ Reflectors Down } & \multicolumn{2}{|c|}{ Reflectors Up } \\
\hline & & Observed & Corrected $*$ & Observed & Corrected* \\
\hline $1(\mathrm{a})$ & 36 & 113.3 & 113.4 & 138.6 & 138.8 \\
\hline $1(\mathrm{~b})$ & 42 & 130.7 & 130.9 & - & - \\
\hline $1(b)$ & 48 & 147.0 & 147.3 & - & - \\
\hline $1(\mathrm{~b})$ & 54 & 161.3 & 161.6 & - & - \\
\hline $1(b)$ & 66 & 192.9 & 193.3 & - & - \\
\hline $1(\mathrm{~b})$ & 108 & 346.0 & 347.5 & 392.4 & 394.3 \\
\hline 2 & 216 & 926.2 & 936.8 & 1067 & 1081 \\
\hline 3 & 264 & 1267 & 1287 & - & - \\
\hline 3 & 282 & 1417 & 1442 & 1706 & 1742 \\
\hline 4 & 288 & 1480 & 1507 & - & - \\
\hline 4 & 306 & 1691 & 1727 & - & - \\
\hline 4 & 348 & 2245 & 2310 & 2921 & 3031 \\
\hline 5 & 402 & 3085 & 3210 & 4423 & 4684 \\
\hline 6 & 456 & 4415 & 4676 & 7528 & 8336 \\
\hline 7 & 486 & 5575 & 5999 & 11380 & 13400 \\
\hline 8 & 504 & 6603 & 7212 & 16090 & 20730 \\
\hline 9 & 516 & 7567 & 8385 & 21670 & 32080 \\
\hline 10 & 524 & 8060 & 8997 & 24970 & 41460 \\
\hline 11 & 531 & 8492 & 9543 & - & - \\
\hline 12 & 534 & 8647 & 9742 & - & - \\
\hline
\end{tabular}

*Using a paralyzable type dead time of $12.23 \mu \mathrm{sec}$. 
$\underline{\text { TABLE III-2 }}$

COUNT RATES ON IN-CORE He-3 DETECTOR 非 2

\begin{tabular}{|c|c|c|c|c|c|}
\hline \multirow{3}{*}{$\begin{array}{l}\text { Loading Step } \\
\text { Number }\end{array}$} & \multirow{3}{*}{$\begin{array}{l}\text { Number of Fuel } \\
\text { Rods in Core }\end{array}$} & \multicolumn{4}{|c|}{ Average Count Rate (counts/sec.) } \\
\hline & & \multicolumn{2}{|c|}{ Reflectors Down } & \multicolumn{2}{|c|}{ Reflectors Up } \\
\hline & & Observed & Corrected* & Observed & Corrected ${ }^{*}$ \\
\hline $1(\mathrm{a})$ & 36 & 133.9 & 134.0 & 164.4 & 164.6 \\
\hline $1(\mathrm{~b})$ & 42 & 153.1 & 153.2 & - & - \\
\hline $1(b)$ & 48 & 172.9 & 173.1 & - & - \\
\hline $1(\mathrm{~b})$ & 54 & 192.0 & 192.3 & - & - \\
\hline $1(\mathrm{~b})$ & 66 & 230.2 & 230.6 & - & - \\
\hline $1(\mathrm{~b})$ & 108 & 417.0 & 418.4 & 469.8 & 471.5 \\
\hline 2 & 216 & 1120 & 1131 & 1288 & 1302 \\
\hline 3 & 264 & 1536 & 1555 & - & - \\
\hline 3 & 282 & 1712 & 1735 & 2065 & 2099 \\
\hline 4 & 288 & 1786 & 1812 & - & - \\
\hline 4 & 306 & 2052 & 2086 & - & - \\
\hline 4 & 348 & 2727 & 2788 & 3551 & 3655 \\
\hline 5 & 402 & 3748 & 3865 & 5390 & 5636 \\
\hline 6 & 456 & 5409 & 5657 & 9294 & 10070 \\
\hline 7 & 486 & 6868 & 7275 & 14220 & 16160 \\
\hline 8 & 504 & 8109 & 8686 & 20430 & 24870 \\
\hline 9 & 516 & 9304 & 10080 & 28370 & 38460 \\
\hline 10 & 524 & 9918 & 10800 & 33710 & 50100 \\
\hline 11 & 531 & 10410 & 11390 & - & - \\
\hline 12 & 534 & 10640 & 11670 & - & - \\
\hline
\end{tabular}

*Using a paralyzable type dead time of $7.91 \mu \mathrm{sec}$. 
TABLE III-3

COUNT RATES ON START-UP CHANNELS

(SOURCE RANGE MONITORS)

\begin{tabular}{|c|c|c|c|c|c|}
\hline \multirow{4}{*}{$\begin{array}{l}\text { Loading Step } \\
\text { Number }\end{array}$} & \multirow{4}{*}{$\begin{array}{l}\text { Ilumber of Fuel } \\
\text { Rods in Core }\end{array}$} & \multicolumn{4}{|c|}{ Counts per Minute } \\
\hline & & \multirow{2}{*}{\multicolumn{2}{|c|}{$\frac{\text { SRM No. } 1}{\text { Reflectors }}$}} & \multicolumn{2}{|c|}{ SRM No. 2} \\
\hline & & & & & ectors \\
\hline & & Down & Up & Down & Up \\
\hline 1 (a) & 36 & 18 & 24 & 18 & 24 \\
\hline $1(\mathrm{~b})$ & 108 & 71 & 104 & 76 & 103 \\
\hline 2 & 216 & 200 & 305 & 205 & 326 \\
\hline 3 & 282 & 302 & 507 & 326 & 529 \\
\hline 4 & 348 & 488 & 874 & 507 & 932 \\
\hline 5 & 402 & 660 & 1355 & 715 & 1436 \\
\hline 6 & 456 & 960 & 2432 & 1047 & 2616 \\
\hline 7 & 486 & 1253 & 3900 & 1341 & 4203 \\
\hline 8 & 504 & 1459 & 5907 & 1602 & 6309 \\
\hline 9 & 516 & 1728 & 9108 & 1823 & 9614 \\
\hline 10 & 524 & 1834 & 11950 & 1959 & 12800 \\
\hline 11 & 531 & 1958 & 15980 & 2056 & 16980 \\
\hline 12 & 534 & 1986 & 18320 & 2122 & 19580 \\
\hline 13 & 540 & 2111 & 26150 & 2232 & 27580 \\
\hline 14 & 545 & 2266 & 78960 & 2366 & 82360 \\
\hline 15 & 546 & 2292 & 95640 & 2382 & 99950 \\
\hline 16 & 547 & 2281 & 142300 & 2458 & 148900 \\
\hline 17 & 548 & 2274 & 271100 & 2406 & 281900 \\
\hline 18 & 549 & 2454 & 690300 & 2700 & 753500 \\
\hline 19 & 550 & & Critical & & Critical \\
\hline
\end{tabular}




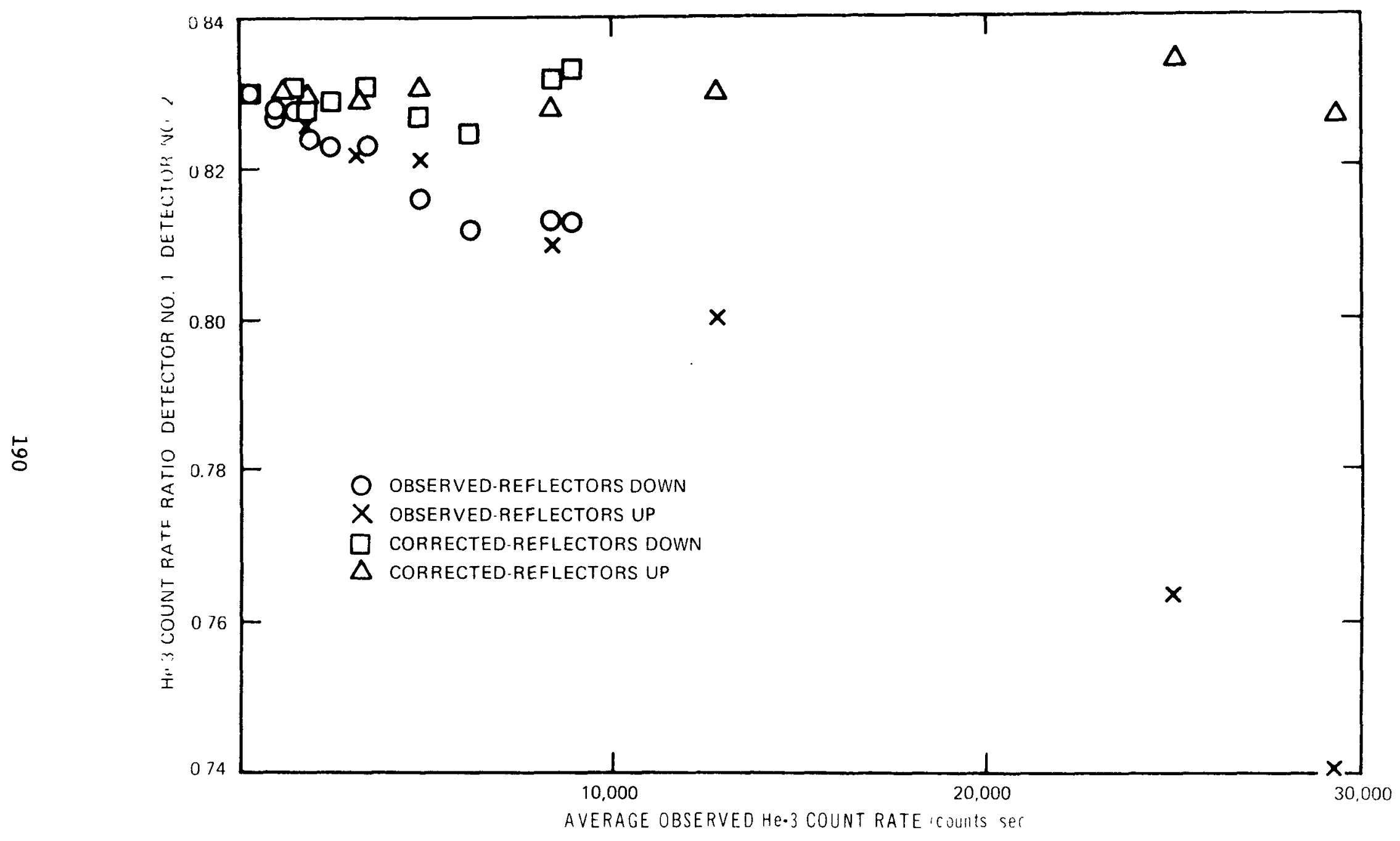

FIGURE III-1. RATIO OF COUNTING RATES IN HE-3 DETECTORS 


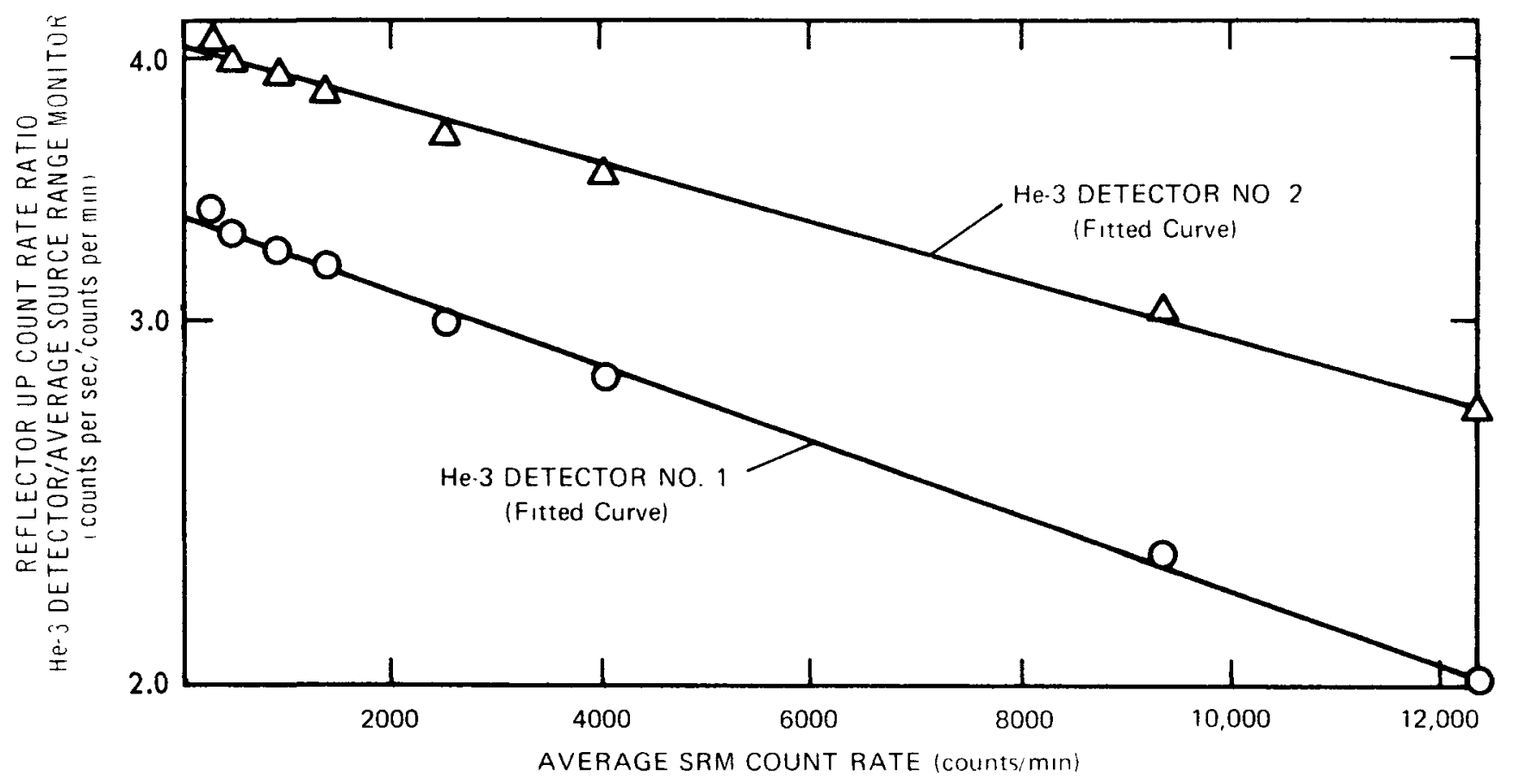

FIGURE III-2. COUNT RATE RATIO BETWEEN HE-3 DETECTOR AND SOURCE RANGE MONITORS 


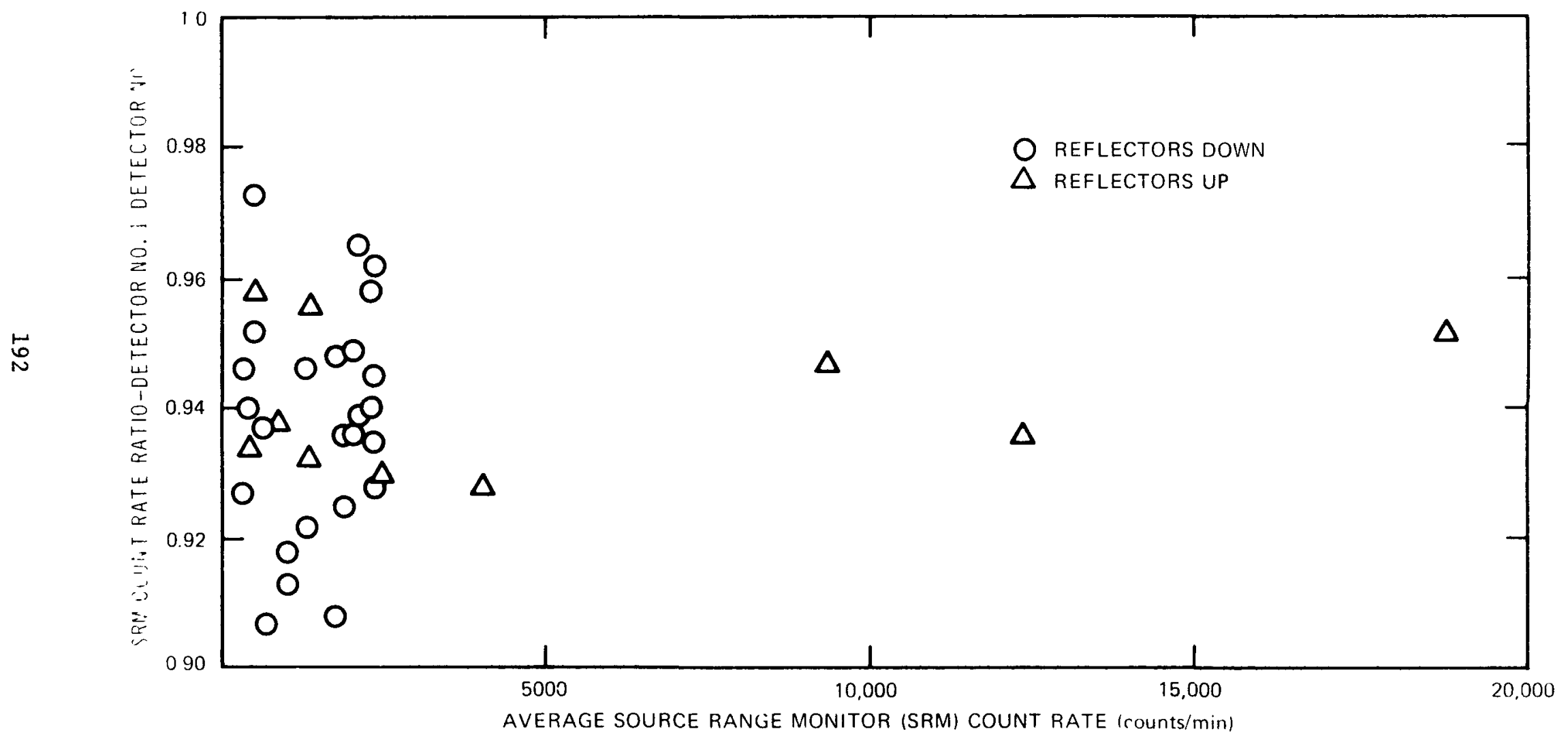




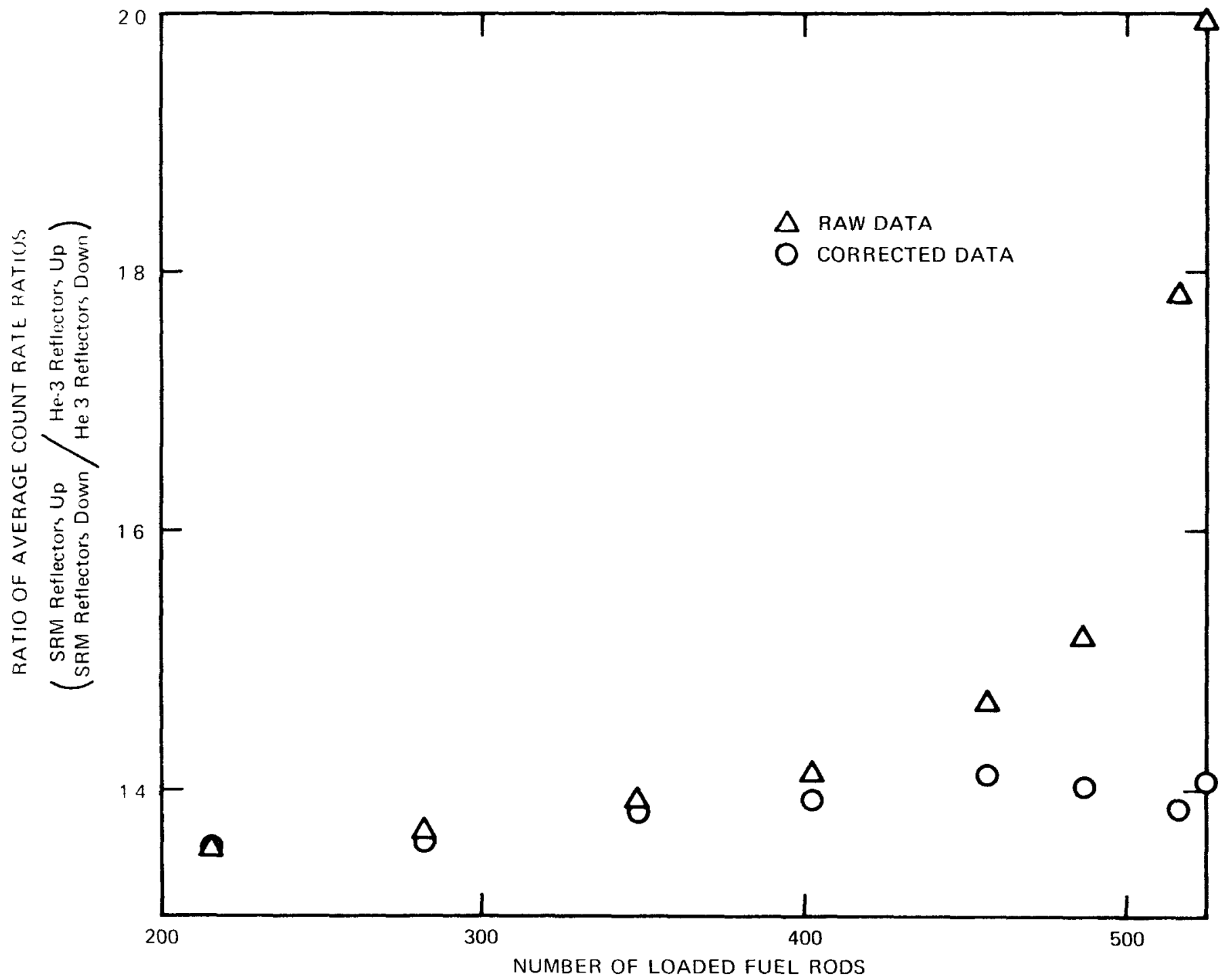

FIGURE III-4. EFFECT OF REFLECTOR POSITION ON COUNTING-RATE RATIOS 


\section{APPENDIX IV}

\section{A SIMPLE ONE-GROUP MODEL FOR THE PARTIALLY LOADED CORE}

A simplified model for the SEFOR reactor is sketched in Figure IV-1. For simplicity it was assumed that the reactor is infinite in height and that it contains a central void, a core with fissionable material and a constant source of neutrons per unit volume, a source free sodium-steel region, and a reflector. It was further assumed that all material properties of the core and sodium-steel region are constant, and that all radii except $R_{1}$ in Figure $I V-1$ are fixed. Within the core, the flux solution of the one group diffusion equation with a constant source in the core, and conventional boundary conditions can be expressed as follows.

$$
\phi(r)=\sum_{n=1}^{\infty} \phi_{n} F_{n} \quad\left(\alpha_{n} r\right)
$$

The eigen functions, $F_{n}\left(\alpha_{n} r\right)$ are defined in terms of Bessel functions of the first and second kinds by

$$
F_{n}\left(\alpha_{n} r\right)=J_{0}\left(\alpha_{n} r\right)-Y_{0}\left(\alpha_{n} r\right) J_{1}\left(\alpha_{n} R_{0}\right) / Y_{1}\left(\alpha_{n} R_{0}\right)
$$

and the expansion coefficients $\phi_{n}$ can be expressed as

$$
\phi_{\mathrm{n}}=\frac{1}{\mathrm{D}_{1}\left(\alpha_{\mathrm{n}}{ }^{2}-\mathrm{B}^{2}\right)} \quad\left[\frac{2 \mathrm{~S}\left(\mathrm{CR}_{1} / \mathrm{D}_{1}\right) \mathrm{F}_{\mathrm{n}}\left(\alpha_{\mathrm{n}} \mathrm{R}_{1}\right)}{\left(\alpha_{\mathrm{n}}{ }^{2} \mathrm{R}_{1}{ }^{2}+\mathrm{C}^{2} \mathrm{R}_{1}{ }^{2} / \mathrm{D}_{1}{ }^{2}\right) \mathrm{F}_{\mathrm{n}}{ }^{2}\left(\alpha_{\mathrm{n}} \mathrm{R}_{1}\right)-\alpha_{\mathrm{n}}{ }^{2} \mathrm{R}_{0}{ }^{2} \mathrm{~F}_{\mathrm{n}}{ }^{2}\left(\alpha_{\mathrm{n}} \mathrm{R}_{0}\right)}\right]
$$

where $B^{2}$ is the critical buckling of the system with reflectors raised (i.e., $B^{2}=\alpha_{1}{ }^{2}$ when the reactor is critical), and $S$ is the value of the constant neutron source. Except for the parameter $\mathrm{C}$, which is defined 


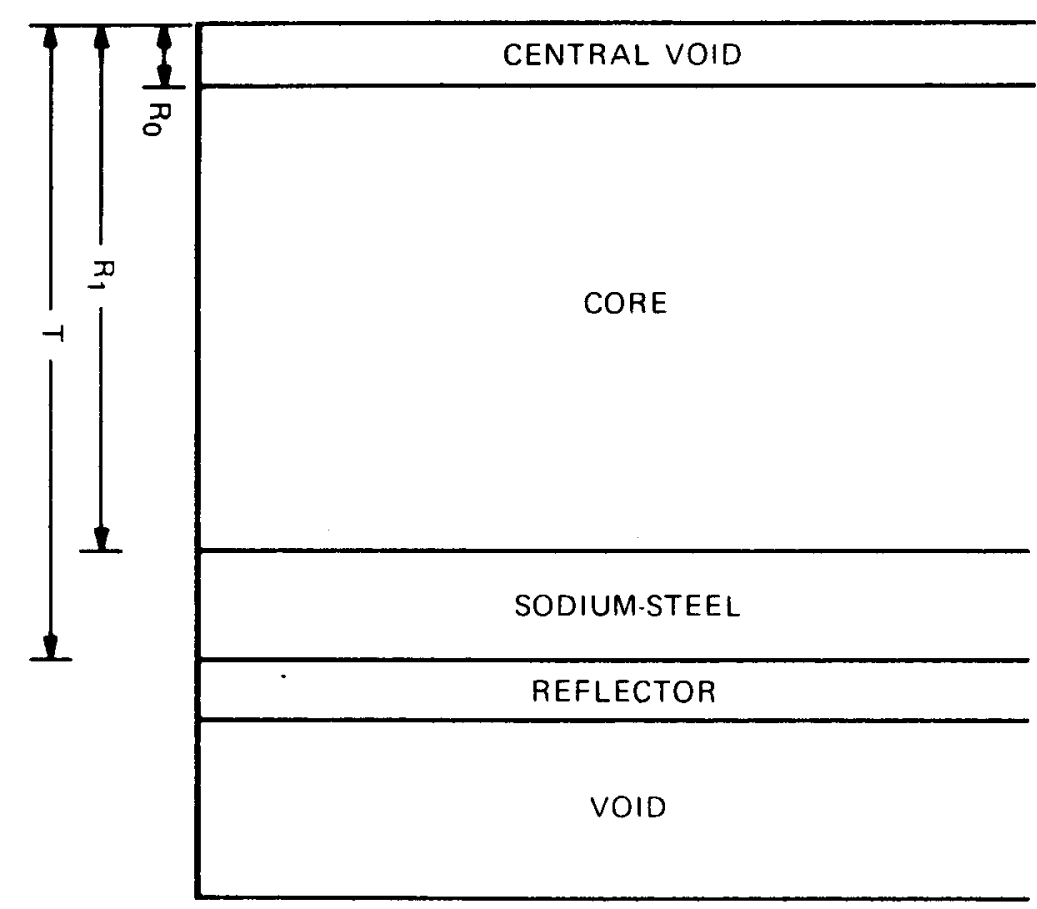


below, conventional notation is used with dimension symbols defined by Figure IV-1, with $\alpha_{n}{ }^{2}$ denoting the core bucklings, $D_{1}$ the core diffusion coefficient, etc. The bucklings are the solutions $\alpha_{n}$ of the following expression

$$
-D_{1} F_{n}^{\prime}\left(\alpha_{n} R_{1}\right) / F_{n}\left(\alpha_{n} R_{1}\right)=C
$$

where $F_{n}$ denotes the derivate of $F_{n}$ with respect to $r$, and $C$ is the neutron current to flux ratio at the outer core boundary. The parameter $\mathrm{C}$ may be written interms of the modified Bessel functions of the first and second kinds (the solution of the diffusion equation in the sodium-steel region) as follows:

$$
C=\frac{D_{2} \beta\left[K_{1}\left(\beta R_{1}\right)+A I_{1}\left(\beta R_{1}\right)\right]}{K_{0}\left(\beta R_{1}\right)-A I_{0}\left(\beta R_{1}\right)}
$$

where $D_{2}$ is the diffusion coefficient and $B$ is the reciprocal of the diffusion length in the sodium-steel region, and where $A$ is defined as follows:

$$
A=\frac{b K_{0}(\beta T)-D_{2} \beta K_{1}(\beta T)}{b I_{0}(\beta T)+D_{2} \beta I_{1}(\beta T)}
$$

The parameter $b$ in the above expression is the neutron current to flux ratio at the inner edge, $T$, of the reflector region, and is thus an indicator of reflector position (raised-reflection; lowered-no reflection). From equation (3) it is seen that the parameter $A$ is independent of core radius and depends only on reflector configuration (i.e. the parameter A takes on one value when the reflectors are in the raised position and a second value when the reflectors are lowered: these two values are independent of core size). For constant material properties in the sodium-steel region, the parameter $C$ is dependent 
only on the outer core radius, $R_{1}$, and the parameter $A$ which indicates the position of the reflectors. Thus, for constant material properties, the complete solution can be obtained by specifying the parameter $A$ and the core radius $R_{1}$. These two values are used to calculate the parameter $C$ with Equation (2), and $C$ is in turn used in Equation (1) to determine the $\alpha_{n}$, and the preceding expressions are used to determine the flux.

The flux at the core center was calculated using the values shown in Table IV-1. The diffusion coefficients and the reciprocal diffusion length of the sodium-steel region are representative one group values for the critical SEFOR reactor. The value for the parameter $A$ in the reflector-1owered condition represents a case with little neutron reflection at the outer edge of the sodium-steel region, and was calculated from Equation (3) for a value of $T=58.26 \mathrm{~cm}$ and a value for the parameter $b$ of slightly less than 0.5 . The value of $A$ in the reflector raised condition was not calculated from Equation (3) but was determined from the experimental data as described below.

\section{NORMALIZATION OF THE MODEL}

A best fit of the fundamental mode description of the flux at the core center to the experimental count rate data observed on the He-3 detectors located in the core was used to select the value of the parameter $A$ in the reflector-raised condition and to normalize the calculated flux to the observed count rates. The selection was based on the assumption that there should be a constant relationship, independent of core size and reflector configuration, between the calculated flux at the core center and the observed He-3 count rates. 
With the value of $A$ for the reflector lowered condition and the actual critical size (550 fuel rods) held constant, a value of $A$ in the reflector raised condition was selected (by trial and error) to provide the best fit to the data between core sizes of $\sim 200$ and 550 rods. The value listed in Table IV-1 (0.506) provided the best fit. Only the fundamental mode was used to represent the flux at the core center. The calculations showed that the second and higher modes contribute only a small correction to the fundamental mode solutionover the range of interest. The contribution of the higher modes was $\leqslant 3 \%$ even for fuel rod loadings as low as 20 rods. 
Parameter

Core Diffusion Coefficient

Na-Steel Region Diffusion Coefficient

Reciprocal Diffusion Length in $\mathrm{Na}-\mathrm{Steel}$ Region

Inner Core Radius

Critical Core Buckling

(550 fuel rods with a critical radius of $40.678 \mathrm{~cm}$ )

Indicator of reflector position
1) reflectors raised

2) reflectors lowered
Symbo1

$\mathrm{D}_{1}$

$\mathrm{D}_{2}$

$\beta$

$\mathrm{R}$

$\mathrm{B}^{2}$

A

0.506

A

0.620
Value

\author{
$1.200 \mathrm{~cm}$
}

$2.728 \mathrm{~cm}$

$0.010325 \mathrm{~cm}^{-1}$

$4.226 \mathrm{~cm}$

$2.2107 \times 10^{-3} \mathrm{~cm}^{-2}$ 


\section{APPENDIX V}

\section{IN-HOUR RELATION FOR SEFOR}

The in-hour equation was used to convert the measured reflector position versus period relationships into a relationship between position and reactivity. The relation between asymptotic period $(T)$ and reactivity $(K)$ for SEFOR is illustrated in Figure $V-1$. The relationship was calculated from the in-hour equation taking into account 24 delayed neutron groups, 6 each for Pu-239, Pu-240, U-238, and U-235. The resulting expression may be written as follows:

$$
K=\left(\frac{1}{T}\right) \quad\left(\frac{\ell}{\beta}\right)+\sum_{i=1}^{6} \sum_{j=1}^{4} \frac{\bar{B}_{i j} / \beta}{1+\lambda_{i j} T}
$$

with

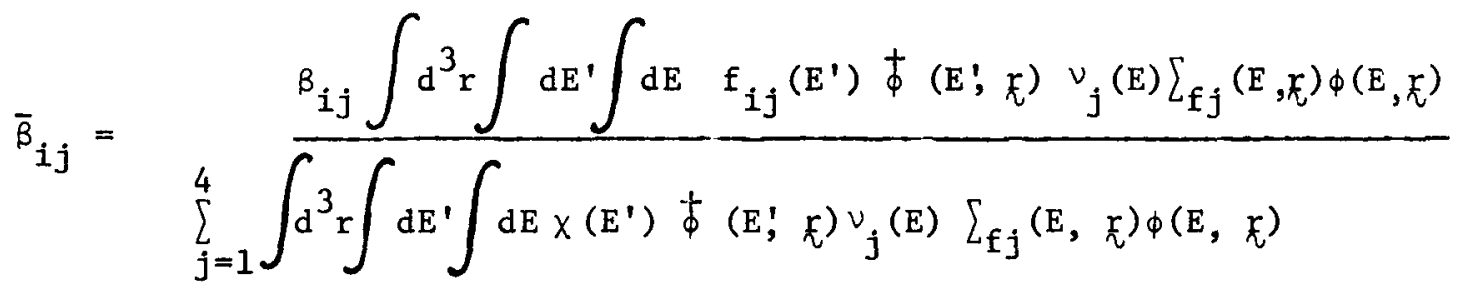

and with the effective delayed neutron fraction, $\beta$, defined by

$$
B=\sum_{i=1}^{6} \sum_{j=1}^{4} \bar{\beta}_{i j}
$$

where:

$$
\begin{aligned}
& k=\text { reactivity in dollars } \\
& \ell=\text { neutron lifetime } \\
& f_{i j}(E)=\text { energy spectrum for delay group } i \text { and isotope } j
\end{aligned}
$$




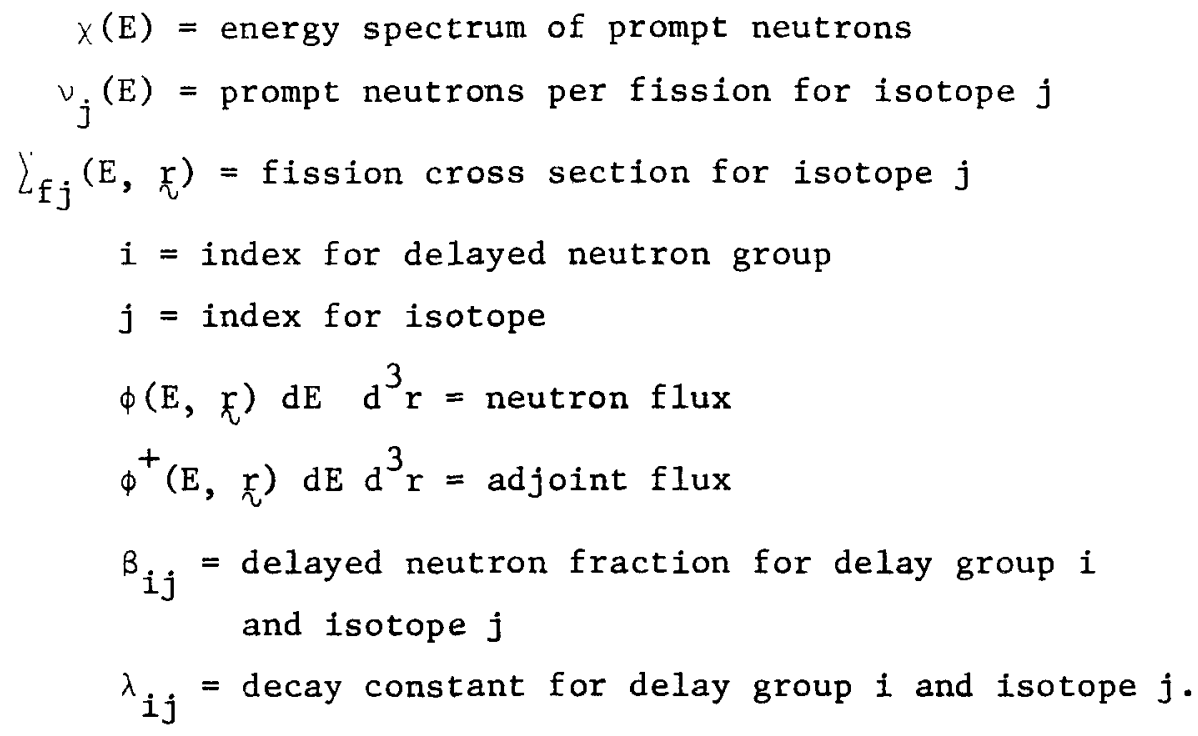

The effective delayed neutron fractions by group and by isotope, $\bar{\beta}_{i j}$, were calculated from the above expression with the BISYN ${ }^{(25)}$ program. The values for $\lambda_{i j}, \beta_{i j}$, and $f_{i j}$ (E) were taken from Keepin ${ }^{(26)}$. The calculated $\bar{\beta}_{i j}$ as well as the $\lambda_{i j}$ taken from Keepin ${ }^{(26)}$ are shown in the table. The value of the lifetime, $\ell$, inferred from the measured ratio $\ell / \beta=2.0 \times 10^{-4} \mathrm{sec}$, and the calculated effective delayed neutron fraction $B$ are also shown. 
TABLE $\quad \mathrm{V}-1$

DELAYED NEUTRON PARAMETERS

\begin{tabular}{|c|c|c|c|c|c|c|c|c|}
\hline \multirow{2}{*}{$\begin{array}{c}\text { Delay Group } \\
\text { Index }\end{array}$} & \multicolumn{2}{|c|}{$\mathrm{Pu}-239$} & \multicolumn{2}{|c|}{$\mathrm{Pu}-240$} & \multicolumn{2}{|c|}{$\mathrm{U}-238$} & \multicolumn{2}{|c|}{$\mathrm{U}-235$} \\
\hline & $\bar{\beta}_{1 j} \times 10^{4}$ & ${ }_{\left(\mathrm{Sec}^{\lambda} \mathrm{C}^{-1}\right)}$ & $\bar{\beta}_{2 j} \times 10^{4}$ & $\left(\sec ^{\lambda}{ }^{-1}\right)$ & $\bar{B}_{3 j} \times 10^{4}$ & $\left.{ }^{\lambda_{3 j}} \sec ^{-1}\right)$ & $\bar{\beta}_{4 j} \times 10^{4}$ & $\left(\sec ^{\lambda} .^{-1}\right)$ \\
\hline 1 & 0.62 & 0.0129 & 0.01 & 0.0129 & 0.18 & 0.0132 & 0.02 & 0.0127 \\
\hline 2 & 4.63 & 0.0311 & 0.13 & 0.0313 & 1.94 & 0.0321 & 0.10 & 0.0317 \\
\hline 3 & 3.53 & 0.134 & 0.09 & 0.135 & 2.26 & 0.139 & 0.09 & 0.115 \\
\hline 4 & 5.41 & 0.331 & 0.16 & 0.333 & 5.48 & 0.358 & 0.19 & 0.311 \\
\hline 5 & 1.70 & 1.26 & 0.06 & 1.36 & 3.17 & 1.41 & 0.06 & 1.40 \\
\hline 6 & 0.57 & 3.21 & 0.01 & 4.04 & 1.06 & 4.02 & 0.01 & 3.87 \\
\hline
\end{tabular}

$\bar{\beta}_{i j}=$ effective delayed neutron fraction (based on Keepin's ${ }^{(26)}$ data)

$\lambda_{i j}=$ decay constants (taken from Keepin ${ }^{(26)}$ )

$B=\sum_{i} \sum_{j} \quad \bar{B}_{i j}=0.003148$

Iifetime $(\ell)=6.3 \times 10^{-7} \mathrm{sec}$. 
GEAP-13588

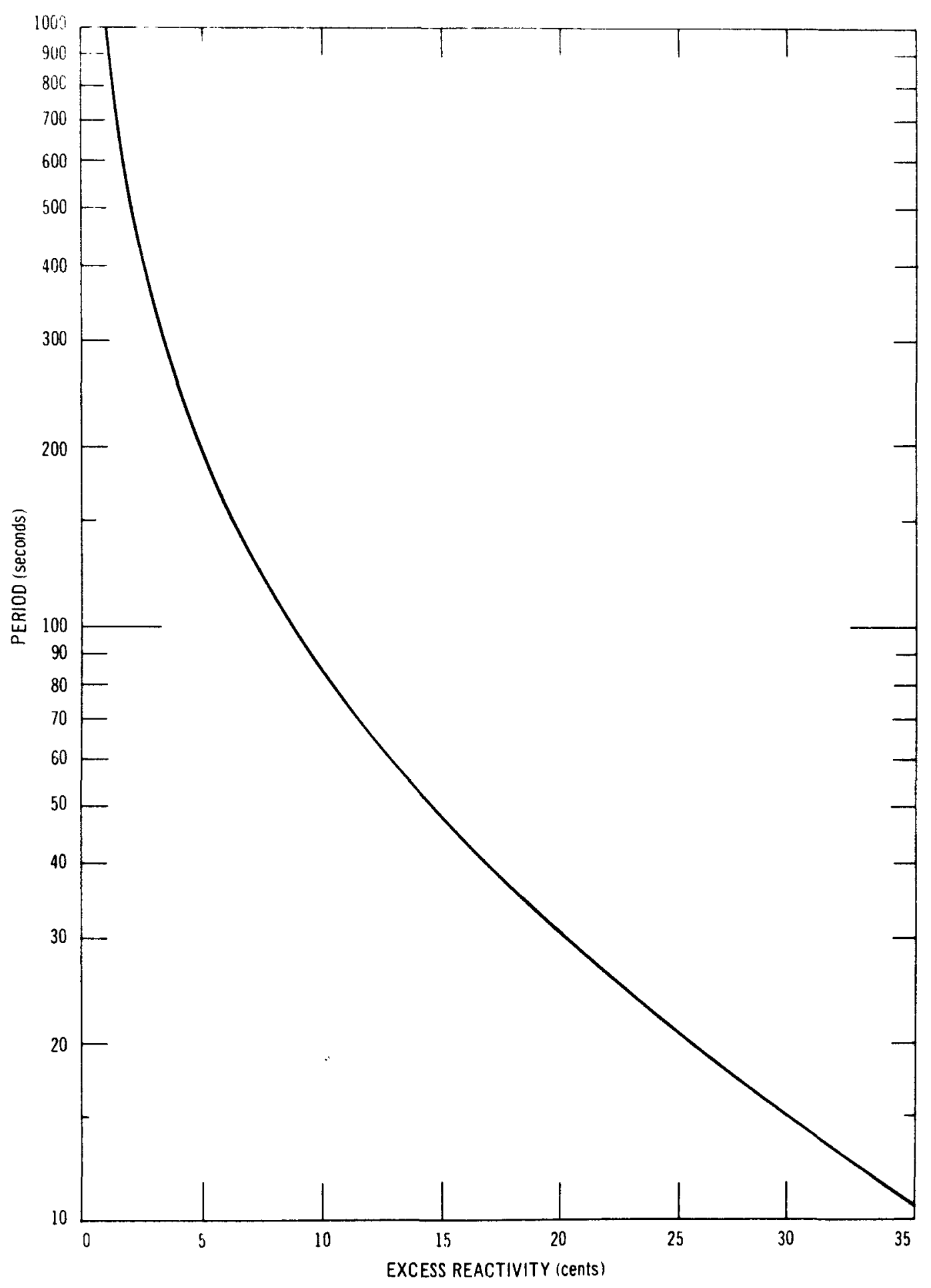

FIGURE V-1. ASYMPTOTIC REACTOR PERIOD FOR SEFOR 


\section{FINE REFLECTOR CALIBRATION DATA}

The two fine reflectors (非 3 and 非) were calibrated by means of period measurements according to the procedure outlined in section 3.3.2. The in-hour relation that was used to convert the measured periods into reactivities is described in Appendix V. The positions of the coarse reflectors during these calibrations are discussed at the end of Section 3.3.2.

The results of the calibrations of both reflectors in Assemblies $I-B$ and I-D, and in Assembly I-E at two different temperatures, $350^{\circ} \mathrm{F}$ and $650^{\circ} \mathrm{F}$ are summarized in Tables VI-1 through VI-8. The calibration data for reflector $\# 8$ in Assembly $I-F$ at $350^{\circ} \mathrm{F}$ is summarized in Table VI-9. 
TABLE VI-1

REFLECTOR \#3 CALIBRATION - ASSEMBLY I-B

\begin{tabular}{|c|c|}
\hline$(\mathrm{cm})$ & \\
\hline From & To \\
\hline 0.46 & 10. \\
\hline 10.11 & \\
\hline 18.18 & 25. \\
\hline 25.15 & \\
\hline 31.18 & \\
\hline 36.27 & 41 \\
\hline 41.19 & 46 \\
\hline 46.22 & 50 \\
\hline 50.94 & o \\
\hline 55.61 & 60 \\
\hline 60.56 & 65. \\
\hline 65.74 & 71. \\
\hline 71.97 & 7 \\
\hline 78.98 & 86 \\
\hline 86.56 & 01 \\
\hline 94.47 & 97 \\
\hline
\end{tabular}

$\frac{\text { Period }}{\text { (sec })}$

115.41
95.07
85.11
85.11
98.68
94.92
93.77
99.69
104.59
104.88
104.45
98.68
102.43
132.29
230.83
1180.12

$\frac{\text { Reactivity }}{(\phi)}$ *

7.847

9.152

9.967

9.967

8.889

9.163

9.250

8.818

8.490

8.471

8.499

8.889

8.632

7.021

4.362

0.945

*Estimated uncertainty in individual measured reactivities is $\pm 1 \%$ of tabulated values. 


\section{TABLE VI-2}

\section{REFLECTOR \#8 CALIBRATION - ASSEMBLY I-B}

Reflector No. 8

From $(\mathrm{cm})$ To

$\begin{array}{rr}0.65 & 9.52 \\ 9.52 & 18.52 \\ 18.52 & 26.11 \\ 26.11 & 32.23 \\ 32.23 & 36.31 \\ 36.31 & 41.48 \\ 41.48 & 46.54 \\ 46.54 & 51.73 \\ 51.73 & 56.50 \\ 56.50 & 61.51 \\ 61.51 & 66.54 \\ 66.54 & 71.63 \\ 71.63 & 76.56 \\ 76.56 & 83.46 \\ 83.46 & 87.40 \\ 87.40 & 95.18 \\ 95.18 & 98.16\end{array}$

$\frac{\text { Period }}{\text { (sec })}$

127.42

82.83

78.07

83.98

131.60

92.35

94.66

92.64

107.65

108.22

116.88

136.36

160.46

136.36

387.16

256.13

1080.72 $\frac{\text { Reactivity }}{(\phi)}$

7.241

10.176

10.642

10.070

7.052

9.361

9.183

9.338

8.292

8.263

7.768

6.848

5.976

6.848

2.731

3.976

1.029 


\section{TABLE VI-3}

\section{REFLECTOR \#3 CALIBRATION - ASSEMBLY I-D}

Reflector No. 3 From ${ }^{(\mathrm{cm})}$ To

$\begin{array}{ll}00.44 & 10.31 \\ 10.31 & 19.30 \\ 19.30 & 25.46 \\ 25.46 & 30.67 \\ 30.67 & 35.59 \\ 35.59 & 40.49 \\ 40.49 & 45.16 \\ 45.16 & 50.10 \\ 50.10 & 54.75 \\ 54.75 & 59.84 \\ 59.84 & 65.44 \\ 65.44 & 72.19 \\ 72.19 & 81.53 \\ 81.53 & 90.19 \\ 90.19 & 97.67\end{array}$

$$
\frac{\text { Period }}{(\mathrm{sec})}
$$

Reactivity

117.89

7.727

82.39

10.233

97.69

8.974

105.77

8.429

105.05

8.475

101.29

8.722

103.17

8.596

94.08

9.242

104.47

8.512

97.69

8.974

96.82

9.036

90.05

9.560

77.23

10.745

146.82

6.450

367.14

2.873 
GEAP-13588

TABLE VI-4

REFLECTOR \# 8 CALIBRATION - ASSEMBLY I-D

\begin{tabular}{|c|c|c|c|}
\hline \multicolumn{2}{|c|}{ Reflector No. 8} & \multirow[t]{2}{*}{$\frac{\text { Period }}{(\mathrm{sec})}$} & \multirow[t]{2}{*}{$\frac{\text { Reactivity }}{(c)}$} \\
\hline From & To & & \\
\hline 0.64 & 8.19 & 174.17 & 5.582 \\
\hline 8.19 & 16.13 & 105.19 & 8.460 \\
\hline 16.13 & 22.03 & 119.19 & 7.660 \\
\hline 22.03 & 27.04 & 120.92 & 7.569 \\
\hline 27.04 & 32.13 & 103.31 & 8.587 \\
\hline 32.13 & 37.10 & 101.87 & 8.683 \\
\hline 37.10 & 42.10 & 95.95 & 9.100 \\
\hline 42.10 & 47.14 & 92.64 & 9.353 \\
\hline 47.14 & 52.22 & 94.08 & 9.241 \\
\hline 52.22 & 57.46 & 92.92 & 9.331 \\
\hline 57.46 & 62.24 & 115.15 & 7.875 \\
\hline 62.24 & 67.95 & 103.89 & 8.549 \\
\hline 67.95 & 75.45 & 86.72 & 9.841 \\
\hline 75.45 & 82.22 & 136.01 & 6.871 \\
\hline 82.22 & 89.36 & 190.62 & 5.165 \\
\hline 89.36 & 98.17 & 309.09 & 3.363 \\
\hline
\end{tabular}




\section{$\underline{\text { TABLE VI -5 }}$}

\section{REFLECTOR \#3 CALIBRATION - ASSEMBLY I-E} $\left(350^{\circ} \mathrm{F}\right)$

Reflector No. 3

From

$0.44 \quad 8.10$

$8.10 \quad 16.00$

$16.00 \quad 23.05$

$23.05 \quad 29.01$

$29.01 \quad 34.46$

$34.46 \quad 40.00$

$40.00 \quad 45.07$

$45.07 \quad 49.94$

$49.94 \quad 55.01$

$55.01 \quad 60.16$

$60.16 \quad 65.47$

$65.47 \quad 71.51$

$71.51 \quad 77.11$

$77.11 \quad 85.94$

$85.94 \quad 97.66$ $\frac{\text { Period }}{(\mathrm{sec})}$

159.42

147.44

85.7

89.02

87.21

79.35

85.12

87.14

89.45

91.61

97.39

89.59

122.63

99.98

153.36

\section{$\frac{\text { Reactivity }}{(ф)}$}

6.019

6.428

9.932

9.646

9.799

10.529

9.983

9.806

9.610

9.434

8.996

9.598

7.484

8.812

6.219 


\section{TABLE VI-6}

\section{REFLECTOR \#8 CALIBRATION - ASSEMBLY I-E}

$\left(350^{\circ} \mathrm{F}\right)$

Reflector No. 8 $(\mathrm{cm})$

From

$01.03 \quad 09.10$

$09.10 \quad 17.03$

$17.03 \quad 23.72$

$23.76 \quad 29.04$

$29.04 \quad 34.01$

$34.01 \quad 39.17$

$39.17 \quad 44.13$

$44.13 \quad 48.71$

$48.71 \quad 53.98$

$53.98 \quad 58.89$

$58.89 \quad 64.15$

$64.15 \quad 70.02$

$70.02 \quad 76.03$

$76.03 \quad 82.87$

$82.87 \quad 90.03$

$90.03 \quad 98.18$ $\frac{\text { Period }}{(\mathrm{sec})}$

$\frac{\text { Reactivity }}{(\Phi)}$

161.29

5.960

110.51

8.139

101.13

8.733

114.41

7.916

110.66

8.131

99.69

8.832

102.72

8.626

106.76

7.987

96.08

9.091

113.40

7.973

110.08

8.165

107.63

8.313

125.23

7.357

147.16

6.438

201.26

4.928

317.68

3.280 


\section{TABLE VI-7}

\section{REFLECTOR \#3 CALIBRATION - ASSEMBLY I-E} $\left(650^{\circ} \mathrm{F}\right)$

$\frac{\text { Reflector No. } 3}{(\mathrm{~cm})}$

From $\quad$ To

$8.52 \quad 15.98$

$15.98 \quad 22.98$

$22.98 \quad 29.05$

$29.05 \quad 34.32$

$34.32 \quad 39.16$

$39.16 \quad 43.71$

$43.71 \quad 48.20$

$48.20 \quad 52.66$

$52.66 \quad 57.20$

$57.20 \quad 62.00$

$62.00 \quad 67.00$

$67.00 \quad 72.20$

$72.20 \quad 78.01$

$78.01 \quad 84.01$

$84.01 \quad 91.01$

$91.01 \quad 97.66$

132.03

7.044

100.00

8.811

$\frac{\text { Period }}{\text { (Sec) }}$

$\frac{\text { Reactivity }}{(\phi)}$

78.93

10.571

78.49

10.615

83.54

10.126

87.59

9.767

93.93

9.253

96.24

9.079

98.98

8.882

102.02

8.673

100.72

8.761

110.10

8.163

115.00

7.883

123.52

7.440

165.22

5.839

212.12

4.706

462.48 
GEAP-13588

\section{TABLE VI -8}

\section{REFLECTOR \#8 CALIBRATION - ASSEMBLY I-E}

$\left(650^{\circ} \mathrm{F}\right)$

\begin{tabular}{|c|c|c|c|}
\hline \multicolumn{2}{|c|}{$\frac{\text { Reflector No. } 8}{(\mathrm{~cm})}$} & \multirow[t]{2}{*}{$\frac{\text { Period }}{(\text { sec })}$} & \multirow[t]{2}{*}{$\frac{\text { Reactivits }}{(\phi)}$} \\
\hline From & To & & \\
\hline 01.03 & 10.17 & 117.58 & 7.743 \\
\hline 10.17 & 16.38 & 130.28 & 7.122 \\
\hline 16.38 & 21.91 & 120.61 & 7.585 \\
\hline 21.91 & 26.00 & 155.67 & 6.141 \\
\hline 26.00 & 30.97 & 109.36 & 8.208 \\
\hline 30.97 & 34.83 & 140.95 & 6.674 \\
\hline 34.83 & 39.85 & 94.35 & 9.221 \\
\hline 39.85 & 44.01 & 120.61 & 7.585 \\
\hline 44.01 & 48.77 & 103.73 & 8.560 \\
\hline 48.77 & 53.60 & 101.42 & 8.713 \\
\hline 53.60 & 58.55 & 103.88 & 8.550 \\
\hline 58.55 & 63.72 & 106.90 & 8.358 \\
\hline 63.72 & 69.40 & 108.35 & 8.269 \\
\hline 69.40 & 75.55 & 118.59 & 7.690 \\
\hline 75.55 & 82.38 & 135.04 & 6.915 \\
\hline 82.38 & 90.09 & 187.84 & 5.231 \\
\hline 90.09 & 98.18 & 448.97 & 2.384 \\
\hline
\end{tabular}




\section{TABLE VI-9}

REFLECTOR \#8 CALIBRATION - ASSEMBLY I-F $\left(350^{\circ} \mathrm{F}\right)$

\begin{tabular}{|c|c|}
\hline \multicolumn{2}{|c|}{$(\mathrm{cm})$} \\
\hline From & To \\
\hline 1.03 & 9.14 \\
\hline 9.14 & 17.73 \\
\hline 17.73 & 24.35 \\
\hline 24.35 & 30.30 \\
\hline 30.30 & 35.36 \\
\hline 35.36 & 40.18 \\
\hline 40.18 & 44.93 \\
\hline 44.93 & 49.53 \\
\hline 49.53 & 54.06 \\
\hline 54.06 & 59.88 \\
\hline 59.88 & 66.27 \\
\hline 66.27 & 72.64 \\
\hline 72.64 & 80.02 \\
\hline 80.02 & 88.50 \\
\hline 88.50 & 18 \\
\hline
\end{tabular}

$$
\frac{\text { Period }}{(\sec .)}
$$

$\underline{\text { Reactivity }}$

(c)

$\begin{array}{rr}99.2 & 6.588 \\ 66.6 & 9.090 \\ 67.3 & 9.016 \\ 68.5 & 8.892 \\ 70.5 & 8.693 \\ 71.4 & 8.606 \\ 70.4 & 8.702 \\ 77.4 & 8.070 \\ 83.2 & 7.613 \\ 61.8 & 9.633 \\ 60.4 & 9.804 \\ 70.7 & 8.673 \\ 74.7 & 8.303 \\ 95.1 & 6.823 \\ 186.8 & 3.805\end{array}$




\section{APPENDIX VII}

\section{INHERENT SOURCE MEASUREMENT}

A series of measurements were performed in the initial critical core Assembly I-A and in the fully loaded core, Assembly I-D to determine the relationship between steady-state detector readings (power) and reflector position (subcritical reactivity) in a near critical core. These measurements served two purposes. They experimentally established flux levels (instrument readings) for which the source contribution was insignificant and the reactor could be considered critical when the steady state flux levels were greater than or equal to the established value. In addition the measurements provided a means for determining the strength of the inherent source - or conversely of estimating the absolute power level. The results are shown in Table VII-1 and VII-2. (The indicated subcritical reactivity of the systems were obtained from the respective reflector calibration data using a four point difference formula.)

The data show that both systems are critical for all steady-state wide range monitor (WRM) readings greater than $\sim 50 \times 10^{-5}$ and that the product of the WRM reading and the subcritical reactivity is essentially constant. The latter result is in agreement with theory and provides a means of relating the WRM readings to the reactor power and the inherent source of neutrons resulting from the spontaneous fission of $\mathrm{Pu}-240$ and the alpha-neutron reaction in oxygen from $\mathrm{Pu}-239$ and $\mathrm{Pu}-240$ alpha decay.

A modal one-energy-group analysis (Appendix IV) for a system containing a constant source of neutrons per unit core volume provides 
the following relationship between the total power, $P$, in watts, the total source of neutrons per second, $S$, and the subcritical reactivity $k$ (in cents) in a near critical core:

$$
\mathrm{p}=\frac{100 \mathrm{~S}}{\nu \mathrm{k} \beta C} \mathrm{~F}
$$

where $\nu=2.94$ is the average number of neutrons per fission, $\beta=0.0032$ is the effective delayed neutron fraction, $C=3 \times 10^{10}$ fissions per $W-\sec$, and $F$ is the square of the core average of the fundamental flux shape divided by the average of the square of the fundamental flux shape. For SEFOR, $F \simeq 0.9$, and the above expression can be written as

$$
P=3.2 \times 10^{-7} \frac{\mathrm{S}}{\mathrm{k}}
$$

where the power $P$, source $S$, and subcritical reactivity are in units of watts, neutrons/sec, and cents, respectively.

The above expression corresponds to the measured relations (Table VII-1 and VII-2) between WRM reading, $\phi$, and reactivity $k$ :

$$
\phi=\mathrm{A} / \mathrm{k}
$$

where $A=11.6 \times 10^{-6}$ for Assembly $I-A$ and has a value of $9.8 \times 10^{-6}$ for Assembly I-D.

Thus, if the source strength is known, the relation between WRM reading and power can be determined. Conversely, if the relation between WRM reading and power is known, the inherent source can be determined. It may be possible to determine the latter relation after the heat balances have been performed and the instruments have been calibrated.

An approximate value for the source strength can be calculated. 
According to a previous study ${ }^{(27)}$ the source is given (within an estimated uncertainty of a factor of 1.5) by:

$$
S=\left(1.29 \times 10^{6} \mathrm{M}_{1}+7.8 \times 10^{4} \mathrm{M}_{2}\right) \mathrm{N}
$$

where $N$ is the number of fuel rods; $M_{1}=0.0493 \mathrm{~kg} /$ rod is the $\mathrm{Pu}-240$ mass per rod; and $M_{2}=0.5489 \mathrm{~kg} / \mathrm{rod}$ is the $\mathrm{Pu}-239$ mass per rod. For the 550 rod core, $S^{2}=5.9 \times 10^{7}$ neutrons/sec and the calculated power level for a WRM reading of $50 \times 10^{-5}$ is 810 watts. If the values from the 634 rod Assembly I-D are used, $S=6.8 \times 10^{7}$ neutrons/sec and the calculated power level for a WRM reading of $50 \times 10^{-5}$ is 1100 watts. 
TABLE VII-1

\section{INHERENT SOURCE MEASUREMENT (AISEMBLY I-A)}

\section{Wide Range Monitor}

Reading

$40 \times 10^{-8}$
$8 \times 10^{-7}$
$15 \times 10^{-7}$
$42 \times 10^{-7}$
$8.3 \times 10^{-6}$
$14.5 \times 10^{-6}$
$28 \times 10^{-6}$
$53 \times 10^{-6}$
$25 \times 10^{-5}$
$50 \times 10^{-5}$
$7.5 \times 10^{-4}$

No. 3 Reflector

$$
\text { Position }
$$

(cm)

62.36

71.10

75.61

79.70

80.93

81.35

81.99

82.44

82.60

82.65

82.65
Subcritical Reactivity** at $351.25^{\circ} \mathrm{F}$

Temperature

$\left({ }^{\circ} \mathrm{F}\right)$

351.5

351.5

351.5

351.0

351.0

350.75

$351.0 *$

351.25

351.25

351.25

351.25
(Cents)

26.90
13.70
7.84
2.76
1.49
0.88
0.44
0.20
0.05
0.00
0.00

Product of Subcritucal Reactivit and wide-Range-Mopitor Reading [(cents) $\times 10^{\circ}$ ]

$$
\begin{aligned}
& 10.8 \\
& 11.0 \\
& 11.8 \\
& 11.6 \\
& 12.3 \\
& 12.8 \\
& 12.4 \\
& 10.4 \\
& 11.8 \\
& -- \\
& --
\end{aligned}
$$$$
\text { Average }=11.6
$$

*Adjusted to provide agreement with theory. The recorded value of $351.25^{\circ} \mathrm{F}$ gives a value for the product in the last column of 17.5

**Using the estimated temperature coefficient for this assembly of $-0.74 \mathrm{C} /{ }^{\circ} \mathrm{F}$. 


\section{TABLE VII-2}

INHERENT SOURCE MEASUREMENT (ASSEMBLY I-D)

\section{Wide Range Monitor} Reading

$$
39 \times 10^{-8}
$$$$
50 \times 10^{-8}
$$$$
6.2 \times 10^{-7}
$$$$
8.0 \times 10^{-7}
$$$$
18.0 \times 10^{-7}
$$$$
24.4 \times 10^{-7}
$$$$
34.0 \times 10^{-7}
$$$$
48.0 \times 10^{-7}
$$$$
7.5 \times 10^{-6}
$$$$
15.0 \times 10^{-6}
$$$$
29.0 \times 10^{-6}
$$$$
49.0 \times 10^{-6}
$$$$
20.0 \times 10^{-5}
$$$$
32.0 \times 10^{-5}
$$$$
49.0 \times 10^{-5}
$$$$
44.0 \times 10^{-4}
$$

No. 8 Reflector Position (cm)

45.60

48.56

51.64

53.26

57.00

57.73

58.29

58.90

59.24

59.59

59.82

59.83

59.93

60.11

60.11

60.11
Subcritical Reactivity**
at $375.0^{\circ} \mathrm{F}$

Temperature

$\left({ }^{\circ} \mathrm{F}\right)$

375.0

375.0

375.0

375.0

375.0

375.0

375.0

374.75

374.75

374.75

374.75

374.5

$374.5 *$

375.0

375.0

375.0

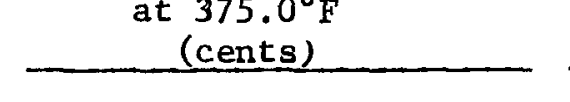

25.87

20.42

14.83

11.90

5.25

3.99

3.04

1.86

1.29

0.71

0.33

0.16

0.0

0.0

0.0

0.0
Product of Subcritical Reactivity and wide=Range-Mopttor Reading $\left[\right.$ (cents) $\left.\times 10^{6}\right]$

10.1

10.2

9.2

9.5

9.5

9.7

10.3

8.9

9.7

10.7

9.6

7.8
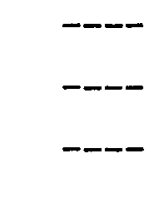

*Adjusted to provide agreement with theory. The recorded value of $374.75^{\circ} \mathrm{F}$ gives a value for the product in the last column of 30.0 .

$* *$ Using the measured temperature coefficient for this assembly of $-0.60 \mathrm{C} /{ }^{\circ} \mathrm{F}$. 


\section{APPENDIX VIII \\ TEMPERATURE DEPENDENT REACTIVITY DATA IN ASSEMBLY I-E}

The recorded values of the reflector positions and the coolant temperature as indicated by the in-core thermocouple are tabulated in Tables VIII-1 through VIII-10. The temperatures recorded with the other temperature detectors are compared with the in-core thermocouple in Section 7.3.2. The reactivity feedback was determined from the positions of the calibrated fine reflectors and is listed in the last column of the tables.

During the performance of the experiment, one of the coarse reflectors had to be completely raised and another had to be partially raised. This required the use of different fine reflector calibration curves during different portions of the experiment. The calibration curves for Assembly I-E at $350^{\circ} \mathrm{F}$ were used for reflector 非 between reading number 1 and reading number 33 and for reflector $\# 3$ between reading number 34 and reading number 43 . The calibration curve for Assembly I-E at $650^{\circ} \mathrm{F}$ was used for reflector $\# 8$ between reading number 34 and reading number 283, since the calibration of reflector \#8 at $650^{\circ} \mathrm{F}$ was performed with reflector $\# 10$ in the same position completely raised - (see Section 3.3.2) as these measurements were performed. This choice of calibration curves should minimize the "shadowing" effects discussed in Section 3.

The differential worth of a fine reflector near the midpoint of its stroke, or $1.9 \mathrm{c} / \mathrm{cm}$, was used to adjust the reactivities for the drift of reflector $\$ 5$ away from $50.0 \mathrm{~cm}$ between some of the measurements subsequent to reading number 117 . Since these corrections 
are small (< 1c), the exact differential worth of reflector $\# 5$ is not required.

In order to obtain one composite set of integral reactivity feedback data such as that listed in Tables VIII-1 through VIII-10, the reactivity data obtained from the fine reflector calibration curves had to be renormalized whenever the coarse reflector configuration was changed. Such renormalizations were required between reading number 33 and 34 , and again between reading number 116 and 117. These normalizations were performed by requiring that a fitted curve (a straight line in this case) describe a continuous relationship between reactivity and temperature through the change over point between the different coarse reflector configurations. In addition to the normalizations just described, the composite integral set of data was normalized to a temperature of $350^{\circ} \mathrm{F}$ by adjusting the data so that the linearly extrapolated reactivity at $350^{\circ} \mathrm{F}$ was zero. 
GEAP -13588

TABLE VIII-1

TEMPERATURE - REACTIVITY MEASUREMENTS

\begin{tabular}{|c|c|c|c|}
\hline $\begin{array}{l}\text { Reading } \\
\text { Number }\end{array}$ & $\begin{array}{c}\text { Reflector Positions* }(\mathrm{cm}) \\
\# 8\end{array}$ & $\begin{array}{r}\text { Coolant Temperature } \\
\left({ }^{\circ} \mathrm{F}\right)\end{array}$ & $\begin{array}{l}\text { Negative Reactivity*: } \\
\text { Feedback (cents) }\end{array}$ \\
\hline 1 & 40.80 & 353.5 & 2.5 \\
\hline 2 & 41.00 & 354.75 & 2.8 \\
\hline 3 & 41.72 & 356.5 & 4.1 \\
\hline 4 & 42.78 & 359.5 & 5.9 \\
\hline 5 & 43.67 & 360.5 & 7.4 \\
\hline 6 & 44.58 & 363.75 & 9.0 \\
\hline 7 & 45.98 & 366.75 & 11.5 \\
\hline 8 & 46.66 & 370.0 & 12.7 \\
\hline 9 & 48.76 & 373.0 & 16.3 \\
\hline 10 & 49.65 & 379.0 & 17.9 \\
\hline 11 & 51.63 & 381.0 & 21.3 \\
\hline 12 & 52.56 & 384.25 & 22.9 \\
\hline 13 & 54.86 & 389.25 & 26.8 \\
\hline 14 & 55.95 & 393.75 & 28.6 \\
\hline 15 & 58.19 & 398.5 & 32.2 \\
\hline 16 & 60.34 & 403.5 & 35.6 \\
\hline 17 & 62.73 & 409.0 & 39.3 \\
\hline 18 & 65.48 & 415.5 & 43.4 \\
\hline 19 & 68.21 & 421.25 & 47.3 \\
\hline 20 & 70.79 & 426.75 & 50.8 \\
\hline 21 & 74.00 & 432.75 & 54.8 \\
\hline 22 & 77.40 & 437.5 & 58.6 \\
\hline 23 & 81.06 & 443.5 & 62.1 \\
\hline 24 & 84.74 & 448.0 & 65.0 \\
\hline 25 & 88.03 & 450.75 & 67.3 \\
\hline 26 & 88.94 & 451.75 & 67.9 \\
\hline 27 & 89.24 & 452.0 & 68.1 \\
\hline 28 & 89.24 & 451.75 & 68.1 \\
\hline 29 & 89.10 & 451.75 & 68.0 \\
\hline 30 & 88.98 & 451.75 & 67.9 \\
\hline
\end{tabular}

* Reflectors $\equiv_{1} 5$ and $\|_{10}$ were down, a11 other reflectors were up. ** Relative to $350^{\circ} \mathrm{F}$. 


\section{TABLE VIII-2}

\section{TEMPERATURE - REACIIVITY MEASUREMENTS}

\begin{tabular}{|c|c|c|c|c|}
\hline $\begin{array}{l}\text { Reading } \\
\text { Number } \\
\end{array}$ & $\begin{array}{l}\text { Reflector } \\
\text { \#3 }\end{array}$ & $\begin{array}{c}\text { Positions* }(\mathrm{cm}) \\
\# 8 \\
\end{array}$ & $\begin{array}{c}\text { Coolant Temperature } \\
\left({ }^{\circ} \mathrm{F}\right)\end{array}$ & $\begin{array}{l}\text { Negative Reactivity: } \\
\text { Feedback (cents) }\end{array}$ \\
\hline 31 & up & 89.12 & 451.75 & 68.0 \\
\hline 32 & up & 89.12 & 451.75 & 68.0 \\
\hline 33 & up & 89.12 & 451.75 & 68.0 \\
\hline $34 *$ & 75.55 & 1.03 & 451.75 & 67.9 \\
\hline 35 & 75.64 & 1.03 & 451.75 & 68.0 \\
\hline 36 & 75.74 & 1.03 & 453.0 & 68.1 \\
\hline 37 & 78.82 & 1.03 & 456.75 & 71.8 \\
\hline 38 & 80.61 & 1.03 & 461.0 & 73.8 \\
\hline 39 & 84.21 & 1.03 & 466.0 & 77.2 \\
\hline 40 & 86.04 & 1.03 & 469.25 & 78.7 \\
\hline 41 & 88.78 & 1.03 & 472.5 & 80.7 \\
\hline 42 & 94.07 & 1.03 & 476.25 & 83.6 \\
\hline 43 & up & 3.99 & 483.0 & 87.0 \\
\hline 44 & up & 7.77 & 488.0 & 90.3 \\
\hline 45 & up & 11.88 & 492.5 & 94.4 \\
\hline 46 & up & 15.16 & 497.75 & 98.2 \\
\hline 47 & up & 16.65 & 502.75 & 100.1 \\
\hline 48 & up & 20.29 & 507.0 & 105.0 \\
\hline 49 & up & 20.29 & 511.5 & 105.0 \\
\hline 50 & up & 22.28 & 516.25 & 107.9 \\
\hline 51 & up & 26.21 & 519.75 & 113.8 \\
\hline 52 & up & 26.57 & 524.5 & 114.4 \\
\hline 53 & up & 28.55 & 528.25 & 117.6 \\
\hline 54 & up & 28.55 & 530.0 & 117.6 \\
\hline 55 & up & 31.45 & 535.0 & 122.5 \\
\hline 56 & up & 32.50 & 539.5 & 124.3 \\
\hline 57 & up & 33.40 & 540.25 & 125.8 \\
\hline 58 & up & 34.95 & 546.75 & 128.6 \\
\hline 59 & up & 35.90 & 549.5 & 130.3 \\
\hline 60 & up & 36.41 & 551.0 & 131.2 \\
\hline
\end{tabular}

* Reflectors $\equiv^{5}$ and $\equiv_{10} 10$ were both down prior to Reading Number 34 . For Reading Number 34, reflector 非 5 was down and reflector \#10 was up. All other reflectors were up.

** Relative to $350^{\circ} \mathrm{F}$. 
TABLE VIII-3

\section{TEMPERATURE - REACTIVITY MEASUREMENTS}

\begin{tabular}{|c|c|c|c|}
\hline $\begin{array}{l}\text { Reading } \\
\text { Number } \\
\end{array}$ & $\begin{array}{c}\text { Reflector Positions* }(\mathrm{cm}) \\
\text { \# } 8\end{array}$ & $\begin{array}{c}\text { Coolant Temperature } \\
\left({ }^{\circ} \mathrm{F}\right)\end{array}$ & $\begin{array}{l}\text { Negative Reactivity** } \\
\text { Feedback (cents) }\end{array}$ \\
\hline 61 & 36.89 & 551.5 & 132.1 \\
\hline 62 & 36.89 & 551.25 & 132.1 \\
\hline 63 & 36.54 & 550.0 & 131.5 \\
\hline 64 & 36.38 & 549.5 & 131.2 \\
\hline 65 & 36.19 & 549.0 & 130.8 \\
\hline 66 & 36.35 & 549.5 & 131.1 \\
\hline 67 & 36.57 & 550.0 & 131.1 \\
\hline 68 & 36.57 & 550.5 & 131.5 \\
\hline 69 & 36.76 & 551.25 & 131.9 \\
\hline 70 & 37.55 & 554.0 & 133.3 \\
\hline 71 & 38.66 & 556.25 & 135.4 \\
\hline 72 & 39.65 & 559.5 & 137.2 \\
\hline 73 & 40.61 & 562.75 & 139.0 \\
\hline 74 & 41.55 & 567.5 & 140.7 \\
\hline 75 & 42.78 & 569.75 & 142.9 \\
\hline 76 & 43.99 & 573.75 & 145.1 \\
\hline 77 & 45.13 & 577.0 & 147.2 \\
\hline 78 & 45.97 & 581.0 & 148.7 \\
\hline 79 & 47.23 & 584.25 & 151.0 \\
\hline 80 & 48.64 & 588.0 & 153.5 \\
\hline 81 & 49.60 & 591.25 & 155.2 \\
\hline 82 & 50.84 & 594.75 & 157.5 \\
\hline 83 & 51.62 & 597.75 & 158.9 \\
\hline 84 & 52.73 & 600.5 & 160.9 \\
\hline 85 & 53.84 & 603.75 & 162.9 \\
\hline 86 & 54.79 & 606.25 & 164.5 \\
\hline 87 & 55.40 & 608.75 & 165.6 \\
\hline 88 & 56.52 & 611.25 & 167.5 \\
\hline 89 & 57.01 & 613.75 & 168.4 \\
\hline 90 & 58.24 & 616.25 & 170.5 \\
\hline
\end{tabular}

* Reflector 非 was down, all other reflectors were up ** Relative to $350^{\circ} \mathrm{F}$. 
Reading Reflector Positions* (cm) Number

$\begin{array}{rll}91 & \text { down } & 59.00 \\ 92 & \text { down } & 59.79 \\ 93 & \text { down } & 60.34 \\ 94 & \text { down } & 61.12 \\ 95 & \text { down } & 62.13 \\ 96 & \text { down } & 63.18 \\ 97 & \text { down } & 64.18 \\ 98 & \text { down } & 65.00 \\ 99 & \text { down } & 65.35 \\ 100 & \text { down } & 66.00 \\ 101 & \text { down } & 67.47 \\ 102 & \text { down } & 68.46 \\ 103 & \text { down } & 69.56 \\ 104 & \text { down } & 69.56 \\ 105 & \text { down } & 70.96 \\ 106 & \text { down } & 71.35 \\ 107 & \text { down } & 72.03 \\ 108 & \text { down } & 72.64 \\ 109 & \text { down } & 72.63 \\ 110 & \text { down } & 72.63 \\ 111 & \text { down } & 72.86 \\ 112 & \text { down } & 73.00 \\ 113 & \text { down } & 73.14 \\ 114 & \text { down } & 73.23 \\ 115 & \text { down } & 73.13 \\ 116 & \text { down } & 72.4 \\ 117 & 50.0 & 28.07 \\ 118 & 50.0 & 28.07 \\ 119 & 50.0 & 28.49 \\ 120 & 50.0 & 29.1\end{array}$

Coolant Temperature Negative Reactivity* $\left({ }^{\circ} \mathrm{F}\right)$ Feedback (cents)

$\begin{array}{ll}618.75 & 171.7 \\ 621.25 & 173.1 \\ 623.25 & 174.0 \\ 625.0 & 175.2 \\ 627.75 & 176.8 \\ 629.75 & 178.5 \\ 631.5 & 180.1 \\ 634.0 & 181.3 \\ 635.5 & 181.8 \\ 637.75 & 182.8 \\ 639.75 & 184.9 \\ 641.75 & 186.3 \\ - & 187.8 \\ 645.0 & 187.8 \\ - & 189.7 \\ 649.0 & 190.2 \\ 650.25 & 191.1 \\ 651.0 & 191.8 \\ 651.5 & 191.8 \\ 651.5 & 191.8 \\ 652.0 & 192.1 \\ 652.0 & 192.3 \\ 652.0 & 192.5 \\ 652.75 & 192.6 \\ 652.25 & 192.4 \\ 650.0 & 191.5 \\ 649.5 & 190.5 \\ 650.25 & 190.5 \\ 650.25 & 191.2 \\ 652.0 & 192.2\end{array}$

* All other reflectors were up ** Relative to $350^{\circ} \mathrm{F}$. 
TABLE VIII-5

TEMPERATURE - REACTIVITY MEASUREMENTS

\begin{tabular}{|c|c|c|c|c|}
\hline $\begin{array}{l}\text { Reading } \\
\text { Number } \\
\end{array}$ & $\begin{array}{l}\text { Reflector } \\
\text { 非 }\end{array}$ & $\begin{array}{c}\text { Positions* }(\mathrm{cm}) \\
\text { 非 }\end{array}$ & $\begin{array}{c}\text { Coolant Temperature } \\
\left({ }^{\circ} \mathrm{F}\right)\end{array}$ & $\begin{array}{l}\text { Negative Reactivity** } \\
\text { Feedback (cents) }\end{array}$ \\
\hline 121 & 50.0 & 29.8 & 653.5 & 193.4 \\
\hline 122 & 50.0 & 30.77 & 656.25 & 195.0 \\
\hline 123 & 50.0 & 31.40 & 657.5 & 196.1 \\
\hline 124 & 50.0 & 32.14 & 659.5 & 197.4 \\
\hline 125 & 49.5 & 32.60 & 661.25 & 197.2 \\
\hline 126 & 49.5 & 33.58 & 663.5 & 198.9 \\
\hline 127 & 49.5 & 34.77 & 666.25 & 201.0 \\
\hline 128 & 49.5 & 35.33 & 669.0 & 202.0 \\
\hline 129 & 49.2 & 36.21 & 670.5 & 203.0 \\
\hline 130 & 49.0 & 36.94 & 672.75 & 204.0 \\
\hline 131 & 50.0 & 36.24 & 675.25 & 204.6 \\
\hline 132 & 49.9 & 37.24 & 677.5 & 206.2 \\
\hline 133 & 49.9 & 38.01 & 678.75 & 207.7 \\
\hline 134 & 49.8 & 39.11 & 682.5 & 209.5 \\
\hline 135 & 50.0 & 39.83 & 685.0 & 211.2 \\
\hline 136 & 49.9 & 41.17 & 690.0 & 213.5 \\
\hline 137 & 50.0 & 42.40 & 693.0 & 215.9 \\
\hline 138 & 49.9 & 43.55 & 696.0 & 217.8 \\
\hline 139 & 49.9 & 44.58 & 700.0 & 219.7 \\
\hline 140 & 49.9 & 45.45 & 703.5 & 221.3 \\
\hline 141 & 49.7 & 46.44 & 706.75 & 222.7 \\
\hline 142 & 50.0 & 47.05 & 709.5 & 224.3 \\
\hline 143 & 50.0 & 47.84 & 712.25 & 225.7 \\
\hline 144 & 50.0 & 48.93 & 716.0 & 227.7 \\
\hline 145 & 50.0 & 49.76 & 718.75 & 229.2 \\
\hline 146 & 49.8 & 50.69 & 721.75 & 230.5 \\
\hline 147 & 49.7 & 51.61 & 724.5 & 232.0 \\
\hline 148 & 49.9 & 51.61 & 724.5 & 232.4 \\
\hline 149 & 49.9 & 52.94 & 729.5 & 234.8 \\
\hline 150 & 49.9 & 53.67 & 731.5 & 236.1 \\
\hline
\end{tabular}

* All other reflectors were up ** Relative to $350^{\circ} \mathrm{F}$ 


\section{TABLE VIII-6}

\section{TEMPERATURE - REACTIVITY MEASUREMENTS}

\begin{tabular}{|c|c|c|c|c|}
\hline $\begin{array}{l}\text { Reading } \\
\text { Number } \\
\end{array}$ & $\begin{array}{l}\text { Reflector } \\
\# 5\end{array}$ & $\begin{array}{c}\text { Positions* } \\
\text { 非 } 8\end{array}$ & $\begin{array}{r}\text { Coolant Temperature } \\
\left({ }^{\circ} \mathrm{F}\right)\end{array}$ & $\begin{array}{l}\text { Negative Reactivity** } \\
\text { Feedback (cents) }\end{array}$ \\
\hline 151 & 49.9 & 54.94 & 734.5 & 238.3 \\
\hline 152 & 49.9 & 55.54 & 736.75 & 239.3 \\
\hline 153 & 49.9 & 56.38 & 739.0 & 240.8 \\
\hline 154 & 49.9 & 56.85 & 740.75 & 241.6 \\
\hline 155 & 49.7 & 57.68 & 743.0 & 242.6 \\
\hline 156 & 50.0 & 56.38 & 744.5 & 241.0 \\
\hline 157 & 50.0 & 58.18 & 747.0 & 244.1 \\
\hline 158 & 50.0 & 58.74 & 747.5 & 245.0 \\
\hline 159 & 50.0 & 59.32 & 750.0 & 246.0 \\
\hline 160 & 50.0 & 60.03 & 751.25 & 247.1 \\
\hline 161 & 50.0 & 60.58 & 752.75 & 248.0 \\
\hline 162 & 50.0 & 61.44 & 755.0 & 249.4 \\
\hline 163 & 49.9 & 61.89 & 756.0 & 250.0 \\
\hline 164 & 49.8 & 62.67 & 757.75 & 251.0 \\
\hline 165 & 50.0 & 62.31 & 757.5 & 250.8 \\
\hline 166 & 50.0 & 62.31 & 758.25 & 250.8 \\
\hline 167 & 50.0 & 63.36 & 759.0 & 252.5 \\
\hline 168 & 50.0 & 63.28 & 758.75 & 252.4 \\
\hline 169 & 50.0 & 62.52 & 759.0 & 251.2 \\
\hline 170 & 50.0 & 62.56 & 758.75 & 251.2 \\
\hline 171 & 50.0 & 62.76 & 758.75 & 251.5 \\
\hline 172 & 50.0 & 62.86 & 758.5 & 251.7 \\
\hline 173 & 50.0 & 63.09 & 759.0 & 252.1 \\
\hline 174 & 49.9 & 63.30 & 759.0 & 252.2 \\
\hline 175 & 50.0 & 62.88 & 759.0 & 251.7 \\
\hline 176 & 50.0 & 63.00 & 759.25 & 251.9 \\
\hline 177 & 50.0 & 63.11 & 758.75 & 252.1 \\
\hline 178 & 50.0 & 63.55 & 759.0 & 252.8 \\
\hline 179 & 50.0 & 63.19 & 759.25 & 252.2 \\
\hline 180 & 50.0 & 62.76 & 757.0 & 251.5 \\
\hline
\end{tabular}

* All other reflectors were up

** Relative to $350^{\circ} \mathrm{F}$. 


\begin{tabular}{|c|c|c|c|c|}
\hline $\begin{array}{l}\text { Reading } \\
\text { Number }\end{array}$ & $\begin{array}{l}\text { Reflector } \\
\text { \#5 }\end{array}$ & $\begin{array}{c}\text { Positions* } \\
\# 8\end{array}$ & $\begin{array}{l}\text { Coolant Temperature } \\
\left({ }^{\circ} \mathrm{F}\right) \\
\end{array}$ & $\begin{array}{l}\text { Negative Reactivity** } \\
\text { Feedback (cents) }\end{array}$ \\
\hline 181 & 50.0 & 59.94 & 750.0 & 247.0 \\
\hline 182 & 50.0 & 57.41 & 744.25 & 242.7 \\
\hline 183 & 50.0 & 55.44 & 733.25 & 239.4 \\
\hline 184 & 50.0 & 53.29 & 727.50 & 235.6 \\
\hline 185 & 50.0 & 51.21 & 722.0 & 231.8 \\
\hline 186 & 50.0 & 50.00 & 715.25 & 229.6 \\
\hline 187 & 50.0 & 47.97 & 708.25 & 226.0 \\
\hline 188 & 50.0 & 46.76 & 706.75 & 223.8 \\
\hline 189 & 50.0 & 47.00 & 705.5 & 224.2 \\
\hline 190 & 50.0 & 46.00 & 704.25 & 222.4 \\
\hline 191 & 50.0 & 46.00 & 704.5 & 222.4 \\
\hline 192 & 50.0 & 46.40 & 705.25 & 223.2 \\
\hline 193 & 50.0 & 47.00 & 706.5 & 224.2 \\
\hline 194 & 50.0 & 47.00 & 707.0 & 224.2 \\
\hline 195 & 50.0 & 47.00 & 707.0 & 224.2 \\
\hline 196 & 50.0 & 47.44 & 708.0 & 225.0 \\
\hline 197 & 50.0 & 47.81 & 708.25 & 225.7 \\
\hline 198 & 50.0 & 47.81 & 708.5 & 225.7 \\
\hline 199 & 50.0 & 47.30 & 708.25 & 224.8 \\
\hline 200 & 50.0 & 47.53 & 708.0 & 225.2 \\
\hline 201 & 50.0 & 47.79 & 708.0 & 225.7 \\
\hline 202 & 50.0 & 47.79 & 708.0 & 225.7 \\
\hline 203 & 50.0 & 48.13 & 710.5 & 226.3 \\
\hline 204 & 50.0 & 48.13 & 710.5 & 226.3 \\
\hline 205 & 50.0 & 47.81 & 710.5 & 225.7 \\
\hline 206 & 50.0 & 47.98 & 711.0 & 226.0 \\
\hline 207 & 50.0 & 48.24 & 711.25 & 226.5 \\
\hline 208 & 50.0 & 48.34 & 711.75 & 226.6 \\
\hline 209 & 50.0 & 48.43 & 711.75 & 226.8 \\
\hline 210 & 50.0 & 48.43 & 711.75 & 226.8 \\
\hline
\end{tabular}


TABLE VIII-8

TEMPERATURE - REACTIVITY MEASUREMENTS

\begin{tabular}{|c|c|c|c|c|}
\hline $\begin{array}{l}\text { Reading } \\
\text { Number }\end{array}$ & $\begin{array}{l}\text { Reflector } \\
\text { \#5 }\end{array}$ & $\begin{array}{c}\text { Positions* }(\mathrm{cm}) \\
\# 8 \\
\end{array}$ & $\begin{array}{c}\begin{array}{c}\text { Coolant Temperature } \\
\left({ }^{\circ} \mathrm{F}\right)\end{array} \\
\end{array}$ & $\begin{array}{l}\text { Negative Reactivity** } \\
\text { Feedback (cents) }\end{array}$ \\
\hline 211 & 50.0 & 48.94 & 712.75 & 227.7 \\
\hline 212 & 50.0 & 49.00 & 714.5 & 227.8 \\
\hline 213 & 50.0 & 49.45 & 716.75 & 228.6 \\
\hline 214 & 50.0 & 50.05 & 718.5 & 229.7 \\
\hline 215 & 50.0 & 50.96 & 720.5 & 231.4 \\
\hline 216 & 50.0 & 51.47 & 722.5 & 232.3 \\
\hline 217 & 50.0 & 52.10 & 724.75 & 233.4 \\
\hline 218 & 50.0 & 52.70 & 726.0 & 234.5 \\
\hline 219 & 50.0 & 53.30 & 727.5 & 235.6 \\
\hline 220 & 50.0 & 53.74 & 729.0 & 236.4 \\
\hline 221 & 49.9 & 54.11 & 730.25 & 236.8 \\
\hline 222 & 50.0 & 54.66 & 731.25 & 238.0 \\
\hline 223 & 50.0 & 54.28 & 732.5 & 237.3 \\
\hline 224 & 50.0 & 54.53 & 733.25 & 237.8 \\
\hline 225 & 50.0 & 55.00 & 733.75 & 238.6 \\
\hline 226 & 50.0 & 55.31 & 734.5 & 239.1 \\
\hline 227 & 50.0 & 55.71 & 735.75 & 239.8 \\
\hline 228 & 50.0 & 55.96 & 736.5 & 240.3 \\
\hline 229 & 49.9 & 56.41 & 736.75 & 240.8 \\
\hline 230 & 49.9 & 56.81 & 738.0 & 241.5 \\
\hline 231 & 49.9 & 57.21 & 739.5 & 242.2 \\
\hline 232 & 50.0 & 57.31 & 740.5 & 242.6 \\
\hline 233 & 50.0 & 57.91 & 742.0 & 243.6 \\
\hline 234 & 49.9 & 58.48 & 743.5 & 244.4 \\
\hline 235 & 49.8 & 59.12 & 745.0 & 245.3 \\
\hline 236 & 50.0 & 59.03 & 746.0 & 245.5 \\
\hline 237 & 50.0 & 59.26 & 746.5 & 245.9 \\
\hline 238 & 50.0 & 59.61 & 748.0 & 246.4 \\
\hline 239 & 49.9 & 60.02 & 748.5 & 246.9 \\
\hline 240 & 49.9 & 60.36 & 749.0 & 247.5 \\
\hline
\end{tabular}

* All other reflectors were up ** Relative to $350^{\circ} \mathrm{F}$. 
GEAP-13588

TABLE VIII-9

TEMPERATURE - REACTIVITY MEASUREMENTS

Reading Reflector Positions* (cm) Number

\section{1}

242

243

244

245

246

247

248

249

250

251

252

253

254

255

256

257

258

259

260

261

262

263

264

265

266

267

268

269

270

Reflector Positions*
\#1 5

49.9

49.9

49.9

49.7

50.0

50.0

50.0

50.0

50.0

50.0

50.0

50.0

50.0

49.6

50.0

50.0

50.0

50.0

50.0

50.0

50.0

49.9

50.0

50.0

50.0

50.0

50.0

50.0

50.0

50.0
60.73

61.03

61.33

61.44

60.87

60.99

61.03

61.40

61.20

61.2

61.5

61.5

61.6

61.81

60.68

60.80

60.98

60.98

60.98

61.10

61.10

61.23

60.45

60.37

60.37

60.25

59.96

60.08

60.36

60.19
Coolant Temperature Negative Reactivity** $\left.{ }^{\circ} \mathrm{F}\right)$ Feedback (cents)
248.1

248.6

249.1

248.9

248.5

248.7

248.8

249.4

249.0

249.0

248.7

249.5

249.7

249.3

248.2

248.4

248.7

248.7

248.7

248.9

248.7

248.9

247.8

247.7

247.7

247.5

247.0

247.2

246.7

247.4

* A11 other reflectors were up

** Relative to $350^{\circ} \mathrm{F}$. 


\section{TABLE VIII-10}

\section{TEMPERATURE - REACTIVITY MEASUREMENTS}

Reading

Number

$\begin{array}{ll}271 & 50.0 \\ 272 & 50.0 \\ 273 & 50.0 \\ 274 & 50.0 \\ 275 & 50.0 \\ 276 & 50.0 \\ 277 & 50.0 \\ 278 & 50.0 \\ 279 & 50.0 \\ 280 & 50.0 \\ 281 & 50.0 \\ 282 & 50.0 \\ 283 & 50.0\end{array}$

60.88

61.11

62.17

63.24

63.76

64.03

64.27

63.56

63.91

63.98

64.16

64.16

64.31
Coolant Temperature Negative Reactivity*; $\left({ }^{\circ} \mathrm{F}\right)$ Feedback (cents)

$\begin{array}{ll}750.5 & 248.5 \\ 751.25 & 248.9 \\ 753.5 & 250.6 \\ 757.0 & 252.3 \\ 758.75 & 253.1 \\ 759.25 & 253.5 \\ 760.0 & 253.9 \\ 759.5 & 252.8 \\ 759.5 & 253.3 \\ 759.75 & 253.4 \\ 759.75 & 253.7 \\ 759.5 & 253.7 \\ 759.5 & 253.9\end{array}$

\footnotetext{
*A11 other reflectors were up. ** Relative to $350^{\circ} \mathrm{F}$
} 


\section{REFERENCES}

\section{SECTION I}

1. G. R. Pflasterer, "SEFOR Experimental Program Planning, Volume 1 Specifications for the Plant and Experimental Equipment" GEAP-5092, August 1966.

2. G. R. Pflasterer and L. Caldarola, "SEFOR Experimental Program Planning, Volume II Descriptions of Planned Tests, GEAP-5092, August 1966.

3. L. D. Noble, G. R. Pflasterer, C. D. Wilkinson, and L. Caldarola, "Recent Developments in the SEFOR Experimental Program" Proceedings of the International Conference on Fast Critical Experiments and Their Analysis October 10-13, 1966; ANL-7320.

4. L. D. Noble and C. D. Wilkinson, "Final Specifications for the SEFOR Experimental Program"; GEAP-5576, January 1968.

5. G. Billuris, et.al., "SEFOR Plant Design" Fast Reactors National Topical Meeting, San Francisco, April 1967, ANS-101.

6. R. A. Meyer, et al., "Design and Analysis of SEFOR Core I", (GEAP to be issued)

7. "Southwest Experimental Fast Oxide Reactor Development Program, Ninth Quarterly Report, May-July 1966"; GEAP-5208, August 1966.

8. "Southwest Experimental Fast Oxide Reactor Development Program, Tenth Quarterly Report, August-October 1966"; GEAP-5301, November 1966.

9. "Southwest Experimental Fast Oxide Reactor Development Program, Eleventh Quarterly Report, November 1966-January 1967"; GEAP-5442, February 1967.

10. "Southwest Experimental Fast Oxide Reactor Development Program, Nineteenth Quarterly Report, November 1968-January 1969"; GEAP-5754, February 1969.

11. A.B. Reynolds and S. L. Stewart, "Analysis of the SEFOR Mockup Critical Experiments in ZPR-3", GEAP-5294, March 1967.

12. "Southwest Experimental Fast Oxide Reactor Development Program, Twelfth Quarterly Report, February-Apri1 1967"; May 1967.

13. "Southwest Experimental Fast Oxide Reactor Development Program, Twenty-First Quarterly Report, May-July 1969", GEAP-10010-21, August 1969. 


\section{REFERENCES (Continued)}

\section{SECTION I (Cont'd)}

14. G. R. Pflasterer, et.al., "Investigation of Low Plutonium Content in SEFOR Fuel", (GEAP-13576 to be issued).

15. E. R。Craig, "SEFOR Instrumented Fue1 Assembly Design and Development", GEAP-5615, April 1968.

\section{SECTION II}

1. R. L. McVean, et.al., "Critical Studies of the Southwest Experimental Fast Oxide Reactor (SEFOR) in ZPR-3 (Assembly 47)", ANL-7248, March 1967 .

2. A. B. Reynolds and S. L. Stewart, "Analysis of the SEFOR Mockup Critical Experiments in ZPR-3", GEAP-5294, March 1967.

3. H. Küsters, et.al., "Analysis of Fast Critical Assemblies and Large Fast Power Reactors with Group Constant Sets Recently Evaluated at Karlsruhe", Winter Meeting of ANS, Washington, D. C. Nov. 10-15, 1968 .

4. W. Y. Kato, et. al., "Measurement of Reaction Ratio and Neutron Spectra in a Soft Spectrum Fast Reactor", Winter Meeting of A.N.S., Washington, D. C. Nov. 10-15, 1968.

5. H. H. Humme1, "Correlation, Evaluation and Interpretation of Integral Data", ANL Reactor Physics Division, Progress Report for September 1968.

6. "ENDF/B Summary Documentation", ENDF Newsletter, Volume 3, No.2, Brookhaven National Laboratory, National Neutron Cross Section Center, October 2, 1967.

7. R. Protsik and E. G. Leff, "Users Manual for DOT2DB: A TwoDimensional Multigroup Discrete Ordinates Transport/Diffusion Code with Anisotropic Scattering", GEAP-13537, September 1969.

8. P. Greebler, et.al., "BISYN - A Two-Dimensional Synthesis Program", GEAP-4922, July 1965. 


\section{REFERENCES (Continued)}

\section{SECTION II (Cont'd)}

9. R. Protsik, "Transport vs. Diffusion Theory in Large Fast Reactor Calculations", Conference on Review of the Discrete Ordinates $S_{N}$ Method for Radiation Transport Calculations, Oak Ridge National Laboratory, March; 1968, ORNL-RSIC-19.

10. R. Protsik and J. M. Kelley, "SN1D - A One-Dimensional Discrete Ordinates Transport Code with General Anisotropic Scattering", GEAO-0064, September 1964.

11. R. A. Harris, "A Preliminary Study of the Heterogeneous Effects in the FTR and FTR Critical Mockup", BNWL-CC-963, BattelleNorthwest Laboratories (1967).

12. D. Wintzer, Kernforschungzentrum, Karlsruhe, Germany, Private Communication.

13. S. L. Stewart, G.E. - BRDO, Private Communication.

14. L. P. Abagyan, et al., "Group Constants for Nuclear Reactor Calculations", Consultants Bureau, New York, 1964.

15. B. A. Hutchins, "The ENDRUN Code - General Description", G.E. - BRDO memo, June 11, 1968.

16. G. R.Pflasterer, et. al., "Investigation of Low Plutonium Content in SEFOR Fuel", (GEAP-13576 to be issued).

\section{SECTION III}

1. "Southwest Experimental Fast Oxide Reactor Development Program, Nineteenth Quarterly Report, November 1968-January 1969", GEAP-5754, February 1969.

2. I. D. Noble and C. D. Wilkinson, "Final Specifications for the SEFOR Experimental Program", GEAP-5576, January 1968.

3. A. B. Reynolds and S. L. Stewart, "Analysis of the SEFOR Mockup Experiments in ZPR-III", GEAP-5294, March, 1967.

4. R. Protsik and E. G. Leff, "Users Manual of DOT2DB: A Two-Dimensional Multigroup Discrete Ordinates Transport/Diffusion Code with Anisotropic Scattering", GEAP-13537, September 1969. 


\section{REFERENCES (Continued)}

\section{SECTION III (Continued)}

5. "Southwest Experimental Fast Oxide Reactor Development Program, Eighth Quarterly Report, February-April, 1966, GEAP-5160, May 1966.

6. G. R. Keepin, "Physics of Nuclear Kinetics", Addison-Wesley, Palo Alto, 1965.

\section{$\underline{\text { SECTION IV }}$}

1. G. R. Pflasterer, et. al., "Investigation of Low Plutonium Content in SEFOR Fuel (GEAP-13576 to be issued).

2. R. Protsik, "Users Manual for DOT2DB: A Two-Dimensional Multigroup Discrete Ordinates Transport/Diffusion Code with Anisotropic Scattering", GEAP-13537, September 1969.

3. P. Greebler, et.a1., "BISYN - A Two-Dimensional Synthesis Program", GEAP $=4922$, July 1965 .

\section{SECTION V}

1. W. F. Welsh, "Determination of Absolute Power in SNAP-50 Critical Assemblies by Ba-140 Fission Product Measurements, "PWAC 474, July, 1965.

2. P. Greebler, et.al, "BISYN - A Two-Dimensional Synthesis Program", GEAP-4922, July 1965.

3. R. Protsik and E. G. Leff, "Users Manua1 for DOT2DB: A Two-Dimensiona1 Multigroup Discrete Ordinates Transport/Diffusion Code with Anisotropic Scattering", GEAP-13537, September 1969.

4. "Southwest Experimental Fast Oxide Reactor Development Program, Twenty-First Quarterly Report, May-July, 1969"; GEAP-10010-21, August 1969.

5. "Southwest Experimental Fast Oxide Reactor Development Program, Tenth Quarterly Report, August-October 1966", GEAP-5301, November 1966.

6. "Southwest Experimental Fast Oxide Reactor Development Program, Twelfth Quarterly Report, February-Apr11 1967", GEAP-5498, May, 1967. 


\section{REFERENCES (Continued)}

\section{SECTION VI}

1. R. P. Morre11, "SEFOR $B / \ell$ Measurements by Noise Analysis Techniques IDO-17210 August 1966.

2. J. P. Dragt, "Reactor Noise, A Study of Neutronic Fluctuations in Low Power Nuclear Reactors with Special Emphasis on Accurate Time Domain Analysis", RCN Report RCN-101.

3. B. C. Diven et.al., "Multiplicities of Fission Neutrons," Phys. Rev. 1956, Vo1. 101., No. 3.

4. A. I. Mogilner et.al., "Experimental Study of Neutron Detectors Frequency Responses ", RCN-REport 98, July 1968.

5. W. Seifritz, "The Polarity Correlation of Reactor Noise in the Frequency Domain", Nuclear Applications \& Technology Vo1.7, Dec. 1969.

6. G. S. Brunson and R. I. Huber, "Precision Pulsed Measurements with Reflected Fast Critical Assemblies", ANL-7320, Proc. of the Int. Conf. on Fast Critical Exp. and Their Analysis, Oct.10-13, 1966.

7. A. B. Reynolds and S. L. Stewart, "Analysis of the SEFOR Mockup Critical Experiments in ZPR-3", GEAP-5294, March 1967.

\section{$\underline{\text { SECTION VII }}$}

1. L. D. Noble and C. D. Wilkinson, "Final Specifications for the SEFOR Experimental Program", GEAP-5576, January 1968.

2. "Southwest Experimental Fast Oxide Reactor Development Program Twentieth Quarterly Report, February-April 1969", GEAP-10010, May 1969.

3. "Southwest Experimental Fast Oxide Reactor Development Program, Twenty-First Quarterly Report, May-July, 1969", GEAP-10010-21, August 1969.

4. "Southwest Experimental Fast Oxide Reactor Development Program, Twenty-Second Quarterly Report, August-October 1969, GEAP-10010-22, December 1969.

5. "Southwest Experimental Fast Oxide Reactor Development Program, Twenty-Third Quarterly Report, November 1969-January 1970", GEAP10010-23, February 1969. 


\section{REFERENCES (Continued)}

\section{SECTION VII (Cont'd)}

6. R. A. Meyer, et al., "Design and Analysis of SEFOR Core I", (GEAP to be issued)

7. P. Greebler, et.al., "BISYN - A Two-Dimensional Synthesis Program", GEAP-4922, July 1965.

\section{APPENDICES}

1. "Sodium-Cooled Reactors Fast Ceramic Reactor Development Program, Twenty-Seventh Quarterly Report, May-July 1968", GEAP-5671, August 1968.

2. S. L. Stewart, G.E. -BRDO, Private Communication.

3. G. I. Bell, "A Single Treatment for Effective Resonance Absorption Cross Sections in Dense Lattices", Nuc. Sec. and Eng. 5, Pg.138, (1959)

4. L. B. Abagyan, et.al., "Group Constants for Nuclear Reactor Calculations", Consultants Bureau, New York, 1954.

5. B. A. Hutchins", The ENDRUN Code - General Description", G.E. BRDO Memo, June 11, 1968.

6. "ENDF/B Summary Documentation, "ENDF Newsletter, Vo1.3, No. 2., Brookhaven National Laboratory, National Neutron Cross Section Center, October 2, 1967.

7. P. H. White, J. G. Hodgkinson, G. L. Wa1l, "Measurements of Fission Cross Sections for Neutrons of Energies in the Range 40-500 keV", Proc. Conf. on Physics and Chemistry of Fission, IAEA, Salzburg, Austria, EANDC (UK) 535, (1964).

8. R. Gwin, et a1., "Measurements of the Neutron Fission and Absorption Cross Section of Pu-239 Over the Energy Region $0.01 \mathrm{eV}$ to $30 \mathrm{keV} "$, NPD Annual, May 15, 1968.

9. R. N. Evatt, "Pu-239 Resonance Parameters in the Unresolved Region," G. E. Memo to B. A. Hutchins, November 8, 1968. 
GEAP-13588

REFERENCES (Continued)

\section{APPENDICES (Cont'd)}

10. J. B. Garg, et al, Phys, Rev. 135, B985 (1964)

11. K. H. Beckurts, et al, "Neutron Capture and Fission Cross Section Data in the keV Energy Range,"Fast Reactor Physics Conf., Karlsruhe, Germany, October 30 - November 3, 1967, SM-101/9.

12. J. F. Barry, J. Bunce, P':H. White, "Cross Section for the Reaction ${ }^{238} \mathrm{U}(\mathrm{n}, \gamma)^{239} \mathrm{U}$ in the Energy Range $0.12-7.6 \mathrm{MeV}, " \mathrm{~J}$. Nuc1. Energy 18 , 481 (1964).

13. D. H. Byers, et al. s $_{\text {, }}$ Fission Cross Sections from Petre1", LA-3586, p. 59 (1966).

14. T. A. Pitterle, E. M. Page, M. Yamamoto, "Analysis of Sodium Reactivity Measurements," Volumes I and II, Atomic Power Dev. Associates, Inc., APDA-216, June 1968.

15. H. Küsters, et al., "Analysis of Fast Critical Assemblies and Large Fast Power Reactors with Group Constant Sets Recently Evaluated at Karlsruhe", Winter Meeting of American Nuclear Society, Washington, D. C., November 10-15, 1968.

16. W. Y. Kato, et al., "Measurement of Reaction Ratios and Neutron Spectra in a Soft Spectrum Fast Reactor," Winter Meeting of American Nuclear Society, Washington, D. C., November 10-15, 1968.

17. H. H. Hummel, "Correlation, Evaluation and Interpretation of Integral Data," ANL Reactor Physics Division, Progress Report for September, 1968.

18. B. A. Zolotar, B. R. Gehgal, J. M. Kallfetz, "Fast Reactor Integral Studies of Modifications to ENDF/B U-238 Inelastic Scattering", American Nuclear Society Winter Meeting, San Francisco, December 1969.

19. N. W. Glass, et al., "U-238 Neutron Capture Results from Bomb Source Neutrons", Conf. of Neutron Cross Sections and Technology, Washington, D. C., March 4-7, 1968.

20. C. D. James, TRDWP/P30, 1965; or AERE-PR/NP6, 1964.

21. E. Barnard, et al, "Scattering of Fast Neutrons by U-238", International Conference on Study of Nuclear Structure with Neutrons, Antwerp, Belgium, EAiNDC-50-S, P/26 (1965). 


\section{APPENDICES (Cont'd)}

22. P. Benoist, "Theorie du Coefficient de Diffusion des Neutrons dans un Reasau Comportant des Cavites", CEA-R-2278 (1964)

23. R. Protsik and J. M. Kelley, "SN1D - A One-Dimensional Discrete Ordinates Transport Code with General Anisotropic Scattering", GEAO-0064, September 1964.

24. Robley D. Evans, "The Atomic Nucleus", McGraw-Hil1, New York, (1955).

25. P. Greebler, et al, "BISYN - A Two-Dimensional Synthesis Program", GEAP-4922, July 1965.

26. G. R. Keepin, "Physics of Nuclear Kinetics", Addison-Wesley, Palo Alto, 1965.

27. L. D. Noble and C. D. Wilkinson, "Final Specifications for the SEFOR Experimenta1 Program", GEAP-5576, January 1968. 


\section{ACKNOWLEDGEMENTS}

The work reported here is based on the

contributions of several people. The authors

especially wish to acknowledge the contributions

of the following people:

J. Arterburn

P. Greebler

J. H. Haar

B. Hutchins

M. L. Johnsan

R. Protsik

C. Russe11

S. Stewart 


\section{DISTRIBUTION}

Division of Technical Information Extension U.S. Atomic Energy Commission

P. O. Box 62

Oak Ridge, Tennessee

\section{Director}

Research and Development Division

U.S. Atomic Energy Commission

Richland Operations Office

P. O. Box 550

Richland, Washington 99352

Mr. G. Vendryes

Cen Saclay

Boite Postale 2

Gif-Sur-Yvette (S et O) France

Dott, Ing. F. Pierantoni

CNEN

Viz Mazzini 2

Bologna, Italy

Chief

Fuel Fabrication Branch

DRD\&T, USAEC

Washington, D. C. 20545

Mr. F. W: Lewis, President

Lousiana Power and Light Company 142 Delaronde Street

New Orleans, Louisiana 70114

Mr. R. C. Green, President

Missouri Public Service Co.

10700 East 50 Highway

Kansas City, Missouri

Mr. L. J. Cucullu, President

New Orleans Public Service Inc.

317 Baronne Street

New Orleans, Louisiana 70160

Mr. B. S. Jeffrey, President

Kansas Power and Light Company

808 Kansas Avenue

Topeka, Kansas 66601

Mr. J. Robert Welsh

Chairman of the Board

Southwestern Electric Power Company

P. O. Box 1106

Shreveport, Louisiana 71102

Power Reactor Development Company

1191 First Street

Detroit, Michigan 48226
15 Project Manager $\quad 5$

FFTF Project

Pacific Northwest Laboratory

Richland, Washington 99352

1 Chief,

Fuels and Materials Branch

DRD\&T, USAEC

Washington, D. C. 20545

Assistant Director for Reactor Projects

Division of Reactor Licensing

DRD\&T, USAEC

Washington, D. C. 20545

Director

Los Alamos Scientific Laboratory

Los Alamos, New Mexico 87544

Dr. John C. Woodhouse

21 Woodbrook Circle

Wilmington, Delaware 19803

Senior Representative

U.S. Mission to EURATOM Communities c/o U. S. Embassy

Brussels, Belgium

Chief,

Liquid Metal Project Branch

DRD\&T, USAEC

1

Washington, D. C. 20545

Asst. Director for Nuclear Safety

DRD\&T, USAEC

Washington, D. C. 20545

1

Director, Contracts Division

U. S. Atomic Energy Commission

San Francisco Operations Office

2111 Bancroft Way

1

Berkeley, California 94704

F. W. Thalgott

1

Associate Director, Idaho Division

Argonne National Laboratory

Box 1096

Idaho Falls, Idaho 83401

1

Director, Argonne National Laboratory

Argonne, Illinois 60439 
Chief,

Reactor Physics Branch

DRD\&T, USAEC

Washington, D. C. 20545

Mr. C. C. Czeschin, President

Arkansas-M issouri Power Company

104 South Fifth Street

Blytheville, Arkansas 72316

Mr. T. Flynn

Ebasco Services, Inc.

2 Rector Street

New York City 6, N. Y.

USAEC

Office of RDT Site Representative

310 DeGuigne Drive

Sunnyvale, California 94086

Attn: J. Levy

\section{Director}

Liquid Metals Information Center

P. O. Box 309

Canoga Park, California 91305

(Topicals only)

Mr. S. Golan, Project Manager 1000 MWe LMFBR Follow-On Study

Atomics International

P. O. Box 309

Canoga Park, California 91304

Mr. M. W. Croft, Project Manager

1000 MWe LMFBR Follow-On Study

The Babcock \& Wilcox Company

5061 Fort Avenue

P. O. Box 1260

Lynchburg, Virginia 24505

Dr. W. P. Staker, Project Manager

1000 MWe LMFBR Follow-On Study

Combustion Engineering, Inc.

P. O. Box 500

Windsor, Connecticut 06095

Mr. C. A. Anderson, Project Manager

1000 MWe LMFBR Follow-On Study

Westinghouse Electric Corporation

Advanced Reactors Division

Waltz Mill Site

P. O. Box 158

Madison, Pennsylvania 15663

Mr. L. W. Fromm, Manager

1000 MWe LMFBR Follow-On Study Project

Building 208

Argonne National Laboratory

9800 South Cass Avenue

Argonne, Illinois 60439
1 USAEC Scientific Representative

United States Embassy, Box 40

FPO

New York, N. Y. 09510

1

General Directorate

Research and Training

EURATOM

51-53 Rue Belliard

1 Brussels, Belgium

Attn: A. DeStordeur

Mr. F. H. Coughlin, Chairman of Board

Central Louisiana Electric Co., Inc.

P. O. Box 111

Alexandria, Louisiana 71301

Mr. John Stewart, President

The Central Kansas Power Company

111 East 11th Street

Hays, Kansas 67601

Mr. Reeves Ritchie, President

Arkansas Power and Light Company

Ninth and Louisiana Street

Little Rock, Arkansas 72203

2

Mr. J. T. Jones, President

The Empire District Electric Co.

602 Joplin Street

Joplin, Missouri 64802

2 Mr. Harold E. Mortimer

Vice President

Assistant to Chairman of the Board

Gulf States Utilities Company

P. O. Box 2951

Beaumont, Texas 77704

2

Mr. C. F. Edwards, Vice President

Western Power Division

Central Telephone \& Utilities Corp.

P. O. Box 170

Great Bend, Kansas

2 Gesellschaft fur Kernforschung m.b.H.

Projekt Schneller Bruter

75) Karlsruhe, Germany

Postfach 947

Director,

2

LMFBR Program Office

Argonne National Laboratory

South Cass Avenue

Argonne, Illinois 60439

Asst. Director for Plant Engineering

Washington, D. C. 20545 
Asst. Director for Reactor Engineering DRD\&T, USAEC

Washington, D. C. 20545

Brookhaven National Laboratory Associated Universities, Inc.

Upton, Long Island, N. Y. 11973

Attn: Dr. C. H. Raseman

Project Manager

Special Projects Branch

DRD\&T, USAEC

Washington, D. C. 20545

Mr. G. W. Evans, President

Kansas Gas and Electric Company 201 North Market Street

Wichita, Kansas 67201

Mr. L. F. C. Reichle

Ebasco Services, Inc.

2 Rector Street

New York 6, New York
2 Mr. R. B. Wilson, President

Mississippi Power and Light Company

Electric Building

1

Jackson, Mississippi 39205

Mr. Ray W. Call, President

Missouri Utilities Company

400 Broadway

1 Cape Girardeau, Missouri 63701

Mr. W. A. Parker, President

Oklahoma Gas and Electric Company

1321 North Harvey Street

Oklahoma City, Oklahoma 73101

1 Mr. D. J. Tuepker, Chairman

1 600 South Main Street Tulsa, Oklahoma 74102 